\title{
Radioactivity: A Tool to Explore the Past
}

\author{
By Hans R. von Gunten \\ Paul Scherrer Institut, CH-5232 Villigen PSI, Switzerland
}

(Received October 28, 1994; revised March 23, 1995)

\author{
Dating / Age determinations / Time markers / \\ Cosmogenic radionuclides / Lead-210 / \\ Uranium-thorium-lead / Rubidium-strontium / \\ Potassium-argon / Radioactive disequilibrium / \\ Fission tracks / Thermoluminescence
}

\begin{abstract}
The use of the radioactive decay for dating purposes is reviewed. The most important dating methods are discussed. They include radioactive time markers (e.g., ${ }^{137} \mathrm{Cs}$ ), cosmogenic radionuclides (e.g., ${ }^{14} \mathrm{C},{ }^{10} \mathrm{Be}$ ), decay products of ${ }^{226} \mathrm{Ra}\left(\right.$ e.g., ${ }^{222} \mathrm{Rn},{ }^{210} \mathrm{~Pb}$ ), uranium-thorium-lead chronometers, rubidium-strontium and potassium-argon nuclide pairs, applications of radioactive disequilibrium, dating with fission tracks, and thermoluminescence. Some important results, for instance the age of the Earth and the Moon, are also presented.
\end{abstract}

\section{Introduction}

Priests, astronomers, philosophers and other educated people of the great Oriental, Antique, and other societies, already wanted to known more about creation and past times. In this context, one of the important questions was to establish the origin and age of the Earth and Cosmos. However, these problems remained unsolved or were answered by rough estimates only, until radioactivity was discovered in 1896 and enabled an accurate dating. The following historic résumé is extracted by the present author from a more detailed overview by Roth [1] in the comprehensive book about dating methods based on nuclear phenomena by Roth and Poty [2]:

"Until the 18th century, the Bible set the age of the Earth very accurately to 4004 years. But still today, 'creationists' derive from studies of the Old Testament an age between 6000 and 10,000 years. At the end of the 19th century Lord Kelvin used heat balances to estimate the Earth's age to 50 to 100 million years (MY). However, already then, geologists concluded from many observations that this age was too short. After the discovery of radioactivity by Becquerel in 1896 , and the demonstration of heat evolution in this process by Curie and Laborde, Lord Rutherford recognized in 1904 that Kelvin's Earth's age was indeed much too short, because he had neglected the important additional heat source in the interior of the Earth. Using for the first time a decay constant, Rutherford estimated the Earth's age from the amount of helium in uranium minerals to $500 \mathrm{MY}$. Assuming, without experimental verification, that lead was the final prod- uct in the decay chain of uranium, Boltwood assigned 1907 about the same age value to uranite samples. Based on the first modern geological time scale, Holmes attributed, in 1913, an age of $1600 \mathrm{MY}$ to certain archaic rocks".

Scientifically sound dating involving the radioactive decay started with the work of Nier $[3,4]$ on lead isotopes, in combination with the decay chains of uranium isotopes and of thorium. These authors demonstrated that different isotopic compositions of the analyzed lead samples resulted from mixtures of a 'primitive' lead and 'radiogenic' lead. Their findings enabled Holmes [5] and Houtermans [6], independently, to calculate an Earth's age which was close to the presently accepted value of $4500 \mathrm{MY}$.

The discovery of 'cosmogenic' radionuclides (e.g., ${ }^{14} \mathrm{C}$; Libby [7]), and the use of relatively short-lived nuclides of the natural decay chains (e.g., ${ }^{210} \mathrm{~Pb}$; Goldberg [8]), have made age determinations of archeological artifacts, and estimates of time scales for the natural environmental cycles possible.

The extensive testing of atomic bombs in the atmosphere in the late fifties and early sixties, along with other nuclear activities (and accidents) have left narrow and discrete radioactive time markers that can be used to date certain environmental archives very accurately. But more generally, the radioactive dating methods are based on the temporal decrease of the number of radioactive atoms and often on the related ingrowth of radioactive or stable daughter nuclides. These changes are accurately described by the radioactive decay laws. Radioactive decay follows first order kinetics which cannot be changed by external influences, thus providing a very accurate clock. Of prime importance are the decay constants (or the halflives) of the involved radionuclides.

Besides the radioactive time markers, four general methods of age determination can be distinguished: i) the present day activity of a radionuclide in a sample of interest is compared to the known initial activity of the same radionuclide; ii) a radioactive parent nuclide decays into a stable daughter nuclide; iii) a radioactive daughter is separated from a radioactive parent nuclide by natural chemical or physical processes; and iv) the cumulative radiation damage or the total energy deposition resulting from the decay of long-lived radionuclides present in or close to a sample.

If the decay constant of the radionuclide in method i) from above is known, the age of the sample can be calculated. In method ii), the age of the sample is 
calculated from the number of stable daughter atoms formed (which equal the number of decayed parent atoms) during the elapsed time since the formation of the sample (e.g., the time of solidification). This method applies also to the end members of the radioactive decay chains, if radioactive equilibrium is reached among all chain members, and no loss or gain of either parent or daughter occurs other than by radioactive decay. In method iii), the decay of the separated daughter or its ingrowth into a sample can be used to calculate the time span since the separation. In this case one speaks of radioactive disequilibrium between parent and daughter nuclide.

Nuclear dating methods have been discussed to some extent in most textbooks on nuclear and radiochemistry (e.g., Choppin and Rydberg [9]; Friedlander et al. [10]; Ehmann and Vance [11]; Lieser [12]). Comprehensive reviews of the subject have been published by Currie [13], Roth and Poty [2], Durrance [14] and Faure [15]. In the following, a personally biased selection of methods and applications is discussed.

\section{Dating methods}

\section{Radioactive time markers}

Fallout from atmospheric testing of very large nuclear devices (e.g., the largest $\mathrm{H}$-bombs developed by the Soviet Union, 1961/62) has left discrete and well-conserved radioactive deposits in the environment. For some radionuclides, and under favorable environmental conditions these deposits remained essentially at the original site and can be used as radioactive time markers. For instance, ${ }^{3} \mathbf{H},{ }^{14} \mathbf{C}$, the fission product ${ }^{137} \mathrm{Cs}$ or unreacted ${ }^{239} \mathrm{Pu}$ are firmly sorbed onto soils, sediments and other samples (e.g., glacier ice), and buried by soil forming processes, ongoing sedimentation, or precipitation (e.g., snow). These activities mark the year 1962/63 very accurately. More recently, the widespread fallout from the reactor accident at Chernobyl has formed (at least in Europe) a well defined marker of the year 1986 . Because ${ }^{137} \mathrm{Cs}$ is easily detected by $\gamma$-ray spectroscopy, the two time markers (i.e., fallouts of bombs and from the Chernobyl reactor accident) covering a time interval of about 23 years, can be used in a simple way to determine the recent sedimentation rate in lakes and other aquatic systems, and the accumulation rate of glaciers. Fig. 1 presents a ${ }^{137} \mathrm{Cs}$ peak in sediments of Lake Zürich, Switzerland, together with a ${ }^{210} \mathrm{~Pb}$ activity/depth profile (discussed in a later paragraph). The relatively narrow ${ }^{137} \mathrm{Cs}$ peak of the year 1962/63 allows assignment of an absolute time scale to the ${ }^{210} \mathrm{~Pb}$ data.

Tritium $\left({ }^{3} \mathrm{H}\right)$ resulting from hydrogen bombs, has left a time marker in glacier ice (e.g., Gäggeler $\boldsymbol{e t}$ al. [16]). Tritium can, furthermore, be used to estimate residence times of groundwater. If no ${ }^{3} \mathrm{H}$ is detected, the groundwater would have to have been isolated from surface waters for more than 30 years, i.e., before $1962 / 63$. The relatively narrow time window for the input of bomb produced ${ }^{14} \mathrm{C}$ can be used in investigations of ocean mixing.

\section{Comparison of present and initial radioactivity}

In this simple case the radioactive decay law, $\mathbf{A}_{\mathbf{t}}=\mathbf{A}_{\mathbf{0}} \cdot \mathrm{e}^{-\lambda t}$, applies.

$\mathbf{A}_{\mathrm{t}}$, is the present-day activity, $\mathbf{A}_{\mathbf{0}}$, the initial activity, and $\lambda$, the decay constant of the radionuclide of interest.

The number $\mathbf{N}$ of radioactive atoms is related to the activity by $\mathbf{A}=\lambda \cdot \mathbf{N}$.

The range of the applicability of a radionuclide for dating purposes is very roughly 0.1 to 10 half-lives.

\subsection{Cosmogenic radionuclides}

The simple decay law applies very often to radionuclides that are produced in the atmosphere by interactions of highly energetic cosmic radiation. A selection of 'cosmogenic' radionuclides is presented and discussed in this paragraph.

Carbon-14 $\left[T_{1 / 2}=5730\right.$ years]

The most important cosmogenic radionuclide is unquestionably ${ }^{14} \mathrm{C}$. Its application for dating purposes was first proposed by Libby [7] in 1952, and has since found thousands of applications in archeology, geology, hydrology, glaciology and other fields. The radionuclide is produced at a practically constant rate in the natural atmosphere by interactions of cosmic rays with nitrogen, i.e., $\left[{ }^{14} \mathrm{~N}(\mathrm{n}, \mathrm{p}){ }^{14} \mathrm{C}\right]$. After production, the 'hot' ${ }^{14} \mathrm{C}$ atoms are rapidly oxidized to form ${ }^{14} \mathrm{CO}_{2}$, which then follows the natural $\mathrm{CO}_{2}$-cycle in the environment. Like inactive $\mathrm{CO}_{2}$, it participates in the biocycle, reaching steady state concentrations dictated by the living biomass. After the death of an organism the $\mathrm{CO}_{2}$-exchange with the environment is interrupted, and ${ }^{14} \mathrm{C}$ starts to decay.

Calibrations of the method (Fig. 2) by dendrochronology (tree-ring counting) established a variation in the ${ }^{14} \mathrm{C}$ production rate of about 10 percent during the past 10,000 years (Damon et al. [17]; Stuiver [18, 19]). On a longer time scale, variations of the geomagnetic field (Bard et al. [20]) and of the intensity of solar modulation can influence the production rate by about a factor of two. In addition, anthropogenic activities have led to significant changes in the ${ }^{14} \mathrm{C} / \mathrm{C}$ ratio: nuclear weapons tests in the atmosphere and nuclear industry have contributed considerably to the ${ }^{14} \mathrm{C}$ reservoir by artificial production of ${ }^{14} \mathrm{C}$. On the other hand, the accelerated production of $\mathrm{CO}_{2}$ in this century due to burning of fossil fuels (which contain no ${ }^{14} \mathrm{C}$ ) has led to a reduction of the specific activity of ${ }^{14} \mathrm{C}$. In addition, mass fractionation can occur in the transfer of carbon between different reservoirs. These variations have to be taken into account for accurate age determinations. 


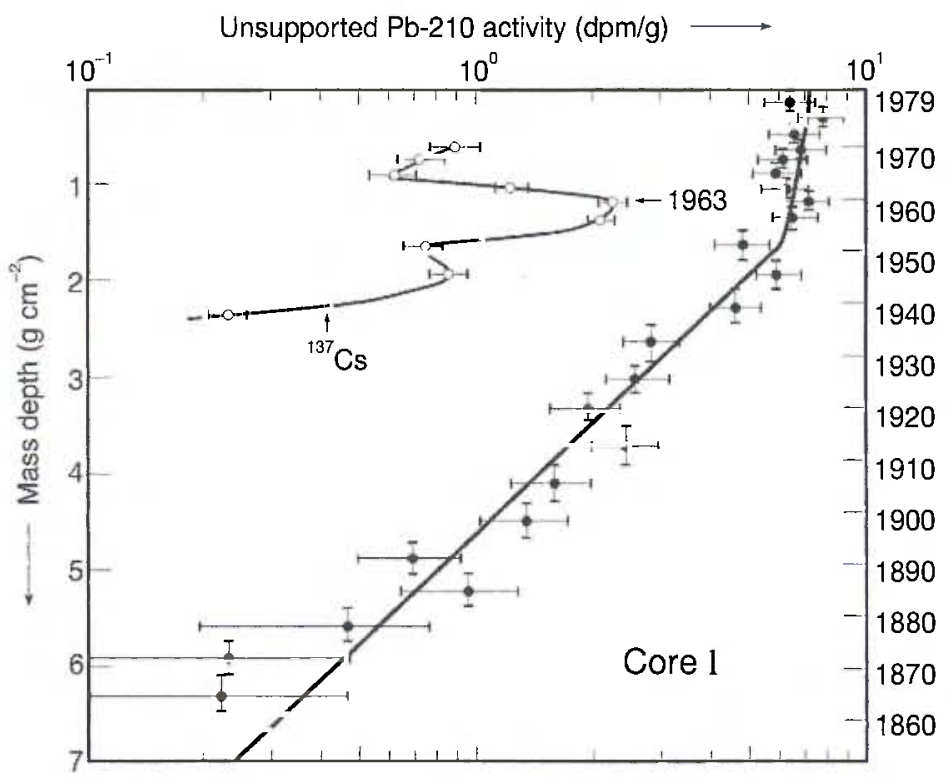

Fig. 1. Activities of 'unsupported' ${ }^{210} \mathrm{~Pb}$ (see text) and ${ }^{137} \mathrm{Cs}$ from a sediment core of Lake Zürich, Switzerland (Erten et al. [49]). The ${ }^{137} \mathrm{Cs}$ peak of $1962 / 63$ enables an absolute dating with ${ }^{210} \mathrm{~Pb}$. Reprinted by permission of Birkhäuser Verlag, Basel, Switzerland.

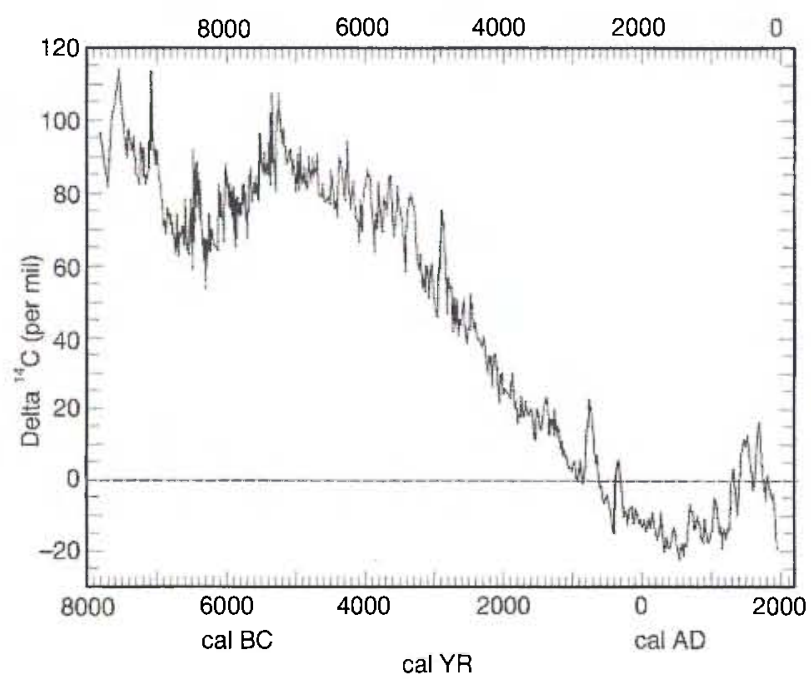

Fig. 2. Atmospheric $\Delta^{14} \mathrm{C}$ during the past 10,000 years (Stuiver et al. [19]). $\Delta^{14} \mathrm{C}$ is the difference (in permil) between the actual ${ }^{14} \mathrm{C}$ specific activity and the ${ }^{14} \mathrm{C}$ specific activity based on a constant production rate. Reprinted by permission of RADIOCARBON.

The sensitivity of the ${ }^{14} \mathrm{C}$ dating method has been increased considerably by the advent of accelerator mass spectrometry (AMS). This method detects ${ }^{14} \mathrm{C}$ atoms directly, after ionization and acceleration in a tandem Van de Graaff (Fig. 3), and enables the analysis of much smaller specimen than by the classic activity measurements of ${ }^{14} \mathrm{C}$. This technique has recently been reviewed by Finkel and Suter [21].

Important applications of ${ }^{14} \mathrm{C}$ dating are in archeology; Quaternary geology (e.g., lake sediments containing organic matter, Zbinden et al. [22]); atmospheric chemistry (Currie et al. [23]); glaciology; hydrology (e.g., Davis and Murphy [24]); oceanography; meteoritics (Jull et al. [25]); etc. For instance, ${ }^{14} \mathrm{C}$ was used to measure ages of seeds that were found at archeolog- ical sites, ages of paper (e.g., the Dead Sea scrolls showing an age of 1900 years), papyrus and textiles (e.g., the shroud of Turin (Damon et al. [26]), and to assess ocean mixing (Broecker and Peng [27]). A very important recent application of ${ }^{14} \mathrm{C}$ is the dating of ice cores, which can be used as archives of climatic history and anthropogenic pollution (e.g., Wilson and Donahue [28]).

Beryllium- $10\left[T_{1 / 2}=1.5 \times 10^{5}\right.$ years $]$ and beryllium -7 [ $T_{1 / 2}=53$ days]

${ }^{7} \mathrm{Be}$ and ${ }^{10} \mathrm{Be}$ are mainly produced by interactions of high energetic cosmic rays with atmospheric nitrogen and oxygen. Beryllium is a very rare element and because of its lithophilic character, is rather immobile in the environment. The very low content of stable beryllium in the environment enables the measurement of radioactive beryllium isotopes at concentrations, that are not accessible for other radionuclides (because they are diluted by their stable isotopes). Whereas ${ }^{7} \mathrm{Be}$ can be used for measurements of short residence times and for mixing investigations in the lower atmosphere or in lakes, the very long half-life of ${ }^{10} \mathrm{Be}$ (Hofmann et al. [29]) has made possible long time investigations in the environment. ${ }^{10} \mathrm{Be}$ has found many useful applications which were reviewed, e.g., by Bourles [30], general; Beer et al. [31], polar ice; Anderson et al. [32], sediments; Brown [33], soils; Nishiizumi [34, 35], meteorites and lunar rocks.

${ }^{10} \mathrm{Be}$ measurements in ice cores provide an important historical record for cosmic ray and solar activity. It has been shown (e.g., Beer et al. [31]) that the concentrations of ${ }^{10} \mathrm{Be}$ in Antarctic ice cores are anticorrelated with sunspot activity. This anticorrelation results from an association of sunspots with the solar magnetic activity which modulates the cosmic ray flux to the Earth's atmosphere. A good correlation has also 


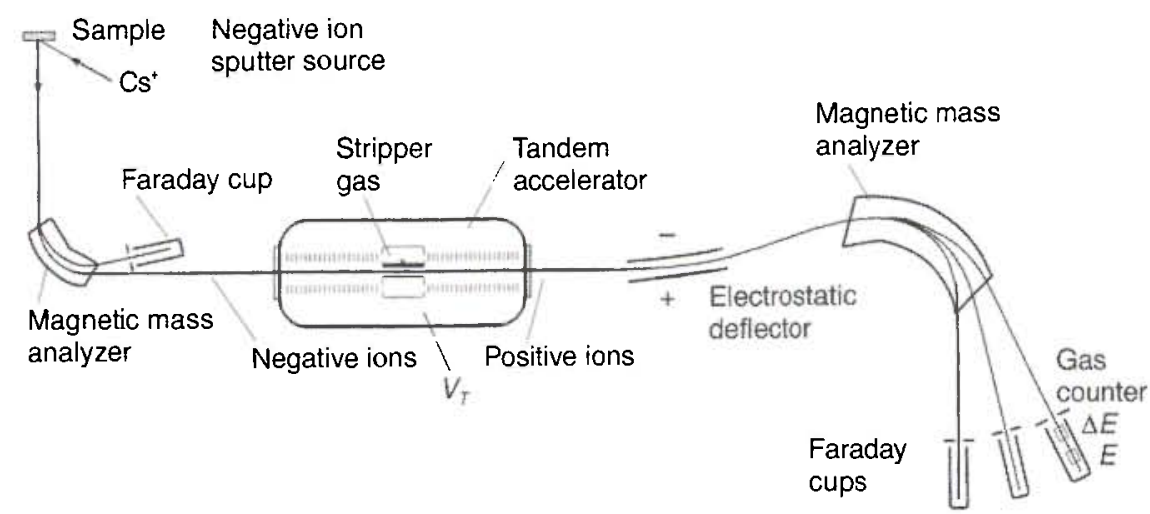

Fig. 3. Schematic diagram of an AMS-facility. Negative ions are produced from the investigated material in a Cs-sputter source. The ions are mass analyzed, and then accelerated in a tandem accelerator. In the 'stripper', the fast ions lose electrons and are converted to a positive charge state. In the second section of the tandem they are further accelerated. They are electrostatically deflected, mass analyzed and finally detected and identified by nuclear counter techniques. Courtesy M. Suter (ETH Zürich).

been observed for variations with a time period of centuries (Suess Wiggles) in the ${ }^{10} \mathrm{Be}$ concentrations and variations of ${ }^{14} \mathrm{C}$ activity in tree rings (Siegenthaler and Beer [36]).

\section{Silicon-32 $\left[T_{1 / 2}=133\right.$ years $]$}

The production rate of ${ }^{32} \mathrm{Si}$ by cosmic ray spallation of Ar in the atmosphere is very small $\left(\sim 1.6\right.$ atoms $/ \mathrm{cm}^{2}$ and s) and its use as a dating nuclide is still under investigation. Its half-life was not well known until recently, but the latest measurements by two different methods (Hofmann et al. [37]; Chen et al. [38]) agree on a value of $133 \pm 9$ years. This half-life would allow to date samples in a time span not accessible neither by ${ }^{210} \mathrm{~Pb}$ (22 years) nor ${ }^{14} \mathrm{C}$ (5730 years). For dating with ${ }^{32} \mathrm{Si}$ by conventional counting techniques, ${ }^{32} \mathrm{P}$ (in radioactive equilibrium with its parent ${ }^{32} \mathrm{Si}$ ) is used. However, ${ }^{32} \mathrm{Si}$ has to be extracted from very large samples ( $\geqslant$ one ton of material; e.g., Gellerman et al. [39]), in order to obtain significant results. This restricts the spacial and time resolution. Presently, the use of accelerator mass spectrometry is under development (Zoppi et al. [40]) for ${ }^{32} \mathrm{Si}$, but the method is still not fully exploited and its sensitivity is at present not better than that attainable using direct radioactive counting. A problem in the use of ${ }^{32} \mathrm{Si}$ as a dating nuclide lies in the ubiquitous occurrence of silicon in the environment leading to very low specific concentrations (i.e., ${ }^{32} \mathrm{Si} / \mathrm{Si}_{\mathrm{tot}} 10^{-15}-10^{-17}$ ).

\section{Additional important cosmogenic nuclides}

Several other radionuclides are produced by the interaction of cosmic rays with constituents of the atmosphere, but the limited length of the present paper allows only a short enumeration.

Aluminium-26 $\left[T_{12}=7.05 \times 10^{5}\right.$ years $]$ has become an important nuclide for investigations on marine archives, erosion studies of rocks, and lunar and meteorite samples. A review of ${ }^{26} \mathrm{Al}$ applications in the geosciences has been provided by Middleton and Klein [41].
Chlorine-36 $\left[T_{1 / 2}=3.01 \times 10^{5}\right.$ years $]$ has found a number of applications in hydrology (Bentley et al. [42]), atmospheric sciences (e.g., Synal et al. [43]), geoscience (Gove [44]; Hallet and Putkonen [45]) and cosmology (e.g., Nishiizumi [34]).

Iodine $-129\left[T_{1 / 2}=1.6 \times 10^{7}\right.$ years $]$ may be used for research in hydrology and in extraterrestrial samples. A summary of the current ${ }^{129}$ I research in the geosciences has been published by Fabryka-Martin et al. [46].

\subsection{Decay products of radon}

Radon-222 $\left[T_{I / 2}=3.8\right.$ days $]$, the direct decay product of ${ }^{226} \mathrm{Ra}$ emanates from the Earth's crust and enters into the atmosphere where it decays through a series of shorter lived products into ${ }^{210} \mathrm{~Pb}$. Several of these decay products may be used for residence time studies in the atmosphere, but the most important member in the ${ }^{222} \mathrm{Rn}$ decay chain is certainly ${ }^{210} \mathrm{~Pb}$.

\section{Lead-210 $\left[T_{1 / 2}=22.3\right.$ years $]$}

${ }^{210} \mathrm{~Pb}$ is deposited as wet or dry fallout onto the Earth's surface and can be used to obtain age information over the last 100 to 150 years. Goldberg [8], in 1963, was the first to use the radioactive decay of 'unsupported' ${ }^{210} \mathrm{~Pb}$ to date glacier ice. Several years later, Krishnaswami et al. [47], applied this method to lake sediments.

A basic assumption of the ${ }^{210} \mathrm{~Pb}$ dating method is a constant flux of ${ }^{210} \mathrm{~Pb}$ to the environmental archives. A monitoring experiment, covering a time period of 11 years, has shown that this assumption is accurate, if average fluxes are computed for periods of the order of one year (von Gunten and Moser [48]). For shorter time periods (i.e., $\leq$ a few months), however, considerable and irregular variations in the ${ }^{210} \mathrm{~Pb}$ flux are observed.

${ }^{210} \mathrm{~Pb}$, deposited on glaciers is covered by succeeding precipitations of snow, and that entering lake sediments, by settling particles. Finally, the deposits form a closed system (i.e., no exchange with the surrounding environment, e.g., no percolating water) in 


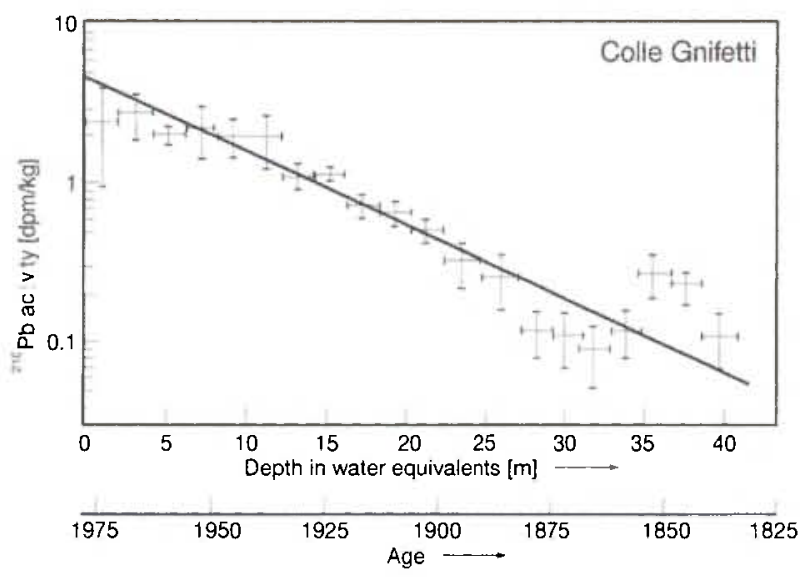

Fig. 4. ${ }^{210} \mathrm{~Pb}$ activity versus depth measured in an ice core from Colle Gnifetti (Monte Rosa, $4450 \mathrm{~m}$, Switzerland). The solid curve shows an exponential fit through data points averaged for core sections of 2-m water equivalent.

which ${ }^{210} \mathrm{~Pb}$ decays with its half-life. The measured ${ }^{210} \mathrm{~Pb}$ activity must be corrected for a background activity resulting from ${ }^{210} \mathrm{~Pb}$ ('supported ${ }^{210} \mathrm{~Pb}$ ') directly produced by the decay of radium in the sample.

The literature on applications of the ${ }^{210} \mathrm{~Pb}$ dating method is abundant. Some dating examples have been discussed by von Gunten and Moser [48]. Examples, for ${ }^{210} \mathrm{~Pb}$ depth profiles in sediments of Lake Zürich [49] and in an ice core from Colle Gnifetti are presented in Figs. 1 and 4, respectively. Dating of sediments, or glacier ice is important because these materials contain conserved information on the concentrations of pollutants in the past. The half-life of ${ }^{210} \mathrm{~Pb}$ allows an excellent archival record from the beginning of the industrial revolution in the past century to the present time.

\section{Radioactive parent and stable decay product}

In this method, the decay to a stable nuclide is considered. Knowing the present-day activity, the half-life of the radionuclide, and the concentration of the stable nuclide that has built-up by the decay of the radioactive parent nuclide, the age of the sample can be determined. This age corresponds for most of the samples to the time since their formation (e.g., crystallization from a melt or solution, etc.). Important examples for this dating possibility are the decays of ${ }^{40} \mathrm{~K}$ into stable ${ }^{40} \mathrm{Ar}$, and that of ${ }^{87} \mathrm{Rb}$ into stable ${ }^{87} \mathrm{Sr}$, and the decay chains of ${ }^{238} \mathrm{U},{ }^{235} \mathrm{U}$ and ${ }^{232} \mathrm{Th}$ leading to the stable lead isotopes ${ }^{206} \mathrm{~Pb},{ }^{207} \mathrm{~Pb}$ and ${ }^{208} \mathrm{~Pb}$, respectively.

The number of parent atoms at the time $t$ of the measurement, $\mathbf{P}_{s}$, is related to the number of parent atoms $\overline{\mathbf{P}}_{\mathbf{0}}$ at time zero (which is assumed to be the time of the formation of a mineral), by

$$
\mathbf{P}_{t}=\mathbf{P}_{0} \cdot \mathbf{e}^{-\lambda t} \text {, }
$$

$S_{t}$, the number of stable daughter atoms at time $t$ is represented by

$$
S_{t}=S_{0}+\left(P_{0}-P_{t}\right)=S_{0}+P_{t}\left(e^{i t}-1\right)
$$

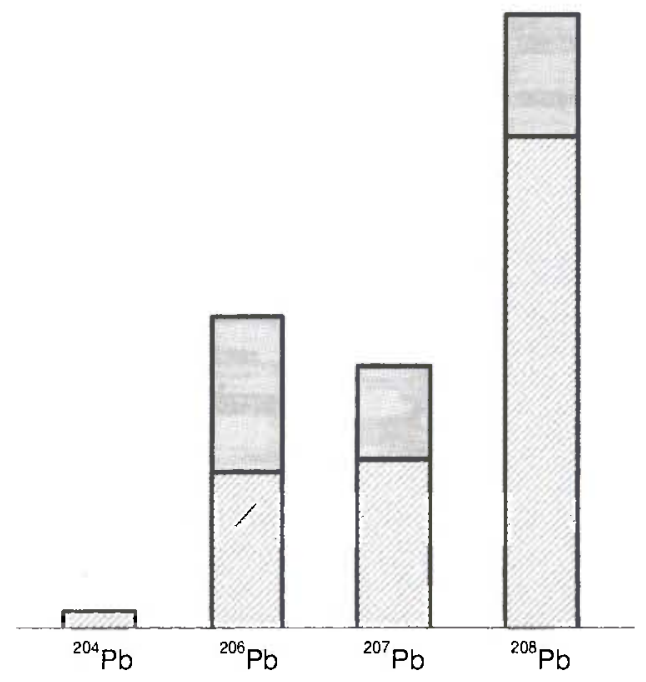

Fig. 5. Mean isotopic composition of present-day 'common' lead (sum of primordial and common lead). primordial lead, 图 radiogenic lead. After Albarede et al. [50]. Reprinted by permission of Kluwer Academic Publishers.

where $\mathbf{S}_{\mathbf{0}}$ is the number of atoms of a stable daughter present in the sample at $\boldsymbol{t}=\mathbf{0}$.

This equation is only valid if no loss or addition (other than by the radioactive transformation) of either parent or daughter nuclide occurred during the time period $t$. This condition is fulfilled if the sample represents a closed system (i.e., is completely isolated from the surrounding environment).

\subsection{Uranium-Thorium-Lead Chronometers}

The U-Th- $\mathrm{Pb}$ decay chains are probably the most accurate possibilities for measurements of geological samples with ages $>30$ million years. A comprehensive discussion of this method has been given by Albarede et al. [50]. The stable end products in the decay chains of ${ }^{238} \mathrm{U}\left(T_{1 / 2}=4.468 \times 10^{9}\right.$ years $),{ }^{235} \mathrm{U}\left(T_{1 / 2}=\right.$ $7.038 \times 10^{8}$ years $)$, and ${ }^{232} \mathbf{T h}\left(T_{12}=1.405 \times 10^{10}\right.$ years) are the lead isotopes ${ }^{206} \mathrm{~Pb},{ }^{207} \mathrm{~Pb}$ and ${ }^{208} \mathrm{~Pb}$, respectively. The abundance of these lead isotopes in a sample can be used to determine the time since the formation of the sample as a closed system. In modern methods, the lead isotopes are always determined by thermal ionisation mass spectrometry, and the amount of the non-radiogenic ${ }^{204} \mathrm{~Pb}$ can be used to estimate and correct the concentrations of the other lead isotopes that were in the sample at time $t=0$. The composition of common lead is shown in Fig. 5.

The age based on the decay of ${ }^{238} \mathrm{U}$ is obtained by transformation of Eq. (4):

$$
t=1 / \lambda_{238} \ln \left\{1+\left[\left({ }^{206} \mathrm{~Pb}_{t}-{ }^{206} \mathrm{~Pb}_{0}\right) /{ }^{238} \mathrm{U}_{t}\right]\right\} \text {. }
$$

Similar equations apply for ${ }^{235} \mathrm{U} /{ }^{207} \mathrm{~Pb}$ and ${ }^{232} \mathrm{Th} /$ ${ }^{208} \mathbf{P b}$. Comparison of different dating methods can be used for the verification of the closed system condition (i.e., concordia, Wetherill [51]). The curve in Fig. 6 represents data that are in agreement for the ${ }^{238} \mathrm{U} /{ }^{206} \mathrm{~Pb}$ and the ${ }^{233} \mathrm{U} /{ }^{207} \mathrm{~Pb}$ systems under the concordia for- 


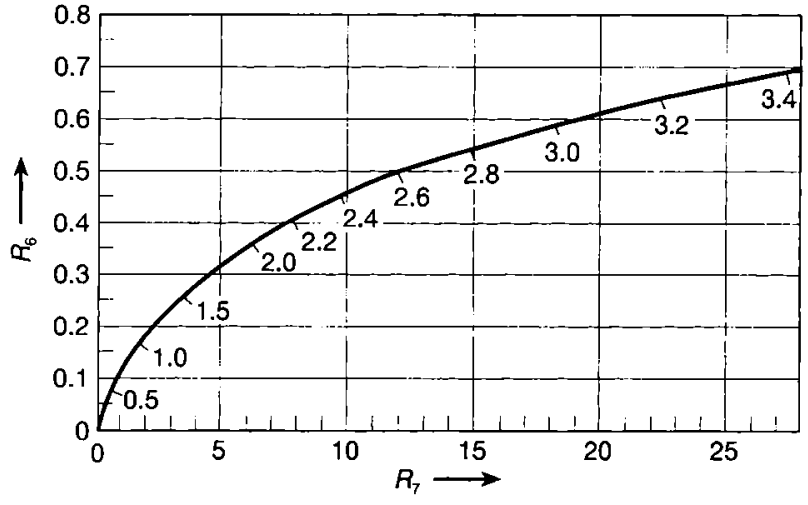

Fig. 6. Concordia diagram for the $\mathrm{U} / \mathrm{Pb}$ system, where:

$$
\begin{aligned}
& \mathrm{R}_{7}=\frac{\left({ }^{207} \mathrm{~Pb} /{ }^{204} \mathrm{~Pb}\right)_{\mathrm{t}}-\left({ }^{207} \mathrm{~Pb} /{ }^{204} \mathrm{~Pb}\right)_{0}}{{ }^{235} \mathrm{U} /{ }^{204} \mathrm{~Pb}}, \\
& \mathrm{R}_{6}=\frac{\left({ }^{206} \mathrm{~Pb} /{ }^{204} \mathrm{~Pb}\right)_{t}-\left({ }^{206} \mathrm{~Pb} /{ }^{204} \mathrm{~Pb}\right)_{0}}{{ }^{238} \mathrm{U} /{ }^{204} \mathrm{~Pb}} .
\end{aligned}
$$

The curve represents data that agree for the ${ }^{238} \mathrm{U} /{ }^{206} \mathrm{~Pb}$ and the ${ }^{235} \mathrm{U} /{ }^{217} \mathrm{~Pb}$ systems, i.e., no losses or gains of lead and uranium occurred since the formation of the samples. The numbers on the concordia curve indicate the age of the samples in $10^{9}$ years. After Friedlander et al. [10], p. 485. Copyright 1981. Reprinted by permission of John Wiley and Sons.

malism. Values below the concordia curve indicate a loss of lead or a gain of uranium, and values above the curve, a gain of lead or a loss of uranium.

Ages can also be determined from the ratio of ${ }^{206} \mathbf{P b} /{ }^{207} \mathrm{~Pb}$, if the sample contains no non-radiogenic lead (indicated by the absence of ${ }^{204} \mathrm{~Pb}$ ), using the following equations:

$$
\begin{aligned}
& { }^{206} \mathrm{~Pb}={ }^{238} \mathrm{U}\left(\mathrm{e}^{\hat{\lambda}_{238^{t}}}-\mathbf{1}\right), \\
& { }^{207} \mathrm{~Pb}={ }^{235} \mathrm{U}\left(\mathrm{e}^{\lambda_{235^{t}}}-\mathbf{1}\right) .
\end{aligned}
$$

Combining Eqs. (6) and (7)

$$
{ }^{2016} \mathrm{~Pb} /{ }^{207} \mathrm{~Pb}={ }^{238} \mathrm{U}\left(\mathrm{e}^{\lambda_{238^{\mathrm{t}}}}-1\right) /{ }^{235} \mathrm{U}\left(\mathrm{e}^{\lambda_{235} \mathrm{t}}-1\right) \text {, }
$$

where $\left({ }^{238} U /{ }^{235} U\right)=137.8$ is the present isotopic ratio.

The variation of the ${ }^{206} \mathrm{~Pb} /{ }^{2017} \mathrm{~Pb}$ ratio with time is shown in Fig. 7.

\subsection{Rubidium-Strontium dating $\left[T_{1 / 2}{ }^{87} R b=4.8 \times 10^{\prime 0}\right.$ years $]$}

${ }^{87} \mathrm{Rb}$ decays by $\beta$-emission into ${ }^{87} \mathrm{Sr}$. A detailed description of the rubidium-strontium method has been published by Bernard-Griffiths [52]. This very accurate dating method is based on a mass spectrometric measurement of ${ }^{87} \mathrm{Rb}$ and of the ${ }^{87} \mathrm{Sr} /{ }^{86} \mathrm{Sr}$ ratio, and a conventional analysis of the elemental concentrations of rubidium and strontium in the sample.

The age of a sample can then be calculated from:

$$
\left({ }^{87} \mathrm{Sr} /{ }^{86} \mathrm{Sr}\right)_{t}=\left({ }^{87} \mathrm{Sr} /{ }^{86} \mathrm{Sr}\right)_{0}+\left({ }^{87} \mathrm{Rb} /{ }^{86} \mathrm{Sr}\right)_{t}\left(e^{\lambda t}-1\right),
$$

where the subscripts $t$ and 0 refer to the present and initial values, respectively. For the stable, nonradio-

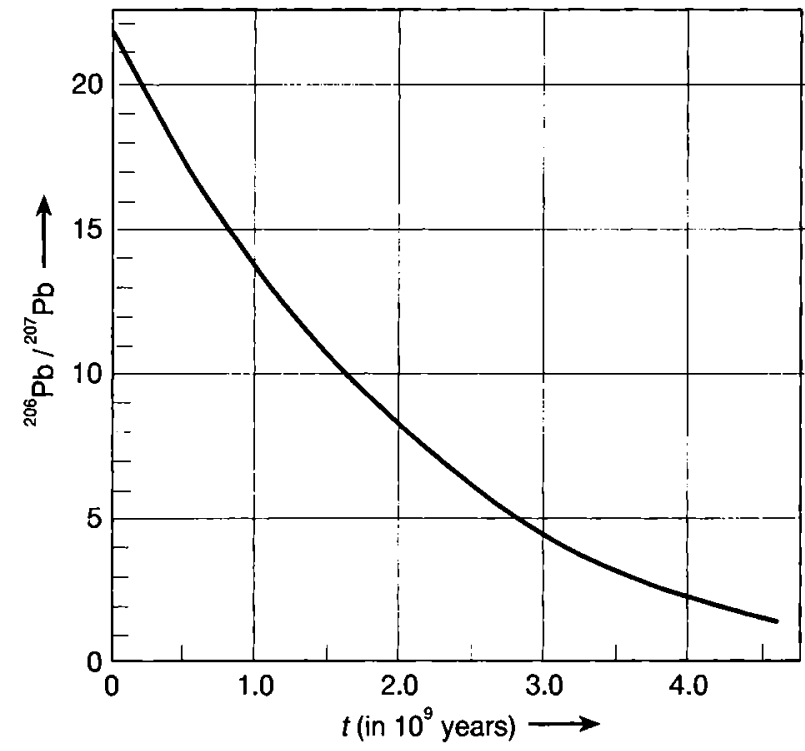

Fig. 7. Variation of radiogenic ${ }^{206} \mathrm{~Pb} /{ }^{207} \mathrm{~Pb}$ with age. After Friedlander et al. [10], p. 486. Copyright 1981. Reprinted by permission of John Wiley and Sons.

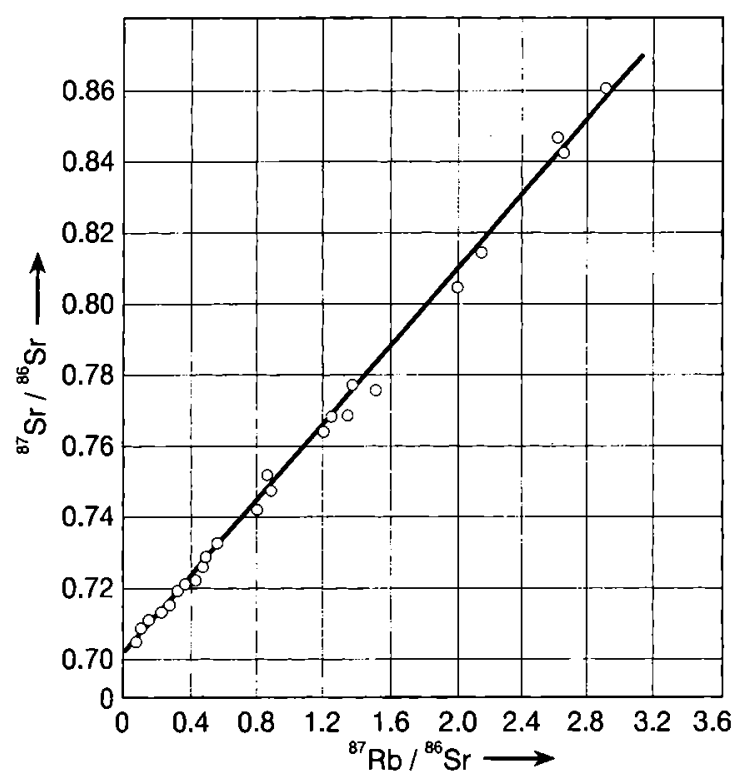

Fig. 8. $\mathrm{Rb} / \mathrm{Sr}$ isochron for a gneiss sample from Greenland [53]. The slope of the isochron shows an age of $3660 \pm 90 \mathrm{MY}$. The intercept with the ordinate indicates the ${ }^{87} \mathrm{Sr} /{ }^{66} \mathrm{Sr}$ ratio at $\mathrm{t}=0$. Reprinted with permission from NATURE. Copyright 1972, MacMillan Magazines Limited, and S. Moorbath.

genic ${ }^{86} \mathrm{Sr}$, the present and the initial values are equal. The initial $\left({ }^{87} \mathrm{Sr} /{ }^{86} \mathrm{Sr}\right)_{0}$ ratio can be obtained from the intercept of the straight line with the ordinate in an isochrone presentation of a group of samples (Fig. 8, Moorbath et al. [53]). The slope of the straight isochrone line corresponds to the age of a group of samples.

\subsection{Potassium-Argon dating $\left[T_{1 / 2}{ }^{40} \mathrm{~K}=1.28 \times 10^{9}\right.$ years $]$}

Potassium-argon dating methods have been reviewed by Montigny [54] and Malusky [55]. The $10.7 \%$ decay 
branch of ${ }^{40} \mathrm{~K}$ to stable ${ }^{40} \mathrm{Ar}$ can be used to date geological, meteoritic and lunar samples if the systems are closed with respect to potassium and argon. The following equation is used, in analogy to the rubidiumstrontium couple:

$$
\left({ }^{40} \mathrm{Ar} /{ }^{36} \mathrm{Ar}\right)_{t}=\left({ }^{40} \mathrm{Ar} /{ }^{36} \mathrm{Ar}\right)_{0}+\mathbf{f}\left({ }^{40} \mathrm{~K} /{ }^{36} \mathrm{Ar}\right)_{t}\left(\mathrm{e}^{\lambda t}-1\right),
$$

where $\mathbf{f}$ represents the branching ratio $\left(\mathrm{EC} / \beta^{-}\right)$in the decay of ${ }^{40} \mathrm{~K} .{ }^{36} \mathrm{Ar}$ is (like ${ }^{86} \mathrm{Sr}$ ) non-radiogenic and its abundance does not change with time. As for rubidium-strontium, isochron plots of ${ }^{40} \mathrm{Ar} /{ }^{36} \mathrm{Ar}$ versus ${ }^{40} \mathrm{~K} /$ ${ }^{36} \mathrm{Ar}$ will give a straight line for a group of related samples. The slope of the isochron represents the age of the samples, and the intercept with the ordinate the value of the initial $\left({ }^{40} \mathrm{Ar} /{ }^{36} \mathrm{Ar}\right)_{0}$ ratio.

In recent years a modification of the potassiumargon dating method has been introduced in many laboratories (Malusky [55]). It involves irradiating the sample with a flux of fast neutrons to produce ${ }^{39} \mathrm{Ar}$ from ${ }^{39} \mathrm{~K}$ (main $\mathrm{K}$ isotope) in a $(\mathrm{n}, \mathrm{p}$ ) reaction. The amount of ${ }^{39} \mathrm{Ar}$ produced is proportional to the potassium concentration in the sample so that one need only measure the ${ }^{40} \mathrm{Ar} /{ }^{39} \mathrm{Ar}$ ratio. The main advantage of this modified method is that reliable ages can be obtained even when diffusion losses have occurred. The ${ }^{40} \mathrm{Ar} /{ }^{39} \mathrm{Ar}$ ratios can be measured with a mass spectrometer during a stepwise heating procedure. The ${ }^{40} \mathrm{Ar} /{ }^{39} \mathrm{Ar}$ will be low in those fractions of the sample where a loss of Ar has occurred ${ }^{39} \mathrm{Ar}$ is a measure of $\mathrm{K})$. A plateau value for the ${ }^{40} \mathrm{Ar} /{ }^{39} \mathrm{Ar}$ ratio in the heating procedure indicates a region with no loss of $\mathrm{Ar}$, and, hence, a reliable age of the sample.

\subsection{Other dating techniques}

Principally, the decay of any long-lived natural radionuclide can be used for dating purposes. Based on the principles described above, the following parentdaughter systems have found many applications and are used extensively by several highly specialized laboratories:

Samarium-neodymium (Bernard-Griffiths and Gruau [56]), rhenium-osmium (Luck [57]), and lutetium-hafnium (Rees [58]).

\subsection{The age of the Earth and of the solar system}

The radionuclides discussed in this section, and, when possible, combinations of several methods, enable a determination of the age of the Earth and meteorites and an estimate of the age of the solar system. These dating methods have helped considerably to increase our knowledge of the development and history of geological, lunar and meteoritic materials (e.g., Wetherill [59]; Faure [15]).

The method of isochrones, as discussed above for rubidium-strontium and potassium-argon can be extended to the uranium lead system, according to:
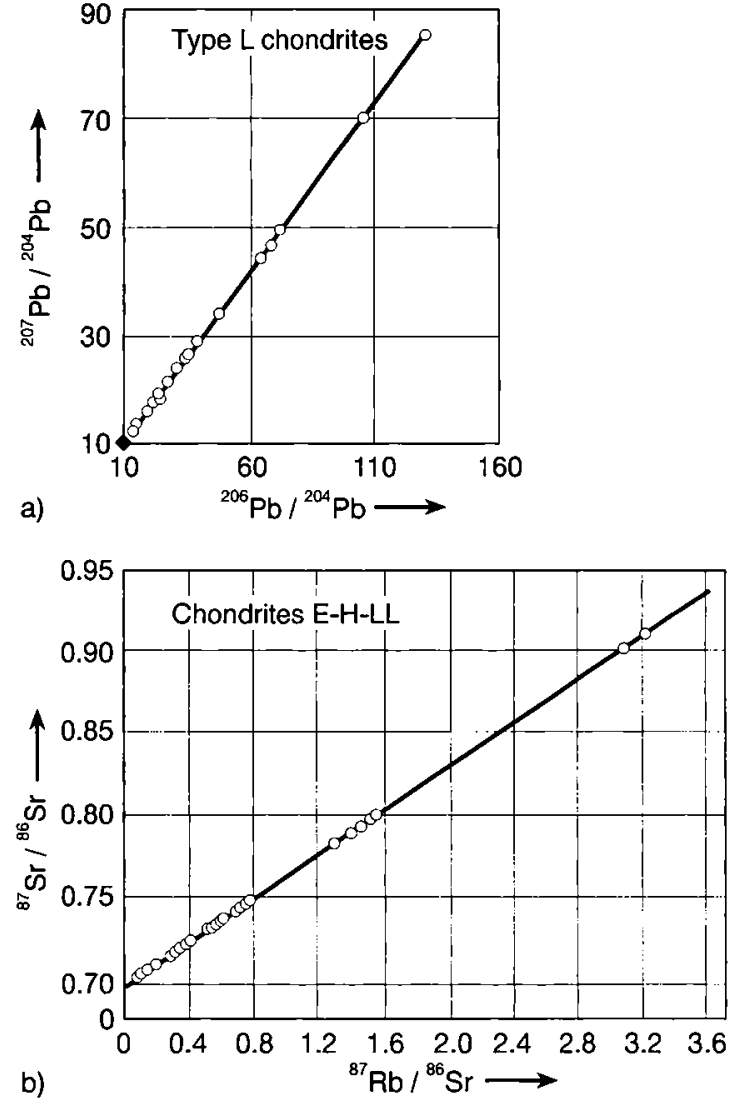

Fig. 9. (a) ${ }^{207} \mathrm{~Pb} /{ }^{204} \mathrm{~Pb}$ isochron of meteorites of the $\mathrm{L}$ type $(\mathrm{O})$ and a troiilite from Canion Diablo $(\downarrow)$ showing an age of $(4.555 \pm 0.014) \times 10^{\circ}$ years (after G. Manhes, Thèse, Univ. de Paris VII, 1982). (b) $\mathrm{Rb} / \mathrm{Sr}$ isochron of $\mathrm{E}, \mathrm{H}$, and LL type chondrites with an age of $(4,504 \pm 0.015) \times 10^{\circ}$ years and an initial ratio ${ }^{87} \mathrm{Sr} /{ }^{86} \mathrm{Sr}_{0}=0.69885 \pm 0.00010$ (after J. F. Minster, Thèse, Univ. de Paris VII, 1979). Reprinted by permission of Kluwer Academic Publishers.

$$
\frac{\left({ }^{207} \mathrm{~Pb} /{ }^{204} \mathrm{~Pb}\right)_{t}-\left({ }^{207} \mathrm{~Pb} /{ }^{204} \mathrm{~Pb}\right)_{0}}{\left({ }^{206} \mathrm{~Pb} /{ }^{204} \mathrm{~Pb}\right)_{t}-\left({ }^{206} \mathrm{~Pb} /{ }^{204} \mathrm{~Pb}\right)_{0}}=\frac{{ }^{235} \mathrm{U}\left(\mathrm{e}^{\lambda_{233 t}}-1\right)}{{ }^{238} \mathrm{U}\left(\mathrm{e}^{\dot{2}_{238^{2}}}-1\right)}
$$

Using isochrones of uranium-lead and rubidiumstrontium, the age of meteorites has been measured very precisely (Fig. 9). These ages fall in a very narrow range of $(4.54 \pm 0.02) \times 10^{\circ}$ years (Albarède [60]), strongly supporting the hypothesis that meteorites were formed simultaneously from a homogeneous cloud of gas and dust.

Patterson [61] found that terrestrial lead from ocean sediments with ${ }^{206} \mathrm{~Pb} /{ }^{204} \mathrm{~Pb}$ and ${ }^{207} \mathrm{~Pb} /{ }^{204} \mathrm{~Pb}$ ratios of 19.0 and 15.8 , respectively, representing a wellmixed sample, matched the isochrone of the meteoritic lead samples (e.g., that of Fig. 9a). Again, this strongly supports the hypothesis that the Earth was formed as an isolated body at the same time as the meteorites, i.e., 4540 MY years ago, or, as suggested by Albarède [60] and others, about $60 \mathrm{MY}$ later. The oldest rocks on Earth have ages between 3500-3700 MY (e.g., Fig. 8, Moorbath [53]). Some Australian zircons may even be older, i.e., 4100-4200 MY (Moorbath [62]). 
Ages of lunar samples show a considerable variation, depending on their origin. This variation is caused by the cratering activity during the intensive meteoritic bombardment of the lunar surface in the early history of the Moon. However, the oldest samples, recovered from the lunar highlands by the Apollo- 17 astronauts, are about $4500 \mathrm{MY}$ old (e.g., Taylor [63]), and represent the age of the Moon. Samples from the mare regions, on the other hand, are younger, about 3500 MY old (Dalrymple [64]; Swindle et al. [65]). This shows that the maria (the dark basins on the Moon, that are visible from Earth) were formed later. Large meteoritic impacts on the Moon probably triggered the outflow of lava streams from the molten interior. A chemical fractionation of parent and daughter nuclides in the lava melt then set back the radioactive clock. An example for a lunar site which was formed by an impact event is the crater Copernicus. Its age was recently redetermined to 800 MY (Bogard et al. [66]). Dating of lunar samples was a very important mean for a reconstruction of the history of the Moon.

\section{Radioactive disequilibrium}

Many aspects of uranium-series disequilibrium have been discussed in detail in the recent book by Ivanovich and Harmon [67] including the application of radioactive disequilibria for dating purposes (Ivanovich et al. [68]). In the natural decay chains of uranium and thorium, the secular radioactive equilibrium is often externally disturbed, i.e., the radioactive decay chain is interrupted at a certain chain member. In this case, the decay of a radionuclide that was separated by chemical or physical means from its precursor (daughter-excess method), or the ingrowth of a radioactive daughter product, which was separated before, into a parent sample (daughter-deficiency method) can be used for dating purposes. A separation of parent and daughter nuclide can, for instance, occur during sedimentation processes, and, thus, initiate a radioactive disequilibrium. If the separated sediments become a closed system, it is possible to determine the date of the separation event. Important examples of this type are disequilibria between ${ }^{230} \mathrm{Th}$ and ${ }^{234} \mathrm{U}$, or between ${ }^{231} \mathbf{P a}$ and ${ }^{235} \mathbf{U}$.

\subsection{Dating methods based on the accumulation of a radioactive daughter}

Determination of groundwater residence times with radon-222 [ $T_{1 / 2}=3,825$ days]

In geological regions containing unconsolidated sediments (e.g., glaciofluvial deposits), surface water may infiltrate and become shallow groundwater. Hoehn and von Gunten [69] and Hoehn et al. [70] have used ${ }^{222} \mathrm{Rn}$ to estimate the residence time and the related flow velocity in groundwater reservoirs of Switzerland. In sur-

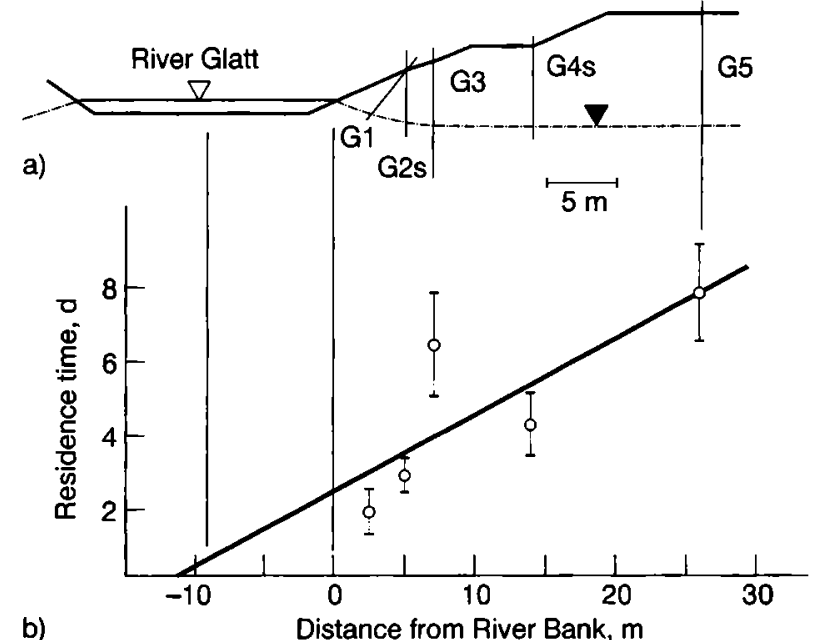

Fig. 10. Dating with radon: (a) schematic cross section of the River Glatt site, Switzerland, and (b) linear regression line through data points corresponding to a mean groundwater flow velocity of $5 \mathrm{~m}$ per day, after [69]. Courtesy American Geophysical Union.

face waters, the radioactive equilibrium between ${ }^{226} \mathrm{Ra}$ and ${ }^{222} \mathrm{Rn}$ is strongly perturbed, because the water is only in contact with the uppermost layers of sediments and outgases to the atmosphere. This leads to very low radon concentrations in surface waters. When this radon-depleted surface water infiltrates into an aquifer, it picks up more and more radon (emanating from aquifer grains) which, finally, at a certain distance from the point of infiltration, reaches a steady state activity. Measurements of this steady state activity, $\mathbf{A}_{\infty}$, and activities, $\mathbf{A}_{t}$, along the flow path, enable a calculation of the groundwater residence time and its related flow velocity, using the radioactive decay law (Fig. 10), e.g.,

$$
A_{t}=A_{\infty}\left(1-\mathbf{e}^{-i t}\right) \text {. }
$$

This method has also been used to obtain information about residence times in artificial bank filtration in the purification process of drinking water (Schulte-Ebbert et al. [71]). The described radon method allows, under favorable conditions, to assess groundwater residence times of about 15 days.

\section{The ${ }^{230} \mathrm{Th}^{238} \mathrm{U}$, and the ${ }^{231} \mathrm{~Pa}{ }^{235} \mathrm{U}$ methods \\ $\left[T_{1 / 2}{ }^{230} \mathrm{Th}=7.54 \times 10^{4}\right.$ years, \\ $T_{1 / 2}{ }^{231} \mathrm{~Pa}=3.276 \times 10^{4}$ years $]$}

The ${ }^{230} \mathrm{Th} /{ }^{234,238} \mathrm{U}$ method is based on the decay of ${ }^{238} \mathrm{U}\left(\alpha, T_{1 / 2}=4.468 \times 10^{9}\right.$ years $)$ through ${ }^{234} \mathrm{Th}\left(\beta^{-}\right.$, 24.1 days), ${ }^{234 \mathrm{~m} .234} \mathrm{~Pa}\left(\beta^{-}, 1.2 \mathrm{~min}\right.$ and $\left.6.7 \mathrm{~h}\right)$ and ${ }^{234} \mathrm{U}$ $\left(\alpha, 2.446 \times 10^{5}\right.$ years $)$ into ${ }^{230} \mathrm{Th} .{ }^{234} \mathrm{Th}$ and ${ }^{234 \mathrm{~m} .234} \mathrm{~Pa}$ always reach secular equilibrium with ${ }^{238} U$. If secular radioactive equilibrium also exists between ${ }^{238} \mathrm{U}$ and ${ }^{234} \mathrm{U}$, the age, $t$, of a sample is calculated according to:

$$
{ }^{230} \mathrm{Th} /{ }^{238} \mathrm{U}=1-\mathrm{e}^{-\lambda t} \text {. }
$$

However, the ratio of ${ }^{234} \mathrm{U} /{ }^{238} \mathrm{U}$ is often not unity, and therefore, taking into account this additional 
disequilibrium, the correct equation becomes more complicated than Eq. (13). The accumulation (ingrowth) of ${ }^{230} \mathrm{Th}$ from ${ }^{238} \mathrm{U}$ can be used to date marine and terrestrial phosphorites (fluorapatite) and carbonates (e.g., fossil corals, shells, speleothems, bones, travertines) and volcanic rocks with ages of $\leq 350,000$ years. These applications have been reviewed by Burnett and Veeh [72], and Schwarcz and Blackwell [73]. For instance, sedimentary apatite contains relatively high concentrations of uranium, but generally low contents of thorium. If the apatite-inclusions in phosphorites acquired mainly uranium and, any or very little ${ }^{230} \mathrm{Th}$ (or ${ }^{231} \mathrm{~Pa}$ ) during mineral formation, and if the time of the mineral formation is short as compared to the half-lives of these radionuclides, and the formed minerals remained as a closed system, the age of formation of the minerals can be determined accurately. These assumptions seem to be valid for marine phosphorites. Marine carbonates (e.g., reef-building corals) contain, at the time of formation, several parts per million (ppm) of uranium, but essentially no ${ }^{230} \mathrm{Th}$. Samples from drill cores showed that ${ }^{230} \mathrm{Th}$ increased in stratigraphically older corals, and finally reached equilibrium values. Calcium carbonate precipitation occurs usually from saturated solutions that contain a few ppm of uranium as carbonate, phosphate or humic acid complexes, but, due to its low solubility, essentially no thorium. The resulting closed calcite formations contain then a few ppm uranium, but no ${ }^{230} \mathrm{Th}$, and are ideally suited for dating samples which are related to archeological and or Quaternary geological problems.

The ${ }^{231} \mathrm{~Pa} /{ }^{235} \mathrm{U}$ method is based on the decay of ${ }^{235} \mathrm{U}$ through ${ }^{231} \mathrm{Th}\left(\beta^{-}, 25.5 h\right)$ into ${ }^{231} \mathrm{~Pa}$. Again, the half-life of ${ }^{231} \mathrm{Th}$ is short enough to be always in secular equilibrium with ${ }^{235} \mathrm{U}$, and the age of a sample can be calculated:

$$
{ }^{231} \mathbf{P a} /{ }^{235} \mathrm{U}=1-\mathbf{e}^{-i t} \text {. }
$$

The applications of the ${ }^{231} \mathrm{~Pa} /{ }^{235} \mathrm{U}$ method are similar as for ${ }^{230} \mathrm{Th} /{ }^{238} \mathrm{U}$, however, the accessible time is shorter, $\leq 150,000$ years.

\subsection{Dating methods based on the decay of separated (excess) uranium daughter products}

In the hydrological cycle a natural chemical fractionation occurs due to different solubilities of uraniumseries daughter nuclides from their parents. The insoluble radioactive daughter nuclides (i.e., ${ }^{230} \mathrm{Th}$ and ${ }^{231} \mathrm{~Pa}$ ) accumulate in bottom sediments of oceans and lakes, whereas uranium remains in solution as stable uranyl carbonate complexes. The excess of the separated radionuclide decays according to the decay constant of the radionuclide. The age or the accumulation rate of a deposit can then be determined by the general radioactive decay law.

A review of these methods, in relation to marine sediments and sedimentation processes, has been pub- lished by Huh and Kadko [74]. The half-lives of ${ }^{230} \mathrm{Th}$ and ${ }^{231} \mathrm{~Pa}$ are very favorable to date sedimentation rates of deep-sea sediments which accumulate by about 1 to $30 \mathrm{~mm}$ in 1000 years. Both nuclides adsorb strongly to particles and accumulate in marine sediments, where they are practically unsupported by their parents. After burial by ongoing sedimentation, the unsupported nuclides decay with depths (time) according to their half-lives. Assumptions for the validity of the method are a constant production in sea water, and a constant sedimentation rate. They were found valid in many investigations.

\section{Fission tracks}

The method of fission track dating has been reviewed by Carpéna and Mailhé [75]. For details, the reader is referred to this publication. Here, only the basic principles are summarized. The energetic fragments resulting from the spontaneous fission of ${ }^{238} U$ produce micro-damages in solid materials which can be enlarged by chemical etching to be visible under a light microscope. The density of tracks (number of tracks per surface unity) is a function of the age of the sample (the duration of the spontaneous fission process), and its concentration of uranium, if no physical (e.g., heating) and chemical changes occurred in the minerals during this time period. For an age determination it is necessary to measure the fission track density, and the uranium content. Usually, this is done in two steps: i) the tracks that were naturally produced in minerals and glasses by ${ }^{238} \mathrm{U}$ spontaneous fission are counted; ii) the uranium concentration is determined from the tracks formed by ${ }^{235} \mathrm{U}$-fission during a reactor irradiation in a well known thermal neutron flux. The age of the sample is calculated from:

$$
t=1 / \lambda_{238} \log \left\{1+\left(D_{235} / D_{238}\right) \cdot\left(\lambda_{238} / \lambda_{\mathrm{SF}}\right) \cdot \sigma \cdot \mathrm{I} \cdot \phi\right\},
$$

where $\lambda_{238}$ and $\lambda_{\mathrm{SF}}$, decay constant of ${ }^{238} U$ and partial decay constant for spontaneous fission of ${ }^{238} U$, respectively,

$\mathbf{D}_{238}$ and $\mathbf{D}_{235}$, natural fission tracks $\left({ }^{238} \mathrm{U}\right)$ per $\mathrm{cm}^{2}$ and tracks produced in the thermal-neutron fission of ${ }^{235} \mathrm{U}$ per $\mathrm{cm}^{2}$, respectively,

I, isotope ratio of natural uranium, i.e., 137.8,

$\sigma$, fission cross-section of ${ }^{235} \mathrm{U}$, and $\phi$, reactor neutron flux per $\mathrm{cm}^{2}$ and $\mathrm{s}$.

There exists still an uncertainty of about $15 \%$ among different authors for the value of the decay constant for spontaneous fission of ${ }^{238} \mathrm{U}$. An other problem inherent to this method is, that the fission tracks may disappear ('anneal') when the samples are subjected to elevated temperatures. The annealing temperatures depend very much on the investigated minerals. For instance, in an autunite the fission tracks disappeared completely already at $60^{\circ} \mathrm{C}$ (Fleischer and Price [76]). On the other hand, the annealing of fission tracks may be directly used to obtain informations on the tempera- 
ture history of a sample, if its age is known from other methods. Sometimes it is also difficult to distinguish fission tracks from other damages in the samples. Furthermore, fission tracks may overlap, be hidden and lost in counting. Due to these problems, the method of fission track dating, is, in the opinion of this author, less reliable and less accurate than other dating methods, like for instance the uranium-lead method. An advantage of the fission track chronometer is that it is less affected than other methods by chemical changes in the minerals. This is due to the fact that the fission fragments produce relatively stable physical damages in the minerals or glasses, and not chemically mobile radionuclides that can migrate out of the samples.

\section{Thermoluminescence}

Many electrically non-conducting minerals, that were exposed to artificial or natural irradiation, emit light when they are heated. This phenomenon, called thermoluminescence, has been observed already in 1663 by Boyle, when he heated a diamond. A comprehensive review of this method has been given by Lalou and Valladas [77].

In this method, as in the fission track method, neither the decrease of the number of radioactive nuclides with time nor the transformation of a parent nuclide into a daughter product is used to obtain the dating information. The age of a sample is deduced from the effects of the radiation energy that is deposited and has accumulated in the sample since its formation. Due to the long half-lives of the main radionuclides involved, the radiation dose rate can be assumed as constant. In nature, minerals of quartz, feldspar, micas, calcite, etc., are continuously irradiated by $\alpha-, \beta$, and $\gamma$-radiation resulting from the decay of members of the natural uranium and thorium decay chains, or from the decay of ${ }^{40} \mathrm{~K}$. Hereby, atoms are ionized and the electrons are trapped in crystal defects, from where they cannot escape without an external excitation. In the thermoluminescence method the external excitation is promoted by heating. Part of the trapped electrons combine with holes, others form luminous centers. With increasing temperature, one may observe several light signals. First, the least stable trapped electrons are released, and at the highest temperature, the most stable ones. Thus, a thermoluminescence curve is obtained which is characteristic for a sample and its irradiation history.

If a sample is heated for a second time, no further light signals are observed. However, if such annealed crystals are exposed to a radiation source, a new thermoluminescence curve is obtained which differs from the first one by showing peaks at lower temperatures (i.e., above $100^{\circ} \mathrm{C}$ ), in addition to the signals at higher temperature $\left(230-400^{\circ} \mathrm{C}\right)$ which were already observed during the first heating. For applications, it is advisable to use the signals emitted at high temperature. Artificial irradiation experiments with increasing radiation doses have shown that the high temperature thermoluminescence is proportional to the irradiation dose of the material. If the investigated sample remained in the same environment during its whole history, then the irradiation dose rate can be assumed as constant, and it is in principal possible to evaluate the age of the sample from the magnitude of the high temperature thermoluminescence peak. The age of a sample can be calculated from the following relation, if the annual irradiation dose is exactly known:

age $=$ natural dose/annual dose .

The natural dose is the total radioactive decay energy acquired per unit mass since the formation (e.g., crystallization) of a sample. The annual dose is the energy corresponding to the radioactive decay of the nuclides in the sample. This emitted decay energy is not related in a simple way to the energy acquired by the sample. By far the largest amount of energy is contributed by $\alpha$-decay of the uranium and thorium decay families. But the range of $\alpha$-particles in solid matter is only $20-50 \mu \mathrm{m}$, depending on their energy and the density of the material. On the other hand, the ranges of $\beta$-particles in solids are of the order of a $\mathrm{mm}$, and $\gamma$-rays travel much farther and have only a few interactions when traversing the solid material. It is, therefore, necessary to establish efficiencies for the energy deposition for each type of radiation and material. Furthermore, corrections for inhomogeneities in the samples have to be made. The range of linearity between the dose and the thermoluminescence signal is limited; at higher doses a saturation effect is observed. For quartz, saturation occurs at $100-500$ Gy $(10-50$ krad), whereas calcite can accept 3000 Gy (300 krads).

Despite these problems (for a more comprehensive review, see the paper by Lalou and Valladas [77]), thermoluminescence has been successfully used to date archaeological (e.g., ceramic artifacts, burned stones used as kitchen utensils, stone tools, etc.), and geological samples (e.g., recent volcanic rocks, young calcite formations in caves, very fine aeolien deposit in which the thermoluminescence was annealed by exposure to bright sunlight when they resided on the surface, etc.).

Thermoluminescence is certainly related to the age of the samples. However, its application is not as straightforward as in many of the other dating methods, and practically each application has its specific and inherent problems. The method should not be applied blindly. But if all the problems are treated properly, it can be used to assess a time-range which falls between that of the applicability of ${ }^{14} \mathrm{C}$ and the lower limit of the potassium-argon method.

\section{Conclusions}

The discovery of the radioactivity in 1896 , and the laws of the radioactive decay have opened the possibility to date accurately many objects in our environ- 
ment. Sensitive instruments and methods, and an impressive number of radionuclides enabled to determine the age of archaeological, geological, cosmological and other samples. These methods have greatly helped to improve our knowledge about archeology and historical developments, and our insight into the evolution of the solar system, and among it, of the Earth and the Moon. The radioactive dating methods are in principle straightforward, quite easy to apply, and accurate, but may lead to erroneous results if the physical and chemical background of the investigated system is not thoroughly understood. In order to avoid misinterpretations and systematic errors it is advisable, whenever possible, to verify the age of a sample by more than one method.

\section{Acknowledgement}

The author thanks J. P. Adloff and an anonymous reviewer for constructive comments, and U. Krähenbühl and K. Tabor for improvements.

\section{References}

1. Roth, E.: Dating methods using natural radioactive phenomena: principles and general aspects. Nuclear Methods of Dating (E. Roth and B. Poty, Eds.), pp. 1-34, Kluwer Academic Publishers, 1989.

2. Roth, E., Poty, B. (Eds.): Nuclear Methods of Dating. Kluwer Academic Publishers, 1989.

3. Nier, A. O.: Variations in the relative abundances of the isotopes of common lead from various sources. J. Am. Chem. Soc. 60, 1571-1576 (1938).

4. Nier, A. O., Thompson, R. W., Murphy, B. F.: The isotopic constitution of lead and the measurement of geologic time III. Phys. Rev. 60, 112-116 (1941).

5. Holmes, A.: An estimate of the age of the Earth. Nature 157, 680-684 (1946).

6. Houtermans, F. G.: Die Isotopen-Häufigkeiten im natürlichen Blei und das Alter des Urans. Naturwissenschaften 33, 185-186 (1946).

7. Libby, W. F.: Radiocarbon Dating, University of Chicago Press 1952.

8. Goldberg, E. D.: Geochronology with lead-210. Symp. Radioactive Dating, pp. 121-131. Internat. Atomic Energy Agency, IAEA, Vienna 1963.

9. Choppin, G. R., Rydberg, J.: Nuclear Chemistry, Theory and Applications. Pergamon Press, 1980.

10. Friedlander, G., Kennedy, J. W., Macias, E. S., Miller, J. M.: Nuclear and Radiochemistry, 3rd ed. Wiley-Interscience, 1981.

11. Ehmann, D. E., Vance, D. E.: Radiochemistry and Nuclear Methods of Analysis. Wiley, 1991.

12. Lieser, K. H.: Einführung in die Kernchemie. 3. Aufl. Verlag Chemie, 1991.

13. Currie, L. A. (Ed.): Nuclear and Chemical Dating Techniques. Interpreting the Environmental Record. ACS Symposium Series 176, American Chemical Society, 1982.

14. Durrance, E. M.: Radioactivity in Geology, Principles and Applications. Ellis Horwood, 1986.

15. Faure, G.: Principles of Isotope Geology, 2nd Ed. Wiley, 1986.

16. Gäggeler, H., von Gunten, H. R., Rössler, E., Oeschger, H., Schotterer, U.: ${ }^{210} \mathrm{~Pb}$-dating of alpine fim/ice cores from Colle Gnifetti, Switzerland. J. Glaciology 29, 165-177 (1983).
17. Damon, P. E., Lerman, J. C., Long, A.: Temporal functions of ${ }^{14} \mathrm{C}$ : Causal factors and Implications. Ann. Rev. Earth Planet. Sci. 6, 457-494 (1978).

18. Stuiver, M., Kromer, B., Becker, B., Ferguson, C. W.: Radiocarbon age calibration back to 13,300 years $\mathrm{BP}$ and the ${ }^{14} \mathrm{C}$ age matching of the German oak and US bristlecone pine chronologies. Radiocarbon 28, 969-979 (1986).

19. Stuiver, M., Pearson, G. W., Braziunas, T.: Radiocarbon age calibration of marine samples back to 9000 cal yr BP. Radiocarbon 28, 980-1021 (1986).

20. Bard, E., Hamelin, B., Fairbanks, R. G., Zindler, A.: Calibration of the ${ }^{14} \mathrm{C}$ time scales over the past 30,000 years using mass spectrometric $\mathrm{U}-\mathrm{Th}$ ages from Barbados corals. Nature 345, 405-410 (1990).

21. Finkel, R. C., Suter, M.: AMS in the Earth Sciences: Techniques and Applications. Adv. Anal. Geochem. 1, 1-114 (1993).

22. Zbinden, H., Andree, M., Oeschger, H., Ammann, B., Lotter, A., Bonani, G., Wölfli, W.: Atmospheric radiocarbon at the end of the last glacial: An estimate based on AMS radiocarbon dates on terrestrial macrofossils from lake sediments. Radiocarbon 31, 795-804 (1989).

23. Currie, L. A., Fletcher, R. A., Klouda, G. A.: On the identification of carbonaceous aerosols via ${ }^{14} \mathrm{C}$ accelerator mass spectrometry and laser microprobe mass spectrometry. Nucl. Instr. Meth. B29, 346-354 (1987).

24. Davis, S. N., Murphy, E.: Dating Ground Water and the Evaluation of Repositories for Radioactive Waste. NUREG/ CR-4912. U.S. Nuclear Regulatory Commission, 1987.

25. Jull, A. J. T., Donahue, D. J., Linick, T. W.: ${ }^{14} \mathrm{C}$ activities in recently fallen meteorites and Antarctic meteorites. Geochim. Cosmochim. Acta 53, 2095-2100 (1989).

26. Damon, P. E., Donahue, D. J., Gore, B. H., Hatheway, A. L., Jull, A. J. T., Linick, T. W., Sercel, P. J., Toolin, L. J., Bronk, C. R., Hall, E. T., Hedges, R. E. M., Housley, R., Law, I. A., Perry, C., Bonani, G., Trumbore, S., Wölfli, W., Ambers, J. C., Bowman, S. G. E., Leese, M. N., Tite, M. S.: Radiocarbon dating of the shroud of Turin. Nature 337 , 611-616 (1989).

27. Broecker, W. S., Peng, T.-H.: Tracers in the Sea. ELDIGIO Press, Palisades, N.Y., 1982.

28. Wilson, A. T., Donahue, D. J.: AMS carbon-14 dating of ice-progress and future prospects. Nucl. Instr. Meth. AMS 5 (1990).

29. Hofmann, H. J., Beer, J., Bonani, G., von Gunten, H. R., Raman, S., Suter, M., Walker, R. L., Wölfli, W., Zimmermann, D.: ${ }^{10} \mathrm{Be}$ : Half-life and AMS-standards. Nucl. Instr. Meth. B29, 32-36 (1987).

30. Bourlès, D. L.: Beryllium isotopes in the Earth's environment. In: Encyclopedia of Earth System Science, pp. 337352. Academic Press, 1992.

31. Beer, J., Blinov, A., Bonani, G., Finkel, R. C., Hofmann, H. J., Lehmann, B., Oeschger, H., Sigg, A., Schwander, J., Staffelbach, T., Stauffer, B., Suter, M., Wölfli, W.: Use of ${ }^{10} \mathrm{Be}$ in polar ice to trace the 11-year cycle of solar activity. Nature 347, 164-166 (1990).

32. Anderson, R. F., Lao, Y., Broecker, W. S., Trumbore, S. E., Hofmann, H. J., Wölfli, W.: Boundary scavenging in the Pacific Ocean: a comparison of ${ }^{10} \mathrm{Be}$ and ${ }^{231} \mathrm{~Pa}$. Earth Planet. Sci. Lett. 96, 287-304 (1990).

33. Brown, L.: ${ }^{10} \mathrm{Be}$ : recent applications in Earth sciences. Philos. Trans. R. Soc. Lond. A323, 75-86 (1987).

34. Nishiizumi, K.: ${ }^{53} \mathrm{Mn},{ }^{26} \mathrm{Al},{ }^{10} \mathrm{Be}$ and ${ }^{36} \mathrm{Cl}$ in meteorites: data compilation. Nucl. Track Radiation Meas. 13, 209-237 (1987).

35. Nishiizumi, K., Imamura, M., Kohl, C. P., Nagai, H., Kobayashi, K., Yoshida, K., Yamashita, H., Reedy, R. C., Honda, M., Amold, J. R.: "Be profiles in lunar surface rock 68815. Proc. Lunar Planet Sci. Conf. 18th, 79-85 (1987).

36. Siegenthaler, U., Beer, J.: Model comparison of ${ }^{14} \mathrm{C}$ and ${ }^{10} \mathrm{Be}$ isotope records. In: Secular Solar and Geomagnetic Variations in the Last 10,000 Years (F. R. Stephenson and A. W. Wolfendale, Eds.), Kluwer Academic Publishers, Vol. 236, 315-328 (1988). 
37. Hofmann, H. J., Bonani, G., Suter, M., Wölfli, W., Zimmermann, D., von Gunten, H. R.: A new determination of the half-life of ${ }^{32} \mathrm{Si}$. Nucl. Instr. Meth. B 52, 544-551 (1990).

38. Chen, Y., Kashy, E., Banzin, D., Benenson, W., Morrissey, D. J., Orr, N. A., Sherrill, B. M., Winger, J. A., Young, B., Yurkon, J.: Half-life of ${ }^{32}$ Si. Phys. Rev. C 47, 1462-1465 (1993).

39. Gellerman, R., Börner, J., Franke, T., Fröhlich, K.: Isotopenpraxis 24, 114-117 (1988).

40. Zoppi, U., Kubik, P. W., Suter, M., Synal, H.-A., von Gunten, H. R., Zimmermann, D.: High Intensity isobar separation at the Zürich AMS facility. Nucl. Instr. Meth. B 92, 142-145 (1994).

41. Middleton, R., Klein, J.: ${ }^{26} \mathrm{Al}$ : Measurements and applications. Philos. Trans. R. Soc. Lond. A 323, 121-143 (1987).

42. Bentley, H. W., Philipps, F. M., Davis, S. N.: Chlorine-36 in the terrestrial environment. In: Handbook of Environmental Isotope Geochemistry (P. Fritz and J. C. Fontes, Eds.), Elsevier Scientific Publishing, Vol. 2, pp. 427-480 (1986).

43. Synal, H.-A., Beer, J., Bonani, G., Suter, M., Wölfli, W.: Atmospheric transport of bomb-produced ${ }^{36} \mathrm{Cl}$. Nucl. Instr. Meth. B 52, 483-488 (1990).

44. Gove, H.: Tandem-accelerator mass-spectrometry measurements of ${ }^{36} \mathrm{Cl},{ }^{129} \mathrm{I}$ and osmium isotopes in diverse natural samples. Philos. Trans. R. Soc. Lond. A 323, 103-119 (1987).

45. Hallet, B., Putkonen, J.: Surface dating of dynamic landforms: young boulders on aging moraines. Science 265, 937-940 (1994).

46. Fabryka-Martin, J., Bentley, H., Elmore, D., Airey, P. L.: ${ }^{124} \mathrm{I}$ as an environmental tracer. Geochim. Cosmochim. Acta 49, 337-347 (1985)

47. Krishnaswami, S., Lal, D., Martin, J. M., Meybeck, M.: Geochronology of lake sediments. Earth Planet. Sci. Lett. 11, 407-414 (1971).

48. von Gunten, H. R., Moser, R. N.: How reliable is the ${ }^{210} \mathrm{~Pb}$ dating method? Old and new results from Switzerland. J. Paleolimnol. 9, 161-178 (1993).

49. Erten, H. N., von Gunten, H. R., Rössler, E., Sturm, M.: Dating of sediments from Lake Zürich (Switzerland) with ${ }^{211} \mathrm{~Pb}$ and ${ }^{137} \mathrm{Cs}$. Schweiz. Z. Hydrol. 47, 5-11 (1985).

50. Albarède, F., Michard, A., Cuney, M.: Uranium-thoriumlead dating. In: Nuclear Methods of Dating (E. Roth and B. Poty, Eds.), pp. 111-161, Kluwer Academic Publishers, 1989.

51. Wetherill, G. W.: Discordant uranium-lead ages I. Trans. Am. Geophys. Union 37, 320-326 (1956).

52. Bernard-Griffiths, J. B.: The rubidium-strontium method. In: Nuclear Methods of Dating (E. Roth and B. Poty, Eds.), pp. 73-94, Kluwer Academic Publishers, 1989.

53. Moorbath, S., O'Nions, R. K., Parkhurst, R. J., Gale, N. H., McGregor, V. R.: Further rubidium strontium age determinations on the very early precambrian rocks of the Godthaab district, West Greenland. Nature Phys. Sci. 240, 78-82 (1972).

54. Montigny, R.: The conventional potassium-argon method. In: Nuclear Methods of Dating (E. Roth and B. Poty, Eds.), pp. 295-324, Kluwer Academic Publishers, 1989.

55. Malusky, H.: Argon- 39 - argon-40 dating. Principles and applications to minerals from terrestrial rocks. In: Nuclear Methods of Dating (E. Roth and B. Poty, Eds.), pp. 325351, Kluwer Academic Publishers, 1989.

56. Bernard-Griffiths, J., Gruau, G.: The samarium-neodymium method. In: Nuclear Methods of Dating (E. Roth and B. Poty, Eds.), pp. 53-72, Kluwer Academic Publishers, 1989.

57. Luck, J.-M.: The rhenium-osmium system. In: Nuclear Methods of Dating (E. Roth and B. Poty, Eds.), pp. 95104, Kluwer Academic Publishers, 1989.
58. Rees, T.: The lutetium-hafnium method. In: Nuclear Methods of Dating (E. Roth and B. Poty, Eds.), pp. 105110, Kluwer Academic Publishers, 1989.

59. Wetherill, G. W.: Radiometric chronology of the early solar system. Ann. Rev. Nucl. Sci. 25, 283-328 (1975).

60. Albarède, F.: The age of the earth and meteorites, and extinct radioactivities. In: Nuclear Methods of Dating (E. Roth and B. Poty, Eds.), pp. 45-52, Kluwer Academic Publishers, 1989.

61. Patterson, C.: Age of meteorites and the Earth. Geochim. Cosmochim. Acta 10, 230-237 (1956).

62. Moorbath, S.: The most ancient rocks? Nature 307, 585$586(1983)$

63. Taylor, S. R.: Lunar Science: A Post-Apollo View. Pergamon Press, 1975.

64. Dalrymple, G. B.: ${ }^{40} \mathrm{Ar} /{ }^{39} \mathrm{Ar}$ ages of six Apollo 15 impact melt rocks by laser stepwise heating. Geophys. Res. Lett. 18, 1163-1166 (1991).

65. Swindle, T. D., Spudis, P. D., Taylor, G. J., Korotev, R. L., Nichols, R. H.: Searching for Crisium Basin ejecta. Chemistry and ages of Luna 20 impact melts. Proc. Lunar Planet. Sci. Conf. 21, 167-181 (1990), Houston 1991.

66. Bogard, D. D., Garrison, D. H., Shih, C.-Y., Nyquist, L. E.: ${ }^{39} \mathrm{Ar}-{ }^{40} \mathrm{Ar}$ dating of two lunar granites: The age of Copernicus. Geochim. Cosmochim. Acta 58, 3093-3100 (1994).

67. Ivanovich, M., Harmon, R. S. (Eds.): Uranium-series Disequilibrium: Applications to Earth, Marine, and Environmental Sciences. Clarendon Press, 2nd Ed., 1992.

68. Ivanovich, M., Latham, A. G., Ku, T.-L.: Uranium series disequilibrium. Applications in geochronology. In: Uranium-series Disequilibrium: Applications to Earth, Marine, and Environmental Sciences, pp. 62-94, Clarendon Press, 2nd Ed., 1992.

69. Hoehn, E., von Gunten, H. R.: Radon in groundwater: A tool to assess infiltration from surface waters to aquifers. Water Resour. Res. 25, 1795-1803 (1989).

70. Hoehn, E., von Gunten, H. R., Stauffer, F., Dracos, T.: Radon-222 as a groundwater tracer. A laboratory study. Environ. Sci. Technol. 26, 734-738 (1992).

71. Schulte-Ebbert, U., Hollerung, R., Willme, U., Kaczmarcyk, B., Bahrig, B., Schöttler, U.: Verhalten von anorganischen Spurenstoffen bei wechselnden Redoxverhältnissen im Grundwasser. Veröffentlichungen des Instituts für Wasserforschung $\mathrm{GmbH}$ Dortmund und der Dortmunder Stadtwerke AG, Nr. 43, p. 128 (1991).

72. Burnett, W. C., Veeh, H. H.: Uranium-series studies of marine phosphates and carbonates. In: Uranium-series Disequilibrium: Applications to Earth, Marine, and Environmental Sciences, pp. 487-512, Clarendon Press, 2nd Ed., 1992.

73. Schwarcz, H. P., Blackwell, B. A.: Archaeological applications. In: Uranium-series Disequilibrium: Applications to Earth, Marine, and Environmental Sciences, pp. 513-552, Clarendon Press, 2nd Ed., 1992.

74. Huh, C.-A., Kadko, D. C.: Marine sediments and sedimentation processes. In: Uranium-series Disequilibrium: Applications to Earth, Marine, and Environmental Sciences, pp. 460-486, Clarendon Press, 2nd Ed., 1992.

75. Carpéna, J., Mailhé, D.: Fission-track dating. In: Nuclear Methods of Dating (E. Roth and B. Poty, Eds.), pp. 189233, Kluwer Academic Publishers, 1989.

76. Fleischer, R. L., Price, P. B.: Techniques for geological dating of minerals by chemical etching of fission fragment tracks. Geochim. Cosmochim. Acta 28, 1705-1714 (1964).

77. Lalou, C., Valladas, G.: Thermoluminescence dating. In: Nuclear Methods of Dating (E. Roth and B. Poty, Eds.), pp. 235-273, Kluwer Academic Publishers, 1989. 


\title{
Radioactivity and Radiation Chemistry of Water
}

\author{
By Ivan G. Draganić \\ The Institute of Nuclear Sciences "Vinča", P.O.B. 522, 11000 Beograd, Serbia, Yugoslavia
}

(Received July 31, 1995)

Radioactivity / Radiolysis of water / Nuclear reactors / Oklo / Early Earth / Cometary nuclei

\begin{abstract}
The chemical changes of water induced by radiation, first observed on aqueous solutions of radium salts, were reported less than five years after the discovery of radioactivity. The importance of the radiolytic behaviour of water was progressively recognized in various domains of nuclear science and technology. More recent interest concerns the roles of radioactivity, radiation and water in chemical evolution processes because of their ubiquitous presence on the Earth and in Space.
\end{abstract}

\section{The early days of radioactivity and water radiolysis}

Already in 1903, Giesel [1] quoted the observation of Runge and Bodländer that a gas consisting of hydrogen and oxygen is constantly released from an aqueous solution of radium bromide; at the same time the solution becomes brownish because of the generation of bromine. It seems, however, that Ramsay [2] was the first physicist to carry out irradiation experiments reported in his article "The chemical action of radium emanation on distilled water". This work and publications by Cameron and Ramsay [3-4] contained a number of quantitative data, among which those on the generation of $\mathrm{H}_{2}$ and $\mathrm{O}_{2}$ under various experimental conditions.

Debierne [5] presented in 1909 the results of a systematic approach with simple experiments. He used a sealed ampoule of radium chloride as the radiation source, placed in a vessel containing nondegassed distilled water. The device was isolated from air and connected to a manometer. The increase in pressure was continuous and proportional to the time of exposure. In the interpretation of his results, Debierne concluded that the decomposition of water was due to the action of penetrating $\beta$ and $\gamma$ rays. The first data on the action of $\alpha$ rays on water were reported in 1913 by Duane and Scheuer [6].

Compared to present day irradiation facilities, the radiation sources used in these experiments were very weak and seldom stronger than $100 \mathrm{mg}$ radium. In addition to the low radiation intensities, the methods of chemical analysis available at the time were relatively insensitive. For these reasons, the investigations were limited mainly to qualitative observations of chemical changes or, less often, to semi-quantitative measurements of gross effects. Nevertheless, the early literature of radiation chemistry contains fine observations on the radiolytic behaviour of water and various aqueous solutions like those of Kailan [7-11] at the Radium Institute in Vienna.

No much efforts were made to explain the origin of the observed facts. An exception was Debierne's hypothesis [12] on the formation of ionized water molecules during the passage of radiation. The latter produce $\mathrm{H}$ and $\mathrm{OH}$ species which react among themselves; molecular products $\mathrm{H}_{2}$ and $\mathrm{H}_{2} \mathrm{O}_{2}$ are formed as well as water molecules by recombination of $\mathrm{H}$ and $\mathrm{OH}$. With this hypothesis, Debierne was well ahead of the time because it contains the main elements of the presently generally accepted model of water radiolysis.

\section{Nuclear reactors: \\ World War II and post-war years}

From the very beginning of the nuclear war program, it was obvious that ordinary as well as heavy water, were an important material for the realization of nuclear reactors, both as neutron moderator and as coolant. The question arose as to how water would behave in a field of radiation equivalent to that from thousands of kilograms of radium. Moreover, the water would be exposed to a complex mixture of charged particles, neutrons and $\gamma$ rays. It was known that the main components were fast neutrons and $\gamma$ rays, but their action on water was not clear. It was thought that neutrons, through the intermediary of recoil protons which they displace in water, would have an effect similar to that of $\alpha$ particles, and hence would decompose water efficiently. In this connection, A. O. Allen, one of the radiation chemist involved in the research wrote [13]: "Physicists had decided that the best scheme for cooling the reactor would be by water rushing through aluminum pipes. The difficulty was that no one knew whether under the influence of the unprecedently intense radiation in these reactors the water might react with aluminum as if it were calcium or sodium, as indeed thermodynamics suggested".

The secret radiation chemistry program was carried out under the guidance of two physicists, Milton 
Burton and James Franck. These scientists based their research on the free radical theory derived from physical concepts. In a first instance, radiation could solely transfer energy to the electrons of the water molecule, leading to its excitation and/or to its ionization. The ionized and excited water molecules participate in various reactions producing free radicals $\mathrm{H}$ and $\mathrm{OH}$. Further reactions of these species lead to the formation of molecular products, $\mathrm{H}_{2}$ and $\mathrm{H}_{2} \mathrm{O}_{2}$.

At the time, the experiments performed and the reasonings could not be published. The American team had no contact with outside research, even not with the British team including F. S. Dainton and N. Miller, who pursued in Canada similar studies of water radiolysis with the same objective [14]. In the USA, the work was conducted under military secrecy in several laboratories. It was progressively recognized that water decomposes under radiation to yield the molecular products, but also that the radicals $\mathrm{H}$ and $\mathrm{OH}$ convert the latter back to water molecules. It become apparent that water used in reactors should be extremely pure, as almost any substance dissolved in water increased the radiolytic decomposition of the solvent. These findings were summarized by Allen after the war [15].

In the fifties, it was generally admitted that the induced radioactivity and the decomposition of water under the intense radiation present in reactors could be controlled [16].

For a while, the possibility of using ionizing radiation as a cheap "by-product" of the operation of nuclear power reactors was considered as a promising tool for industrial applications. However, ten years later, it became evident that any use of nuclear reactor, outside the production energy, was complex and costly, particularly when compared with the increasing availability of irradiation facilities provided by radioisotopic sources and modern, high intensity accelerators. Nevertheless, the experience gained in the unconventional radiation chemistry with large doses of mixed radiations was a valuable heritage [17]. It showed how on prolonged irradiations, the initially present compounds decompose while new products are formed by the action of radiation and take part in chemical processes. Unconventional radiation chemistry is particularly relevant to the field of nuclear waste management and long term waste disposal.

Owing to the important role of water in contemporary nuclear energy programs and in the action of radiation on living matter, the radiation chemistry of water [18] is nowadays a pre-eminent topic in the general field of radiation chemistry [19].

\section{Natural nuclear reactors and underground waters on the early Earth}

Natural nuclear reactors were geological arrangements of uranium and water in configurations such as a fission chain reaction could be triggered. This phenom- enon occurred in uranium deposits on the Precambrian Earth, as was the case at the fossil reactor site discovered in Oklo (Gabon, Africa) [20]. The present concentration of ${ }^{235} \mathrm{U}\left(T_{1 / 2}=700 \mathrm{My}\right)$ in natural uranium is $0.72 \%$ which precludes the start of a chain fission process even in the richest uranium deposits.

On the early Earth, the concentration of ${ }^{235} U$ was up to 40 times higher and could have led to a chain reaction, as was suggested by $P$. K. Kuroda long before the discovery of the Oklo phenomenon [21].

From the point of view of nuclear reactor physics and chemistry, the reactions which occurred at the fossil nuclear reactors site at Oklo (which includes six reactor cores) are well understood [22-23]. The operation time of individual reactors lasted between 0.6 and $0.8 \mathrm{My}$, while the total duration of the Oklo phenomenon was up to several million years. It has also been concluded that none of the geological and geochemical characteristics at the Oklo deposit are unique, and that the latter could not have been a single occurrence on the Precambrian Earth.

Individual natural reactors in operation constituted efficient localized sources of energy over a large geological time span. In comparison with man-made reactors, the natural ones operated at a very low power, on the average about one $\mathrm{kW}$. Routine procedures for inpile dose evaluation [24] show that these natural reactors delivered dose rates of the order of tens of gray (Gy) per hour. Such dose rates are similar to those available in small laboratory irradiation units and could have been very convenient for radiation-induced syntheses.

It is possible to make a rough estimate of the amount of uranium which took part in natural nuclear reactors. Based on the slight variations of the isotopic ratio ${ }^{238} \mathrm{U} /{ }^{235} \mathrm{U}$ in presently accessible uranium ores with $1000 \mathrm{ppm} \mathrm{UO}_{2}$ or more, it appears that thousands of natural reactors were in operation between 1800 and $4100 \mathrm{My}$ ago. On the other hand, if a one $\mathrm{km}$ thick layer of the Earth's crust is taken into account with an average concentration of $3 \mathrm{ppm}$, then hundred million reactor sites of the Oklo type could have been in activity in the past of our planet [24].

Water had an important role in the making of a natural reactor from a uranium deposit. It acted as neutron moderator and coolant and contributed to the propagation and control of the fission chain. At the same time, water was radiolized and the dissolved substances were chemically altered. The material subjected to irradiation was efficiently circulated by underground waters.

Computer simulation helped to examine the action of mixed nuclear radiations on a model system of sandstone underground water [25]. It showed that considerable amounts of $\mathrm{O}_{2}, \mathrm{H}_{2}$ and $\mathrm{H}_{2} \mathrm{O}_{2}$ could have been formed on a geological time scale. Many chemically reactive free radical intermediates could also have been involved in reactions with various inorganic and organic compounds dissolved in waters flowing through or in the vicinity of the reactors. This radi- 
ation-induced oxidizing capacity of underground waters is usually neglected in the explanations of the oxidizing processes in primitive underground waters and in the search of the origins of primary oxidized minerals on the early Earth.

It is worth mentioning that the presence of longlived fission products in the reaction core ensured that the reactor was a place of localized radiations for long periods of time (hundred of years or more) after the chain process was terminated.

On the other hand, some of the fission radionuclides would migrate and pursue the irradiation after fixation in the environment or after uptake in Precambrian living matter. The dose rates were low, but combined with irradiation over large periods of time, they could have been effective in producing evolutionary changes in primitive life. An examination of major events in the early biological evolution, shows that the main evolutionary changes of precariotic life resulted from biochemicals rather than morphological innovations [26]. With the initiation of free radical processes in the early biochemistry, nuclear radiations could have been a very effective mutagenic agent for Precambrian biota.

\section{Radioactive potassium-40 in the early ocean waters}

The presence of potassium salts in primitive ocean waters and the radioactive decay of ${ }^{40} \mathrm{~K}$ ( $T_{1 / 2}=$ $1250 \mathrm{My}$ ) have provided an internal source of radiation in Arachaean oceans [27]. $3800 \mathrm{My}$ ago, the natural abundance of ${ }^{40} \mathrm{~K}$ was $0.1 \%$. The amount of energy delivered by ${ }^{40} \mathrm{~K}$ depended on the concentration of potassium salts in primitive ocean waters. The latter were recycled many times over geological history and may not have retained the information of their past potassium content. Nevertheless, a reliable estimate was possible. It is based on interferences drawn from the nature of ancient sediments and the products of their metamorphism. Various observations suggest that the main components of the lithosphere and the hydrosphere were extant by the time of Issua water-laid sediments of West Greenland [28]. From the average energy released per decay, the calculated absorbed dose rate is $2.95 \times 10^{-4} \mathrm{~J} \mathrm{~kg}^{-1} \mathrm{y}^{-1}$.

Compared to the amounts of energy provided by other sources on the early Earth, the contribution of ${ }^{40} \mathrm{~K}$ is extremely small. However, in many respects, ${ }^{40} \mathrm{~K}$ was an ideal in situ source. The energy was deposited homogeneously throughout the water volume, including in the deep ocean. In addition, owing to the very nature of radioactive decay, the energy deposit occurred undisturbed and uninterrupted so that the total amount of the energy available for radiation chemistry over a geological time-scale was significant.

The chemical effects induced by the radiation were examined by computer simulation [27]. The latter was based on the estimate of the energy deposited and on well established radiation-induced reactions of substances which were assumed to be constituents of sea water. The radiation-induced process was followed over a geological time scale of one hundred million years $(100 \mathrm{My})$. The beginning of the time scale was deliberately fixed at $3800 \mathrm{My}$ ago. This is the age of the oldest known sedimentary rocks and most likely of ocean waters whose content in salt and major chemical elements was not essentially different from the contemporary ones.

The results obtained show that one molecule $\mathrm{H}_{2}$ is formed per $\mathrm{H}_{2} \mathrm{O}$ decomposed. The total amount of molecular hydrogen generated in the sea waters over $100 \mathrm{My}$ is $3.8 \times 10^{18} \mathrm{~g}$, assuming an ocean mass of $1.4 \times 10^{24} \mathrm{~g}$. This amount is similar to that released by volcanic activity on the early Earth over the same period of time [28]. A considerable total amount of radiolytically generated molecular oxygen over $100 \mathrm{My}$ was also calculated: $3.0 \times 10^{19} \mathrm{~g}$ (for comparison the content of the contemporary atmosphere is $1.2 \times 10^{21} \mathrm{~g}$ ).

In addition to $\mathrm{H}_{2}$ and $\mathrm{O}_{2}$, hydrogen peroxide is produced in significant amounts. A survey of reaction mechanisms shows the presence of strongly oxidizing hydroxyl radicals $(\mathrm{OH})$ produced by direct decomposition of water. Many other oxidizing free radicals appeared as intermediates, contributing also to the total oxidizing capacity of early ocean water. They may have played a significant role in the chemistry of Earth before the emergence of oxygen due to photosynthetic microorganisms, for example in the origin of primary oxidized iron minerals [31] in the oldest known terrestrial sediments, the $3800 \mathrm{My}$-old rocks in the Isua Supracrustal Group of West Greenland.

It has been proposed that comets brought vast quantities of water to the primitive Earth, which by this acquired an exogenous ocean of water [32] with a significant delivery of organic compounds [33]. Organic compounds of endogenous and exogenous origins potentially present may have contributed to the radiation-induced synthesis of biogenic molecules of importance for chemical evolution processes.

\section{Radiation processing of water in cometary nuclei}

Isotopic anomalies found in meteorites, particularly that pointing to the presence of ${ }^{26} \mathrm{Al}$ in the early solar system, suggest that very likely a supernova explosion occurred at the beginning of the accretion process [34]. The nucleosynthesis during the explosion has provided a large number of radionuclides which were built into the comet nuclei like in all other bodies in the solar system. Radiation emitted in their decays, as well as decays from long-lived radionuclides already present in the nebula like isotopes of $U$ and $T h$, constituted a source of energy available for chemical reactions in the icy interior of a comet's body [35].

The surface layers were constantly exposed to cosmic rays, a mixture of electromagnetic radiation and 
charged particles. The latter aIso produced hot atoms and cosmogenic radionuclides, which on their way contributed to radiation chemical changes [36-37].

The intensities of radiations were rather weak, in average about a tenth of gray per year or less, but the time available for irradiation is enormous, $10^{\circ}$ years. In addition, the environmental conditions, such as low temperature and density of matter, are almost ideal for the accumulation of radiolytic products and preservation of radiation-induced alterations.

The International Halley Watch Program was prepared and carried out with a general belief that the event will be an encounter with a pristine material of a dense interstellar cloud where the solar system and comets were born. Some findings in 1986 indeed confirmed the presence of simple interstellar molecules which are also believed to be the primitive constituents of the presolar nebula. However, for a water-dominated body, an unexpected solid dark-gray surface of the cometary nucleus appeared. It was attributed to some unknown chemical compound(s); the puzzling presence of larger nitrogen-containing organics was found in ejected dust. These and some other findings suggest that the pristine cometary material must have been chemically altered, most likely by the action of radiation.

Simulation experiments performed in the laboratory offer an insight into the radiation chemistry involved. The inventory of radiolytic products found is impressive: about forty compounds including some of primary biological importance, as well as larger ones with molecular weights up to $80000 \mathrm{amu}$ [38]. The experiments suggest that the material in the comet nucleus is more likely a remnant of material in the presolar nebula which has been chemically altered to various degrees by radiations from imbedded radionuclides and cosmic rays.

\section{Perspectives}

The first century of the nuclear era ends with an impressive inventory of knowledge on radioactivity and radiation, both on the early and on the contemporary Earth and in the interplanetary medium. Nevertheless, various challenging problems are bequeathed to the coming generation [39]. Some of them will be mostly technological, like the decommissioning of hundreds of nuclear power plants, the reprocessing (or safe storage) of hundred thousands tons of spent nuclear fuel elements and the disposal of million tons of intermediate and high-level nuclear waste. Water will be an unavoidable tool in some stages of the handling of huge amounts of radioactive material, often in conditions seldom met in routine laboratory work: materials exposed to large radiation doses and radiogenic heat, sometimes very complex chemical systems. A better understanding of radiation-induced chemical processes at high temperature will be needed to find technological solutions. More data on free radical intermediates and on rate constants of their reactions will also be required.

Other challenging problems will be less urgent, but not less exciting, like those relevant to radiation chemistry of water in cometary nuclei [40] or on the early Earth [41]. Radioactivity is generally considered as a minor contributor to the energy sources available for chemistry in these media. Yet, it deserves more attention than presently given because of the efficiency in producing chemically reactive species (ions, free radicals, radical ions) in conditions hostile for chemistry, such as those in water-dominated commentary icy matrix or in the ocean depths and underground primitive waters. Present achievements in radiation and hot atom chemistry provide a solid foundation for further research.

\section{References}

1. Giesel, F.: Ber. Dtsch. Chem. Ges. 36, 342 (1903).

2. Ramsay, W.: J. Chem. Soc. 91, 937 (1907).

3. Cameron, A. T., Ramsay, W.: J. Chem. Soc. 92, 966 (1908).

4. Cameron, A. T., Ramsay, W.: J. Chem. Soc. 92, 992 (1908).

5. Debierne, A.: C. R. Acad. Sci. Paris 148, 703 (1909).

6. Duane, W., Scheuer, O.: Radium 10, 33 (1913).

7. Kailan, A.: Wien. Ber. 120, 1213 (1911).

8. Kailan, A.: Wien. Ber. 120, 1373 (1911).

9. Kailan, A.: Monatsh. Chem. 33, 1329 (1912).

10. Kailan, A.: Monatsh. Chem. 33, 1361 (1912).

11. Kailan, A.: Monatsh. Chem. 34, 1269 (1913).

12. Debierne, A.: Ann. Phys. (Paris) 2, 97 (1914).

13. Allen, A. O.: J. Chem. Educ. 45, 290 (1968).

14. Allen, A. O.: Chpt. 1 in Early Developments in Radiation Chemistry (J. Kroh, Ed.); The Royal Society of Chemistry, Cambridge 1989.

15. Allen, A. O.: J. Phys. Colloid Chem. 52, 479 (1948).

16. Roth, E.: Chimie nucléaire appliquée, Masson and Cie, Paris 1968.

17. Draganić, I. G.: Chpt. 7 in Early Developments in Radiation Chemistry (J. Kroh, Ed.), The Royal Society of Chemistry, Cambridge 1989.

18. Draganić, I. G., Draganić, Z. D.: The Radiation Chemistry of Water, Academic Press, New York 1971.

19. Spinks, J. W. T., Woods, R. J.: An Introduction to Radiation Chemistry, John Wiley and Sons, New York 1990.

20. Neuilly, M., Bussac, J., Frejacques, C., Nief, G., Vendryes, G., Yvon, J.: C. R. Acad. Sci. 275 D, 1847 (1972).

21. Kuroda, P. K.: J. Chem. Phys. 25, 781 (1956).

22. The Oklo Phenomenon, IAEA, Vienna 1975.

23. Natural Fission Reactors, IAEA, Vienna 1978.

24. Draganić, I. G., Draganić, Z. D., Altiparmakov, D.: Precambrian Res. 20, 283 (1983).

25. Bjergbakke, E., Draganić, Z. D., Sehested, K., Draganić, I. D.: Radiochim. Acta 48, 73 (1989).

26. Schopf, J. W. (edit.): Earth's Earliest Biosphere, Princeton University Press, Princeton 1983.

27. Draganić, I. G., Bjergbakke, E., Draganić, Z. D., Sehested, K.: Precambrian Res. 52, 337 (1991).

28. Holland, H. D.: The Chemical Evolution of the Atmosphere and Oceans. Princeton University Press, Princeton 1984.

29. Weast, R. G. (Ed.): CRC Handbook of Chemistry and Physics, CRC Press, Boca Raton 1987.

30. Miller, S. L., Orgel, L. E.: The Origins of Life on the Earth, Prentice-Hall 1974.

31. Dymek, F. R., Klein, C.: Precambrian Rés. 39, 247 (1988). 
32. Chyba, C. F.: Nature 330, 129 (1987).

33. Chyba, C. F., Thomas, P. J., Brookshaw, L., Sagan, C.: Science 249, 366 (1990).

34. Reeves, H.: Astrophys. J. 231, 229 (1979).

35. Draganić, I. G., Draganić, Z. D., Vujošević, S.: Icarus 60, 464 (1984).

36. Ryan Jr., M. P., Draganić, I. G.: Astrophys. Space Sci. 125. 49 (1986).

37. Draganić, I. G., Ryan, M. P., Draganić, Z. D.: Adv. Space Sci. 5, 13 (1987).
38. Draganić, Z. D., Vujošević, S. I., Negron-Mendoza, A., Azamar, J. A., Draganić, I. G.: J. Mol. Evol. 22, 175 (1985).

39. Draganić, I. G., Draganić, Z. D., Adloff, J. P.: RADIATION and RADIOACTIVITY on EARTH and BEYOND, 2nd edition, CRC Press, Boca Raton 1993.

40. Draganić, I. G., Draganić, Z. D.: J. Chim. Phys. 86, 55 (1988).

41. Draganić, I. G., Vujošević, S. I.: in Chemical Evolution: Origin of Life (C. Ponnamperuma and J. Ch. Flores, Eds.), A. Deepak Pub., Hampton 1993. 



\title{
Radioactivity and the Nuclear Environment
}

\author{
By A. G. Maddock \\ The Chemical Laboratories, Lensfield Road, Cambridge CB2 1 EW, UK
}

(Received July 7, 1995)

\section{Change of half-life / Mössbauer spectroscopy / Perturbed angular correlation}

\begin{abstract}
Radioactive decay provides the basis of three methods of exploring the nuclear environment. Changes in the decay constant with the state of chemical combination of the disintegrating atom are difficult to measure and only provide very limited information. The time dependence of the angular correlation between the directions of emission of successive photons is more useful, but the method has serious limitations.

The outstanding successful technique of Mössbauer spectroscopy however has proved remarkably versatile in its applications. The quantitative data it yields are often difficult to obtain in any other way.
\end{abstract}

The study of radioactivity has led to the discovery of three techniques for exploring the environment of the nucleus that suffers decay. One of them is of extraordinary versatility and its importance overwhelms that of the other two.

\section{Changes in radioactive decay constant}

The first to be discovered has proved to be of limited application. For nearly fifty years it was always stated that radioactive decay could not be influenced by any treatment accessible in a laboratory. However in the explosion of interest in nuclear physics following the Second World War the Daudels [1a, b] in Paris and Segré [2] in California pointed out that radioactive decay, at least under terrestrial conditions, involved the atom and not simply the nucleus. Hence the decay constant for orbital electron capture decay of ${ }^{7} \mathrm{Be}$, which must depend on the orbital electron density at the nucleus, must be affected by the state of chemical combination of the beryllium.

\section{Changes in decay constant for orbital electron capture and isomeric transition}

This dependence was soon verified; the fractional change in decay constant, $\delta \lambda / \lambda$, for different pairs of beryllium compounds was found to be as much as $7.4 \times 10^{-4}$ in some cases [3]. Even the difference in the decay rates of ${ }^{7} \mathrm{Be}$ in the two crystal modifications of beryllium oxide could be measured.

For elements of greater $Z$ the values of $\delta \lambda / \lambda$ were generally smaller and their measurement was very time consuming. Measurements of such small differences in decay constant require close attention to the experimental conditions. They are most commonly made using Rutherford's balanced ionisation chambers method.

An interesting alternative is possible for isotopes where orbital electron capture competes with positron emission. In these systems only the former decay mode should be noticeably sensitive to the environment of the nucleus, so that the ratio of the two decay modes should depend on the chemical state of the affected element [4].

The fractional change in decay constant, $\delta \lambda / \lambda$, like the difference in isomer shift found from Mössbauer spectra, depends on the difference in the electron density at the nuclei in the two compounds. A comparison of the two measurements, where this is possible, is of interest. It can be done for example using ${ }^{71} \mathrm{Ge}$, which decays by orbital electron capture, and ${ }^{73} \mathrm{Ge}$ which can provide Mössbauer spectra [5].

Analogous changes can be found in the constants for decay by isomeric transition, when there is substantial internal conversion, especially if this takes place mainly in the outer orbitals of the atom containing the decaying nucleus.

Examples of species for which quantitative data are available include ${ }^{99 \mathrm{~m}} \mathrm{Tc},{ }^{90 \mathrm{~m}} \mathrm{Nb}$ and ${ }^{125 \mathrm{~m}} \mathrm{Te}$, in the first two cases the excitation of the isomeric state is so small that internal conversion is only energetically possible in the $\mathrm{O}$ and $\mathrm{N}$ shells $[6 \mathrm{a}, \mathrm{b}, \mathrm{c}]$. The $76 \mathrm{eV}$ excited state of ${ }^{235} \mathrm{U}$ would seem especially favourable for study [7a,b, c]. In these systems $\delta \lambda / \lambda$ values of a few times $10^{-3}$ have been found.

\section{Changes in $\beta$ decay constant}

Decay by $\beta^{-}$emission should also be influenced by the chemical state of the affected atom [8]. The total beta decay probability is the sum of two terms, the probability of decay yielding an electron in the continuum and the probability of decay giving a bound electron - orbital electron creation [9]. It is interesting to observe that the direct detection of this last mode of decay is one of the unsolved problems in radioactivity.

The bound electron creation is not an important mode if the total decay energy is large, but it becomes more important at low energies and its greater sensitivity to the chemical environment of the nucleus mag- 
nifies its importance in relation to the change of decay probability with environment.

The available energy from the decay process ${ }^{A} Z^{n+}$ $\rightarrow^{A}(Z+1)^{(n+1)+}$ depends on the difference in the energies of the initial and final atoms. This difference is dependent on $n$. Further the product atom may be formed in an electronically excited state or even suffer further ionization due to "shake off". Thus the maximum beta ray energy has a spectrum of values and depends on the state of chemical combination of the decaying atom.

The bound electron creation decay mode also depends on the chemical state of the atom containing the decaying nucleus since it is dependent on the available orbitals for electron creation. The two effects will together determine $\delta \lambda / \lambda$.

Calculations for ${ }^{63} \mathrm{Ni}$, a very soft beta emitter, show that the two contributions are of opposite sign. Hence although the individual contributions are of the order of $10^{-3}$ the overall effect to be expected is of the order $10^{-4}[10]$.

The experimental data on the dependence of the decay constant for beta decay on the state of chemical combination is unsatisfactory and indeed often contradictory. This is at present the case notwithstanding the relevance of such information to some other problems.

Chemical effects should be measurable for the, a priori, favourable case of tritium decay, but present experimental data are only broadly in keeping with calculated effects [11]. A few years ago half life data on ${ }^{24} \mathrm{Pu}$ spanned an unreasonable range of values and the possibility existed that differences in the compounds measured could account for the spread. Calculation showed that this was unlikely and more recent measurements span a narrower range [12].

The decay of ${ }^{187} \mathrm{Re}$ is particularly important because of its significance as a cosmochronometer. It has the remarkably low maximum beta particle energy of $2.7 \mathrm{keV}$ and bound electron creation might make a significant contribution to the overall decay. The constant for decay giving an electron in the continuum can be measured, albeit with difficulty, but the decay by bound electron production and the total decay constant are hard to determine [13].

As a means of exploring the atomic environment changes in beta decay constants are unattractive.

\section{Mössbauer spectroscopy}

Almost a decade later than the observations on ${ }^{7} \mathrm{Be}$ decay an enormously more powerful technique that could provide information on the magnetic and electrical environment of the disintegrating nucleus was discovered. While investigating the possibility of resonant fluorescent gamma ray scattering Mössbauer found that if some weakly excited nuclei were present in atoms in a solid lattice some proportion of recoiless emission of photons took place [14]. This emission readily gave rise to resonant absorption and scattering.
The line width for emission was extremely small, being determined by the mean life time of the excited state. A typical mean life of a suitable excited state was $10^{-7} \mathrm{~s}$ so that a line width of about $10^{-8} \mathrm{eV}$ could be obtained.

\section{Mössbauer absorption spectroscopy}

In order to have a useful source of such radiation it is necessary to have a parent radioactive species whose decay feeds the very short lived excited state. A scatterer or absorber containing the stable, or at least very long lived, isotope produced in the de-excitation then gives resonant absorption. By using the Doppler effect, moving the source towards, or away from, the absorber an extremely small range of photon energies could be spanned by the source. It was quickly realized that this tiny band of photon energies would embrace the changes and splittings of nuclear energy levels produced by the magnetic [15] and electrical [16a, b] fields existing at the nucleus by virtue of its presence in an atom, perhaps also combined in a molecule, in the solid.

A monochromatic source could be obtained if the Mössbauer atom was in a cubic environment in the solid and had a full, or empty valence shell. Thence modifying the energy of the emission using the Doppler effect the absorption spectrum of a sample could be investigated. Alternatively, using a single line absorber the spectrum emitted by the source could be examined.

\section{Parameters obtainable from the spectra}

Spectra obtained in this way enable one to compare the electron density at the nuclei in two absorbers, using the isomer shift; to obtain the quantities specifying the electric field gradient at the nucleus, the quadrupole splitting and the asymmetry parameter and, using single crystal absorbers, to determine the orientation of the electric field gradient in relation to the crystal axes. In magnetically ordered solids the magnitude of the field at the nucleus and its orientation could be determined.

The changes in the spectra with the temperature of measurement provided more information, especially regarding the smaller crystal field and spin orbit splittings of the electronic energy levels of the Mössbauer atom in the absorber.

Very different information was supplied by the change in the fraction of recoiless absorption events with temperature. The change in the areas under the absorption lines yielded similar information, regarding the phonon spectrum of the absorber, more simply.

Altogether the technique has led to a much deeper insight into the nature of the solid state.

\section{Simple applications}

The extraordinary variety of the applications of Mössbauer spectroscopy is illustrated in the examples 
that follow. The combination of the isomer shift and quadrupole splitting is usually characteristic of the oxidation state of the Mössbauer species in the absorber. At first sight the application of the spectra for this purpose would seem trivial, but there are compounds where such a spectral identification is very useful.

One of the first applications of Mössbauer spectroscopy in chemistry, the demonstration of the identity of Prussian and Turnbull's blue, was of this kind [17a, b].

In a more recent study an iron(III) tetraphenyl porphyrin complex was oxidized to yield an apparently iron(IV) complex. FeTPPCl gave [FeTPPCl] $\mathrm{SbCl}_{6}$, but the isomer shift and quadrupole splitting of the product was not much different from the parent iron(III) compound; the oxidation predominantly involves the ligand. By contrast $(\mathrm{FeTPP})_{2} \mathrm{~N} \cdot \mathrm{ClO}_{4}$ gives a much lower isomer shift as is appropriate for iron(IV) [18].

The Mössbauer spectra generally show whether there is more than one coordination environment of the Mössbauer atoms in the absorber by giving spectra composed of two or more component spectra. Discontinuities in the spectral parameters, isomer shift and quadrupole splittings, for spectra taken at different temperatures indicated phase changes.

But the more interesting applications are those where alternative methods of investigation are much less satisfactory, if indeed available.

\section{Mixed valence compounds and valence delocalization}

Many transition element compounds are known in which the element is present in more than one oxidation state. If the coordination environments of the two kinds of atoms are not very different electron hopping between the atoms, or valence delocalization, may take place. When the mean life time between gaining and losing an electron is much greater than the mean life of the Mössbauer excited state the spectrum arising from these atoms will be the addition of the spectra due to the two oxidation states of the atom; the valences are localized. But if the electron hopping is much faster than this a single spectrum with parameters determined by the weighted mean of the parameters from the above separate spectra will be obtained. The weighting allows for the proportions of the atoms in the different oxidation states.

When the mean life time of the atom in a given oxidation state becomes comparable to the mean life of the Mössbauer excited state line broadening occurs and a detailed analysis of the spectrum yields the frequency of hopping [19].

Iron chemistry provides many instances of mixed valence compounds. In many the valences are localized and the spectra are a superposition of spectra due to the two oxidation states. This is the case for the hydrates of $\mathrm{Fe}_{2} \mathrm{~F}_{5}$, some mixed valence iron phosphates and the aforementioned Prussian and Turnbull's blue. But in others such as $\mathrm{L}_{2} \mathrm{Fe}_{2}(\mu \mathrm{OH})_{3}\left(\mathrm{ClO}_{4}\right)_{2}$ $\left(\mathrm{CH}_{3} \mathrm{OH}\right)_{2}$, where $\mathrm{L}=\mathrm{NN}^{\prime} \mathrm{N}^{\prime \prime}$ trimethyl triazacyclononane, a single spectrum with an isomer shift of $0.74 \mathrm{mms}^{-1}$ is found even at $4.2 \mathrm{~K}$. This value is about the mean of the isomer shifts expected for $\mathrm{Fe}^{2+}$ and $\mathrm{Fe}^{3+}$ in such a complex [20].

Particular interest attaches to those compounds that undergo a transition from localized to delocalized valences at some temperature. Such transitions may or may not be accompanied by a structural change. One of the earliest examples of such a transition, identified before Mössbauer spectroscopy was discovered, was the Verwey transition in $\mathrm{Fe}_{3} \mathrm{O}_{4}$, magnetite. The compound suffers a structural phase change at about $119 \mathrm{~K}$, at the same time there occur substantial changes in electrical and magnetic properties. This oxide is an inverse spinel and it was suggested that this change was due to electron hopping between the $\mathrm{Fe}^{2+}$ and $\mathrm{Fe}^{3+}$ on the octahedral $B$ lattice above $119 \mathrm{~K}$ [21].

The Mössbauer spectrum provides excellent confirmation of this suggestion. Above $119 \mathrm{~K}$ the spectrum comprises two magnetically split sextets, one due to the $\mathrm{Fe}^{3+}$ on the tetrahedral sites of the $A$ lattice, giving the characteristic isomer shift of $0.27 \mathrm{mms}^{-1}$. The other arising from the $B$ lattice gives an isomer shift of 0.67 a value effectively for $\mathrm{Fe}^{2.5+}$ due to rapid electron hopping from $\mathrm{Fe}^{2+}$ to $\mathrm{Fe}^{3+}[22 \mathrm{a}, \mathrm{b}]$.

It was some time before similar temperature dependent valence delocalization was identified in other iron compounds. However the series of compounds that can be represented by the formula $\mathrm{Fe}_{3} \mathrm{O}$ $\left(\mathrm{O}_{2} \mathrm{C} \cdot \mathrm{R}\right)_{6} \mathrm{~L}_{3} \cdot \mathrm{S}$ nearly all show temperature dependent delocalization of valences. The complexes consist of planar triangular $\mathrm{Fe}_{3} \mathrm{O}$ units stacked on a threefold axis with solvent molecules, $S$, between planes. The $L$ are generally nitrogen bases such as 3 methyl pyridine and the $\mathrm{S}$ benzene, toluene, $\mathrm{CH}_{3} \mathrm{CN}$ or other solvent. The temperatures of onset of delocalization vary considerably with $\mathrm{R}, \mathrm{S}$ and $\mathrm{L}$. In most cases the transition is not sharp but extends over a range of temperatures in which both localized and delocalized spectra can be seen. Some of the effects observed may be due crystal size and density of defects; macro-crystalline and finely powder material from the same preparation behave differently. Hardly any single crystal data are available [23].

It is interesting to note that the comparatively slow Mössbauer spectrum measurement, effective time of measurement about $10^{-7} \mathrm{~s}$ is advantageous in these measurements. If the much faster technique of infra red spectroscopy, $10^{-13} \mathrm{~s}$, is used all the iron atoms appear to have localized valences.

Another group of compounds that have been extensively investigated are the one electron oxidation products of the biferrocenes. For these a somewhat different approach is necessary, the isomer shifts for low spin iron(II) and iron(III) are too close for mean values to be identified but the similar averaging of the larger quadrupole splittings can be sought. With these complexes the role of conjugation in facilitating the elec- 
tron hopping can be shown. In compound shown in the figure, with $\mathrm{R}=\mathrm{CH} \cdot \mathrm{CH}_{3}$ delocalization is incomplete at $300 \mathrm{~K}$, but with $\mathrm{R}=-\mathrm{CH}=\mathrm{CH}-$ delocalization is essentially complete at $\approx 78 \mathrm{~K}$ [24].

These studies have shown that the localized - delocalized transition depends not only on the chemical identity of the substance but also on the properties of the solid it forms. Cooperative effects in the solid are involved.

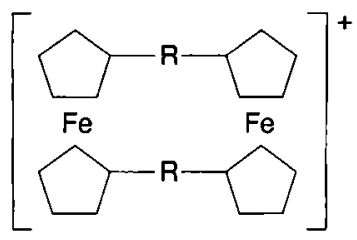

\section{Spin cross over systems}

Another area of investigation by Mössbauer spectroscopy, sharing some of the unusual features of the mixed valence solids, is the study of spin cross over. Although compounds which change from high spin to low spin configurations on lowering the temperature were discovered many years ago, using magnetic measurements, such behaviour is much more conveniently investigated quantitatively by Mössbauer spectroscopy. With iron(II) complexes the high and low spin forms give spectra with substantially different isomer shifts and quadrupole splittings and the areas under the absorption lines can be used to measure the proportions of the two forms present at the temperature of measurement. In some compounds the transition from high to low spin forms takes place like a first order phase change; in others the transition extends over a substantial temperature range within which spectra due to both forms are seen. In some compounds only partial conversion of one form to the other takes place $[25 \mathrm{a}, \mathrm{b}]$.

Like the delocalization in mixed valence compounds the spin cross over transition is sensitive to the characteristics of the solid involved; different solvates generally behave differently, even to the extent of the cross over failing to take place. Deuteration of the solvent produces easily measurable changes in the transition process. Macrocrystalline and powder samples often behave quite differently.

These two examples show how Mössbauer spectroscopy is yielding a detailed picture of processes taking place in solids.

\section{Solid state decompositions}

The technique is invaluable in the investigation of reactions, such as thermal decompositions, occurring in solid substances. The sample is not destroyed by the measurement and the emergence of new phases can be detected. It must be remarked, however, that the technique is not very sensitive to small amounts. In most systems it gives information about the major components of the solid [26].
The temperature and condition of the firing, whether oxidizing or reducing, can be inferred from the Mössbauer spectra of pottery. Spectra of shards of ancient pottery have been used to try to identify the kiln used in its manufacture [27].

\section{Changes in bond character}

The spectra often contain information about the bonding of the Mössbauer atom that is difficult to obtain in other ways. Analysis of the spectrum gives the electric field gradient at the nucleus of the Mössbauer atom. Examination of such data for tin(IV) compounds, for which there is no free ion contribution to the electric field gradient, shows that, to a reasonable approximation, each ligand attached to the tin makes its individual contribution to the quadrupole splitting [28]. This point charge model had already been developed by nuclear quadrupole spectroscopists.

With some compounds however this model failed rather badly. For example it predicts that the quadrupole splittings for the tetrahedral compounds $\mathrm{SnR}_{3} \mathrm{X}$ and $\mathrm{SnRX}_{3}$ should be of equal magnitude but opposite sign. The experimental data for the compounds with $\mathrm{R}=\mathrm{C}_{6} \mathrm{H}_{5}$ and $\mathrm{X}=\mathrm{Cl}$ gave splittings of $1.39 \mathrm{mms}^{-1}$ and $1.19 \mathrm{mms}^{-1}$ respectively. The discrepancy was not due to the tin acquiring a higher coordination number than four in the solid since quickly frozen solutions gave practically the same values. This and related anomalies could be accounted for by supposing that the four bonds in such compounds are not equivalent $s-p$ hybrids [29a, b]. As proposed in Bent's rule the bond to the least electronegative ligand has the higher $s$ content. Similar conclusions about changes in hybridization were reached in studies of complexes of gold(I) of the type LAuX [30].

\section{Calculations of isomer shifts and electric field gradients}

It is possible to calculate both isomer shifts and electric field gradients. The difficulties in calculating the former quantities are familiar. The calculations must use wave functions referring not to the isolated Mössbauer atom but to the cluster in which it is present, a simple example is $\mathrm{FeF}_{6}^{3-}$. Relativistic wave functions are essential. The measured isomer shifts give the difference in electron density at the nuclei for two compounds; it is the difference of two large quantities, the greater part of the electron density being due to the sub valence shell electrons. Screening effects of the $p$ and other orbitals are difficult to calculate. Calculations avoiding serious approximations are very time consuming.

As might be expected in these circumstances the calculated value is very often not too close to the observed value. The observed isomer shifts provide an interesting test of the validity of such calculations. 
Calculations of electric field gradients are generally rather more successful, but they also demand considerable computer time.

\section{Magnetic studies}

Mössbauer spectroscopy has proved to be of great value in the study of the magnetic properties of solids. The most extensive work has concerned iron compounds, especially the mixed oxides such as the spinels and perovskites.

The onset of magnetic ordering of the iron atoms leads to a persistent hyperfine magnetic field at the nuclei and magnetic splitting of the spectrum ensues. The magnitude of the field and its orientation in relation to the principal axis of the electric field gradient can be deduced from the spectrum.

Using an externally applied field and single crystal samples the nature of the ordering, antiferromagnetic, ferrimagnetic or ferromagnetic, can be determined and the sign and orientation of the hyperfine field in relation to the crystal axes obtained. Magnetic phase changes are readily detected. Using an applied field normal to the Mössbauer photon beam the spin flop transition is clearly revealed [31].

By substituting diamagnetic ions, such as $\mathrm{Ga}^{3+}$, for the iron information about the magnetic coupling between the lattices can be explored. In the substituted samples next nearest neighbour effects, as described in section 18, are observed [32].

In conjunction with other techniques Mössbauer spectroscopy has helped disentangle the complicated magnetic behaviour of chemically simple substances like magnetite, $\mathrm{Fe}_{3} \mathrm{O}_{4}$.

Magnetic properties, since they arise from cooperative interactions in the solid, depend on the particle size in the sample measured. Very small particles behave paramagnetically at temperatures below the Néel temperature, this behaviour is called superparamagnetism. This has provided the basis of a technique in which the Mössbauer spectra at different temperatures can be used to deduce something about the particle size in the sample [33].

\section{Conversion electron Mössbauer spectroscopy}

The absorption events regenerate the excited state of the Mössbauer nucleus in the absorber. De-excitation leads to re-emission of Mössbauer photons in all directions, so that besides measuring the reduction in the intensity of the photon beam from the source along the beam axis the scattered photons can be measured in other directions. In such a measurement the velocity of movement of the source leading to greatest reduction in beam intensity will give the highest intensity of the scattered photons [34].

With most Mössbauer nuclei however internal conversion dominates the decay and a high proportion of the de-excitation takes place with electron and X-ray emission. Hence it is more satisfactory to measure these scattered radiations. Both the electrons and the $\mathrm{X}$-rays are generally of low energy, $7.3 \mathrm{keV}$ and $6.45 \mathrm{keV}$ respectively in the case of ${ }^{57} \mathrm{Fe}$ spectra, and if the scatterer, that is absorber, is incorporated directly in a proportional counter the spectrum recorded will be determined by the superficial and near surface layers of the scatterer. This is because the conversion electrons have a very limited range in a solid sample.

Much greater specificity as to the depth below the surface of the sample from which the spectrum emanates can be obtained using more elaborate apparatus. The scatterer and conversion electron detector are housed in a vacuum chamber. The detector is a channel electron multiplier and conversion electrons of selected energy are recorded so that the spectra are determined by the material at selected depths below the surface of the scatterer [35].

These techniques, often called CEMS, have been used extensively for the study of the corrosion of metals, especially iron [36]. They are also convenient for the study of thin films. The way in which the magnetic ordering in iron metal films changes with the thickness has been explored with this technique [37]. Not surprisingly the various treatments that have been used to modify the properties of iron, including nitriding and phosphate treatments to reduce corrosion, have been studied in this way [38]. An example of industrial interest is the way the spectrum from steel ballbearings changes as the bearings age [39].

\section{Applications in mineralogy and petrology}

A high proportion of minerals contain iron, an especially favourable element for Mössbauer spectroscopy. In the numerous silicate minerals the iron is most frequently present as $\mathrm{Fe}^{2+}$. The isomer shift helps to determine whether the iron cations are $4,5,6$ or 8 coordinate. It also distinguishes $\mathrm{Fe}^{2+}$ from $\mathrm{Fe}^{3+}$. A very wide variety of quadrupole splittings are found for the $\mathrm{Fe}^{2+}$ ions even with the same coordination number. The environments are always distorted from the ideal tetrahedral and octahedral arrangements for four and six coordination.

Since the free ion and ligand contributions to the quadrupole splitting are normally of opposite sign the splitting is generally greatest for the least distorted environment. As a result the Mössbauer spectrum of a mineral is a unique property and can be used for identification $[40 \mathrm{a}, \mathrm{b}]$.

The nondestructive measurement of the Mössbauer spectrum was particularly useful for the identification of minerals in precious samples such as those collected on the moon [41]. Terrestrial pyroxenes and plagioclase usually show some $\mathrm{Fe}^{3+}$ in their spectra but none could be seen in the spectra of moon rock samples. However the Mössbauer spectrum is not very sensitive to the presence of $\mathrm{Fe}^{3+}$ in the presence of much larger amounts of $\mathrm{Fe}^{2+}$, less than $1 \%$ of the iron in the 
oxidized form will not normally be seen. The moon "soil" contains ilmenite and in the impact craters glassy materials. No $\mathrm{Fe}^{3+}$ could be detected in the spectra of either of these, although more sensitive methods of detection showed tiny amounts of $\mathrm{Fe}^{3+}$ in superficial material [42].

In many metamorphosed rocks both $\mathrm{Fe}^{2+}$ and $\mathrm{Fe}^{3+}$ are present and the determination of their proportions by classical analysis is not always reliable; the solution of the sample for analysis often leads to oxidation of some $\mathrm{Fe}^{2+}$. The area of the absorption peaks due the iron in a given valence and lattice site is proportional to the amount of iron in that form in the absorber. It is necessary that the spectrum be measured with a thin sample, that there is minimal overlap of component spectra and that the Mössbauer fractions for the iron in the different sites are about the same. The latter condition is likely to be fulfilled if spectra are measured at low temperature and the sites have the same coordination number.

Although the precision of this method of analysis is limited the results are at least as reliable as those from chemical analysis [43].

\section{Cation ordering in minerals}

Many minerals have more than one kind of cationic site which can be occupied by $\mathrm{Fe}^{2+}$ or other divalent cations such as $\mathrm{Mg}^{2+}, \mathrm{Ca}^{2+}$ etc. Often a range of minerals are available in which various proportions of the sites are occupied by $\mathrm{Fe}^{2+}$ and the question arises does the iron prefer to occupy one kind of site more than another. The number of kinds of site and their local configuration is generally known from diffraction studies. In many cases this will permit the spectrum arising from iron in a given site to be identified and the area under the absorption lines gives the amount of iron in that kind of site. With two kinds of site a random occupation will lead to half the total iron in each kind of site. More generally the areal measurements will give the mole fraction of iron in each site and, supposing sites not occupied by iron are occupied by magnesium, the data will yield an equilibrium constant for the reaction $\mathrm{Fe}^{2+}(1)+\mathrm{Mg}^{2+}(2) \geq \mathrm{Fe}^{2+}(2)+$ $\mathrm{Mg}^{2+}(1)$ the 1 and 2 referring to the two kinds of site. A refinement is to introduce activity coefficients, for example on the basis the theory of regular solutions.

At very high temperatures the equilibrium constant will always approach unity, but at lower temperatures it may differ very substantially from one. Measurement of the $\mathrm{Fe}^{2+}$ occupation of the sites may then supply information about the thermal history of the mineral [44].

\section{Valence delocalization in minerals}

Some minerals, usually giving very complex Mössbauer spectra, have component spectra with anomalous isomer shifts and, usually, very temperature dependent spectra. The anomalous isomer shifts are too high for four or six coordinate $\mathrm{Fe}^{3+}$ but too small for even four coordinate $\mathrm{Fe}^{2+}$. These characteristics are typical of delocalization between $\mathrm{Fe}^{2+}$ and $\mathrm{Fe}^{3+}$. The minerals include Deerite, Howeite, Ilvaite, Augite, Schorlomite and others. No other technique of investigation can reveal this delocalization so clearly [45].

\section{Next nearest neighbour effects}

The electric field gradient at the iron atom in minerals is affected not only by the coordination geometry of the oxide ion ligands but also by the next nearest neighbour ions. This is because these ions are also interacting with the ligand oxide ions. If there are two or more cationic components in the mineral and they are randomly distributed over the cation sites there will be a distribution of the proportions of the two cations as the next nearest neighbours to different iron atoms. Thus there will be a distribution of electric field gradients and the lines in the spectrum will broaden. By contrast with one cationic species or an ordered occupation of cationic sites, leading to a constant next nearest neighbour environment, sharp line spectra will ensue [46].

\section{Soil analysis}

The determination of the identity and proportions of the various iron oxides and hydroxides present in soils and earthy deposits is a matter of considerable difficulty. Combined with X-ray diffraction studies Mössbauer spectra supply the best solution to the problem. However rather extensive measurements are needed, including recording of spectra at temperatures down to liquid helium temperature. Long measurements ensuring a low statistical error on each point on the spectrum are required. Conclusions from one set of spectra should then be used to calculate expected values for other spectra and an analysis of the quality of the fit made [47].

\section{Dating}

Several possibilities of using Mössbauer spectra for dating minerals have been suggested. They include a slow cis-trans change in minerals with octahedral $\mathrm{Fe}^{2+}$ with two $\mathrm{OH}$ ligands and a slow ordering of next nearest neighbours if, these are initially disordered. As yet none of the procedures can be regarded as established.

\section{An example of potential industrial application}

Since good quality spectra generally take a day to accumulate and expert interpretation is usually necessary Mössbauer spectra are not attractive for industrial application. However there are exceptions. In a number of coals their sulphur content is largely present as py- 
rites. A two point measurement can be made, one at a velocity giving an absorption maximum for pyrites, the other at a velocity far off resonance. The difference in counting rate at the two velocity will be a measure of the pyrites content of the coal. A measurement of this kind can be made in less than an hour [48].

\section{Application to iron containing natural products}

Mössbauer spectra have proved of considerable value in helping to elucidate the structure and mode of operation of the numerous biologically important iron complexes. Most of these iron-protein compounds are very complex and no single method of investigation gives a complete picture of their nature and properties. In many cases their iron content is very low, perhaps one iron atom in a molecule of weight $10^{4}$ to $10^{6}$. The abundance of ${ }^{57} \mathrm{Fe}$ in natural iron is only about $2 \%$ so that it is best to use samples produced from organisms which have been supplied with ${ }^{57} \mathrm{Fe}$ enriched iron. Good quality spectra with small statistical errors are important for these studies and a very detailed computer analysis of the spectra is essential.

Perhaps the simplest of these generally complicated compounds are the iron transport complexes, these include transferrin, lactoferrin and the siderochromes. The last of these may have molecular weights as low as 1000 . They are formed in the simpler organisms. These compounds behave as strong high spin iron(III) complexes, over a wide range of temperatures they give quadrupole split paramagnetic spectra but at very low temperatures magnetic splitting ensues. The iron atoms in the solid complex are well separated and there is no magnetic coupling. An analysis of the spectra yields details of the symmetry at the iron site and the ligand field splittings. In higher organisms the iron transport compounds appear to contain two iron atoms per molecule and the spectra suggests they may occupy different sites.

\section{The iron storage compounds, such as ferritin and hemosiderin, are also amongst the simpler of these compounds}

They have a relatively high iron content and give somewhat simpler spectra than the other compounds that will be considered. They consist of a core of iron(III) hydroxide, usually containing some phosphate, surrounded by a protein sheath. At low temperatures they give magnetically split spectra but over some temperature range below room temperature the magnetic spectrum collapses to give a quadrupole split doublet. This suggests superparamagnetic behaviour (See section 13). The size of the iron hydroxide core can be estimated on this basis. Ferritins from different organisms, animals, plants or fungi, differ substantially in core size $[49 a, b, c]$.

\section{Not surprisingly extensive work has been done on the Heme group of iron proteins}

In these compounds the iron is in a quasi-octahedral environment, surrounded in the equatorial positions by four nitrogens in a porphyrin type ligand. The fifth axial position binds to a nitrogen in a histidine unit in the protein aminoacid chains. The sixth position can be occupied by oxygen, water, cerbon monoxide or other ligands, or be vacant. Hemoglobin has four such units in the molecule, myoglobin only one. Mössbauer spectroscopy has confirmed and amplified conclusions from earlier work on these compounds and uncovered new information.

In deoxyhemoglobin, where the iron is not in the plane of the four nitrogens, the spectra confirm that it contains high spin $\mathrm{Fe}^{2+}$. A quadrupole split spectrum is obtained even at low temperatures, but magnetic splitting takes place in an external applied magnetic field. From the temperature dependence of these spectra information about the environment of the iron can be obtained.

Another complication is revealed by these and other data. Model porphyrin complexes of iron have shown that abnormal spin states, $S=1$ and $S=3 / 2$ for iron(II) and iron(III) respectively, may occur. Ferricytochrome $c$ seems to contain a heme unit of this kind [50]. The deoxyhemoglobin data suggest a low lying state of spin unity. A further complication is the possibility of spin cross over with these compounds.

In oxyhemoglobin the iron is low spin and a quadrupole split spectrum is found even at very low temperatures. The unusual temperature dependence of quadrupole splitting provides information about the orientation and rotation of the oxygen around the iron oxygen bond. The $\mathrm{O}-\mathrm{O}$ axis is neither parallel nor normal to the plane of the four nitrogens.

Other heme complexes can be shown to contain high spin or low spin iron(III) and there is even evidence for iron(IV) complexes [51].

\section{Another rather numerous group of natural iron compounds are the iron sulphur proteins}

These contain iron interacting with four sulphur atoms in a tetrahedral arrangement. In the rubredoxins all the sulphur atoms are in cysteinyl units of the protein giving units with a single iron atom. In the ferridoxins there are two bridging sulphide ligands giving a unit containing two iron atoms. There are also ferridoxins with three iron atoms with the same proportions of sulphide and cysteinic sulphur ligands and a ring . Indeed Mössbauer spectroscopy played an important role in the identification of this group [52]. Finally a very important group contain a quasi-cubic, or cubane, unit with four sulphidic atoms and four iron atoms each bonded to three sulphidic and one cysteinic sulphurs [53].

These compounds are often involved in natural redox reactions. Mössbauer spectroscopy plays an im- 
portant part in the investigation of these compounds, very detailed studies are essential. In the compounds containing two or more iron atoms the question of the oxidation state of the iron atoms is complicated by valence delocalization [54].

Numerous iron containing enzymes as well as the iron molybdenum species nitrogenase involved in nitrogen fixation, have been studied by Mössbauer spectroscopy [55].

\section{Differential perturbed angular correlation (DPAC)}

The third technique in which radioactive decay yields information about the environment of the radioactive atom depends on the angular correlation between the directions of emission of successive photons emitted by the nucleus. In these circumstances the emission of the first photon coincides with spin polarisation of the nucleus, different spin orientations are no longer equally populated, therefore the emission of the second photon is not isotropic in relation to the direction of the first.

In the absence of any perturbing fields the relative probability of the second photon being emitted in a direction making an angle $\theta$ with the direction of the first photon is given by the sum of a number of products composed of a coefficient and a Legendre polynomial. Only the even Legendre functions are involved. The coefficients are functions of the spin quantum numbers for the nuclear states involved and the multipolarity of the emission.

Considering now a differential measurement in which the relative probability is measured a time $t$ after the emission of the first photon, the result will be the above mentioned sum corrected for the decay of the intermediate state during the interval $t$. This correction term will be the only time dependent term.

If however the nucleus is perturbed by a magnetic field or an electric field gradient the spin polarisation of the intermediate state will be affected and the relative probability for emission at an angle $\theta$ becomes time dependent. This time dependent term contains the components of the electric field and the magnetic field at the nucleus, the same quantities as are obtained from the Mössbauer spectrum.

The theory of perturbed angular correlation was developed in the early 1950's [56a, b, c] but experimental data only began to appear about the time Mössbauer spectroscopy developed.

\section{Experimental considerations}

The nuclear state emitting the first photon, or its parent, should have a reasonably long half life, preferably longer than an hour to permit measurements over a long enough period for good statistics. The intermediate state should have a half life appreciably longer than the magnetic or quadrupole precession times and the time interval $\delta t$ set by the circuit detecting coincidence of first and second photons. A convenient species for DPAC is the nuclear isomer ${ }^{111 \mathrm{~m}} \mathrm{Cd}$, the first photon has an energy $150 \mathrm{keV}$ and a half life of $48.6 \mathrm{~min}$, rather shorter than desirable. The second photon of $247 \mathrm{keV}$ is emitted by a state with a half life of $84 \mathrm{~ns}$. With a coincidence resolution time of $2 \mathrm{~ns}$ the time dependence can be followed over some hundreds of nanoseconds. Such measurements on a cadmium compound labelled with the nuclear isomer will yield the same information as a hypothetical Mössbauer spectrum of the compound, except that nothing corresponding to the isomer shift will be obtained.

Unfortunately there are not very many suitable nuclear isomers available [57]. Several more systems become available if one produces the state emitting the initiating photon by another radioactive decay processes. But this introduces a complicating factor; how far has the decay of the parent species affected the chemical state of the species emitting the first photon?

The recoil following soft $\beta$ particle emission is generally too small to effect bond rupture but both $\beta$ decay and orbital electron capture lead to considerable electronic disturbance. In metals and conductors such disturbance is quickly repaired and PDAC is entirely suitable for measuring electric field gradients and magnetic fields. In insulators however the measurements may be more useful for what they tell one about the chemical effects of the decay of the parent species.

Sometimes both DPAC and Mössbauer data are available for a compound. Agreement of the electric field gradient values obtained by the two methods is satisfactory. Discrepancies can be attributed to the effects of the decay. DPAC measurements are possible producing excited states of ${ }^{111} \mathrm{Cd}$ by $\beta$ decay of ${ }^{111} \mathrm{Ag}$ and by orbital electron capture in ${ }^{11}$ In. In both cases comparison with nuclear isomer data shows that both decay processes lead to some ${ }^{11} \mathrm{Cd}$ in abnormal environments.

An interesting simple result is to find that a closed shell parent almost always leads to a closed shell decay product [58].

DPAC is especially well suited to exploring relaxation effects taking place faster than the life time of the intermediate state, such as a fluctuating electric field gradient. Unlike Mössbauer spectroscopy it can be used with solutions or gases. In solutions it provides a means of measuring the rotation period of large molecules after labelling with a suitable radioactive species [58].

\section{References}

1. (a) Bouchez, R., Daudel, R., Daudel, P., Muxaet, R.: J. Phys. Radium 8, 336 (1947).

(b) Daudel, R.: Rev. Sci. 87, 162 (1947).

2. Segré, E.: Phys. Rev. 71, 274 (1947).

3. Johlige, H. W., Aumen, D. C., Born, H. J.: Phys. Rev. C2, $1616(1970)$

4. Remeikis, V., Dragunas, A., Makariunas, K., Ruzece, B.: Izv. Akad. Nauk S.S.R. Ser. Fiz. 52, 2 (1988). 
5. Makariunas, K., Dragunas, A., Makariuniene, E.: Hyperfine Interact. 36, 211 (1987).

6. (a) Geresimov, V. N., Zelekov, A. G., Kulakov, V. M., Pchelin, V. A., Sokolovskaya, M. V., Soldavac, A. A., Chistyakov, L. V.: Zh. Eksp. Teor. Fiz. 86, 1169 (1984).

(b) Bainbridge, K. T., Goldharber, M., Wilson, E.: Phys. Rev. 90, 430 (1953).

(c) Makariunas, K., Makariuniene, E., Dragunas, A.: Liet. Fiz. Rinkinys 22, 114 (1982). [Chem. Abstr. 98, 186880].

7. (a) Mazaki, H., Shimizu, S.: Phys. Rev. 148, 1161 (1966).

(b) Nève de Mevergnies: Phys. Lett. 32B, 482 (1970).

(c) Koltsov, V. V.: Izv. Akad. Nauk S.S.R. Ser. Fiz. 57, 100 (1993).

8. de Benedetti, S., de S. Barros, F., Hoy, G. R.: Ann. Rev. Nucl. Sci. 16, 31 (1966).

9. Pyper, N. C., Harston, M. R.: Proc. Roy. Soc. Lond. 420A, 277 (1988).

10. Harston, M. R., Pyper, N. C.: J. Phys. 17B, L839 (1984).

11. Harston, M. R., Pyper, N. C.: Phys. Rev. 48A, 268 (1993).

12. Harston, M. R., Pyper, N. C.: Phys. Rev. Lett. 56, 1790 (1986).

13. (a) v.e.g. Zhongua Chen, Rosenberg, L., Spruch, L.: Adv. At. Mol. Opt. Phys. 26, 297 (1990).

(b) Janecke, J. W., Becchetti, F. D., Roberts, D. A.: Phys. Rev. 47C, 2954 (1993).

14. Mössbauer, E.: Z. Physik 151, 124 (1958).

15. Hanna, S. S., Heberle, J., Littlejohn, C., Perlow, G. J., Preston, R. S., Vincent, D. H.: Phys. Rev. Lett. 4, 177 (1960).

16. (a) Kistner, O. C., Sunyar, A. W.: Phys. Rev. Lett. 4, 412 (1960).

(b) de Benedetti, S., Lang, G., Ingalls, R.: Phys. Rev. Lett. 6, 60 (1961)

17. (a) Kerler, W., Neuwirth, W., Fluck, E., Kuhn, P., Zimmermann, B.: Z. Physik 173, 321 (1963).

(b) Duncan, J. F., Wigley, P. W. R.: J. Chem. Soc. 1963, 1120 .

18. Ercolani, C., Gardini, M., Pennesi, G., Rossi, G., Russo, V.: Inorg. Chem. 27, 422 (1988).

19. v.e.g. Dattagupta, S.: in Mössbauer Spectroscopy, Eds. D. P. E. Dickson and F. J. Berry, Camb. Univ. Press (1986)

20. Xiao Q. Ding, Bominaar, E. L., Eckhard, B., Heiner, W., Trautwein, A. X., Druece, S., Chaudhuri Phalgun, Winkler, K.: J. Chem. Phys. 92, 178 (1990).

21. Verwey, F. J. W.: Nature 144, 327 (1939).

22. (a) Bauminger, R., Cohen, S. G., Marinov, A., Ofer, S., Segal, E.: Phys. Rev. 122, 1447 (1961).

(b) Banerjee, S. K., O'Reilly, W., Johnson, C. E.: J. Appl. Phys. 38, 1289 (1967).

23. v.e.g. Wohler, S. E., Williams, R. J., Oh, S. M., Hendrickson, D. N., Inniss, D., Strause, C. E.: J. Am. Chem. Soc. 108, 2938 (1986)

24. Kramer, J. A., Hendrickson, R. N.: Inorg. Chem. 19, 3330 (1980).

25. For review see (a) Gütlich, P.: Struct. Bonding 44, 83 (1981).

(b) Konig, E., Ritter, G., Kulshreshtha, S. K.: Chem. Rev. 55, 219 (1985).

26. v.e.g. Bancroft, G. M., Dharmarwardena, K. G., Maddock, A. G.: J. Chem. Soc. A, 1969, 2914.

27. v.e.g. Chevalier, R., Coey, J. M. D., Bouchez, R.: J. Physique 37, C6, 861 (1976).

28. Clark, M. G., Maddock, A. G., Platt, R. H.: J. Chem. Soc. Dalton, 1972, 281.

29. (a) Parish, R. V.: in Mössbauer Spectroscopy applied to Chemistry, Vol. 1, Ed. G. J. Long, Plenum Press, 1984.

(b) Marks, A. P., Drago, R. S., Herber, R. H., Potasek, M. J.: Inorg. Chem. 15, 257 (1976).

30. Jones, P. G., Maddock, A. G., Mays, M. J., Muir, M. M., Williams, A. F.: J. Chem. Soc. Dalton 1977, 1434.
31. For review see Thomas, M. F., Johnson, C. E.: Chapter 4 in Mössbauer Spectroscopy, Eds. D. P. E. Dickson and F. J. Berry, Camb. Univ. Press, 1986.

32. v.e.g. Kostikas, A., Simopoulos, A., Gangas, N. N. J.: Phys. Status Solidi 42, 705 (1970).

33. Mørup, S., Dumesic, J. A. Topsoe, H.: in Applications of Mössbauer Spectroscopy, Ed. R. L. Cohen, Academic Press N.Y., 1980.

34. For review see Berry, F. J.: Trans. Met. Chem. 4, 209 (1979).

35. Liljquist, D., Bodlund-Ringstrom, B.: Nucl. Instrum. Methods 160, 131 (1979).

36. (a) Sete Camara, A., Keune, W.: Corrosion Sci. 15, 441 (1973).

(b) Simmons, G. W., Kellerman, E., Leidheiser, H.: Corrosion 29, 227 (1973).

37. Przybyski, M., Koreki, J., Gradmann, V.: Appl. Phys. A52, 33 (1981).

38. Berry, F. J., Maddock, A. G.: Chem. Commun. 1978, 308.

39. Spijkerman, J. J.: in Mössbauer Methodology 7, 86 (1971).

40. (a) Pollak, H., de Coster, M., Amelinkx, S.: Phys. Status Solidi 2, 1653 (1962).

(b) Bancroft, G. M.: Introduction to Mössbauer Spectroscopy for Inorganic Chemists and Geochemists, Van Nostrand, 1973.

41. See Proc. $1^{\text {st. }}, 2^{\text {nd. }}, 3^{\text {rd. }}$ and $4^{\text {th. }}$ Lunar Sci. Confs. Published in Supplements to Geochim. Cosmochim. Acta 1970-1973.

42. Niebuhr, H. H., Zeira, S., Hafner, S. S.: in Proc. $4^{\text {th }}$ Lunar Sci. Conf. 1973.

43. Bancroft, G. M.: Chem. Geol. 5, 255 (1970).

44. Bancroft, G. M., Burns, R. G., Maddock, A. G.: Am. Mineral. 52, 1009 (1967).

45. Evans, B. J., Amthauer, G.: J. Phys. Chem. Solids 41, 985 (1980).

46. Bancroft, G. M., Osbourne, M. B., Fleet, M. E.: Solid State Commun. 47, 623 (1983).

47. For review see Bowen, L. H., Webb, S. B.: in Mössbauer Spectroscopy and its chemical applications, Advances in Chemistry Series, ACS No 194, 247 (1981).

48. Williamson, D. L., Guettinger, T. W., Dickerhoof, D. W. Advances in Chemistry, ACS 194, 177 (1981).

49. (a) Boas, J. F., Window, B.: Aust. J. Phys. 19, 573 (1966). (b) Oosterhuis, W. T., Spartalian, K.: in Applications of Mössbauer Spectroscopy, Ed. R. L. Cohen, Academic Press, Vol. 1, 1976

(c) Bauminger, E. R., Harrison, P. M., Hechel, D., Nowik, I., Treffry, A.: Biochem. Biophys. Acta 48, 1118 (1991).

50. Maltempo, M. M., Moss, T. H., Spartalian, K.: J. Chem. Phys. 73, 2100 (1980).

51. For review see Spartalian, K., Long, G.: in Applications of Mössbauer Spectroscopy, Ed. R. L. Cohen, Academic Press, Vol. 2, 1980

52. Huynh, B. H., Moura, J. J. G., Moura, I., Kent, T. A., Le Gall, J., Xavier, A. V., Munck, E.: J. Biol. Chem. 225, 3242 (1980).

53. For review see Trautwein, A. X., Bill, E., Bominaar, E. L., Winkler, H.: Struct. Bonding 78, 1 (1991).

54. Dickinson, D. P. E., Johnson, C. E.: in Structural and Resonance Techniques in Biological Research, Ed. D. L. Rousseau, Academic Press 1984

55. Newton, W. E., Chelier, S. F., Sands, R. H., Durham, W. R. Biochem. Biophys. Res. Commun. 162, 882 (1989).

56. (a) Goertzel, G.: Phys. Rev. 70, 897 (1946).

(b) Alder, K., Albers-Schonberg, H., Heer, E., Novey, T. B.: Helv. Phys. Acta 26, 761 (1953).

(c) Abragam, A., Pound, R. V.: Phys. Rev. 92, 943 (1953).

57. Shirley, D. A., Haas, H.: J. Chem. Phys. 58, 3339 (1973).

58. For review see Boyer, P., Baudry, A.: in Hot Atom Chemistry, Ed. Tatsuo Matsuura, Kodansha Press, 1984. 



\title{
X-Rays and Radiochemistry
}

\author{
By H. K. Yoshihara \\ Japan Isotope Data Institute, Nishikatsuyama 25-20, Aobaku, Sendai 981, Japan
}

(Received May 29, 1995 ; revised June 19, 1995)

\author{
X-Rays / Historical review / \\ Analysis of radioactive materials / PIXE / TXRF / \\ Chemical effects
}

\begin{abstract}
The contribution of X-rays to the development of radiochemistry is reviewed. Historical accounts are presented together with the present status of the applications of X-rays, including PIXE and synchroton radiation, to structural and analytical chemistry. Finally, the chemical effects on X-ray emission and their application to chemical speciation are discussed.
\end{abstract}

\section{Introduction}

$\mathrm{X}$-rays were discovered by Roentgen in November 1895 , less than 4 months before Becquerel's discovery of radioactivity. The succession of both events appears logical, because $\mathrm{X}$-rays are generated in the inner electron shells of the atom, while radioactivity is a property of the atomic nucleus itself. The high penetrating power of the X-rays was surprising to scientists who were familiar only with visible, IR and UV radiations. Radioactivity was accompanied by the emission of even more energetic and penetrating radiations.

The recognition of X-rays not only imposed a revolutionary change in the concept of the atom proposed by Dalton and his contemporaries, but opened the way to the discovery of radioactivity on grounds of the relation between $\mathrm{X}$-rays and fluorescence. The famous French mathematician Henri Poincaré suggested that since X-rays seem to emerge from the fluorescence of the walls of a Crookes tube, any other fluorescence, whatever its origin, should also be a source of X-rays. This observation prompted Henri Becquerel to verify whether the phosphorecence of uranium salts, a phenomenon already investigated by his father, was accompanied by the emission of X-rays. As is well known, Becquerel did not observe X-rays but rather a new kind of radiation which was able to blacken a photographic plate. The origin of this emission was the radioactivity of uranium, which was confirmed later by the Curies.

The chemical action of X-rays was gradually elucidated in the years following 1910 by S. Lind. This aspect is relevant to radiation chemistry and will not be covered in this review.

In 1914, Moseley established his law which relates the wavelength of $\mathrm{X}$-rays to the atomic number of the associated element. This law was applied successfully by G. von Hevesy, the pioneer of the use of X-rays in chemistry and 1944 Nobel Laureate, to the identification in 1923 of a new element with atomic number 72 (hafnium).

At that time, Hevesy, a Hungarian of noble birth, was working at the Niels Bohr Institute in Copenhagen and was helped by Coster, a Dutch specialist on X-ray spectroscopy. The fruitful collaboration between the chemist and the physicist was stimulated by the international and interdisciplinary atmosphere which prevailed at the Institute. The new element discovered by Hevesy and Coster resembled $\mathrm{Ti}$ and $\mathrm{Zr}$, contrary to the belief that it should belong to the group of rare earths. The discovery of hafnium supported the atomic theory of Bohr, who heard about the discovery during his stay in Stockholm on the occasion of his Nobel Prize lecture delivered in 1922.

A young Japanese scientist, attracted by Bohr's reputation, joined the Institute in Copenhagen. This was Y. Nishina, who was to become famous for his quantum mechanical calculation, together with Klein, of the cross section of Compton scattering, and later also for the discovery of the symmetric fission of uranium induced by fast neutrons. In 1925, Nishina and Coster successfully performed the first quantitative chemical analysis based on X-rays. They used standards of Ta and $\mathrm{Lu}$ to determine the amount of $\mathrm{Hf}$, a practice which was later extensively applied in radioactivation analysis, the major radioanalytical method introduced by Hevesy in 1936.

Coster was also interested in the chemical effects of the X-ray absorption edge, which had been observed in the early 1920's, by Bergenbren, Lindh and others. He suggested that the chemical shift of the absorption wavelength was closely related to the deformation of the outer electron shells caused by the chemical state of the atom investigated.

Nishina extended his stay in Copenhagen and showed in 1927 that the chemical shift of the X-ray absorption in $\mathrm{Ca}, \mathrm{Cl}$ and $\mathrm{S}$ could be explained quantitatively in terms of the lattice energy and of the character of chemical bonding. This work was achieved in cooperation with two other Japanese visitors in Copenhagen, Aoyama and Kimura. The latter is well known for the discovery of the first nuclide in the neptunium family, the $\beta^{-}$emitter ${ }^{237} \mathrm{U}$.

Inspired by the spirit of the Bohr Institute, Nishina was to become the most influential physicist for the 


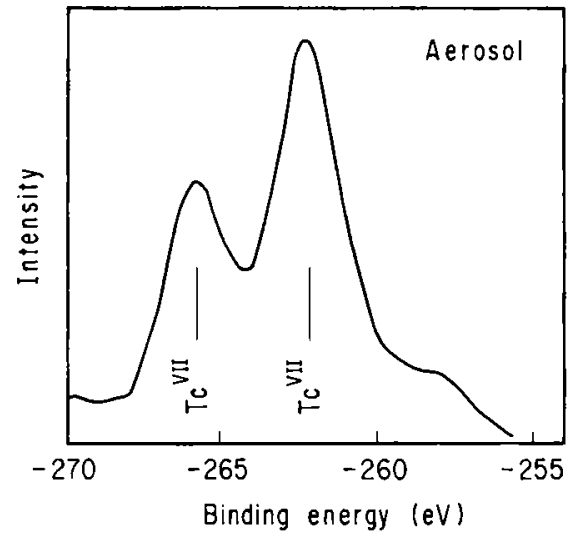

Fig. 1. The XPS spectrum of aerosol from high level wastes [3].

following generation of Japanese nuclear scientists, as pointed out by Segré in his book "From X-rays to Quarks" published in 1976. This role has been acknowledged by Yukawa, 1949 Nobel Laureate for his prediction of the existence of the meson.

Nishina's impact was not limited to the physicists' circles, since he also stimulated interest on nuclear chemistry. Back in Japan, Kimura, who had participated in Hevesy's work, undertook the search for transuranium elements at the Physical and Chemical Research Institute of Tokyo shortly after McMillan's discovery of neptunium in 1940. One of his students, N. Saito, was for a time Director at the International Atomic Energy Agency. Kimura's laboratory was well equipped with a Siegbahn X-Ray spectrometer for analytical purposes. The present author was one of Kimura's youngest students.

The importance of X-rays in radiochemistry is well established today. Striking examples are X-ray measurements in particle-induced X-ray emission (PIXE), $\mathrm{X}$-ray diffraction studies of Tc compounds and actinide elements, structural analysis by XAFS (including EXAFS and XANES) and X-ray fluorescence (XRF) analysis, including total reflection X-ray fluorescence (TXRF) of synchrotron radiation (SR).

However, X-rays have further potentialities. The chemical effects on X-ray characteristics are being elucidated step by step. Progress in the field is expected with the advent of instruments with higher resolution. Speciation of elements based on chemical effects has a promising future and recent studies in this field are included in the review.

\section{2. $X$-rays in the analysis of radioactive materials}

For a time, $\mathrm{X}$-ray measurements were considered relatively inconvenient when compared to the detection of the radiations emitted by radioactive nuclides. The demerits were overcome with the advent of semiconductor detectors in the 1960's. $\mathrm{Si}(\mathrm{Li})$ detectors are now extensively used in energy-dispersive $\mathrm{X}$-ray spectrometers (EDX). Compared to the wavelength-dispersive systems (WDX), which resolve the X-rays with

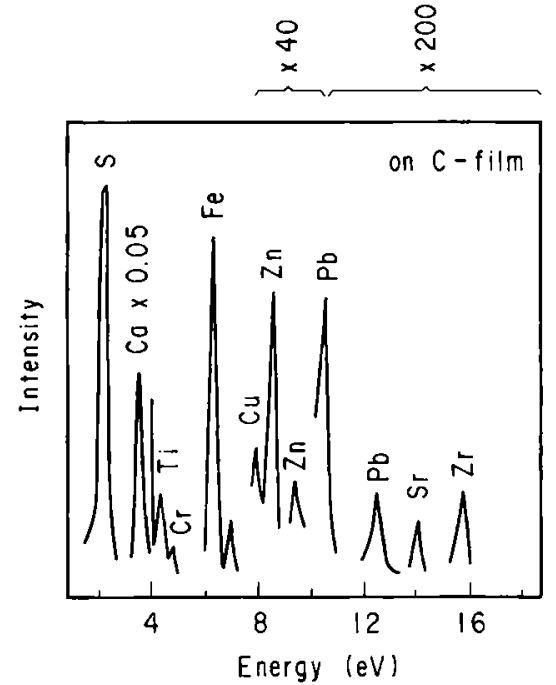

Fig. 2. PIXE analysis of atmospheric deposits on a carbon film [5].

an analyzing crystal coupled to a goniometer, they offer the advantages of a higher counting efficiency, a shorter measurement time and easier data treatment. However, the resolution of the EDX systems is definitely below that of the other type of spectrometer.

EDX spectrometers with X-ray tubes are widely used for the multielemental and fast analysis of numerous materials. They are convenient for the determination of $U$ and $T h$, but the sensitivity is relatively poor. A more sophisticated analysis is performed on small samples with an electron probe X-ray microanalyzer (EPMA). With this technique, Bradbury et al. [1] first demonstrated that the fission products $\mathrm{Ru}$, Mo, $\mathrm{Ce}$ and $\mathrm{Ba}$ existed as solid solutions in slices of irradiated $\mathrm{UO}_{2}$ pellets. Interestingly, metallic inclusions of noble metals such as $\mathrm{Ru}, \mathrm{Rh}$ and Pd were also found as a consequence of the redistribution of oxygen in irradiated fuels. Cladding interactions in neutron-irradiated MOX fuels $\left(\mathrm{UO}_{2}-\mathrm{PuO}_{2}\right)$ were studied by Johnson et al. [2]. With EPMA, these authors showed that intergranular attack of the stainless steel cladding had occurred at the fuel-cladding interface; in particular, fission-produced iodine played an important role in the corrosion of the cladding.

An energy-dispersive spectrometer combined with a scanning electron microscope (SEM-EDX) is a powerful tool for drawing an elemental map of the material to be measured. Baumgärtner and coworkers [3] investigated the chemical behaviour of technetium in aerosols generated from high level wastes by means of SEM-EDX, Auger electron spectroscopy (AES) and X-ray photoelectron spectroscopy (XPS or ESCA). All these methods rely on X-rays, either as the excitation source or as the radiation emitted in relaxation processes. The authors found that the behaviour of Tc in the map was similar to that of Cs measured by SEMEDX and AES. Since the XPS spectrum revealed Tc as pertechnetate, the authors concluded that $\mathrm{CsTcO}_{4}$ was present in the aerosol (Figure 1). This observation 


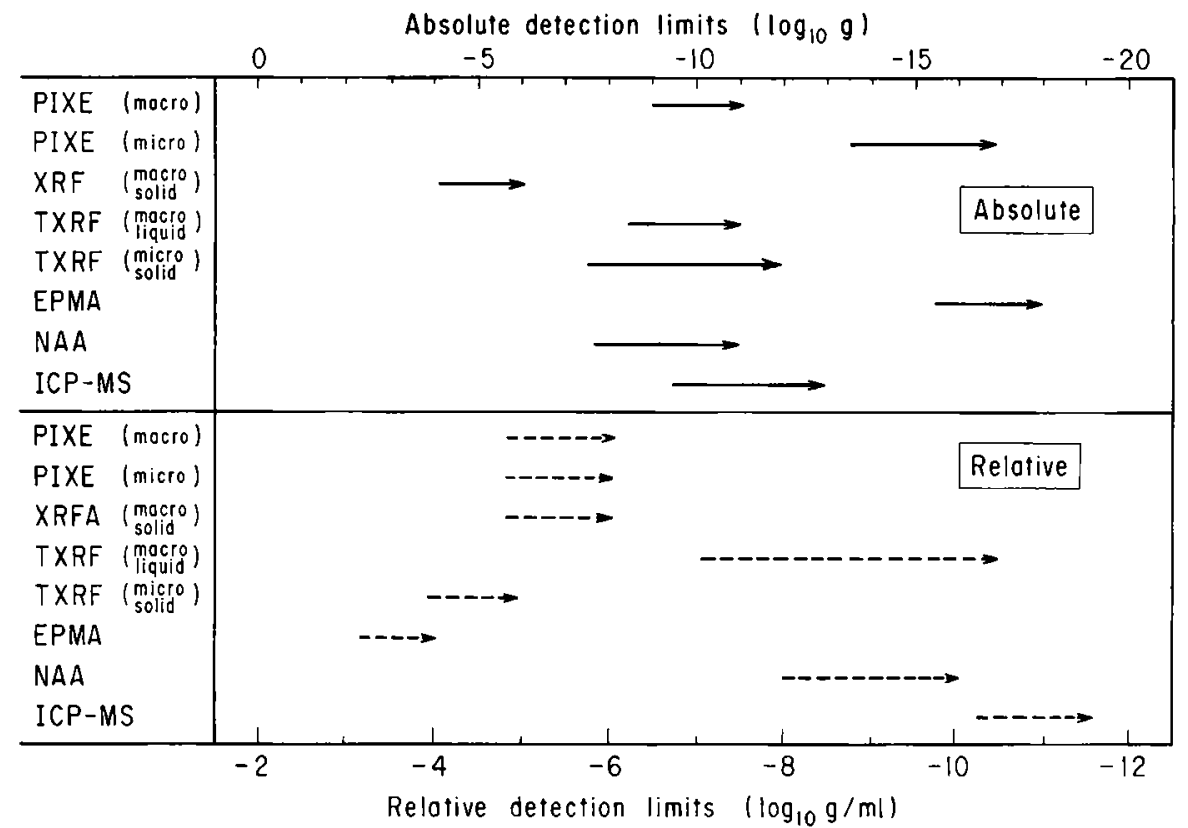

Fig. 3. Comparison of the detection limit of PIXE with those of other methods. XRF: X-ray fluorescence, TXRF: total reflection Xray fluorescence, EPMA: electron probe X-ray microanalysis, NAA: neutron activation analysis, and ICP-MS: inductively coupled plasma mass spectrometry.

is compatible with the known behaviour of fission iodine in spent nuclear fuels that combines with $\mathrm{Cs}$ as CsI [4].

\section{Analysis of environmental and biological samples by PIXE}

Protons, deuterons, helium ions and heavy ions delivered by accelerators have large interaction cross sections with atomic electrons, followed by the emission of X-rays, thus enabling a highly sensitive and multielemental analysis of various materials. This is the essence of the PIXE method (particle-induced X-ray emission), which has been applied successfully to the analysis of trace elements since its introduction in 1970 by Johansson and coworkers [5]. Before Johansson's decease in 1992, the PIXE method had been recognized as a standard technique in analytical chemistry with a wide range of applications in physics, chemistry, biology and medicine, as well as in technology.

The first example of PIXE analysis presented by Johansson $e t$ al. is shown in Figure 2 [5]. A carbon film was exposed outdoors overnight and the X-ray spectrum of the sample bombarded for one hour with $5 \mathrm{MeV}$ protons was measured with a $\mathrm{Si}(\mathrm{Li})$ detector. The characteristic X-rays of the elements $\mathrm{S}, \mathrm{Ca}, \mathrm{Ti}, \mathrm{V}$, $\mathrm{Cr}, \mathrm{Fe}, \mathrm{Cu}, \mathrm{Zn}, \mathrm{Sr}, \mathrm{Zr}$ and $\mathrm{Pb}$ were clearly identified.

The sensitivities of PIXE and of other methods are compared in Figure 3. The absolute sensitivity is high for PIXE, but the method is less efficient on a relative sensitivity scale. It can be improved with preconcentration procedures and detection of trace elements in water at the ng/l level has been reported [6]. The de- tection limit of PIXE, as well as that of other analytical methods, is greatly enhanced by the use of microbeams ( $\mu$ PIXE).

PIXE is very commonly applied to environmental samples and is particularly useful for the analysis of aerosols. Cahill suggested the establishment of an international network for the control of fine sulfate aerosols which arise largely from human activities [7]. Data useful for meteorology, based on PIXE measurements of aerosols in Europe, have recently been obtained by Koltay [8]. A model has been established to estimate the relative fractions of anthropogenic aerosols arising from local emissions and from sources in neighbouring countries.

Environmental pollution caused by studded car tires has been demonstrated by a Japanese group using the PIXE method [9]. It was found that at the beginning and end of the snow-fall season in the northern districts of Japan (Sapporo, Sendai), the erosion of asphalt roads by studded tires released dusts. The profile of elements found in dusts, shown in Figure 4, is in good agreement with that of asphalt, i.e., rich in $\mathrm{Ca}$ and quite different from that in cities (e.g. Nagoya) where studded tires are not in use. Legal regulation for the use of studded tires was established in consequence.

Biology and medicine are also important fields for application of PIXE. Human blood serum and hair samples have been analysed by Valković [10]. The uptake of environmental pollutants by hair has obvious implications in public health.

Yumoto et al. have analysed the content of $\mathrm{Al}$ in brain [11]. The element is suspected to contribute to Alzheimer's disease. Upon administration (oral or by injection) of $\mathrm{Al}$ in rats, the metal accumulates in the 

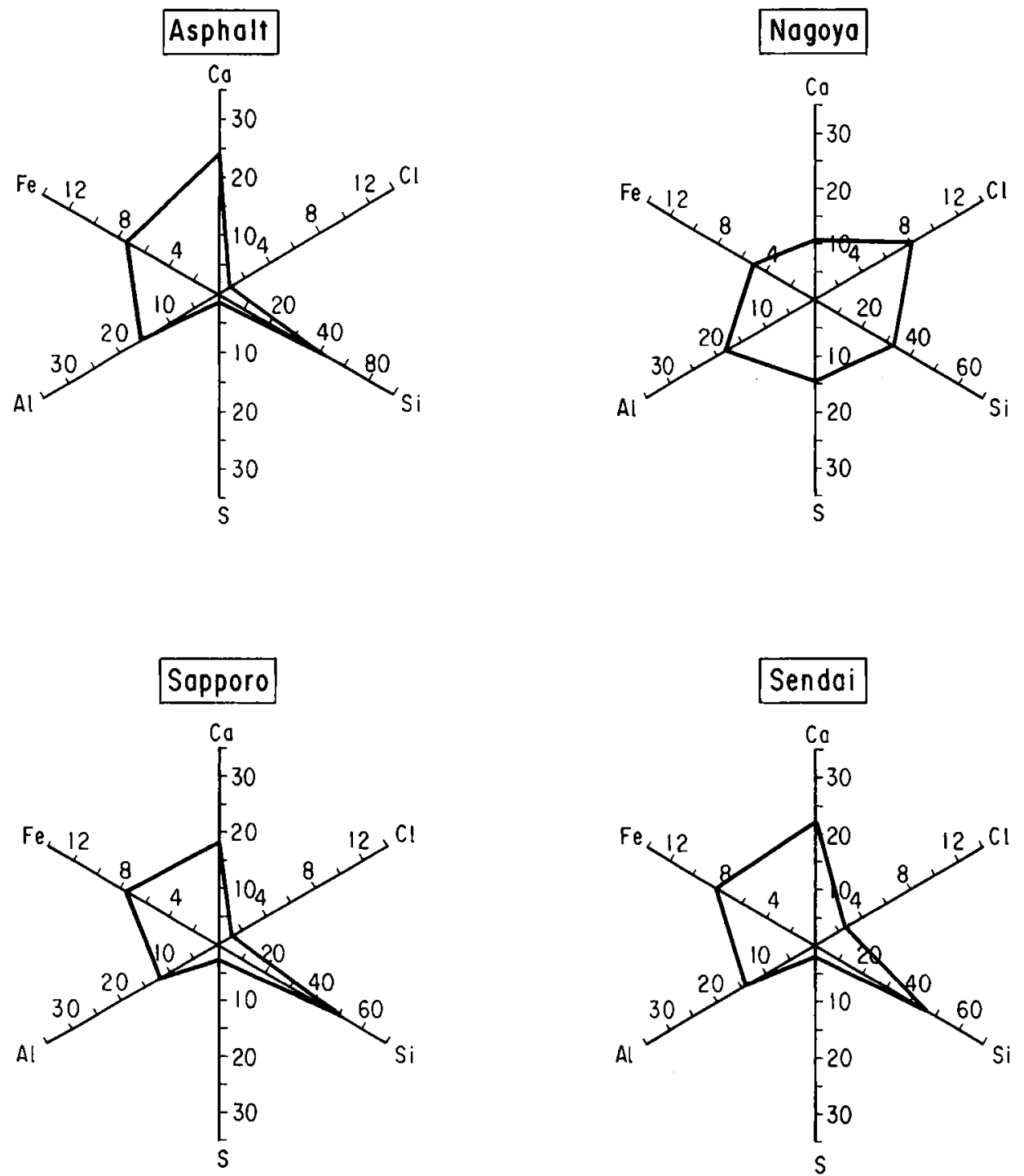

Fig. 4. The elemental concentration of six main elements for asphalt, and for airborne particulates in Sapporo, Sendai and Nagoya [9].

brain and morphological changes occur simultaneously. The authors concluded that Alzheimer's disease is caused by irreversible accumulation of $\mathrm{Al}$ in the brain, as well as in the nuclei of brain cells.

For the examination of fine art and paintings, the object is bombarded with a proton beam extracted from the accelerator window. The non-destructive PIXE technique with an external beam is convenient for surface analysis of precious samples of very small sizes. Works of art from the Louvre and other museums have been analysed [12]. The external PIXE milliprobe was used in the investigation of the 42-line Bible printed by Gutenberg in the 1450's. Different lots of papers used for the document could be distinguished on the basis of their $\mathrm{Fe} / \mathrm{Ca}$ and $\mathrm{Mn} / \mathrm{Ca}$ ratios [13].

With the development of a focussing device for accelerated ions, a powerful method for scanning microprobes became available. $\mu$ PIXE using a scanning proton, microbeam has been applied by Vis et al. to biomedical samples (serum, tissues and hair) [14]. An elemental map drawn with the same technique has provided useful information on the formation of aerosols, Al uptake in beech plant roots [15] and in sphagnum leaves [16]. The usefulness of $\mu$ PIXE in life sciences, geosciences, environmental sciences, archaeometry, material science and in industry has been demonstrated with the scanning proton microprobe at the University of Oxford [17].

In the practice of PIXE analysis, pile-up and charge buildup must be avoided. Peisach et al. have noted an abnormal X-ray yield for insulating fluoride compounds [18]; in the case of $\mathrm{CuF}_{2}$ the enhancement exceeded 1000 for the $\mathrm{Cu} \mathrm{K} \mathrm{X-rays} \mathrm{with} \mathrm{respect} \mathrm{to}$ metallic $\mathrm{Cu}[19]$. This anomaly was ascribed to charge buildup followed by a discharge which could generate extra X-rays. It has been pointed out that the phenomenon might find applications in the production of monoenergetic ultra-soft X-rays in ESCA studies [20].

Applications of PIXE are found in the proceedings of the conferences "Particle induced X-ray Emission and its Analytical Applications" (in Nuclear Instru- 
ments and Methods in Physics Research B: Special issues) and in the International Journal of PIXE.

\section{Synchrotron radiation (SR) in structural and analytical chemistry}

Synchrotron radiation is emitted when relativistic charged particles move along a curved path in a magnetic field. Many synchrotron facilities are in operation in the world, and provide a wide range of spectra with wavelengths extending from the infrared to the $\mathrm{X}$-ray region. In this section, applications of SR to structural and analytical problems related in some way to radiochemistry are described.

\subsection{EXAFS using synchrotron radiation}

Extended X-ray absorption fine structure (EXAFS) studies of Tc compounds have been performed by the Cincinnati group [21]. The oligomer/polymer structure in aqueous solution of the bone-seeking agent TcMDP (MDP = methylene diphosphonate) was elucidated. An Australian group has been concerned with the determination of the $\mu$-oxo or bis( $\mu$-oxo) dimer of Tc compounds [22]. The two varieties yield different EXAFS pattern, thus enabling confirmation of the presence of the bis $(\mu$-oxo) dimer in the nitridotechnetium complex.

\subsection{TXRF using synchrotron radiation}

Total reflection $\mathrm{X}$-ray fluorescence spectrometry (TXRF) was pioneered by Yoneda and applied to spectrochemical analysis [23]. The technique is widely used for surface analysis. Superficial concentrations of elements and impurities on Si wafers have been measured with a detection limit down to $10^{9}$ atoms $\mathrm{cm}^{-2}$ [24]. The analysis is rapid, multielemental and non destructive.

The method has been combined with intense SR sources. The very high sensitivity of SR-TXRF has been demonstrated for the elements $\mathrm{K}$ to $\mathrm{Zn}[25,26]$. The detection limit is enhanced with polarized SR beams, with a limit of $3 \mathrm{pg}$ for Co [27].

\section{Chemical effects on X-rays characteristics}

The chemical shift of X-ray wavelengths is known since the 1920's, but detailed features of chemical effects on the properties of X-rays have been elucidated only within the last two or three decades. In the simple case of $\mathrm{X}$-ray emission, four different types of chemical effects are observed (Figure 5):

(a) energy (wavelength) shift; (b) change in the emission probability (intensity); (c) appearance of satellite lines as a result of multiple electron vacancies and electron pick-up from central atoms; (d) change of the
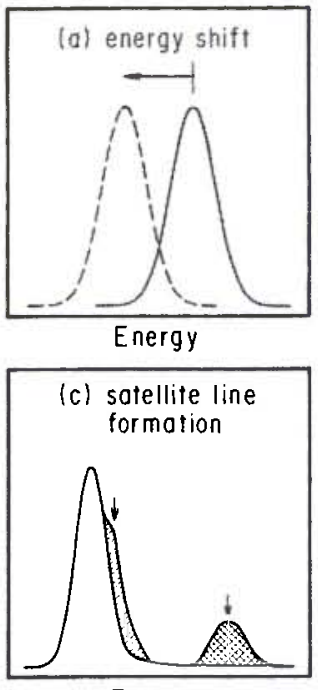

Energy
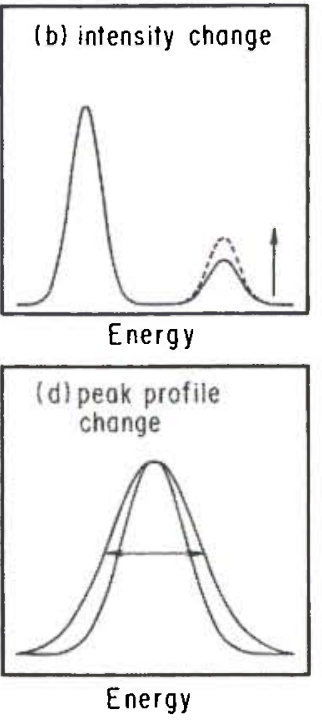

Fig. 5. Chemical effects on X-ray spectra.

peak profile (broadening) [28]. Although these effects may sometimes perturb X-ray measurements, they are very useful for chemical state analysis and chemical speciation [29].

\subsection{X-ray energy shift}

$\mathrm{X}$-ray energy shifts due to chemical effects have been reported for various elements. Assignment to specific chemical states has been attempted for S [30-33], Al [34-36], Si [31], Sn [31] and other elements. For example, Gohshi determined the distribution of sulfur species in coke (or coal) with a high resolution X-ray spectrometer equipped with two crystals [37]. Figure 6 shows the spectra of thiosulfate, which serves as standard, and of coke. The coke spectrum was deconvoluted into two components corresponding to $\mathrm{S}^{6+}$ and $\mathrm{S}^{2-}$. Typical analyses of coal samples are given in Table 1. Kawai $e t$ al. have found a linear relationship between the chemical shift of the Sc $K \alpha$ line and the electronegativity of the counter atom [38].

Recently, Iihara and coworkers have reported chemical shifts in iodine and antimony compounds with equipment similar to that of Gohshi [39]. The energy shifts for the $L \gamma_{4}, L \gamma_{1}$ and $L \beta_{2.15}$ iodine lines are shown in Table 2 . The most important shift is observed for $L \gamma_{4}$ owing to the location of iodine valence electrons in the corresponding level.

Sugiura measured the X-ray emission from the valence band in metal complexes [40-42]. The $L \beta_{2,15}$ lines of $\mathrm{Pd}$ and $\mathrm{Pt}$ and the chlorine $K \beta$ line have been recorded for the square planar complexes $\mathrm{K}_{2} \mathrm{PdCl}_{4}$, $\left(\mathrm{NH}_{4}\right)_{2} \mathrm{PdCl}_{4}$, trans- $\left[\mathrm{Pd}\left(\mathrm{NH}_{3}\right)_{2} \mathrm{Cl}_{2}\right],\left[\mathrm{Pd}\left(\mathrm{NH}_{3}\right)_{2} \mathrm{Cl}_{2}\right] \cdot \mathrm{H}_{2} \mathrm{O}$, $\mathrm{K}_{2} \mathrm{PtCl}_{4}$, cis- and trans-[Pd( $\left.\left(\mathrm{NH}_{3}\right)_{2} \mathrm{Cl}_{2}\right]$. The spectra of geometrical isomers are different.

\subsection{Change in the $\mathrm{X}$-ray emission probability}

A change in the intensity of $\mathrm{X}$-ray emission with the chemical state has been observed at Tohoku University 

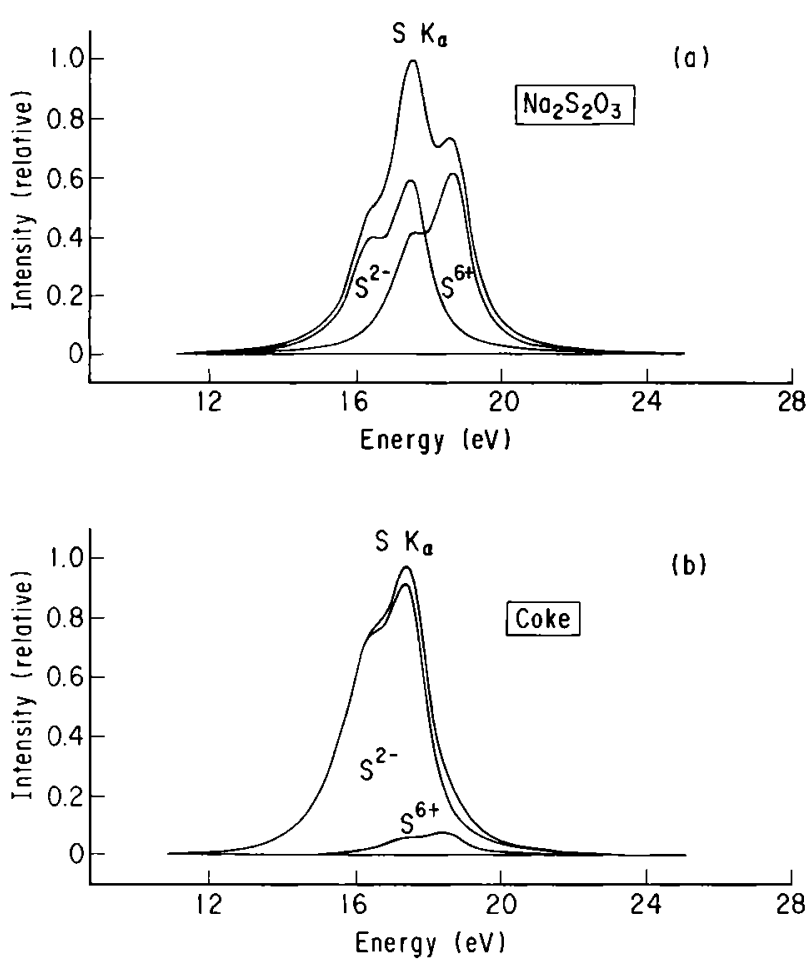

Fig. 6. Sulfur $K \alpha$ spectrum and its components; (a) sodium thiosulfate and (b) coke [31].

Table 1. Analysis of sulfur composition by X-ray fluorescence (weight\%)

\begin{tabular}{cccc}
\hline Sample & Total & $\mathrm{S}^{6+}$ & $\mathrm{S}^{2-}$ \\
\hline A & 0.31 & 0.02 & 0.29 \\
B & 0.99 & 0.21 & 0.78 \\
C & 0.36 & 0.06 & 0.30 \\
D & 0.70 & 0.25 & 0.45 \\
E & 0.51 & 0.04 & 0.47 \\
F & 0.22 & 0.01 & 0.21 \\
G & 0.37 & 0.03 & 0.34 \\
H & 2.71 & 0.37 & 2.34 \\
\hline
\end{tabular}

Table 2. X-ray energy shift of iodine compounds

\begin{tabular}{lrrr}
\hline Compound & \multicolumn{3}{c}{ Energy shift (eV) } \\
\cline { 2 - 4 } & $L \gamma_{4}$ & $L \gamma_{1}$ & $L \beta_{2,15}$ \\
\hline $\mathrm{NaI}$ & 0.94 & -0.36 & -0.44 \\
$\mathrm{KI}$ & 0.82 & -0.51 & -0.41 \\
$\mathrm{CuI}$ & 1.35 & -0.52 & -0.57 \\
$\mathrm{SnI}_{2}$ & 0.60 & -0.68 & -0.60 \\
$\mathrm{HIO}_{3}$ & -0.11 & -0.37 & -0.46 \\
$\mathrm{KIO}_{3}$ & -0.33 & 0.06 & 0.01 \\
$\mathrm{KIO}_{4}$ & 0.00 & 0.00 & 0.00 \\
\hline
\end{tabular}

in Sendai in the electron capture decay of ${ }^{51} \mathrm{Cr}$ [43] and in the isomeric transition of ${ }^{99 \mathrm{~m}} \mathrm{Tc}$ [44]. The $K \beta_{2}$ / $K \alpha$ intensity ratio for ${ }^{99 \mathrm{~m}} \mathrm{Tc}$ has been compared to that of ${ }^{95 \mathrm{~m}} \mathrm{Tc}$ and ${ }^{97 \mathrm{~m}} \mathrm{Tc}$. Mukoyama et al. [45] used the simplified model of Brunner [46] to correlate successfully the change with the effective charge on Tc. The

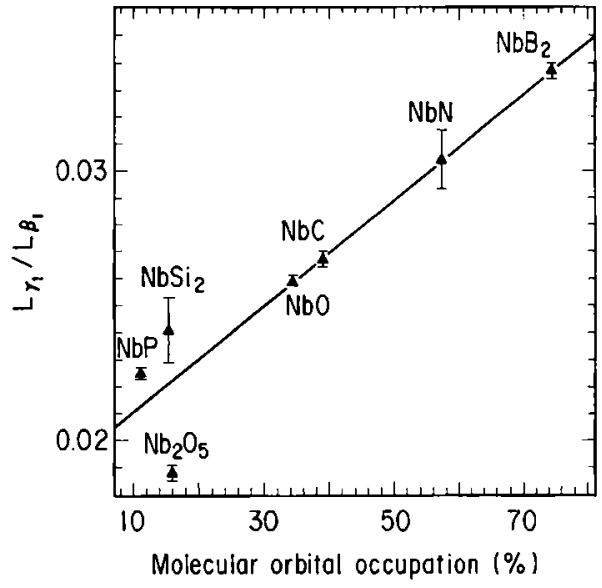

Fig. 7. The $L \gamma_{1} / L \beta_{1} \mathrm{X}$-ray intensity ratios for various niobium compounds bombarded with protons as a function of molecular orbital occupation [47].

changes are small, being $10-20 \%$ for chromium and at maximum $4 \%$ for technetium, because the electronic transitions at the origin of the emission lines occur between the subvalence shells $3 p$ for $\mathrm{Cr}$ and $4 p$ for Tc.

More significant effects on the X-ray intensity ratio have been observed in the PIXE $L \gamma_{1}$ lines of niobium and molybdenum. Ihara $e t$ al. have measured the $L \gamma_{1} / L \beta_{1}$ intensity ratio in proton-bombarded $\mathrm{Nb}$ and Mo compounds [47]. As shown in Figure 7, the intensity ratio in $\mathrm{Nb}$ increases with the molecular orbital occupation calculated by the GAMESS-MO method. The maximum change is as high as $60 \%$, demonstrating the effectiveness of direct transitions starting with the $4 d$ valence shell. The linear relationship seen in the figure could be explained by the change in the electron density in the orbital concerned. The emission probability $T$ is

$$
T=A N_{i} E_{x}^{3} D_{i, j}^{2}
$$

where $A$ is a constant, $N_{i}$ the electron density in the orbital $i, \mathrm{E}_{x}$ the X-ray transition energy and $D_{i, j}$ the dipole matrix element. The subscripts $i$ and $j$ denote respectively the initial and final orbitals in the transition. The terms $E_{x}$ and $D_{i, j}$ are only slightly dependent on the chemical state. Therefore the intensity is essentially determined by the population of the molecular orbital.

The Tohoku group has also measured X-ray intensity ratios in iodine and antimony. The chemical effects are more pronounced for the $L \gamma_{4} / L \beta_{3}$ ratio (with a maximum of 60 to $70 \%$ ) than for $L \gamma_{1} / L \beta_{1}$ or $L \beta_{2,15}$ because the $L \gamma_{4} \mathrm{X}$-ray line corresponds to transitions involving valence shells, while the latter lines arise from subvalence shells.

In general, electronic transitions from the valence shell are more sensitive to the chemical environment than those occurring in subvalence shells. This trend has been verified by comparing in the same chromium compounds the $L \beta / L \alpha$ ratio to the $K \beta / K \alpha$ ratio in the Cr X-ray spectrum [48]. 


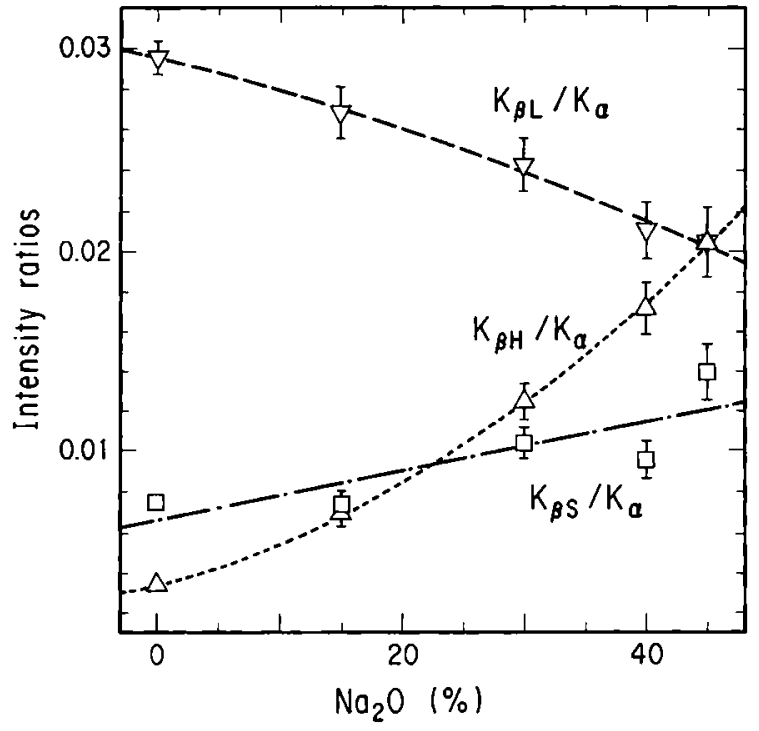

Fig. 8. The Si $K \beta / K \alpha$ intensity ratios against the content of $\mathrm{Na}_{2} \mathrm{O}$ in glasses [49].

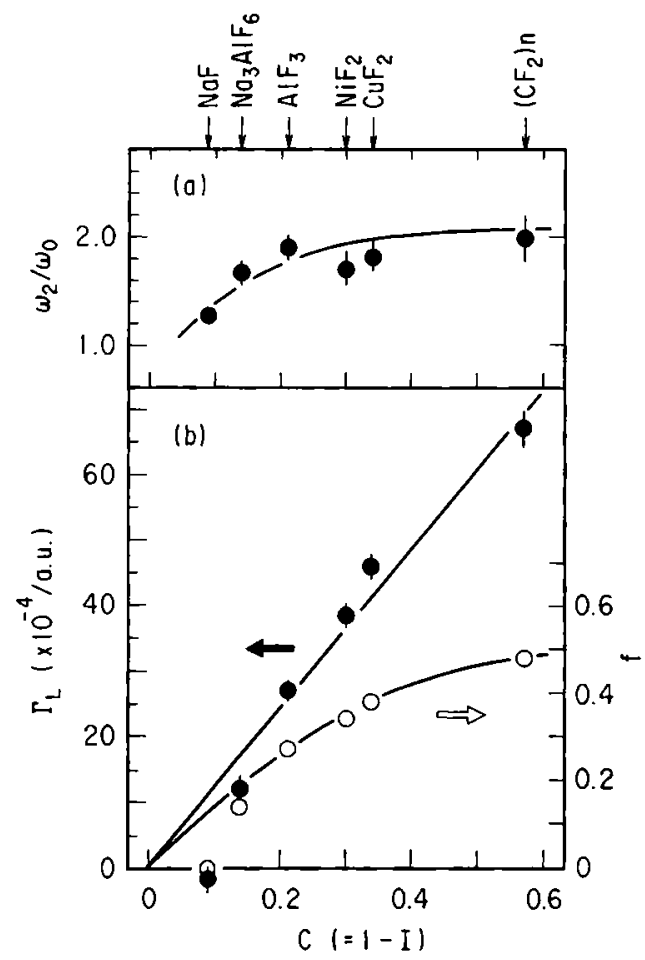

Fig. 9. The fluorescence yield ratio $\omega_{2} / \omega_{0}$, the $L$-shell refilling probability $f$ and the $L$-shell width $\Gamma_{L}$ plotted as a function of covalency $C$ [52].

A large variation of the $K \beta / K \alpha$ ratio has been observed in $\mathrm{Na}_{2} \mathrm{O}-\mathrm{SiO}_{2}$ glasses as a function of the $\mathrm{Na}_{2} \mathrm{O}$ content [49]. The intensity ratios of fine structure components $\left(K \beta_{S}, K \beta_{L}\right.$ and $\left.K \beta_{H}\right)$ of the $K \beta$ line to $K \alpha$ change remarkably with the $\mathrm{Na}_{2} \mathrm{O}$ content. The intensity of $K \beta_{L}$ decreases while the intensities of $K \beta_{H}$ and $K \beta_{s}$ increase with $\mathrm{Na}_{2} \mathrm{O}$ content, as shown in Figure 8. This behaviour has been explained theoretically by assuming direct interactions between $\mathrm{Si}$ and $\mathrm{Na}$.

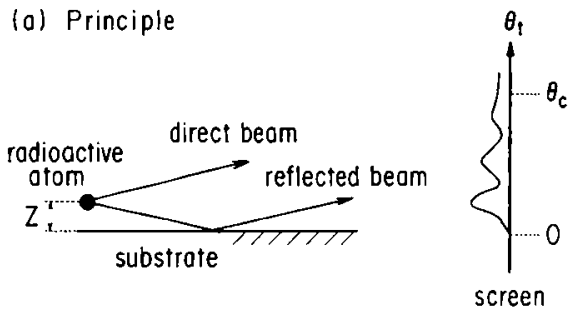

(b) Interference pattern

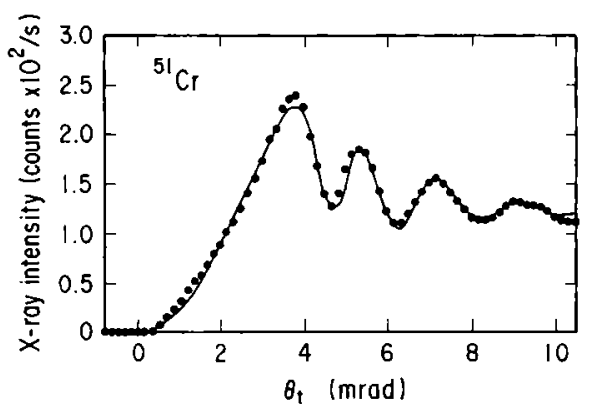

Fig. 10. The interference pattern from radioisotope-originated $\mathrm{X}$-rays: (a) principle and (b) a result for ${ }^{61} \mathrm{Cr}$-labeled arachidate [57].

\subsection{Satellite lines}

Satellite lines in X-ray spectra have various origins, such as multivacancy satellites and charge transfer satellites. In particular, satellite peaks appear in PIXE spectroscopy with heavy ions. The intensity of the $K L^{n}$ peak follows a binomial probability distribution

$$
I\left(K L^{n}\right)=\left(\begin{array}{l}
8 \\
n
\end{array}\right) P_{L}^{n}\left(1-P_{L}^{n}\right)^{8-n}
$$

where $P_{L}$ is the probability of ionization of the $L$ shell and $n$ the number of $L$ vacancies. As pointed out by Watson et al., the $K L^{n}$ satellite line is closely related to the electronegativity of the neighbouring atoms of the X-ray emitter [50]. Results obtained by Benka et $a l$. indicated a strong influence of the chemical environment on the second and third peaks in the spectra [51]. Uda et al. found that various parameters were related to the covalency term $C$ (or $1-I$, where $I$ is the ionicity): the fluorescence yield ratio $\omega_{2} / \omega_{0}$ of the first to the third peak, the probability $f$ of refilling the $L$ shell, and the $L$ shell width $\Gamma_{L}$, as shown in Figure 9 [52]. The authors suggested that chemical speciation could be achieved with these relations. $\mathrm{Cr} K \alpha$ satellite lines emitted in the bombardment of four chromium targets with $14 \mathrm{MeV} / \mathrm{u} \mathrm{O}^{4+}$ were clearly resolved by Folkmann with a $20 \times 50 \mathrm{~mm}$ analyzing crystal [53]. As in the previous cases [51, 52], chemical effects appear in the second and third peaks.

Charge transfer satellites in Be K X-ray spectra formed by pick-up of electrons from the $L$ shell in oxygen have been observed in the bombardment of $\mathrm{BeO}$ with nitrogen or oxygen ions [54].

Quantum mechanical calculations have been performed by Kawai et al. to interpret the formation of charge transfer satellites [55]. The $K \beta^{\prime \prime}$ satellite in the 
Sc X-ray spectrum is strong in $\mathrm{ScF}_{3}$, but weak in $\mathrm{Sc}_{2} \mathrm{O}_{3}$. This pattern was assigned to electron transitions from an antibonding MO involving Sc $3 p$ and ligand $2 s$ electrons to the $1 s^{-1}$ hole. Strong $K \alpha^{\prime \prime}$ and $K \beta^{\prime \prime}$ satellites appear in metallic Sc owing to a better screening of the core hole by electrons in the conduction band than by $3 p^{-1}$ holes. The $K \beta^{\prime \prime}$ satellite was assigned to the hole transition from $1 s^{-1}$ to an antibonding MO formed between Sc $3 p$ electrons and electrons of neighbouring atoms. Satellite lines due to splitting of molecular orbitals have been reported [55].

\subsection{Peak profile change}

The profile of X-rays peaks may change by broadening or deformation. The broadening of the $\mathrm{Nb} L \gamma_{1}$ peak in amorphous $\mathrm{Nb}-\mathrm{Ni}$ alloy with respect to that of metallic $\mathrm{Nb}$ has been observed by lihara and Yoshihara [56], and attributed to mixed band formation involving $\mathrm{Nb} 4 d$ and Ni $3 d$ electrons.

Chemical effects are also known for more energetic muonic and pionic $\mathrm{X}$-rays, but they are not yet fully explored [29].

\section{Other applications}

Interfering effects of $\mathrm{X}$-rays following electron capture decay of ${ }^{51} \mathrm{Cr}$ have been reported recently [57]. When the radioactive atom is located at a short distance over the surface of a substrate, X-rays from glancing reflections interfere with the direct beam (Figure 10). The interference pattern recorded on an imaging plate depends on the distance $z$ between the radionuclide and the surface of the substrate and on the take-off angle $\theta_{1}$. The $\mathrm{X}$-ray yield $Y$ is determined by the relations

$$
\begin{aligned}
& I\left(\theta_{t}, z\right)=\left|E_{d}+E_{r}\right|^{2} \\
& Y\left(\theta_{t}\right)=\int \mathrm{N}(z)\left(\theta_{v} z\right) d z
\end{aligned}
$$

where $I\left(\theta_{v}, z\right)$ is the intensity of the characteristic Xray, $E_{d}$ and $E_{r}$ are the field plane waves $E$ for the direct and reflected emissions and $\mathrm{N}(z)$ is the distribution of atoms at the distance $z$. From the experiment performed by Sasaki et al. [57] with ${ }^{51} \mathrm{Cr}$-arachidate LB films, a distance $z$ shorter than the theoretically expected value has been determined. The authors argued that the surface monolayer was unstable in air owing to its hydrophilic nature and may have undergone a reversal of orientation known as overtuning.

\section{Concluding remarks}

In this review, the importance and role of X-rays in radiochemistry have been described, together with the fields of application. X-rays are indispensable as analytical tools. Chemical effects on $\mathrm{X}$-ray properties are not only of interest for basic science, but bear promising applications to chemical analysis. However, the acquisition of further and refined data is essential.

\section{References}

1. Bradbury, B. T., Demant, J. T., Martin, P. M., Poole, D. M.: J. Nucl. Mater. 17, 227 (1965).

2. Johnson, I., Johnson, C. E., Crouthamel, C. E., Seils, C. A.: J. Nucl. Mater. 48, 21 (1973).

3. Henkelmann, R., Baumgärtner, F.: Fresenius Z. Anal. Chem. 319, 795 (1984).

4. Cronenberg, A. W., Langer, S.: Nucl. Technol. 87, 234 (1989).

5. Johansson, T. B., Akselsson, R., Johansson, S. A. E.: Nucl. Instrum. Methods 84, 151 (1970).

6. Johansson, E. M., Johansson, S. A. E.: Nucl. Instrum. Methods B3, 154 (1984).

7. Cahill, T. A.: Nucl. Instrum. Methods B75, 217 (1993).

8. Koltay, E.: Nucl. Instrum. Methods B85, 75 (1994).

9. Amemiya, S., Tsuriya, Y., Masuda, T., Asawa, A., Tanaka, K., Katoh, T., Mohri, M., Yamashita, T.: Nucl. Instrum. Methods B3, 516 (1984).

10. Valković, V.: Nucl. Instrum. Methods 142, 151 (1977).

11. Yumoto, S., Ohashi, H., Nagai, H., Ogawa, Y., Iwata, Y., Ishii, K.: Intern. J. PIXE 2, 493 (1992); Yumoto, S., Ohashi, H., Nagai, H., Kakimi, S., Ishikawa, A., Kobayashi, K., Ogawa, Y.: Nucl. Instrum. Methods B75, 188 (1993).

12. Menu, M.: Nucl. Instrum. Methods B75, 469 (1993).

13. Eldred, A., Kusko, B. H., Cahill, T. A.: Nucl. Instrum. Methods B3, 579 (1984); Kusko, B. H, Cahill, T. A., Eldred, R. A., Schwab, R. N.: ibid 689 (1984).

14. Vis, R. D., Van der Stap, C. C. A. H., Bos, A. J. J.: Nucl. Instrum. Methods B3, 319 (1984).

15. Hult, M., Bengtsson, B., Larsson, N. P.-O., Yang, C.: Scanning Microsc. 6/2, 581 (1992).

16. Watkinson, S. C., Watt, F.: Biologist 95, 181 (1992).

17. Grim, G. W., Watt, F.: Nucl. Instrum. Methods B75, 495 (1993).

18. Peisach, M.: J. Radioanal. Nucl. Chem. 110, 461 (1987).

19. Peisach, M.: Nucl. Instrum. Methods B85, 100 (1994).

20. Pillay, A. E., Peisach, M.: J. Radioanal. Nucl. Chem. 189, 283 (1995).

21. Martin Jr., J. L., Yuan, J., Lunte, C. E., Elder, R. C., Heineman, W. R., Deutsch, E.: Inorg. Chem. 28, 2899 (1989).

22. Williams, G. A., Martin, L. J.: Private communication.

23. Yoneda, Y.: Phys. Rev. 131, 2010 (1963).

24. Prange, A.: Spectrochim. Acta 48B, 107 (1993).

25. Horowitz, R., Howell, J.: Science 178, 608 (1972).

26. Iida, A., Yoshinaga, A., Sakurai, K., Gohshi, Y.: Anal. Chem. 58, 394 (1986).

27. Wobrauschek, P., Kregsamer, P., Ladisich, W., Rieder, R., Streli, C.: Spectrochim. Acta 48B, 143 (1993).

28. Yoshihara, K., Iihara, J.: Intern. J. PIXE 2, 93 (1992).

29. Yoshihara, K.: Top. Current Chem. 157, 1 (1990).

30. Hurley, R. G., White, E. W.: Anal. Chem. 46, 2234 (1976).

31. Gohshi, Y., Hirao, O., Suzuki, I.: Adv. X-Ray Anal. 18, 406 (1975).

32. Watanabe, T., Hashiguchi, Y., Sato, H.: Trans. Iron Steel Inst. Jap. 21, 173 (1981).

33. Ban, Y., Sugiura, T., Furuya, K., Gohshi, Y.: Bunseki Kagaku 34, 238 (1985).

34. Gel'mukhanov, F. K., Mazalov, L. N., Kondratenko, A. V.: Chem. Phys. Lett. 46, 133 (1977).

35. Gohshi, Y.: Spectrochim. Acta 36B, 763 (1981).

36. Grimaldi, R., Paris, V., Mariani, E.: X-Ray Spectrometry 10, 163 (1981).

37. Gohshi, Y., Fukao, Y., Hori, K.: Spectrochim. Acta 27B, 135 (1972); Gohshi, Y., Kamada, H., Kohra, K., Utaka, T., Arai, T.: Appl. Spectrosc. 36, 171 (1982).

38. Kawai, J., Nakamura, E., Nihei, Y., Fujisawa, K., Gohshi, Y.: Spectrochim. Acta 45B, 463 (1990).

39. Iihara, J., Fukuhara, K., Yagi, M., Omori, T., Yoshihara, K.: Hyperfine Interactions 84, 433 (1994).

40. Sugiura, C.: J. Phys. Soc. Jap. 59, 2134 (1990).

41. Sugiura, C.: Jap. J. Appl. Phys. 29, 1116 (1990).

42. Sugiura, C.: Jap. J. Appl. Phys. 29, 2426 (1990). 
43. Tamaki, Y., Omori, T., Shiokawa, T.: Radiochem. Radioanal. Lett. 20, 255 (1975).

44. Yamoto, I., Kaji, H., Yoshihara, K.: J. Chem. Phys. 84, 522 (1986).

45. Mukoyama, T., Kaji, H., Yoshihara, K.: Phys. Lett. A118, 44 (1986).

46. Brunner, G., Nagel, M., Hartmann, E., Amdt, E.: J. Phys. B15, 4517 (1982).

47. Iihara, J., Izawa, G., Omori, T., Yoshihara, K.: Nucl. Instrum. Methods A299, 394 (1990).

48. Iihara, J., Omori, T., Yoshihara, K., Ishii, K.: Nucl. Instrum. Methods B75, 32 (1993).

49. Iihara, J., Kawai, J., Sekine, T., Yoshihara, K.: Intern. J. PIXE 3, 177 (1993).
50. Watson, R. L., Leeper, A. K., Sonobe, B. I., Chiao, T., Jensen, F. E.: Phys. Rev. A15, 914 (1977).

51. Benka, O., Watson, R. L., Bandong, B.: Phys. Rev. A28, 3334 (1983).

52. Uda, M., Benka, O., Fuwa, K., Maeda, K., Sasa, Y.: Nucl. Instrum. Methods B22, 5 (1987).

53. Folkmann, F.: Nucl. Instrum. Methods B75, 9 (1993).

54. Kawatsura, K., Ozawa, K., Fujimoto, F., Terasawa, M.: Phys. Lett. 60A, 327 (1977).

55. Kawai, J.: Nucl. Instrum. Methods B75, 3 (1993).

56. Iihara, J., Yoshihara, K.: Intern. J. PIXE 3, 215 (1993).

57. Sasaki, Y. C., Suzuki, Y., Tomioka, Y., Ishibashi, T., Satoh, I., Hirokawa, K.: Phys. Rev. B50, 15516 (1994). 



\section{E. Radionuclides in the Environment and Nuclear Energy}





\title{
Radioactivity in the Atmosphere
}

\author{
By H. W. Gäggeler \\ Institut für anorganische, analytische and physikalische Chemie, Labor für Radio- und Umweltchemie, \\ Universität Bern, 3012 Bern, Switzerland \\ and Labor für Radio- und Umweltchemie, Paul Scherrer Institut, 5232 Villigen PSI, Switzerland
}

(Received August 24, 1995)

\section{Radioactivity / Atmosphere / Radon / Thoron / Cosmogenic radionuclides}

\begin{abstract}
A short review is made on atmospheric radionuclides with emphasis on their activity concentrations in the troposphere, mostly for surface air over Europe. Discussed are those species which have activity concentrations above about $1 \mathrm{mBq} / \mathrm{m}^{3}$. For this atmospheric layer highest average activity concentrations $\left(\geq 1 \mathrm{~Bq} / \mathrm{m}^{3}\right)$ have i) ${ }^{222} \mathrm{Rn}$ ("radon") and its short-lived decay products, (ii) ${ }^{220} \mathrm{Rn}$ ("thoron"), however, only for the lowest meter above ground, and iii) ${ }^{85} \mathrm{Kr}$. In the range $1 \mathrm{mBq} / \mathrm{m}^{3}$ to $1 \mathrm{~Bq} / \mathrm{m}^{3}$ are $\mathrm{T}\left({ }^{3} \mathrm{H}\right),{ }^{14} \mathrm{C},{ }^{37} \mathrm{Ar}$ and ${ }^{7} \mathrm{Be}$ as well as the "thoron" decay product ${ }^{212} \mathrm{~Pb}$. Average activity concentrations slightly below $1 \mathrm{mBg} / \mathrm{m}^{3}$ has ${ }^{211} \mathrm{~Pb}$, the only long-lived decay product of "radon". The sources of these radionuclides are discussed. Not included in this review are radionuclides contained in the atmosphere at very low activity concentrations or from single emissions such as e.g. from the Tschernobyl accident in 1986.
\end{abstract}

\section{Introduction}

Environmental radioactive nuclides have three different sources; they are either primordial, cosmogenic or anthropogenic.

Primordial radionuclides are those which were produced during element evolution and which have (partly) survived since then due to their long half-lives. Our solar system has an age of about $4.5 \cdot 10^{9}$ years; this means that nuclides with half-lives longer than about $10^{8}$ years can still be found in our environment. With respect to the atmosphere, progenies of the primordial nuclides ${ }^{238} \mathrm{U}$ and ${ }^{232} \mathrm{Th}$ with half-lives of $4.5 \cdot 10^{9}$ and $1.4 \cdot 10^{10}$ years, respectively, are of special importance. These actinides are mainly contained in the lithosphere and decay via several nuclides to different isotopes of lead. In both decay chains one intermediate nuclide is an isotope of the noble gas radon, ${ }^{222} \mathrm{Rn}$ (called "radon") in case of ${ }^{238} \mathrm{U}$ and ${ }^{220} \mathrm{Rb}$ ("thoron") in case of ${ }^{232} \mathrm{Th}$ which have half-lives of 3.8 days and $56 \mathrm{~s}$, respectively. These gases can escape from the lithosphere into the atmospheres. Of less importance with respect to the atmosphere - is ${ }^{235} \mathrm{U}$ with a halflife of $7.0 \cdot 10^{8}$ years, caused by its low isotopic abundance of $0.7 \%$ in natural uranium and the fact that the corresponding radon isotope ${ }^{219} \mathrm{Rn}$ ("actinon") has a very short half-life of $4 \mathrm{~s}$.

The second reservoir of radionuclides is the upper atmosphere. The earth is permanently bombarded by cosmic ray particles. These particles are of solar or galactic origin and are predominantly protons. Mainly the high energy galactic protons (typical energies $100 \mathrm{MeV}-3 \mathrm{GeV}$ with a flux of about $3 \mathrm{~cm}^{-2} \mathrm{~s}^{-1}$ [1]) interact with the atmospheric species in nuclear reactions and form a variety of radionuclides. Also secondary particles such as neutrons and myons have high enough energies to produce several nuclides. The beam flux of galactic cosmic ray particles onto the earth surface is not constant in time; it is modulated by the solar activity which has a well known 11 year cycle. In time periods with high solar activity (i.e. high sun spot number) the flux of galactic particles bombarding the earth surface is low and vice versa. This is due to a magnetic shielding of the earth caused by the solar activity. In addition, the solar activity has low-frequency variabilities e.g. with a time constant of several hundred years. This leads to time periods with extremely low solar activities such as e.g. during the Maunder minimum between 1645-1715. During this time period the production of cosmogenic nuclides was increased.

Finally, with the beginning of nuclear technology, humans have started to emit radioactive species into the environment. This was for the first time a serious problem during the atmospheric nuclear weapons testing programs of USA and the former Soviet Union in the late $50^{\text {th }}$ and early $60^{\text {th }}$. Most pronounced were the ejections into the atmosphere in 1962 which led to a test-stop agreement for overground explosions on 5 August 1963 in Geneva. Even now, the radioactive debris from these nuclear weapons testing period can be found in archives such as lake or sea sediments or in glacier ice cores. During the following period of underground testing only radioactive gases such as ${ }^{85} \mathrm{Kr}$ or ${ }^{37} \mathrm{Ar}$ (a secondary product from the ${ }^{40} \mathrm{Ca}(\mathrm{n}, \alpha)^{37} \mathrm{Ar}$ reaction) were released into the atmosphere.

Nuclear power plants and nuclear reprocessing plants emit radionuclides into the atmosphere too. Of special importance was the Tschernobyl accident: on April 26, 1986, due to human failure, a $1 \mathrm{GW}$ reactor exploded and caused a high contamination of the local environment. By long-range atmospheric transport Tschnerobyl fallout could be detected nearly everywhere in the northern hemisphere.

Also the non-nuclear industry releases some radionuclides into the atmosphere such as $\mathrm{T},{ }^{14} \mathrm{C}$ or several 
isotopes of iodine from tracer applications in industry, chemistry or nuclear medicine.

In the following, the main radionuclides contained in the different atmospheric compartments will be discussed, with main emphasis on their activity concentrations in the planetary boundary layer, i.e. in the lower troposphere. No general overview on all existing radionuclides will be given but rather a discussion according to decreasing average activity levels, mainly over Europe. As a lower limit, nuclides with about $\geq 1 \mathrm{mBq} / \mathrm{m}^{3}$ average activity concentration will be discussed. Therefore, some radionuclides of great importance to environmental studies but of low average activity concentration will not be included into this review. Examples of this latter category are ${ }^{10} \mathrm{Be}$ which can be used to reconstruct the history of the solar activity, ${ }^{11} \mathrm{Kr}$ as a nuclide of great potential to study very old aquatic systems, ${ }^{129} \mathrm{I}$ as a tracer to reconstruct the total emission history from nuclear industry or ${ }^{32} \mathrm{Si}$ to be used to date environmental archives over time periods between about $10^{2}$ and $10^{3}$ years.

\section{2. ${ }^{222} \mathrm{Rn}$ and its decy products}

\subsection{Radon-222}

${ }^{222} \mathrm{Rn}$ and its decay products are important atmospheric radionuclides because they are responsible for a sizable fraction of the total public exposure to ionizing radiation. Typical exhalation rates of ${ }^{222} \mathrm{Rn}$ from the soil are on the order of one atom $/ \mathrm{cm}^{2} \mathrm{~s}$ or $2 \cdot 10^{-4}$ $\mathrm{Bq} / \mathrm{cm}^{2} \mathrm{~s}$ [2]. ${ }^{222} \mathrm{Rn}$ can highly accumulate in houses, especially in cases with low ventilation rates. According to estimates [3], indoor ${ }^{222} \mathrm{Rn}$ exposure may be responsible for more than $10 \%$ of the US incidence of lung cancer. Indoor activity concentrations are typically between 10 and $10^{2} \mathrm{~Bq} / \mathrm{m}^{3}$ [3-6], for e.g. Swiss houses on the average $60 \mathrm{~Bq} / \mathrm{m}^{3}[6]$.

For outdoor conditions, emanating ${ }^{222} \mathrm{Rn}$ and its decay products distribute in the troposphere mainly via turbulent mixing which is characterized by the eddy diffusivity. Eddy diffusion is strongly depending on micrometeorological conditions. This may cause pronounced diurnal variations of the ${ }^{222} \mathrm{Rn}$ activity concentration at low altitudes (1-10 $\mathrm{m}$ above ground) [2, $5,7]$. Average diurnal variations for clear weather condition at e.g. $1.5 \mathrm{~m}$ above ground in a river valley in Germany for the time period May/July 1989 showed minimum activity concentrations of about $5 \mathrm{~Bq} / \mathrm{m}^{3}$ in the afternoon and maximum values of about $40 \mathrm{~Bq} / \mathrm{m}^{3}$ at $4 \mathrm{am}[7,8]$.

Exhalation rates of ${ }^{222} \mathrm{Rn}$ are about 100 times higher over continents if compared to the sea [9]. This leads to a gradient of the average activity concentrations of ${ }^{222} \mathrm{Rn}$ over the continent. Average values (annual means for $1980-1983$ ) were about $0.8 \mathrm{~Bq} / \mathrm{m}^{3}$ on the research platform Nordsee, $3.3 \mathrm{~Bq} / \mathrm{m}^{3}$ at Waldhof, $5 \mathrm{~Bq} / \mathrm{m}^{3}$ at Heidelberg and $6.5 \mathrm{~Bq} / \mathrm{m}^{3}$ at Krakau [10]. The surface activity concentrations of ${ }^{222} \mathrm{Rn}$ are nearly equal over the different continents, except for

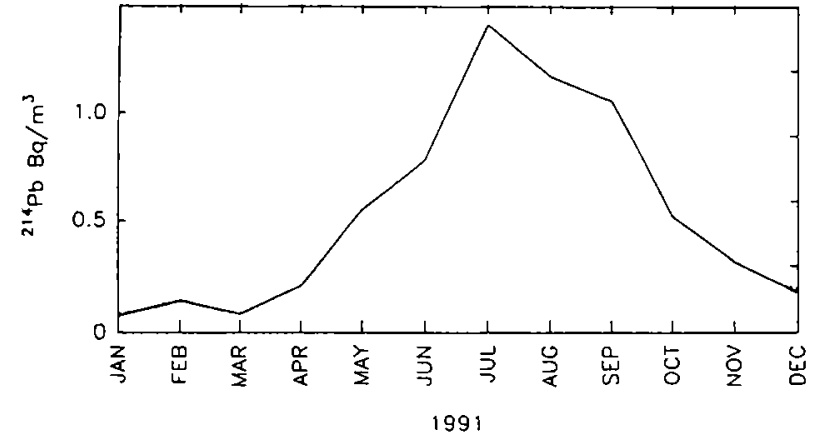

Fig. 1. Monthly mean activity concentrations of the short-lived ${ }^{222} \mathrm{Rn}$ ("radon") decay product ${ }^{214} \mathrm{~Pb}$ at Jungfraujoch $(3450 \mathrm{~m}$ asl), Switzerland, for the year 1991 (from [15]).

arctic areas [11]. For Antarctica, typical values are $(1-3) \cdot 10^{-2} \mathrm{~Bq} / \mathrm{m}^{3}[12]$. Over the sea, at distances far from land masses, ${ }^{222} \mathrm{Rn}$ activity concentrations are typically $0.1 \mathrm{~Bq} / \mathrm{m}^{3}$ [13].

This weil defined source term of ${ }^{222} \mathrm{Rn}$ makes this radionuclide a good marker for air parcels of continental or maritime origin $[11,14,15] .{ }^{222} \mathrm{Rn}$ measurements can therefore be used as an additional help to identify source regions of air masses. Examples are measurements at Jungfraujoch ( $3450 \mathrm{~m}$ asl), Switzerland. This is a high-alpine site, where high radon activities could be correlated with air trajectories arriving to this site from southerly (Africa) or easterly (continental) direction, but not from westerly direction (maritime origin) [15]. In Antarctica, high ${ }^{222} \mathrm{Rn}$ activities were connected to air mass transport from South America [12]. Another example is Mauna Loa, Hawaii, where high ${ }^{222} \mathrm{Rn}$ activity concentrations could be attributed to long-range transport from Asia [16].

The vertical concentration profile of ${ }^{222} \mathrm{Rn}$ within the planetary boundary layer is mainly determined by the atmospheric stability. The activity decreases exponentially, as predicted theoretically [17] and found experimentally $[18,19]$. Within the lowest $4 \mathrm{~km}$ it decreases by about a factor of four to ten $[19,20]$. For ground-based measurements at elevated sites, meteorological conditions strongly influence the local ${ }^{222} \mathrm{Rn}$ activity concentrations. Especially during the summer period convective vertical transport from nearby valleys cause an increase of the local activity concentrations (Fig. 1) [15, 21].

${ }^{222} \mathrm{Rn}$ activity concentrations reach values of about 10 to $100 \mathrm{mBq} / \mathrm{m}^{3}$ (STP) in the tropopause and lower stratosphere $[20,22,23]$. However, it was found that advective transport of radon-rich air from the boundary layer can reach the upper troposphere [24] or even the stratosphere [22] which can lead to bimodal distributions of the ${ }^{222} \mathrm{Rn}$ activity concentration [24].

\subsection{Short-lived decay products of ${ }^{222} \mathrm{Rn}$}

${ }^{222} \mathrm{Rn}$ decays by a chain of $\alpha$ - and $\beta$-emissions via ${ }^{218} \mathrm{Po}$ $\left(T_{1 / 2}=3.1 \mathrm{~min}\right),{ }^{214} \mathrm{~Pb}\left(T_{1 / 2}=26.8 \mathrm{~min}\right),{ }^{214} \mathrm{Bi}\left(T_{1 / 2}=\right.$ $19.9 \mathrm{~min})$ and ${ }^{214} \mathrm{Po}\left(T_{1 / 2}=164 \mu \mathrm{s}\right)$ to the long-lived 


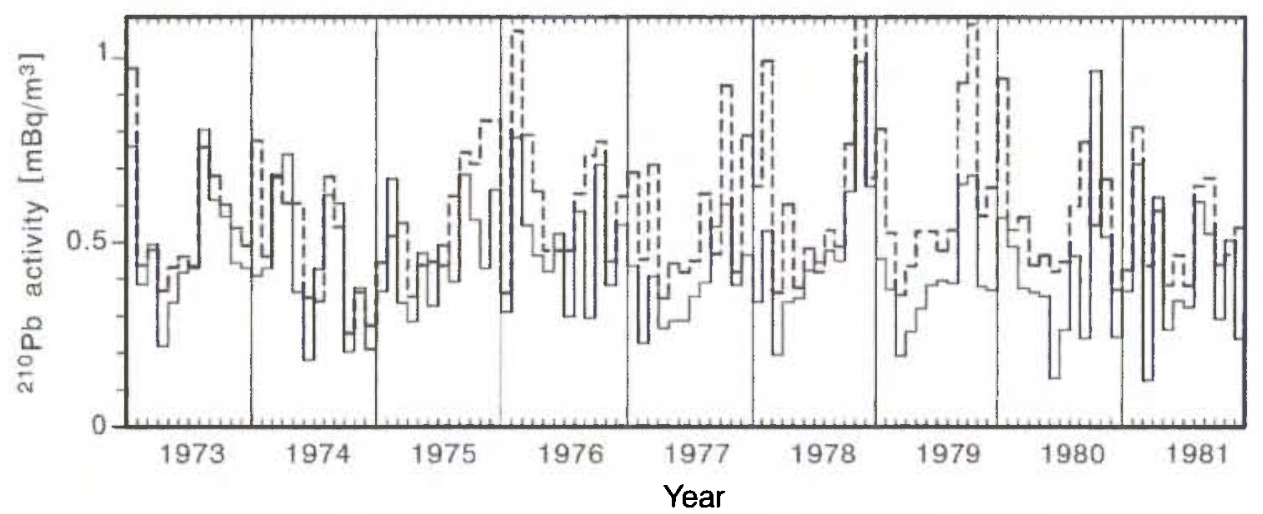

Fig. 2. Monthly mean activity concentrations of ${ }^{211} \mathrm{~Pb}$ in surface air of Fribourg, Switzerland [37] (solid line) and Neuherberg, Munich, Germany for 1973-1981 [36] (dashed line). Both sites are located on the northern side of the Alps at a distance of $360 \mathrm{~km}$.

nuclide ${ }^{210} \mathrm{~Pb}\left(T_{1 / 2}=22\right.$ years $)$. Since these progenies of radon are non-gaseous species, they adsorb to aerosol particles. It is assumed that this process proceeds in two steps. First, after thermalization of the primary nuclides in the gas, the atoms or positive ions form clusters of $0.5 \mathrm{~nm}$ to $5 \mathrm{~nm}$ size - depending on parameters such as temperature and humidity - by attachment of $\mathrm{H}_{2} \mathrm{O}$ molecules $[2,25]$. These clusters are called "unattached" radon progenies. Second, these clusters attach to aerosol particles. Typical attachment rates for outdoor conditions (aerosol particle concentration $(2-7) \cdot 10^{4} \mathrm{~cm}^{-3}$ ) were found to be $20-100 \mathrm{~h}^{-1}$ [26], corresponding to average attachment times of $40 \mathrm{~s}$ to $3 \mathrm{~min}$. For an aerosol particle concentration of only $100 \mathrm{~cm}^{-3}$, an attachment time of about 1 hour was observed [27]. Of special relevance is the fact, that due to a $112 \mathrm{keV}$ nuclear recoil, the first progeny of the $\alpha$-emitting nuclide ${ }^{218} \mathrm{Po}$, the daughter nuclide ${ }^{214} \mathrm{~Pb}$, escapes with about $80 \%$ probability [28, 29] from the particles which have typical median aerodynamic diameters of 50 to $200 \mathrm{~nm}$ [28]. In addition, for indoor condition or outdoor situations close to ground, prior to an attachment of the short-lived ${ }^{222} \mathrm{Rn}$ progenies to aerosol particles, these nuclides may plate-out to nearby-surfaces. Since the diffusion coefficients of the nm-size clusters are much higher compared to those of aerosol particles, the plate-out effect may deplete the progenies of ${ }^{222} \mathrm{Rn}$ considerably in the lowest few meters above ground [9, 17]. This is of special importance if aerosol particle collection techniques such as air-filter measurements are used to determine the ${ }^{222} \mathrm{Rn}$ activity concentrations.

At altitudes higher than about $10 \mathrm{~m}$ above ground ${ }^{222} \mathrm{Rn}$ is generally in secular equilibrium with its shortlived decay products [17].

\subsection{Lead-210}

The only long-lived ( $\geq$ years) decay product of ${ }^{222} \mathrm{Rn}$ is ${ }^{210} \mathrm{~Pb}$. This nuclides is attached to aerosol particles in the sub-micron range and therefore considered to be a good tracer for an aerosol produced by gas-toparticle conversion [30]. Its residence time in the atmosphere is determined by the average residence time of sub-micron aerosol particles from the accumulation mode which is typically one to two weeks [31, 32]. Removal from the atmosphere occurs mainly by wet and dry deposition of the carrier aerosol particles. Estimated continental deposition rates are about $20 \mathrm{mBq} / \mathrm{cm}^{2}$ y $[33,34]$. Yearly average activity concentrations in surface air over Europe are about 0.2$0.7 \mathrm{mBq} / \mathrm{m}^{3}$, except for arctic regions with lower values, e.g. $15 \mu \mathrm{Bq} / \mathrm{m}^{3}$ at Franz Joseph Island [35]. Similar to the European values are those in America, Asia and Australia [35]. Lower values are found in Antarctica, e.g. $13 \mu \mathrm{Bq} / \mathrm{m}^{3}$ at the South Pole [35].

Monthly mean activity concentrations exhibit no pronounced seasonal variation, except for some maxima during long-periods with clear weather [36-38]. Fig. 2 shows monthly mean activity concentrations for ${ }^{210} \mathrm{~Pb}$ from Fribourg, Switzerland [37] and Neuherberg, Germany [36] for the time period 1973-1981. Both locations are on the northern side of the Alps at a distance of $360 \mathrm{~km}$. The very similar concentration patterns at both locations indicates that ${ }^{210} \mathrm{~Pb}$ is well mixed in the planetary boundary layer over large areas.

Due to the long half-life of ${ }^{210} \mathrm{~Pb}$ it can be used to date environmental archives such as lake sediments or glacier ice [34]. Nuclear dating is, however, only possible if the input function is known over the time period to be determined. Surprisingly, recent ${ }^{210} \mathrm{~Pb}$ measurements in ice cores from Greenland indicated that the deposition rates changed significantly during the last 150 years $[39,40]$. Also for high-alpine ice cores recent ${ }^{210} \mathrm{~Pb}$ measurements give evidence for variations in the deposition rates over the same time period $[41,42]$. Presently there is no explanation for this observation.

The vertical profile of the ${ }^{210} \mathrm{~Pb}$ activity concentration is expected to be rather constant up to an altitude of about $10 \mathrm{~km}$ [17]. Experimental data from e.g. United States show, however, that the activity concentration of ${ }^{210} \mathrm{~Pb}$ decreases by about a factor of five within this atmospheric layer [20], presumably due to lower residence times of aerosol particles than assumed in [17]. Also data from Jungfraujoch (3450 m 
asl) yield annual mean values of about $0.2 \mathrm{mBq} / \mathrm{m}^{3}$ [15] which is a factor of two lower compared to the values at the nearby low-altitude site Fribourg [38].

\section{Decay products of ${ }^{210} \mathrm{~Pb}$}

${ }^{210} \mathrm{~Pb}$ decays via ${ }^{210} \mathrm{Bi}\left(T_{1 / 2}=5.0 \mathrm{~d}\right)$ to ${ }^{210} \mathrm{Po}\left(T_{1 / 2}=\right.$ $138.38 \mathrm{~d}$ ). Average activity concentrations of ${ }^{210} \mathrm{Po}$ in air at e.g. Neuherberg measured during 1976-1982 were found to be a factor of 10 to 20 lower than those of ${ }^{210} \mathrm{~Pb}$ [36].

Activity ratios of the decay products of ${ }^{210} \mathrm{~Pb}$ are commonly used to determine residence times of aerosol particles in the troposphere. In general, values deduced from measurements of ${ }^{210} \mathrm{Bi}$ and ${ }^{210} \mathrm{~Pb}$ are typically one week [43], in good agreement with theoretical estimates for the lower troposphere. On the other hand, residence times obtained from measurements of ${ }^{210} \mathrm{Po}$ and ${ }^{210} \mathrm{~Pb}$ are usually significantly higher, mostly about one month $[44,45]$. Such high values are discussed controversially in the literature: most authors assume additional sources of ${ }^{210} \mathrm{Po}$ besides radioactive decay of ${ }^{210} \mathrm{~Pb}[20]$ such as the soil [46, 47] or pollution sources of volcanic origin or from fossil fuel burning [47].

\section{3. ${ }^{220} \mathrm{Rn}$ and its decay products}

Due to the short half-life of about one minute, ${ }^{220} \mathrm{Rn}$ ("thoron") escapes only from a small surface soil layer into the atmosphere. For the same reason the gradient of the activity concentration in the lowest atmospheric layer is very steep, typically decreasing by more than a factor of five within the first meter above ground [9]. Since the average thorium concentration in surface soil is generally higher than that of uranium, in the atmospheric layer below $1.5 \mathrm{~m}$ above ground, ${ }^{220} \mathrm{Rn}$ activity concentrations are higher than those of ${ }^{222} \mathrm{Rn}$. Typical values measured for outdoor conditions at $1.5 \mathrm{~m}$ height in New Mexico were $22 \mathrm{~Bq} / \mathrm{m}^{3}$ for ${ }^{220} \mathrm{Rn}$ and $5.5 \mathrm{~Bq} / \mathrm{m}^{3}$ for ${ }^{222} \mathrm{Rn}$ [47]. In a flat river valley close to Göttingen strong diurnal variations of the activity concentrations of ${ }^{220} \mathrm{Rn}$ were found during a summer month, similar to those of ${ }^{222} \mathrm{Rn}$, with up to a factor of 50 higher values during night compared to the noon minima [48]. Average values at this site at the $1.5 \mathrm{~m}$ level were about $80 \mathrm{~Bq} / \mathrm{m}^{3}$ [7]. During late fall with strongly reduced vertical advective mixing, no diurnal variation of the activity concentrations for the same level above ground were observed [2].

With respect to radiation dose it is presently unclear whether the thoron decay products ${ }^{212} \mathrm{~Pb}\left(T_{1 / 2}=\right.$ $10.6 \mathrm{~h}),{ }^{212} \mathrm{Bi}\left(T_{1 / 2}=60.6 \mathrm{~min}\right)$ and ${ }^{212} \mathrm{Po}\left(T_{1 / 2}=\right.$ $0.3 \mu \mathrm{s})$ are of relevance. For indoor conditions it is estimated that these radionuclides may add up to $20 \%$ relative to that of the ${ }^{222} \mathrm{Rn}$ decay products [49].

Atmospheric measurements of ${ }^{220} \mathrm{Rn}$ decay products are scarce. In Malaga, Spain, close to the sea shore, during a 6 month measuring campaign of air collected $2 \mathrm{~m}$ above ground, ${ }^{212} \mathrm{~Pb}$ activity concentrations of about $0.1 \mathrm{~Bq} / \mathrm{m}^{3}$ and ${ }^{222} \mathrm{Rn}$ activity concentrations of about $2 \mathrm{~Bq} / \mathrm{m}^{3}$ were determined [50]. Continuous measurements of ${ }^{212} \mathrm{~Pb}$ over 3.5 months in a river valley close to Göttingen resulted in average activity concentration of $0.4 \mathrm{~Bq} / \mathrm{m}^{3}$, with large variations of the single measurements by nearly two orders of magnitude [48]. At Mauna Loa, ${ }^{212} \mathrm{~Pb}$ activity concentrations were strongly depending on meteorological conditions with up to $4 \mathrm{mBq} / \mathrm{m}^{3}$ for up-slope wind conditions and much lower values for non-up-slope wind conditions [51]. At Jungfraujoch, ${ }^{212} \mathrm{~Pb}$ monthly mean activity concentrations showed large variations with minimum values of $1 \mathrm{mBq} / \mathrm{m}^{3}$ in winter and maximum values of $8 \mathrm{mBq} / \mathrm{m}^{3}$ in summer [15].

\section{Krypton-85}

${ }^{85} \mathrm{Kr}$ is a noble gas isotope with a half-life of 10.76 years. It is produced in the thermal neutron induced fission of ${ }^{235} \mathrm{U}$ with a cumulative yield of $0.28 \%$, which is the product of the isobaric chain yield of $1.32 \%$ and the yield of the internal transition of ${ }^{85 m} \mathrm{Kr}$ of $21.4 \%$. This radionuclide is emitted into the atmosphere during nuclear weapons testing (both above and underground), from nuclear power plants as well as from nuclear reprocessing plants. The average activity concentrations of ${ }^{85} \mathrm{Kr}$ in the northern hemisphere is presently slightly higher than $1 \mathrm{~Bq} / \mathrm{m}^{3}$ [52]. Its activity concentration is steadily increasing with a doubling time of about 20 years [53]. At collection sites within the planetary boundary layer, activity peaks are frequently observed, presumably due to well defined releases from reprocessing plants $[53,54]$. At Jungfraujoch, which is in the free troposphere, the average activity concentration of ${ }^{85} \mathrm{Kr}$ is also about $1 \mathrm{~Bq} / \mathrm{m}^{3}$ but with much less pronounced fluctuations with time [52]. This means that this radionuclide is well mixed in the troposphere of the northern hemisphere [54]. In antarctica, the activity concentration of ${ }^{85} \mathrm{Kr}$ is about $20 \%$ lower compared to the values in the northern hemisphere [53]. This is caused by the average transportation time from the emission sources, all being in the northern hemisphere, to Antarctica, which is on the order of a few years.

Even though ${ }^{85} \mathrm{Kr}$ is the artificial radionuclide with the highest average activity concentration in the troposphere, its radiological importance is negligible, because - unlike ${ }^{222} \mathrm{Rn}$ - it has no non-gaseous radioactive decay products which can be accumulated in the human body.

\section{Tritium}

Tritium $\left({ }^{3} \mathrm{H}=\mathrm{T}\right)$ is a weak $\beta$-emitter $\left(E_{\beta}=18 \mathrm{keV}\right)$ with a half-life of 12.3 years. Tritium is both of natural and anthropogenic origin. The natural production occurs via interaction of cosmic rays with the atmosphere. The anthropogenic production has several 


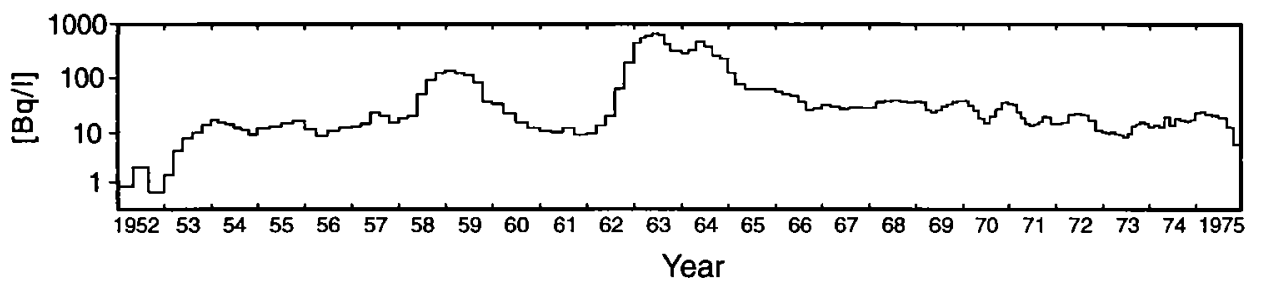

Fig. 3. Tritium activity concentration (corrected for decay) from an ice core from Colle Gnifetti ( $4450 \mathrm{~m}$ asl), Monte Rosa massif (from [37]). The dating is based on the observation of well documented stratigraphic layers (Saharan dust horizons etc.).

sources. First, tritium was released to the atmosphere by thermonuclear explosions. Second, a release into the atmosphere occurs from nuclear power plants or reprocessing plants as well as from industry. Due to its widespread applications, the actual tropospheric activity concentration of tritium is significantly increased compared to the natural level from prenuclear times. The activity concentration of tritium is often given in T.U. (Tritium Units), with $1 \mathrm{TU}=1 \mathrm{~T}$ atom per $10^{18} \mathrm{H}$ atoms. 1 T.U. corresponds to a specific tritium activity of $0.12 \mathrm{~Bq} / \mathrm{kg}$ water.

In the atmosphere - except for the upper stratosphere - the dominating species containing tritium is HTO $[55,56]$. Most of the tritium is deposited on the earth surface by precipitation. However, depending on humidity and temperature, in the atmosphere a large part of tritium is in form HTO vapor. Due to isotopic enrichment, the $\mathrm{T} / \mathrm{H}$ ratio in liquid $\mathrm{HTO}$ is 1.1 higher compared to that in gaseous HTO [57]. Some minor part of tritium is also found in form of HT.

\subsection{Natural tritium}

As a cosmogenic radionuclide, tritium is produced in the stratosphere in spallation reactions of galactic cosmic rays, mainly protons, with oxygen and nitrogen. In addition, tritium is also produced by secondary particles, high-energy ( $E \geq 4.4 \mathrm{MeV}$ ) neutrons in the ${ }^{14} \mathrm{~N}(\mathrm{n}, \mathrm{T}){ }^{12} \mathrm{C}$ reaction. As for all cosmogenic radionuclides, the rate of production depends on the solar activity and varies between $(1.5-3) \cdot 10^{17} \mathrm{~Bq} /$ year [56]. Maximum solar flares correspond to minimum production and vice versa.

The specific natural tritium concentration in precipitation depends on the latitude, with about $5 \mathrm{~Bq} / 1$ at the poles and $0.06 \mathrm{~Bq} / 1$ at the equator [57]. For a latitude of $45^{\circ} \mathrm{N}$ or $\mathrm{S}$, the natural specific tritium activity concentration is about $0.6 \mathrm{~Bq} / \mathrm{l}$. This behavior is caused by the stratosphere-troposphere exchange of air masses [57, 58]. In addition, increased downward air mass flow is observed in late spring [55, 59]. This leads to seasonal fluctuations of the tropospheric activity concentration with maxima in late spring [57].

There exists a continental effect of the specific tritium activity concentration with lower values for sites close to the sea shore compared to those located deep inside the continents [57]. For sites close to the coast the isotopic composition of HTO corresponds to that of oceanic surface water whereas for inland sites the
HTO composition is increasingly determined by the tropospheric values at this latitude and by evaporated water from the land surface.

For tritium in form of HT, the specific activity is much higher. However, due to the low abundance of hydrogen in air, the total amount of natural tritium in form of HT is only about $10^{-4}$ compared to that in form of HTO [55].

\subsection{Anthropogenic tritium}

Begemann and Libby [60] estimated, that about $4 \cdot 10^{17} \mathrm{~Bq}$ of tritium was released for each megaton thermonuclear explosion. The total amount of tritium released during the overground test series performed by USA and USSR between 1954 and 1963 is estimated to be about $1.1 \cdot 10^{20} \mathrm{~Bq}$ [55].

French and Chinese tests between 1968 and 1977 have added another $(7-10) \cdot 10^{18} \mathrm{~Bq}[55]$. These nuclear tests have, of course, strongly increased the HTO concentration in the atmosphere. As an example, the measured tritium concentrations in precipitation, as determined from an Alpine glacier ice core from Colle Gnifetti (4450 m asl) near Zermatt, Switzerland, for the time period $1952-1975$ is shown in Fig. 3 [37, 61]. From a level of about $1 \mathrm{~Bq} / 1$ in 1952 the tritium activity concentration increased to $740 \mathrm{~Bq} / 1$ in 1963 and then decreased to about $10 \mathrm{~Bq} / 1$ in 1975 . Since the snow deposition at this high-alpine wind exposed site occurs not very regularly [62], the seasonal fluctuation of the tritium deposition is not well preserved. Between 1975 and present, the tritium activity concentration decreased further. Typical tritium activity concentrations in precipitation, e.g. 1993 in Switzerland at different locations were between 1.5 and $5.5 \mathrm{~Bq} / 1$ $[6,63]$. The reasons for a still increased level of tritium compared to the natural background level are industrial applications, such as e.g. from the production of luminous dials.

\subsection{Atmospheric activity concentration of tritium}

If we assume, as an example for 1992, an average relative humidity of $70 \%$ and an average winter and summer temperature of $2{ }^{\circ} \mathrm{C}$ and $20^{\circ} \mathrm{C}$, respectively (values for Zürich, Switzerland [64, 65]), the measured tritium activity concentrations in precipitation of about 


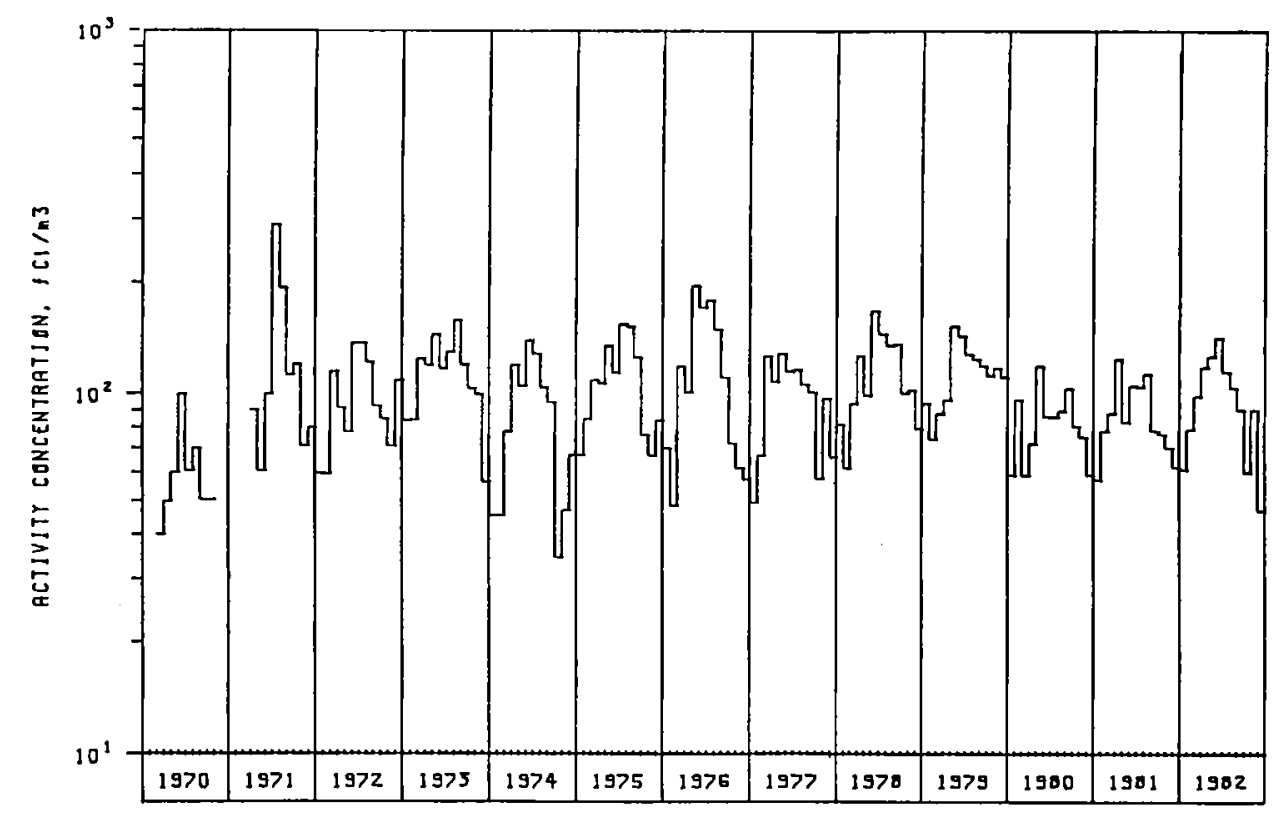

Fig. 4. Monthly mean activity concentrations of ${ }^{7} \mathrm{Be}$ in surface air of Neuherberg, Germany (from [36]). Activities are given in femtocurie $/ \mathrm{m}^{3} .100 \mathrm{fCi} / \mathrm{m}^{3}=3.7 \mathrm{mBq} / \mathrm{m}^{3}$.

$2 \mathrm{~Bq} / 1$ corresponds to an average activity concentrations of gaseous HTO of 8 to $24 \mathrm{mBq} / \mathrm{m}^{3}$ for winter and summer, respectively. However, for the same year, in the neighborhood of a company using tritium for industrial applications, much higher gaseous HTO activity concentrations of about $5-25 \mathrm{~Bq} / \mathrm{m}^{3}$ have been measured [52].

\section{Beryllium-7}

${ }^{7} \mathrm{Be}$ is a cosmogenic radionuclide with a half-life of $53.3 \mathrm{~d}$. It is produced both by primary (mostly protons) and secondary (neutrons) cosmic ray particles with nitrogen and oxygen according to the following reactions: ${ }^{14} \mathrm{~N}(\mathrm{p}, 2 \alpha){ }^{7} \mathrm{Be},{ }^{16} \mathrm{O}\left(\mathrm{p},{ }^{10} \mathrm{~B}\right){ }^{7} \mathrm{Be},{ }^{14} \mathrm{~N}\left(\mathrm{n},{ }^{8} \mathrm{Li}\right){ }^{7} \mathrm{Be}$, and ${ }^{16} \mathrm{O}\left(\mathrm{n},{ }^{10} \mathrm{Be}\right){ }^{7} \mathrm{Be}$.

About $67 \%$ of ${ }^{7} \mathrm{Be}$ is produced in the stratosphere and $33 \%$ in the troposphere [66]. The peak production is approximately in the middle of the atmosphere (in mass units) [67]. After production, ${ }^{7} \mathrm{Be}$ attaches to submicron-sized aerosol particles [68]. Cascade impactor measurements showed that in ambient aerosol particles most of the ${ }^{7} \mathrm{Be}$ was found in the 0.7 to $1.1 \mu \mathrm{m}$ range [69]. Due to its main $\gamma$-line at $478 \mathrm{keV}$ this nuclide can be easily measured in air filter samples. The surface activity concentration of ${ }^{7} \mathrm{Be}$ in air depends on four processes [70], i) stratosphere-troposphere exchange, ii) downward transport in the troposphere, iii) wet scavenging, and iv) horizontal transfer from mid latitudes to higher and lower latitudes. Hence, the annual cycle of ${ }^{7} \mathrm{Be}$ in surface air may be quite different at different sites. For mid latitudes in the northern hemisphere, typical annual cycles with maximum activity concentrations in early summer are found (Fig. 4), caused by tropopause folding during this time period. In polar regions or at subtropical locations the annual cycles of ${ }^{7} \mathrm{Be}$ activity concentrations are more complex as shown in a very thorough review on ${ }^{7} \mathrm{Be}$ in the atmosphere [71].

The question whether the surface activity concentration of ${ }^{\urcorner} \mathrm{Be}$ depends on the solar activity is discussed controversially. In Ref. [71] no such clear correlation was found in contrast to Ref. [72], where for the years $1985-1990$ at 8 stations from $71^{\circ} \mathrm{N}$ to $53^{\circ} \mathrm{S}$ a pronounced decrease of the annual mean activity concentration was correlated to an increase of the solar activity (sun spot number) for the same time period [73].

The annual mean surface activity concentrations are higher at low latitudes compared to high latitudes, which is somewhat different to expectations based on pure vertical stratosphere-troposphere exchange. This might be a result of the complex transport processes mentioned above. As an example, the annual mean activity concentrations for 1987 were (in $\mathrm{mBq} / \mathrm{m}^{3}$ ): 1.4 in Barrow, Alaska $\left(71^{\circ} \mathrm{N}\right), 2.9$ in Moosonee, Canada $\left(51^{\circ} \mathrm{N}\right), 4.5$ in Chester, USA $\left(41^{\circ} \mathrm{N}\right), 5.4$ in Miami, USA $\left(26^{\circ} \mathrm{N}\right), 4.5$ in Lima, Peru $\left(12^{\circ} \mathrm{S}\right), 4.8$ in Perth, Australia $\left(32^{\circ} \mathrm{S}\right), 3.5$ in Cape Grim, Tasmania, Australia $\left(41^{\circ} \mathrm{S}\right)$, and 1.7 in Punta Arenas, Chile $\left(53^{\circ} \mathrm{S}\right)$, respectively [72]. In Europe (e.g. Neuherberg, Germany, or Fribourg, Switzerland), annual man values in surface air are about $3 \mathrm{mBq} / \mathrm{m}^{3}[36,37]$.

The activity concentrations are increasing with altitude. For northern mid latitudes typical values are $18 \mathrm{mBq} / \mathrm{m}^{3}$ at the tropopause and $155 \mathrm{mBq} / \mathrm{m}^{3}$ in the lower stratosphere [74].

\section{Carbon-14}

${ }^{14} \mathrm{C}\left(T_{1 / 2}=5730\right.$ years $)$ is a pure $\beta$-emitter with a maximum energy of $0.2 \mathrm{MeV}$. Similar to tritium, also modern atmospheric ${ }^{14} \mathrm{C}$ is of natural and anthropogen- 
ic origin. Natural ${ }^{14} \mathrm{C}$ is mainly produced in interactions of secondary cosmic ray particles (neutrons) with nitrogen, according to the reaction ${ }^{14} \mathrm{~N}(\mathrm{n}, \mathrm{p}){ }^{14} \mathrm{C}$. About $55 \%$ of ${ }^{14} \mathrm{C}$ is produced in the stratosphere and $45 \%$ in the upper troposphere [75]. Primary ${ }^{14} \mathrm{C}$ oxidizes immediately in the atmosphere to ${ }^{14} \mathrm{CO}_{2}$. The average natural atmospheric activity concentration of ${ }^{14} \mathrm{C}$ is about $40 \mathrm{mBq} / \mathrm{m}^{3}$ air, based on a measured specific activity of $0.219 \mathrm{~Bq}{ }^{14} \mathrm{C} / \mathrm{g}$ total carbon [76] and an atmospheric volume concentration of $0.033 \% \mathrm{CO}_{2}$. This corresponds to a ${ }^{14} \mathrm{C} /{ }^{12} \mathrm{C}$ ratio of $1.2 \cdot 10^{-12}$. The largest reservoir of ${ }^{14} \mathrm{C}$ is the ocean $(94 \%)$, the residual part being distributed in the atmosphere $(1.5 \%)$, biosphere $(2.0 \%)$ and the humus $(2.5 \%)$ [77].

${ }^{14} \mathrm{C}$ is incorporated into living material via $\mathrm{CO}_{2}$ uptake. This nuclide has therefore found widespread applications for dating purposes of dead organic material with an age up to 32,000 years [77]. By comparing "true" ages from dendrochronology of tree rings with the ${ }^{14} \mathrm{C}$-age of the carbon from the corresponding annual layers it was found that the past atmospheric ${ }^{14} \mathrm{C}$ activity concentration was not constant. The longest period of the observed activity fluctuations has a period of about 11,000 years and is attributed to geomagnetic dipole fluctuations of the earth [78]. The shortest fluctuation is caused by the well known 11-year cycle of the solar activity. The amplitudes of these activity fluctuations are usually $\leq 2 \%[79]$.

With the beginning of the nuclear age, anthropogenic ${ }^{14} \mathrm{C}$ was introduced into the atmosphere. In the years 1962/63 with maximum overground testing of thermonuclear weapons, the ${ }^{14} \mathrm{C}$ activity concentration in the northern hemisphere increased by nearly a factor of two [80]. In the southern hemisphere the increase was much smaller [81]. After the stop of overground nuclear explosions in 1963 the anthropogenic ${ }^{14} \mathrm{G}$ activity concentration decreased significantly, every 17 years be a factor of two [81]. Actual ${ }^{14} \mathrm{C}$ activity concentrations are still increased by about $10 \%$ above the natural level, mainly as residual contribution from the nuclear explosions but also due to emissions from nuclear power plants, reprocessing plants and from ${ }^{14} \mathrm{C}$ tracer applications in chemistry. This means that the actual ${ }^{14} \mathrm{C}$ activity concentration in the troposphere is about $45 \mathrm{mBq} / \mathrm{m}^{3}$.

Besides the anthropogenic increase of the ${ }^{14} \mathrm{C}$ activity concentration there exists also an anthropogenic decrease which is caused by human fossil fuel burning. In 1950 it was realized by Suess that ${ }^{14} \mathrm{C}$ activities in modern wood samples were too low by about $2 \%$ [82]. This so-called Suess effect was later masked by the much larger increase of the ${ }^{14} \mathrm{C}$ activity concentration from the nuclear weapons testing.

\section{Argon-37}

${ }^{37} \mathrm{Ar}$ decays via electron capture and has a half-life of $35 \mathrm{~d}$. It is produced in cosmic ray induced reactions with atmospheric argon. In underground nuclear

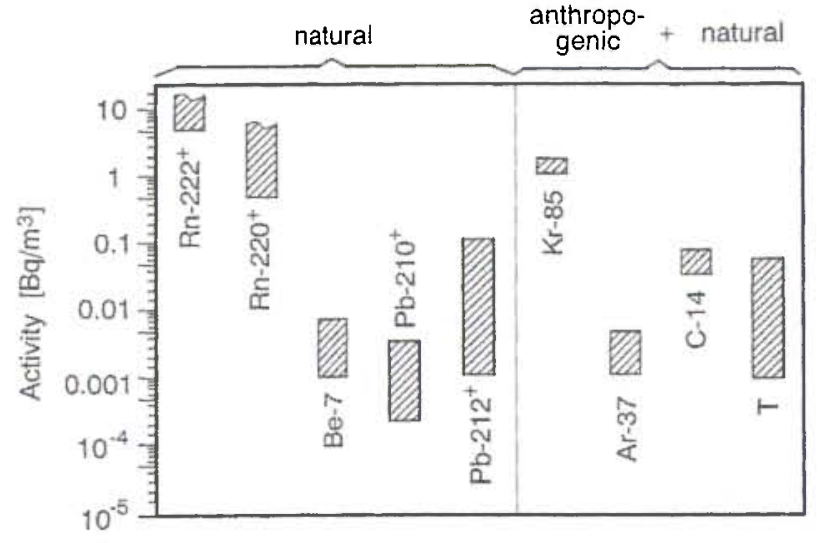

Fig. 5. Average activity concentrations of those radionuclides which have values above about $1 \mathrm{mBg} / \mathrm{m}^{3}$ in surface air over continents - mainly over Europe. The sign ${ }^{+}$means that also short-lived decay products of these nuclides have similar activity concentrations.

weapons tests it is formed in the ${ }^{40} \mathrm{Ca}(\mathrm{n}, \alpha)^{37} \mathrm{Ar}$ reaction. Some release of this nuclide occurs also from nuclear facilities [6]. In surface air the natural activity concentration from cosmic ray production is about $0.5 \mathrm{mBq} / \mathrm{m}^{3}$ [6]. During the early $70^{\text {th }}$ with large underground test series, the ${ }^{37} \mathrm{Ar}$ activity concentration e.g. in Bern, Switzerland, was increased shortly after every explosion by about a factor of 100 [37]. Presently, the activity concentration at the same location is between 0.6 and $3.8 \mathrm{mBq} / \mathrm{m}^{3}$ [6].

\section{Summary}

Typical ranges of actual surface air activity concentrations of different radionuclides over continents are shown in Fig. 5. Only those nuclides are depicted which presently have average activity concentrations above about $1 \mathrm{mBq} / \mathrm{m}^{3}$. Highest values have ${ }^{222} \mathrm{Rn}$ ("radon") and ${ }^{220} \mathrm{Rn}$ ("thoron") including their shortlived decay products. Over the sea, the highest activity concentration has the anthropogenic radionuclide ${ }^{85} \mathrm{Kr}$, due to the much reduced emanation rates of radon and thoron from the oceans.

Fig. 5 also shows that the highest tropospheric activity concentration from all cosmogenic radionuclides has ${ }^{14} \mathrm{C}$, even though about $10 \%$ of its present-day activity is caused by anthropogenic sources.

The gaseous radionuclides shown in Fig. 5 are ${ }^{222} \mathrm{Rn},{ }^{220} \mathrm{Rn},{ }^{85} \mathrm{Kr},{ }^{37} \mathrm{Ar},{ }^{14} \mathrm{C}$ (in form of $\mathrm{CO}_{2}$ ), and $\mathrm{T}$ (in form of water vapor). They are of minor importance with respect to public exposure to ionizing radiation. This is different for those radionuclides which are attached to aerosol particles such as the decay products of ${ }^{222} \mathrm{Rn}$ and ${ }^{220} \mathrm{Rn}$ but also for ${ }^{7} \mathrm{Be}$ because they can be accumulated in the human respiratory organ.

Not included in this review are those radionuclides which were released during the Tschernobyl accident on April 26, 1986 because they caused a contaminations of tropospheric air masses over a few days 
only, e.g. in Switzerland between about April 30 and Mai 3, 1986 [83].

\section{References}

1. Reedy, R. C.: Science 219127 (1983).

2. Porstendörfer, J.: J. Aerosol Sci. 25, 219 (1994), and references therein.

3. Bruno, R. C.: J. Air Pollut. Control. Ass. 33, 105 (1983).

4. Burkart, W.: Nucl. Technol. 60, 114 (1983).

5. Jacobi, W.: Health Phys. 22, 441 (1972).

6. Environmental Radioactivity and Radiation Exposure in Switzerland 1993, Bundesamt für Gesundheitswesen, Bern, ISBN 3-905235-15 (1994).

7. Butterweck, G., Reineking, A., Kesten, J., Porstendörfer, J.: Atmos. Environ. 28, 1963 (1994).

8. Porstendörfer, J., Butterweck, G., Reineking, A.: Health Phys., in press.

9. Jacobi, W.: Die natürliche Radioaktivität der Atmosphäre und ihre Bedeutung für die Strahlenbelastung des Menschen, Hahn Meitner Institut, Berlin, Report HMJ-B21 (1962), in german.

10. Volpp, H. J.: Untersuchung des großräumigen atmosphärischen Transports in Mitteleuropa mit Hilfe von ${ }^{222} \mathrm{Rn}$. Doctoral thesis, Universität Heidelberg (1984), unpublished.

11. Feichter, J., Crutzen, P. J.: Tellus 42B, 46 (1990).

12. Pereira, E. B.: Tellus 42B, 39 (1990).

13. Lambert, G., Ardouin, B., Sanak, J.: Tellus 42B, 76 (1990).

14. Heimann, M., Monfray, P., Polian, G.: Tellus 42B, 83 (1990).

15. Gäggeler, H. W., Jost, D. T., Baltensperger, U., Schwikowski, M., Seibert, P.: Atmos. Environ. 29, 607 (1995).

16. Whittlestone, S., Robinson, E., Ryan, S.: Atmos. Environ. 26A, 251 (1992).

17. Jacobi, W., André, K.: J. Geophys. Res. 68, 3799 (1963).

18. Nazarov, L. E., Kuzenkov, F., Malakhov, S. G., Volokitina, L. A., Gaziyev, Ya. I., Vasil'yev, A. S.: J. Geophys. Res. 75, 3575 (1970).

19. Lambert, G., Polian, G., Sanak, J., Ardouin, B., Buisson, A., Jegou, A., Le Roulley, J. C.: Ann. Géophys. 38, 497 (1982).

20. Moore, H. E., Poet, S. E., Martell, E. A.: J. Geophys. Res. 78, 7065 (1973).

21. Reiter, R., Munzert, K.: Arch. Met. Geoph. Biokl., Ser. B, 31, 39 (1982).

22. Lambert, G., Le Roulley, J.-C., Kritz, M.: Tellus 42B, 135 (1990).

23. Liu, S. C., McAfee, J. R., Cicerone, R. J.: J. Geophys. Res. 89, 7291 (1984).

24. Kritz, M. A., LeRoulley, J. C., Danielsen, E. F.: Tellus 42B, 46 (1990).

25. Rogak, S. N., Baltensperger, U., Flagan, R. C.: Aerosol Sci. and Techn. 14, 447 (1991).

26. Porstendörfer, J., Mercer, T. T.: Atmos. Environ. 12, 2223 (1978).

27. Whittlestone, S.: J. Atmos. Chem. 11, 27 (1990).

28. Mercer, T. T.: Health Phys. 31, 173 (1976).

29. Mercer, T. T., Stowe, W. A.: Radioactive Aerosols produced by radon in room air, in: Inhaled Particles III (Edited by W. H. Walton, Unwin, Old Woking (1971).

30. Sanak, J., Gaudry, A., Lambert, G.: Geophys. Res. Lett. 8, 1067 (1981).

31. Poet, S. E., Moore, H. E., Martell, E. A.: J. Geophys. Res. 77, 6515 (1972).

32. Francis, C. W., Chesters, G., Haskin, L. A.: Environ. Sci. Technol. 4, 587 (1970).

33. El-Dahoushy, F.: Proc. First Int. Summer School on LowLevel Measurements and Their Applications to Environmental Radioactivity, La Rabida, Andalusia, Spain 1987, Published by World Scientific, M. Garcia-Leon and G. Madurga (Eds.), p. 224-273 (1988).

34. von Gunten, H. R., Moser, R. N.: J. Paleolimnol. 9, 161 (1993).
35. Rangarajan, C., Madhavan, R., Gopalakrishnan, S. S.: J. Environ. Radioact. 3, 23 (1986).

36. Report Gesellschaft für Strahlen- und Umweltforschung mbH München, GSF, S-956, ISSN-0721-1694 (1983), in german.

37. Report "25 Jahre Radioaktivitätsüberwachung in der Schweiz", KUER, c/o Physics Institute, University of Fribourg, Switzerland (1982), unpublished.

38. Gäggeler, H., von Gunten, H. R., Nyffeler, U.: Earth Plan. Sci. Lett. 33, 119 (1976).

39. Nijampurkar, V. N., Clausen, H. B.: Tellus 42B, 29 (1990).

40. Dibb, J. E.: Tellus 44B, 72 (1992).

41. Gäggeler, H., von Gunten, H. R., Rössler, E., Oeschger, H., Schotterer, U.: J. Glaciol. 29, 165 (1983).

42. Gäggeler, H. W., von Gunten, H. R., Füeg, B.: unpublished data (1995).

43. Rangarajan, C., Eapen, C. D.: Tellus 42B, 142 (1990) and references therein.

44. Anand, S. J. S., Rangarajan, C.: J. Environ. Radioact. 11, 235 (1990).

45. Kuroda, P. K., Daniel, P. Y., Nevissi, A., Beck, J. N., Meason, J. L.: J. Radioanal. Chem. 43, 443 (1978).

46. Moore, H. E., Martell, E. A., Poet, S. E.: Environ. Sci. Technol. 10, 586 (1976).

47. Zarcone, M. J., Schery, S. D., Wilkening, M. H., McNamee, E.: Atmos. Environ. 20, 1273 (1986).

48. Porstendörfer, J., Butterweck, G.: unpublished data referred to in Ref. [2] (1991).

49. Schery, S. D.: J. Air Waste Manage. Assoc. 40, 493 (1990).

50. Duenas, C., Fernandez, M. C., Senciales, M.: Atmos. Environ. 24A, 1255 (1990).

51. Whittlestone, S., Schery, S. D., Yanxia, Li: Climate Monitoring and Diagnostocs Laboratory, National Oceanic and Atmospheric Administration, U.S. Depart of Commerce, CMDL Summary Report 1992, Boulder, Colorado (1993).

52. Umweltradioaktivität und Strahlendosen in der Schweiz 1992, Bundesamt für Gesundheitswesen, Abteilung Strahlenschutz, Chemin du Musée 3, CH-1700 Fribourg, ISBN 3-905235-09-9 (1993), in german.

53. Weiss, W., presented at: Seminar uiber Umweltbelastung durch langlebige künstlich erzeugte Radionuklide, Verkehrshaus, Luzern, Switzerland, 29. Juni 1995, KUER/KSA Organizers, unpublished.

54. Wilhelmova, L., Tomasek, M., Stukheil, K. : J. Radioanal. Nucl. Chem. Lett. 144, 125 (1990).

55. see e.g. in: A. C. Chamberlin, Radioactive aerosols, Cambridge Environmental Chemistry Series, Cambridge University Press, ISBN 0-521-40121-6 (1991).

56. Tritium in the environment. National Council on Radiation Protection and Measurements (NCRP), Washington DC (1979).

57. Hebert, D.: Tritium in der Atmosphäre - Quellen, Verteilung, Perspektive -, Freiberger Forschungshefte, C 443 Geowissenschaften, ISSN 0071-9404, VEB Deutscher Verlag für Grundstoffindustrie, Leipzig (1990), in german.

58. Douglass, A. R., Stanford, J. L. : J. Geophys. Res. 87, 5001 (1982).

59. Ehalt, D. H.: J. Geophys. Res. 76, 7351 (1971).

60. Begemann, F., Libby, W. F.: Geochim. Cosmochim. Acta 12, 277 (1957).

61. Oeschger, H., Schotterer, U., Stauffer, B., Haeberli, W., Röthlisberger, H., Gäggeler, H. W.: Z. Gletscherk. Glazialgeol. 13, 193 (1977).

62. Schotterer, U., Oeschger, H., Wagenbach, D., Münnich, K. O.: Z. Gletscherk. Glazialgeol. 21, 379 (1985).

63. Schotterer, U.: priv. comm. (1995)

64. Lugauer, M.: priv. comm. (1995).

65. Schriftreihe Umwelt Nr. 207 Luft. NABEL Luftbelastung 1992, Bundesamt für Umwelt, Wald und Landschaft (Eds.), Bern, August (1993), in german.

66. Lal, D., in: Earth Science and Meteoritics, compiled by J. Geiss and E. D. Goldberg 312 pp., North Holland, New York (1963). 
67. Junge, C. E.: Air Chemistry and Radioactivity, 382 pp., Academic, San Diego, Calif. (1963).

68. Bondietti, E. A., Hoffman, F. O., Larsen, I. L.: J. Environ. Radioact. 1, 5 (1984).

69. Papastefanou, C., Ioannidou, A.: J. Environ. Radioact. 26, 273 (1995).

70. Feely, H. W., Larsen, R. J., Sanderson, C. G.: Annual Report of the surface air sampling program, July 1988, Rep. EML497, Environ. Meas. Lab., U.S. Dept. of Energ., New York (1988).

71. Brost, R. A., Feichter, J., Heimann, M.: J. Geophys. Res. D12, $22^{\prime} 423$ (1991).

72. Larsen, R. J.: J. Environ. Radioact. 18, 85 (1993).

73. Barry, R. G., Chorley, R. J.: The sun spot number between 1610 and 1990, Atmosphere, Weather and Climate, $6^{\text {th }}$ ed., Rontledge, London (1992).

74. Dutkiewicz, V. A., Husain, L.: Geophys. Res. Lett. 6, 171 (1979).

75. Damon, P. E., Sternberg, R. E.: Radiocarbon 31(3), 697 (1989).

76. Hagemann, F. T., Gray Jr., J., Machta, L., Turkevich, A.: Science 130, 542 (1959).
77. Stuiver, M.: Nature 273, 271 (1978).

78. see e.g.: Méthodes de datation par les phénomènes nucléaires naturels application, E. Roth, B. Poty (Eds.), Masson, Paris, New York, Barcelone, Milan, Mexico, Sao Paulo (1985).

79. Hauenstein, J.: Herstellung von mikrogramm-großen Kohlenstoffproben für die Bestimmung des ${ }^{14} \mathrm{C}$ Gehaltes sowie Untersuchung von fossilen Pollen und polarem Gletschereis, Dissertation, Universität Bern, Switzerland (1994), unpublished (in german).

80. Levin, I., Bösinger, R., Bonani, G., Francey, R. J., Kromer, B., Münnich, K. O., Suter, M., Trivet, N. E. A., Wölfli, W., in: Radiocarbon after four decades, eds. R. E. Taylor, A. Long, R. S. Kra, Springer Verlag, pp 503-518 (1992).

81. Kaimei, D., Youneng, Q., Fan, C. Y.: Radiocarbon 34(3), 753 (1992).

82. Suess, H. E.: Natural radiocarbon and the rate of exchange of carbon dioxide between the atmosphere and the sea, Proc. Williams Bay Conf. Sept. 1953, NAS-NSF Publ. 52 (1954).

83. Jost, D. T., Gäggeler, H. W., Baltensperger, U., Zinder, B., Haller, P.: Nature 324, 22 (1986). 



\title{
Radionuclides in the Geosphere: Sources, Mobility, Reactions in Natural Waters and Interactions with Solids
}

\author{
By K. H. Lieser \\ Fachbereich Chemie, Zintl-Institut, Technische Hochschule, D-64289 Darmstadt, Germany
}

(Received December 16, 1994; revised February 7, 1995) Radionuclides / Geosphere / Speciation / Solubility /
Natural waters / Sorption / Ion exchange

\begin{abstract}
Summary
The various sources of radioactivity are considered. Natural and anthropogenic radionuclides are selected with regard to their importance in the geosphere and listed according to their chemical properties. The importance of the solubility of the radionuclides is emphasized and in view of their mobility five compartments are distinguished: surface of the earth, atmosphere, near-surface layers (with connection to the surface), nuclear installations and deep layers without connection to the surface.

In a following chapter, the reactions of radionuclides with the components of natural waters are discussed. The importance of the knowledge of the chemical forms (speciation) is stressed and illustrated by examples. The influences of $\mathrm{Eh}$ and $\mathrm{pH}$, inorganic salts, colloids, suspended matter, organic compounds and microorganisms as well as that of precipitation and coprecipitation is brought out. Then, the interaction of radionuclides with solid components of the geosphere are dealt with. After description of general aspects, interactions with consolidated rocks, unconsolidated rocks, various minerals, sediments and soils are discussed. Isotopic and non-isotopic exhange reactions of radionuclides on minerals are also considered. Finally, the problems of modelling are discussed.
\end{abstract}

\section{Introduction}

Radioactivity of uranium has been discovered hundred years ago (1896) by Becquerel [1]. In the following years the natural radionuclides (mainly members of the transmutation series of $U$ and $T h$ ) have been identified, and after the discovery of the neutron by Chadwick (1932), the discovery of nuclear fission by Hahn and Strassmann (1938) and the construction of accelerators a great number of artificial radionuclides and new artificial elements have been produced [2]. Today, the investigation of the behaviour of radionuclides in the geosphere, in particular in the environment, has become one of the most important fields of radiochemistry [3].

In this paper the attempt is made to give a survey on the sources and the mobility of the most important radionuclides, to order their numerous interactions with the various components of the geosphere and to elucidate the diverse chemical aspects of these interactions. Emphasis is laid on the chemical properties of the relevant radionuclides. Because detailed description of all kinds of interactions is not possible within the limited scope of this article, references are given for further reading. From these references it is obvious that besides radiochemistry itself various other fields are involved: chemistry of the elements and their complexes, physical chemistry, organic chemistry, colloid chemistry, geochemistry, chemistry of water, sediments and soils.

In chapter 2 a survey is given on the various natural and man-made sources of radioactivity on the earth. In chapter 3 dispersal, dissolution and mobility of radionuclides are discussed. Chapter 4 is devoted to the reactions of radioactive species with the components of aquatic systems and chapter 5 to their interactions with solid components of the geosphere.

\section{Sources of radioactivity in the geosphere}

Two kinds of sources of radioactivity on the earth can be distinguished: natural sources and anthropogenic sources. Natural sources, like ${ }^{40} \mathrm{~K},{ }^{232} \mathrm{Th},{ }^{235} \mathrm{U}$ and ${ }^{238} \mathrm{U}$, are present on the earth from the beginning. They have been formed in the course of nucleogenesis and are called primordial radionuclides. Further natural sources of radioactivity, like ${ }^{3} \mathrm{H}$ and ${ }^{14} \mathrm{C}$, are produced continuously by the interaction of cosmic rays with the atmosphere.

By mining of ores and minerals appreciable amounts of natural radionuclides, like ${ }^{232} \mathrm{Th},{ }^{235} \mathrm{U},{ }^{238} \mathrm{U}$ and their radioactive daughters are brought up to the surface of the earth and contribute to the radioactivity in the environment. In nuclear power stations artificial radionuclides, mainly fission products and transuranium elements are produced and great care is taken in handling the resulting radioactive waste safely and to localize it at certain places. The optimal conditions of final storage of the high-active waste (HAW) are still a subject of discussion. By application of nuclear weapons, by nuclear weapon tests and nuclear accidents, like the accident at Chernobyl, considerable amounts of fission products and radioelements have been set free and distributed via the atmosphere as radioactive fall-out over large areas, in particular in the northern hemisphere.

Radionuclides of special importance in the geosphere are listed in Table 1. In compiling this list the following criteria have been applied: Half-life $>1 \mathrm{~d}$ (in case of activation products of materials used in nuclear reactors $>1 \mathrm{y}$ ); natural radionuclides of ex- 
Table 1. Radionuclides of importance in geomedia

(Half-lives and fission yields $\sigma_{f}$ from Refs. [4] and [5] - radionuclides with half-lives $>10 \mathrm{y}$ and present in relatively high concentrations are underlined)

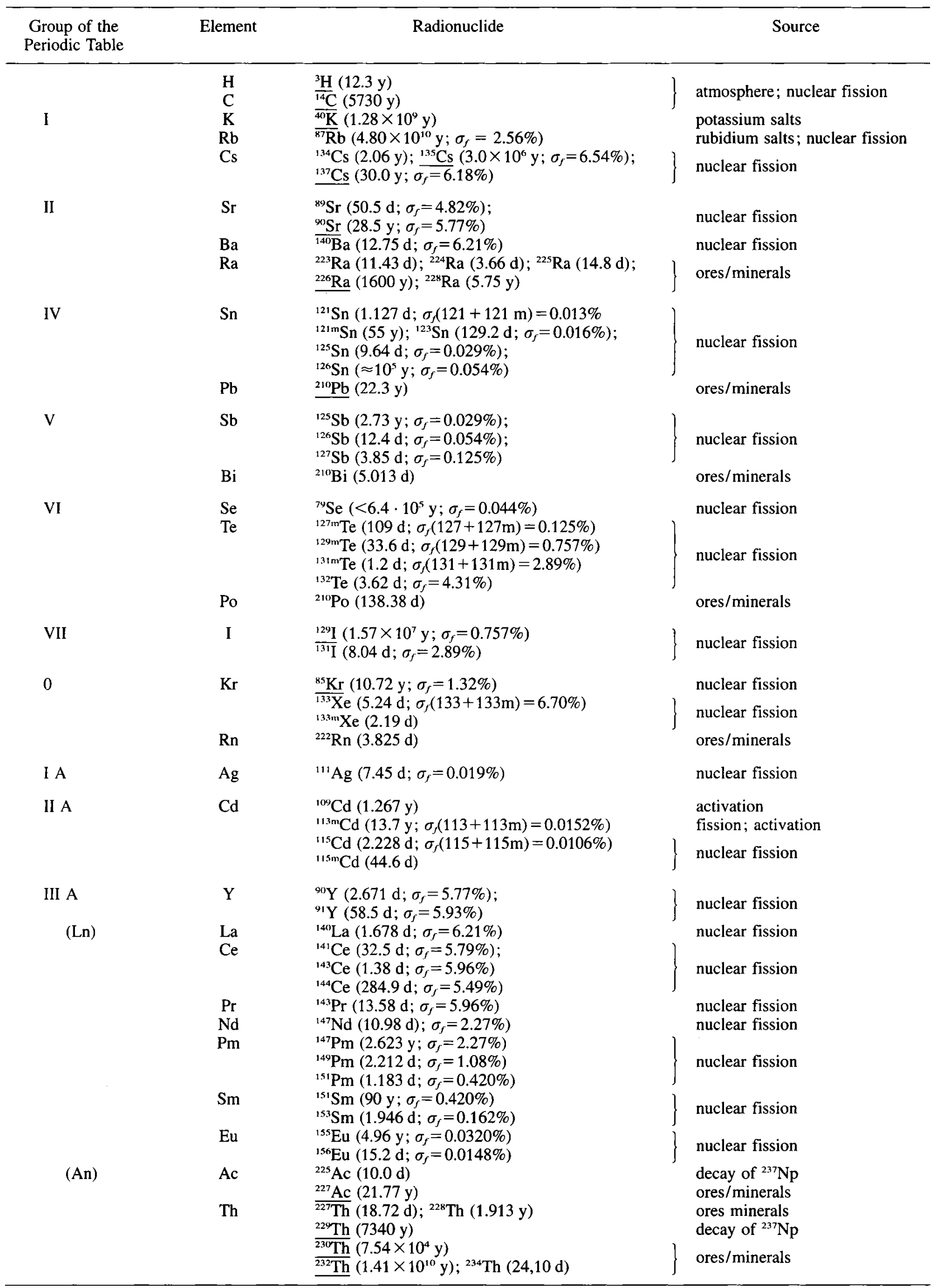


Table 1. (Continued)

\begin{tabular}{|c|c|c|c|}
\hline $\begin{array}{l}\text { Group of the } \\
\text { Periodic Table }\end{array}$ & Element & Radionuclide & Source \\
\hline & $\mathrm{Pa}$ & $\frac{{ }^{231} \mathrm{~Pa}}{{ }^{233} \mathrm{~Pa}}\left(3.276 \times 10^{4} \mathrm{y}\right)$ & $\begin{array}{l}\text { ores } / \text { minerals } \\
\text { decay of }{ }^{237} \mathrm{~Np}\end{array}$ \\
\hline & $\mathrm{U}$ & ${ }^{2.3} \mathrm{U}\left(1.592 \times 10^{5} \mathrm{y}\right)$ & decay of ${ }^{2.37} \mathrm{~Np}$ \\
\hline & & ${ }^{{ }^{234} \mathrm{U}}\left(2.45 \times 10^{5} \mathrm{y}\right) ;{ }^{2.35} \mathrm{U}\left(7.04 \times 10^{8} \mathrm{y}\right)$ & ores/minerals \\
\hline & & $\overline{{ }^{236} \mathrm{U}}\left(2.342 \times 10^{7} \mathrm{y}\right) ;{ }^{237} \mathrm{U}(6.75 \mathrm{~d})$ & nuclear reactors \\
\hline & & ${ }^{238} \mathrm{U}\left(4.468 \times 10^{9} \mathrm{y}\right)$ & ores/minerals \\
\hline & $\mathrm{Np}$ & $\overline{{ }^{236} \mathrm{~N}} p\left(1.55 \times 10^{5} \mathrm{y}\right)$ & nuclear reactors \\
\hline & & ${ }^{237} \mathrm{~Np}\left(2.140 \times 10^{6} \mathrm{y}\right) ;{ }^{238} \mathrm{~Np}(2.117 \mathrm{~d})$ & nuclear reactors \\
\hline & $\mathrm{Pu}$ & $\begin{array}{l}\frac{{ }^{239} \mathrm{Pu}}{2{ }^{241} \mathrm{Pu}}\left(2.411 \times 10^{4} \mathrm{y}\right) ;{ }^{240} \mathrm{Pu}(6560 \mathrm{y}) ;{ }^{242} \mathrm{Pu}\left(3.76 \times 10^{5} \mathrm{y}\right) \\
(3.76 \times 1\end{array}$ & nuclear reactors \\
\hline & Am & 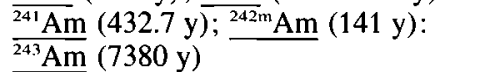 & nuclear reactors \\
\hline & $\mathrm{Cm}$ & ${ }^{242} \mathrm{Cm}(162.9 \mathrm{~d}) ;{ }^{243} \mathrm{Cm}(28.5 \mathrm{~d})$ & \\
\hline & & $\begin{array}{l}\frac{{ }^{244} \mathrm{Cm}}{{ }^{246} \mathrm{Cm}}(18.11 \mathrm{y}) ;{ }^{245} \mathrm{Cm}(8500 \mathrm{y}) \\
{ }^{248} \mathrm{Cm}\left(3.40 \times 10^{5} \mathrm{y}\right)\end{array}$ & nuclear reactors \\
\hline & $\mathrm{Bk}$ & ${ }^{249} \mathrm{Bk}(320 \mathrm{~d})$ & nuclear reactors \\
\hline & $\mathrm{Cf}$ & $\begin{array}{l}{ }^{249} \mathrm{Cf}\left(351 \mathrm{y} ;{ }^{250} \mathrm{Cf}(13.1 \mathrm{y})\right. \\
{ }^{251} \mathrm{Cf}(898 \mathrm{y}) ;{ }^{252} \mathrm{Cf}(2.64 \mathrm{y})\end{array}$ & nuclear reactors \\
\hline IV A & $\mathrm{Zr}$ & $\begin{array}{l}\frac{{ }^{93} \mathrm{Zr}}{}\left(1.5 \times 10^{\mathrm{6}} \mathrm{y} ; \sigma_{f}=6.38 \%\right) \\
{ }^{99} \mathrm{Zr}\left(64.02 \mathrm{~d} ; \sigma_{f}=6.52 \%\right)\end{array}$ & $\begin{array}{l}\text { fission + activation } \\
\text { nuclear fission }\end{array}$ \\
\hline \multirow[t]{2}{*}{ V A } & $\mathrm{Nb}$ & ${ }^{94} \mathrm{Nb}\left(2.0 \times 10^{4} \mathrm{y}\right)$ & activation \\
\hline & & $\begin{array}{l}{ }^{95} \mathrm{Nb}\left(34.97 \mathrm{~d} ; \sigma_{f}(95+95 \mathrm{~m})=6.52 \%\right) \\
{ }_{9.5 \mathrm{~m}} \mathrm{Nb}(3.61 \mathrm{~d})\end{array}$ & nuclear fission \\
\hline VI A & Mo & ${ }^{99} \mathrm{Mo}\left(2.748 \mathrm{~d} ; \sigma_{f}=6.07 \%\right)$ & nuclear fission \\
\hline \multirow[t]{2}{*}{ VII A } & $\mathrm{Tc}$ & ${ }^{99} \mathrm{Tc}\left(2.13 \times 10^{5} \mathrm{y} ; \sigma_{f}=6.07 \%\right)$ & nuclear fission \\
\hline & $\operatorname{Re}$ & ${ }^{187} \operatorname{Re}\left(5 \times 10^{16} y\right)$ & rhenium compounds \\
\hline \multirow{6}{*}{ VIII A } & $\mathrm{Fe}$ & ${ }^{55} \mathrm{Fe}(2.73 \mathrm{y})$ & activation \\
\hline & Co & ${ }^{60} \mathrm{Co}(5.271 \mathrm{y})$ & activation \\
\hline & $\mathrm{Ni}$ & ${ }^{59} \mathrm{Ni}\left(7.5 \times 10^{4} \mathrm{y}\right) ;{ }^{6.3} \mathrm{Ni}(100 \mathrm{y})$ & activation \\
\hline & $\mathrm{Ru}$ & $\begin{array}{l}{ }_{10.3} \mathrm{Ru}\left(39.25 \mathrm{~d} ; \sigma_{f}=\overline{3.03 \%} \%\right) \\
{ }^{106} \mathrm{Ru}\left(1.020 \mathrm{y} ; \sigma_{f}=0.402 \%\right)\end{array}$ & nuclear fission \\
\hline & Rh & ${ }^{10.5} \mathrm{Rh}\left(1.473 \mathrm{~d} ; \sigma_{f}=0.969 \%\right)$ & nuclear fission \\
\hline & $\mathrm{Pd}$ & ${ }^{107} \mathrm{Pd}\left(6.5 \times 10^{6} \mathrm{y} ; \sigma_{f}=0.147 \%\right)$ & nuclear fission \\
\hline
\end{tabular}

tremely long half-lifes $\left(>10^{11} \mathrm{y}\right)$ and radionuclides with fission yields $<0.01 \%$ are not taken into account; radioisotopes of the elements $81-92$ not being members of the decay series of ${ }^{232} \mathrm{Th},{ }^{235} \mathrm{U}$ and ${ }^{238} \mathrm{U}$ and radionuclides produced for medical or technical purposes by activation are not considered. The radionuclides are arranged according to the position of the elements in the Periodic Table, in order to facilitate the discussion of their chemical behaviour. Radionuclides with half-lives $>10 \mathrm{y}$ that are present in relatively high concentrations are underlined, because their behaviour over long periods of time, in particular their migration behaviour during storage in nuclear waste repositories, is of great importance.

With respect to radiation doses and possible hazards, the local concentrations and the radiotoxicities of the radionuclides have to be taken into account. Local concentrations of fission products and transuranium elements are high in anthropogenic sources, like nuclear reactors, reprocessing plants and high-active waste (HAW). Local concentrations of radionuclides are also high in natural sources, like ores of $\mathrm{U}$ or Th. On the other hand, local concentrations are, in general, low in case of fall-out (with the exception of the region of the Chernobyl accident) and off-gas and effluents of nuclear installations. They are also low for dispersed naturally occurring radionuclides, like ${ }^{3} \mathrm{H},{ }^{14} \mathrm{C}$, and the other wide-spread natural sources containing $\mathrm{K}$, $\mathrm{U}$ or Th and daughters in low concentrations. The radiotoxicity of ${ }^{3} \mathrm{H},{ }^{14} \mathrm{C}$ and ${ }^{40} \mathrm{~K}$ is also low, whereas it is high for many fission products and for the actinides.

\section{Mobility of radionuclides}

\subsection{General aspects}

Mobility of radionuclides is the most important aspect in discussing the behaviour of radionuclides in the geosphere. Gaseous species, aerosols and species dissolved in aquifers are mobile and easily transported with air or water. Solids, however, must be dissolved to become mobile. Therefore, if solid forms of radionuclides are taken into account, mobility depends on solubility and dissolution (leaching). Dissolution and dispersal, respectively, are prerequisites of mobility. 
Solubility depends on the nature and the properties of the solid compound containing the radionuclide and on the properties of the solvent, in general water in which various components are dissolved. In the solid, the radionuclide may be present as a macrocomponent or as a microcomponent, and the solubility may vary considerably with the composition. Besides, solubility increases with decreasing size and increasing degree of disorder of the solid particles. Eh, $\mathrm{pH}$ and complexing agents may be of significant influence on solubility, and the effects of radiation can not be neglected. Consequently, many investigations are devoted to the problems of solubility and leaching, respectively [3, $6-11]$. It should also be mentioned that even for pure and well-defined compounds, like $\mathrm{SrSO}_{4}, \mathrm{PbSO}_{4}$ or $\mathrm{AgI}$, solubility is only in a restricted range given by the solubility product and solubility of neutral particles and of complexes has to be taken into account [1217]. Furthermore, in case of solid solutions (mixed crystals) the solubility of the components is different from that of the pure compounds $[18,19]$.

With respect to mobility of radionuclides in the geosphere, five compartments may be distinguished, as illustrated schematically in Fig. 1.

All radionuclides on the surface of the earth (compartment 1) and in the atmosphere (compartment 2) have easy access to the biosphere. From surface waters as well as from near-surface groundwaters, from soils and from the air radionuclides may be taken up by microorganisms, plants, fish and other animals, thus also entering the various pathways of the food chain. As a measure of the relative amounts of radionuclides transferred to living things and to the food chain transfer factors are used. They depend on the chemical properties and the chemical form of the radionuclide considered, the kind of microorganism, plant or animal and their metabolism and may differ by several orders of magnitude for the various chemical and biological species. Some radionuclides are enriched in certain plants and organs of animals and man, whereas others are released again rather early. The study of the behaviour of radionuclides in the biosphere, in particular their transfer to the human body and their metabolism in man, is the field of radioecology and will not be considered in this article.

\subsection{Surface of the earth (compartment 1)}

Compartment 1 comprises the surface of the earth, surface waters, including lakes and oceans. The inventory of radionuclides in this compartment is mobile, provided that the species are soluble in water. The relevant radionuclides are mainly of natural origin [2030]. ${ }^{40} \mathrm{~K}$ is widely distributed in nature and easily soluble in form of $\mathrm{K}^{+}$-ions, which are enriched in clay minerals by sorption. Th present as a minor or major component in minerals is immobile, because the chemical species of $\mathrm{Th}(\mathrm{IV})$ are very sparingly soluble in natural waters. However, some of the transmutation

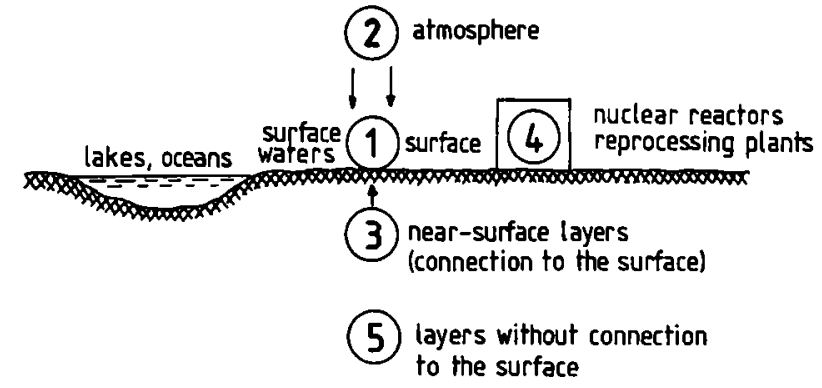

Fig. 1. Compartments of radionuclides in the geosphere.

products, like ${ }^{228} \mathrm{Ra},{ }^{224} \mathrm{Ra}$ and ${ }^{220} \mathrm{Rn}$, are mobile. In contrast to Th(IV), U(IV) is oxidized by air to U(VI) and easily soluble in natural waters containing carbonate or hydrogen carbonate, respectively. The triscarbonato complex $\left[\mathrm{UO}_{2}\left(\mathrm{CO}_{3}\right)_{3}\right]^{4-}$ is found in all rivers, lakes and oceans in concentrations of the order of $10^{-6}$ to $10^{-5} \mathrm{~g} / \mathrm{l}$. The daughters of ${ }^{238} \mathrm{U}$, the long-lived ${ }^{226} \mathrm{Ra}$ and ${ }^{222} \mathrm{Rn}$ are also mobile. ${ }^{226} \mathrm{Ra}$ is found in relatively high concentrations at salt water spas, and ${ }^{222} \mathrm{Rn}$ contributes considerably to the radioactivity in the air. ${ }^{222} \mathrm{Rn}$ and the daughters ${ }^{218} \mathrm{Po},{ }^{214} \mathrm{~Pb},{ }^{214} \mathrm{Bi},{ }^{214} \mathrm{Po},{ }^{210} \mathrm{~Pb}$, ${ }^{210} \mathrm{Bi}$ and ${ }^{210} \mathrm{Po}$ are the major sources of the radioactive dose received by man under normal conditions.

Additional radionuclides are brought into compartment 1 from the compartments 2,3 and 4, and their mobility depends on the chemical form (i.e. the species) and the solubility. Radionuclides set free on the earth's surface from nuclear installations, by nuclear explosions and by nuclear weapon tests will be considered in more detail in section 3.5.

\subsection{Atmosphere (compartment 2)}

In the atmosphere the radionuclides ${ }^{3} \mathrm{H}(\mathrm{T})$ and ${ }^{14} \mathrm{C}$ are generated continuously by nuclear reactions of the neutron component of cosmic radiation with nitrogen in the upper layers of the atmosphere [31-35]. The most important reactions are ${ }^{14} \mathrm{~N}\left(\mathrm{n},{ }^{3} \mathrm{H}\right){ }^{12} \mathrm{C}$ and ${ }^{14} \mathrm{~N}(\mathrm{n}, \mathrm{p}){ }^{14} \mathrm{C}$. $\mathrm{T}$ is also produced by spallation of heavier nuclides. Both radionuclides are mobile. $\mathrm{T}$ is transformed into tritiated water (HTO) and enters the water cycle [36], whereas ${ }^{14} \mathrm{C}$ is predominantly transformed into ${ }^{14} \mathrm{CO}_{2}$ and takes part in the $\mathrm{CO}_{2}$ cycle. The natural concentration of $\mathrm{T}$ in the air is about $1.8 \times 10^{-3}$ $\mathrm{Bq} \mathrm{m}{ }^{-3}$ and that of ${ }^{14} \mathrm{C}$ about $5 \times 10^{-4} \mathrm{~Bq} \mathrm{~m}^{-3}$.

Other radionuclides are emitted from the earth's surface into the atmosphere. The most important radionuclide is ${ }^{222} \mathrm{Rn}$ which will be discussed in more detail in section 3.4. The decay products of ${ }^{222} \mathrm{Rn}$ as well as radionuclides released from nuclear installations into the air are mainly found in form of radioactive aerosols [37].

\subsection{Near-surface layers (compartment 3 )}

From the layers with connection to the surface of the earth (compartment 3 ) radionuclides are brought to the 
surface (compartment 1) by natural processes and by human activities. From a few places ${ }^{222} \mathrm{Rn}$ is able to escape through crevises. Ions, like $\mathrm{Ra}^{2+}$ or $\mathrm{UO}_{2}^{2+}$ are leached from ores or minerals by groundwater and may enter the surface. Volcanic activities are also bringing up radionuclides to the surface, where they may be leached and enter the water cycle.

Mining of uranium ores and of other ores and minerals (e.g. phosphates) has brought up appreciable amounts of $U$, Th and the members of their transmutation series to the surface [21] and initiated mobilization of relevant radionuclides. Large amounts of $\mathrm{Rn}$ are released into the air. The residues of mining and processing operations are stockpiled and the slag heaps as well as the waste waters cause considerable problems. The isotopes of Ra continue to emit Rn. Thus, about $1 \mathrm{GBq}$ of ${ }^{222} \mathrm{Rn}$ are released per ton of ore containing $1 \% \mathrm{U}_{3} \mathrm{O}_{8} . \mathrm{Ra}$ and its daughters are migrating to natural oil and gas reservoirs and constitute the major radioactive contaminants of crude oil. The global activity of $\mathrm{Ra}$ isotopes brought up to the surface by the production of oil is of the order of $10 \mathrm{TBq}$ per year. Mining of potassium salt deposits for use of $\mathrm{K}$ as fertilizer brings additional amounts of ${ }^{40} \mathrm{~K}$ to the surface of the earth, where it is leached and enters the surface waters.

Radionuclides are also set free by the burning of coal in thermal power stations [38]. Depending on the origin, coal contains various amounts of $U$ and $T h$, and these as well as the daughters are released by combustion. Volatile species, in particular $\mathrm{Rn}$, are emitted with the waste gas, ${ }^{210} \mathrm{~Pb}$ and ${ }^{210} \mathrm{Po}$ are emitted with the fly ash, and the rest, including $U$ and $T h$, is found in the ash. The global release of $\mathrm{Rn}$ is of the order of $10^{14} \mathrm{~Bq}$ per year.

Other activities of man have led to the distribution of appreciable amounts of radionuclides in the atmosphere and on the earth's surface. In the first place nuclear explosions and nuclear weapon tests have to be mentioned, by which $\mathrm{Pu}$ and fission products have been deposited, either directly in the ground or via the atmosphere in the form of fall-out. The amount of $\mathrm{Pu}$ released by nuclear weapon tests between 1958 and 1981 is estimated at 4.2 tons, of which 2.8 tons were dispersed in the atmosphere and 1.4 tons disposed locally. By underground nuclear explosions about 1.5 tons of Pu have been set free.

\subsection{Nuclear installations (compartment 4)}

Nuclear reactors and reprocessing plants (compartment 4) are constructed in such a way that the radioactive inventory is confined to certain places and carefully shielded. Only limited amounts of radionuclides are allowed to enter the environment [39-44].

$\mathrm{T}$ and ${ }^{14} \mathrm{C}$ are produced in nuclear reactors by the reactions ${ }^{2} \mathrm{H}(\mathrm{n}, \gamma)^{3} \mathrm{H},{ }^{10} \mathrm{~B}(\mathrm{n}, 2 \alpha)^{3} \mathrm{H},{ }^{17} \mathrm{O}(\mathrm{n}, \alpha){ }^{14} \mathrm{C}$, ${ }^{14} \mathrm{~N}(\mathrm{n}, \mathrm{p}){ }^{14} \mathrm{C}$ and ${ }^{13} \mathrm{C}(\mathrm{n}, \gamma){ }^{14} \mathrm{C}$, respectively. The amounts vary with the type of the reactors: between about $10^{12}$ and $10^{13} \mathrm{~Bq}$ of $\mathrm{T}$ and about $10^{12} \mathrm{~Bq}$ of ${ }^{14} \mathrm{C}$ per $\mathrm{GWe}$ per year. T is released as $\mathrm{HTO}$ and about one third of the ${ }^{14} \mathrm{C}$ is released in form of ${ }^{14} \mathrm{CO}_{2}$.

Under normal operation conditions, very small amounts of fission products are set free from nuclear reactors and reprocessing plants, and strong regulations have been established to ensure that the safety limits are not exceeded. Of greatest importance are the actinides and the long-lived fission products, such as ${ }^{90} \mathrm{Sr},{ }^{99} \mathrm{Tc},{ }^{129} \mathrm{I}$, and ${ }^{137} \mathrm{Cs}$. These radionuclides are released in small amounts, mainly from low-active waste (LAW) streams (e.g. ${ }^{99} \mathrm{TcO}_{4}^{-}$) or as gases (e.g. organic compounds of ${ }^{129} \mathrm{I}$ and ${ }^{131} \mathrm{I}$, respectively, from nuclear reactors or reprocessing plants, and ${ }^{99} \mathrm{TcF}_{6}$ in the course of ${ }^{235} \mathrm{UF}_{6} /{ }^{238} \mathrm{UF}_{6}$ isotope separation). ${ }^{99} \mathrm{Tc}$ is found in practically all stages of reprocessing $[45,46]$ and released in small, but measurable amounts into the sea. ${ }^{129} \mathrm{I}$ is separated from the off-gas of reprocessing plants, mainly in form of $\mathrm{Ag}^{129} \mathrm{I}$. From this compound it is liberated very slowly by radiolytic decomposition [47].

Despite the safety regulations, accidents occurred with nuclear reactors and reprocessing plants, primarily due to mistakes of the operators. By these accidents parts of the inventory of compartment 4 have entered compartment 1 , either directly or via the atmosphere (compartment 2). Mainly gaseous fission products and aerosols have been emitted, but solutions have also been given off. The most severe accident was that at Chernobyl in 1986 [48-54]. Gaseous fission products and aerosols have been transported through the air over great distances [55]. Even molten particles from the reactor core ("hot particles") have been carried with the air over distances of several hundred kilometers.

The behaviour of the radionuclides on the surface of the earth depends primarily on their chemical and physico-chemical form (species) and the solubility, as already mentioned. The degree of dispersal is different (compact solids, coarse particles, fine particles, molecules), and the solubilities vary considerably. In water, the radionuclides may be present in form of suspended matter, colloids, free ions or molecules. Therefore, chemical speciation is of great importance $[3,56,57]$. The formation of radiocolloids has found particular interest $[3,58-66]$. General statements with respect to the mobility can be made on the basis of the properties of the elements [67-70]:

Alkali and alkaline earth ions, such as ${ }^{137} \mathrm{Cs}^{+}$or ${ }^{90} \mathrm{Sr}^{2+}$ are easily dissolved in water, independent of $\mathrm{pH}$, and considered to be mobile species. However, their solubility is restricted and their mobility is limited, if they are incorporated into ceramics or glass or bound in clay minerals. The solubility of the alkaline earth sulfates decreases in the order $\mathrm{SrSO}_{4}>\mathrm{BaSO}_{4}>\mathrm{RaSO}_{4}$, but the solubility product is, in general, not reached. ${ }^{129}$ I forms rather mobile species and reacts easily with organic substances. ${ }^{85} \mathrm{Kr}$ and ${ }^{133} \mathrm{Xe}$ remain predominantly in the air. 
The lanthanides, e.g. ${ }^{144} \mathrm{Ce},{ }^{147} \mathrm{Pm},{ }^{151} \mathrm{Sm}$, are not soluble in water under normal conditions, because of hydrolysis of the $\mathrm{Ln}^{3+}$ cations. However, colloids may be formed, either intrinsic colloids with lanthanides as main components, if their concentration is high enough, or carrier colloids with natural colloids as main components on which the lanthanides are sorbed. Complexes with organic substances may also be formed, in particular with humic substances.

The solubility of the actinides in the oxidation states +3 and +4 is similar to that of the lanthanides, and hydrolysis is more pronounced in case of An(IV). On the other hand, the dioxocations $\mathrm{AnO}_{2}^{+}$and $\mathrm{AnO}_{2}^{2+}$ exhibit relatively high solubility in water in presence of carbonate or hydrogen carbonate, as already mentioned for $\mathrm{UO}_{2}^{2+}$. Consequently, the actinides may show rather high mobility, provided that they are able to form dioxocations, that the redox potential is high enough (aerobic conditions), and that the water contains $\mathrm{HCO}_{3}^{-}$ions in sufficiently high concentrations.

The behaviour of $\mathrm{Zr}(\mathrm{IV}), \mathrm{Nb}$ (IV) and $\mathrm{Tc}(\mathrm{IV})$ is comparable to that of An(IV). The influence of the redox potential is very pronounced in case of $\mathrm{Tc}$ : Whereas Tc(IV) is not dissolved in water and immobile, $\mathrm{Tc}(\mathrm{VII})$ is easily dissolved as $\mathrm{TcO}_{4}^{-}$and very mobile.

\subsection{Layers without connection to the surface (compartment 5)}

Compartment 5 (Fig. 1) comprises all radionuclides in deposits deep under the earth's surface, inaccessible to water and without connection to the surface. Large amounts of ores and minerals with considerable contents of $\mathrm{U}$, Th and their daughters are buried in this compartment. The radionuclides can be considered to be immobile as long as they are not brought up to the surface by geological activities or by man and as long as the contact with water is excluded [43].

The conception with respect to the radioactive waste produced in the shielded compartment 4 (nuclear reactors and reprocessing plants, respectively) is to bring this waste down into compartment 5 in order to confine it there safely for long periods of time. Safety discussions are based on the scenario that water may enter the waste deposits, that the waste containers corrode, that the waste is leached and the radionuclides are set free [43]. The most important step of this scenario is the dissolution of the high-active waste (HAW) by groundwater. In addition, some radionuclides, e.g. ${ }^{129} \mathrm{I}$, may be liberated in form of volatile species [47].

As far as the mobility of radionuclides in the geosphere over long periods of time is concerned, investigations of the natural deposits of $\mathrm{U}$ and $\mathrm{Th}$ and of the natural reactors at Oklo are of great importance [3, 43, 71]. The reactors at Oklo have been in operation about two billion years ago $[72,73]$. Due to the fission of ${ }^{235} \mathrm{U}$, the relative concentration of this isotope of $\mathrm{U}$ is lower than at other places, whereas the relative concentrations of the stable end products of the fission chains are higher, and spreading of the nuclides from their original location in the course of time gives information about their migration behaviour.

\section{Reactions of radionuclides with the components of natural waters}

\subsection{General aspects}

In aqueous solution, the vast majority of the radionuclides listed in Table 1 is present in cationic forms, and the following chemical reactions have to be taken into account:

a) Hydration: By ion-dipole interaction aquo complexes are formed: $\mathrm{M}^{n+}-\stackrel{(\delta-)}{-} \mathrm{O}_{\mathrm{H}^{(\delta+)}}^{-\mathrm{H}^{(\delta+)}}$. The energy of hydration increases with decreasing ionic radius and with increasing positive charge of the cations. Thus, the energy of hydration is low for $\mathrm{Cs}^{+}$and high for $\mathrm{Th}^{4+}$.

b) Hydrolysis: If the charge of the cations is high $(n>2)$, the repulsion of the protons by the cations may lead to the formation of hydroxo complexes:

$$
\mathrm{M}^{n+}---\mathrm{O}_{\mathrm{H}}^{-\mathrm{H}} \rightleftharpoons(\mathrm{M}-\mathrm{OH})^{(n-1)+}+\mathrm{H}^{+} \text {. }
$$

(Additional water molecules are omitted.) As it is evident from Eq. (1), hydrolysis depends strongly on $\mathrm{pH}$. The repulsion and, consequently, hydrolysis increase with the charge of the cations, and hydrolysis is very pronounced in case of $\mathrm{Pa}^{5+}$. Hydrolysis increases also with decreasing ionic radius of the cations.

c) Condensation: Polynuclear complexes are formed by condensation reactions, like

$$
2(\mathrm{M}-\mathrm{OH})^{(n-1)+} \rightleftharpoons(\mathrm{M}-\mathrm{O}-\mathrm{M})^{2(n-1)+}+\mathrm{H}_{2} \mathrm{O}
$$

and subsequent condensation reactions. (Additional water molecules are omitted.) The driving force of this kind of reaction is the formation of the predominantly covalent $\mathrm{M}-\mathrm{O}-\mathrm{M}$ bonds and of one molecule of water. This type of reaction is not only observed with hydroxo complexes of the same metal $\mathrm{M}$, but it takes also place with mononuclear or polynuclear hydroxo complexes of other elements (e.g. polynuclear iron(III) hydroxide), with silicic or polysilicic acid and with colloids carrying hydroxyl groups:

$$
\begin{aligned}
(\mathrm{M}(1))_{m}-\mathrm{OH} & +\mathrm{HO}-\mathrm{M}(2) \\
& \rightleftharpoons(\mathrm{M}(1))_{m}-\mathrm{O}-\mathrm{M}(2)+\mathrm{H}_{2} \mathrm{O} .
\end{aligned}
$$

( $m$ indicates the polynuclear nature of the hydroxo complex; charges and additional water molecules are omitted.)

Anions compete with the formation of aquo and hydroxo complexes, depending on their concentration: 


$$
\begin{aligned}
\mathrm{M}^{n+}\left(\mathrm{H}_{2} \mathrm{O}\right)_{m} & +\mathrm{X}^{-} \\
& \rightleftharpoons \mathrm{MX}^{(n-1)+}\left(\mathrm{H}_{2} \mathrm{O}\right)_{m-1}+\mathrm{H}_{2} \mathrm{O}
\end{aligned}
$$

and

$$
(\mathrm{M}-\mathrm{OH})^{(n-1)+}+\mathrm{X}^{-} \rightleftharpoons \mathrm{MX}^{(n-1)+}+\mathrm{OH}^{-} .
$$

(Water molecules are omitted in Eq. (5).)

In case of cations of transition elements (groups IA to VIIIA in Table 1) the possibility of formation of relatively strong covalent bonds with ligands containing donor atoms has to be considered.

With anionic forms of radionuclides, such as ${ }^{129} I^{-}$ or ${ }^{99} \mathrm{TcO}_{4}^{-}$, these kinds of reactions do not apply.

Various species of radionuclides are formed by interaction with the components of natural waters. Groundwaters, rivers, lakes and the oceans contain a great variety of substances. Besides the main component water, other inorganic components have to be considered:

- Dissolved gases, like oxygen and carbon dioxide, which influence the redox potential Eh and the $\mathrm{pH}$ of the water;

- salts, like $\mathrm{NaCl}, \mathrm{NaHCO}_{3}$ and many others which affect $\mathrm{pH}$ and complexation and are responsible for the ionic strength;

- inorganic colloids, like polysilicic acid, iron oxides/hydroxides and finely dispersed clay min-. erals;

- inorganic suspended matter (i.e. coarse particles, only found in agitated water).

Organic components comprise:

- Compounds of low molecular mass, like organic acids, amines, amino acids and other metabolites;

- compounds of high molecular mass, like humic and fulvic acids, and colloids formed by these substances or by other degradation products of organic matter;

- suspended coarse particles of organic matter;

- microorganisms.

The concentrations of these compounds in natural waters vary over a wide range. Coarse particles are observed only in agitated waters and settle down as soon as agitation decreases or stops. Even though many of the components listed above may be present in rather low concentrations (microcomponents), their concentration is often many orders of magnitude higher than that of the radionuclides in question, and they can therefore not be neglected.

The aspect of very low concentration is of special importance for short-lived isotopes of radioelements, the concentration of which is, in general, extremely low, and the behaviour of single atoms has to be considered [74-76]. In case of radioisotopes of stable elements, on the other hand, the ubiquitous presence of these elements leads to measurable concentrations of the elements with the consequence that these radioisotopes show the normal behaviour of trace elements.

Due to the large number of components, natural waters are rather complex systems. The relative con- centrations of many components, as well as $\mathrm{pH}$ and Eh, are controlled by chemical equilibria. However, there are also components, in particular the colloids and the microorganisms, for which thermodynamic equilibrium conditions are not applicable. The complexity of the chemistry in natural waters and the nonapplicability of thermodynamics to various components are the main reasons for the fact that calculations are very difficult and problematic. The same holds for laboratory experiments with model waters. Results obtained for a special kind of water are, in general, not applicable for other natural waters of different origin.

The species of the radionuclides present in natural waters can be characterized by the chemical form and the physico-chemical state (e.g. free ions, complexes, intrinsic colloids ("Eigenkolloide"), carrier colloids ("Fremdkolloide") and speciation of radionuclides has become an important branch of radiochemistry $[3,57$, 77-95].

The species of the actinides are of special interest. General aspects of speciation and results obtained for trace elements in aqueous systems are also applicable [96-116]. Eh-pH-diagrams [117, 118] give information about the ranges of stability of oxidation states and hydroxo complexes.

A great number of data have been calculated with respect to the chemical form of radionuclides in aquatic systems [3], but the general applicability of these data is limited, due to the reasons mentioned above.

\subsection{Redox potential and $\mathrm{pH}$}

The redox potential Eh (aerobic or anaerobic conditions) is of great influence on the behaviour of radionuclides in geomedia, if different oxidation states have to be taken into account. In this context, the concentrations of oxygen and hydrogen sulfide are significant. The presence of oxygen in natural waters is due to the access of air, whereas that of hydrogen sulfide may be due to weathering of sulfidic minerals or to decomposition of organic compounds. The redox potential $\mathrm{Eh}$ is of special importance for the behaviour of I, U, Np, Pu, and Tc [83-85, 90, 119-121]. Elemental iodine is volatile and reacts with organic compounds, in contrast to $\mathrm{I}^{-}$ions. U(IV) does not form soluble species in natural waters, in contrast to U(VI). Therefore, U(IV) is dissolved under aerobic conditions after oxidation to $\mathrm{UO}_{2}^{2+}$. The latter is reduced again, if the water enters a reducing zone, and redeposited as $\mathrm{UO}_{2}$. The most important feature of $\mathrm{Np}$ in water is the great range of stability of $\mathrm{Np}(\mathrm{V})$ in form of $\mathrm{NpO}_{2}^{+}$, and in this respect $\mathrm{Np}$ differs markedly from the neighbouring elements $\mathrm{U}$ and $\mathrm{Pu}$. Under reducing conditions, $\mathrm{Np}(\mathrm{IV})$ is stable which resembles U(IV) and $\mathrm{Pu}(\mathrm{IV})$. The chemical form of Tc depends also on the redox potential. Under anaerobic conditions, the stable oxidation state is $+4\left(\mathrm{TcO}_{2}, \mathrm{TcO}(\mathrm{OH})_{2}\right)$, and under aerobic conditions $\mathrm{Tc}$ is easily oxidized to $\mathrm{TcO}_{4}^{-}$. This 
anionic form of $\mathrm{Tc}$ shows very different behaviour and has a high tendency to react with proteins [122]. In presence of $\mathrm{H}_{2} \mathrm{~S}$, sparingly soluble sulfides may be formed with elements of groups IV $(\mathrm{Pb}), \mathrm{V}(\mathrm{Sb}, \mathrm{Bi})$, IA ( $\mathrm{Ag})$, IIA (Cd), VIA (Mo), VIIA (Tc), and VIIIA $(\mathrm{Fe}, \mathrm{Co}, \mathrm{Ni})$.

In natural waters $\mathrm{pH}$ varies between about 6 and 8 and influences the chemical behaviour of elements that are sensible to hydrolysis, i.e. elements of groups III, IIIA, IV, IVA, V, VA and VIIIA of the Periodic Table [123-125]. Relevant radionuclides belong mainly to the groups of the lanthanides and the actinides. The tendency of the actinides to hydrolyze increases in the order $\mathrm{MO}_{2}^{+}<\mathrm{M}^{3+}<\mathrm{MO}_{2}^{2+}<\mathrm{M}^{4+}$. As already mentioned in section 4.1, formation of complexes with various inorganic and organic ligands present in natural waters competes with the formation of hydroxo complexes, with the consequence that those complexes are formed that exhibit the highest stability under the given conditions. Whether polynuclear hydroxo complexes are formed by condensation of mononuclear hydroxo complexes of the same kind according to Eq. (2) or by condensation with reactive species of other origin according to Eq. (3) depends on the relative concentrations of the mononuclear hydroxo complexes of the element considered and that of reactive species of other origin. Accordingly, either intrinsic colloids ("Eigenkolloide") or carrier colloids ("Fremdkolloide") may be formed [65, 114]. Reactive species with respect to formation of carrier colloids have already been mentioned in section 4.1 : polysilicic acid, iron(III) oxide/hydroxide and finely dispersed (colloidal) clay particles. Due to hydrolysis and interaction of hydroxo complexes with other components, actinides are not found as monomeric species in natural waters in absence of complexing agents, whereas in presence of carbonate or hydrogen carbonate, respectively, monomeric carbonato complexes prevail.

\subsection{Inorganic salts}

Inorganic salts affect the behaviour of radionuclides in natural waters in various ways. At high salinity (high ionic strength) formation of colloids is hindered and colloids already present are coagulated, if salt water enters the system. Thus precipitation of colloids carried by rivers occurs in a large scale in the estuaries. Further, dissolved salts influence $\mathrm{pH}$, hydrolysis and complexation [126]. They may act as buffers, e.g. in seawater, where $\mathrm{pH}$ is kept constant at about 8.2 by the presence of $\mathrm{NaHCO}_{3}$. Finally, the anions in natural waters form ion pairs and stable complexes with cationic radionuclides and affect solubility, colloid formation and sorption behaviour. Mobility may be enhanced by complexation [127]. $\mathrm{Cl}^{-}$ions are weak complexing agents, but they are able to substitute $\mathrm{OH}^{-}$ ions in hydroxo complexes and to suppress hydrolysis. $\mathrm{HCO}_{3}^{-}$ions are also found in significant quantities in natural waters, particularly in seawater, and form

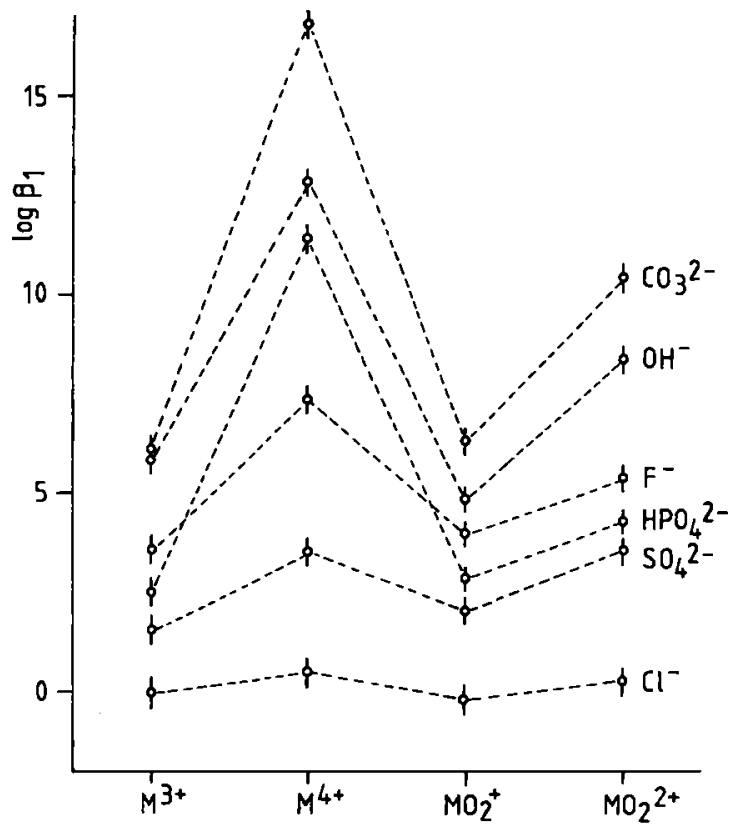

Fig. 2. Logarithms of the stability constants $\beta_{1}$ for the formation of $1: 1$ complexes of the actinide ions $\mathrm{M}^{3+}, \mathrm{M}^{4+}, \mathrm{MO}_{2}^{+}$and $\mathrm{MO}_{2}^{2+}$ with various anions $[67,68]$.

rather stable carbonato and hydrogen carbonato complexes, as already mentioned for $\mathrm{UO}_{2}^{2+}$ ions. Complexation constants are known for the alkaline earth ions, lanthanides and actinides [3, 128, 129]. Dissolution of $\mathrm{CaCO}_{3}$ in groundwater by formation of the hydrogen carbonato complex $\mathrm{Ca}\left(\mathrm{HCO}_{3}\right)_{2}$ in presence of $\mathrm{CO}_{2}$ is responsible for the hardness of water and the transport of $\mathrm{Ca}^{2+} \cdot \mathrm{Sr}^{2+}$ ions show similar behaviour. The carbonato complexes of the lanthanides and the actinides are more stable than the complexes formed with sulfate and fluoride. Carbonato complexes may also stabilize oxidation states. The logarithms of the stability constants for the formation of $1: 1$ complexes of the actinide ions $\mathrm{M}^{3+}, \mathrm{M}^{4+}, \mathrm{MO}_{2}^{+}$and $\mathrm{MO}_{2}^{2+}$ with various inorganic ligands are plotted in Fig. 2.

Quite a number of carbonato, hydrogen carbonato and mixed hydroxo/carbonato complexes are reported in the literature for lanthanides and actinides [129]. Examples for the oxidation state +3 are: $\mathrm{CeCO}_{3}^{+}$, $\mathrm{Ce}\left(\mathrm{CO}_{3}\right)_{2}^{-}, \mathrm{Ce}\left(\mathrm{CO}_{3}\right)_{3}^{3-}, \quad \mathrm{AmHCO} \mathrm{CO}_{3}^{2+}, \mathrm{Am}\left(\mathrm{HCO}_{3}\right)_{2}^{+}$, $\mathrm{AmCO}_{3}^{+}, \mathrm{Am}\left(\mathrm{CO}_{3}\right)_{2}^{-}, \mathrm{Am}\left(\mathrm{CO}_{3}\right)_{3}^{3-}, \mathrm{AmOH}\left(\mathrm{CO}_{3}\right)_{2}^{2-}$; for the oxidation state $+4: \mathrm{PuCO}_{3}^{2+}, \mathrm{Pu}\left(\mathrm{CO}_{3}\right)_{3}^{2-}$, $\mathrm{Pu}\left(\mathrm{CO}_{3}\right)_{4}^{4-}, \mathrm{U}\left(\mathrm{CO}_{3}\right)_{5}^{6-}, \mathrm{Pu}\left(\mathrm{CO}_{3}\right)_{5}^{6-}, \mathrm{PuOHCO}_{3}^{+}$; for the oxidation state $(\mathrm{V}): \mathrm{NpO}_{2} \mathrm{CO}_{3}^{-}, \mathrm{NpO}_{2}\left(\mathrm{CO}_{3}\right)_{2}^{3-}$, $\mathrm{NpO}_{2}\left(\mathrm{CO}_{3}\right)_{3}^{5-}$; for the oxidation state (VI): $\mathrm{UO}_{2}\left(\mathrm{CO}_{3}\right)_{2}^{2-}, \mathrm{UO}_{2}\left(\mathrm{CO}_{3}\right)_{3}^{4-}$.

\subsection{Inorganic colloids}

The interest in the migration behaviour of radionuclides in the geosphere led to a revival of colloid chemistry of inorganic compounds [3, 65, 130-136]. Formation of intrinsic colloids ("Eigenkolloide") in natural waters can be excluded for radioisotopes of el- 
ements of groups 0, I and VII, and the probability that they may be formed is small for radioisotopes of elements of other groups as long as the concentration of the elements is low. Therefore, only carrier colloids ("Fremdkolloide") are considered in this section. Radiocolloids of this kind are formed by interaction of radionuclides with colloids present in natural waters. Clay particles have a high affinity for the heavy alkali ions that are bound by ion exchange in the order $\mathrm{Cs}^{+}$ $>\mathrm{Rb}^{+}>\mathrm{K}^{+}>\mathrm{Na}^{+}$[137]. This leads to the formation of carrier colloids with ${ }^{137} \mathrm{Cs}[65,138]$. Alkaline earth ions are also bound by ion exchange on clay minerals, actually in the order $\mathrm{Ra}^{2+}>\mathrm{Ba}^{2+}>\mathrm{Sr}^{2+}>\mathrm{Ca}^{2+}$ [137]. Due to the difference in affinity for $\mathrm{Cs}^{+}$and $\mathrm{Sr}^{2+}$ ions and the competition of $\mathrm{Ca}^{2+}$ with $\mathrm{Sr}^{2+}$ ions for the sorption sites, fixation of ${ }^{90} \mathrm{Sr}$ on clay particles is not as strong as that of ${ }^{137} \mathrm{Cs}$ [65]. Hydroxo complexes of elements of groups III, IIIA, IV, IVA, V, VA and VIIIA, on the other hand, interact with hydroxyl groups of colloidal polysilicic acid, iron(III) hydroxide, hydrated iron(III) oxide and the hydroxyl groups at the surface of colloidal clay particles in the way mentioned in section 4.1 (Eq. (3)) and described in the literature by the term hydrolytic adsorption [139142].

It should be emphasized that the formation of colloids is not only a matter of the size, but it depends primarily on the surface properties of the particles. They may carry charges (e.g. adsorbed ions), a shell of water molecules, or hydrophobic substances on the surface which lead to mutual repulsion and prevent coagulation $[135,143]$. Without these surface properties, the particles could not exist as colloids. The behaviour of radionuclides bound on natural colloids by ion exchange or sorption follows that of the colloids which serve as carriers.

\subsection{Suspended inorganic matter}

With suspended inorganic matter (coarse particles of quartz, silicates, including clay, iron oxide and other inorganic substances) radionuclides may also interact by sorption or ion exchange [144, 145]. However, these particles are only observed in flowing or agitated natural waters (e.g. in rivers). After transportation over certain distances, that depend on the mass and the density of the particles, the latter are settling down in form of sediments which contain the radionuclides bound on these particles.

\subsection{Organic compounds of low molecular mass}

Organic compounds are primarily found in surface waters, but also in groundwaters, if these are or have been in contact with organic substances [146]. Compounds of low molecular mass may be of natural origin (e.g. metabolites, such as organic acids, amines or amino acids) or anthropogenic (e.g. detergents, aromatic sul- fonic acids used in manufacturing textiles, as colourbrighteners or for fabrication of dyestuffs). Many of these organic compounds are strong complexing agents and well soluble in water. They are able to form stable complexes with elements of groups III, IV, V, and in particular with transition elements (groups IA to VIIIA) [128]. If they are not separated off, they may carry trace elements including radionuclides over large distances $[127,147]$.

\subsection{Organic compounds of high molecular mass, organic colloids and suspended organic matter}

Organic compounds of high molecular mass play an important role in natural waters $[3,102,115,127$, 146-159] and the knowledge about the behaviour of trace elements in aquatic systems $[96,103,106,108$, 160-164] can also be applied to radionuclides. The most important examples are humic and fulvic acids, both degradation products of organic matter. They are polyelectrolytes and contain carboxylic and phenolic hydroxyl groups which make these compounds hydrophylic and enable them to form rather stable complexes. Other compounds of high molecular mass are proteins, lipids and carbohydrates. The concentration of dissolved organic matter in natural waters varies considerably. It may be as low as $0.1 \mathrm{mg} / \mathrm{l}$ DOC (dissolved organic carbon) in deep groundwaters, ranges from 0.5 to $1.2 \mathrm{mg} / 1 \mathrm{DOC}$ in oceans and may go up to about $50 \mathrm{mg} / \mathrm{l}$ DOC in swamp waters. The stability constants of complexes formed between cations and humic or fulvic acids can be expressed as a function of the degree of ionization of the acids. For the actinides rather high stability constants have been measured [146].

With increasing mass of the organic compounds colloidal properties may prevail and a pronounced difference between non-colloidal and colloidal species will not exist any more [135]. Radiocolloids containing organic compounds may be formed in two different ways: By sorption or ion exchange of radionuclides on macromolecular organic compounds or by sorption of organic complexes of the radionuclides on inorganic colloids. These organic complexes may be of low or high molecular mass; they form a coating on the inorganic material. In all cases, the surface properties of the resulting colloids are decisive for their behaviour.

With increasing size of colloidal particles filtration effects become important, in particular, if the water passes through layers or zones with small pores, by which particles of larger size are filtered off [65].

Interaction of radionuclides with suspended coarse particles of organic matter depends on the nature of the substances and is, in principle, comparable to the interaction with colloidal macromolecular compounds. The suspended particles may stay on the surface of rivers or lakes, if their density is low, or they may 
settle down together with other coarse particles in form of sediments, if the agitation decreases [96, 103, $106,108,160-164]$.

\subsection{Microorganisms}

Microorganisms may also influence the fate of radionuclides in natural waters $[109,165-167]$, in particular in surface waters and near-surface groundwaters. Depending on the metabolism of the microorganisms and their preference for certain elements, the radionuclides may be incorporated and migrate with the microorganisms. Incorporation of radionuclides can be studied by microautoradiography $[165,166]$. With the uptake by microorganisms, radionuclides may enter the food chain.

\subsection{Precipitation and coprecipitation}

If a certain supersaturation of a component is reached, precipitation occurs, starting with nucleation and crystal growth $[103,168,169]$. Supersaturation may be caused by entering of those species into the system that form sparingly soluble compounds with the components already present, by change of $\mathrm{pH}$ or temperature, redox reactions, loss of volatile components, like $\mathrm{CO}_{2}$, shift of complexation equilibria or evaporation of water. Examples often observed in natural waters are the precipitation of $\mathrm{CaCO}_{3}$ due to the loss of $\mathrm{CO}_{2}$ and the shift of the equilibrium between $\mathrm{CaCO}_{3}$ and $\mathrm{Ca}\left(\mathrm{HCO}_{3}\right)_{2}$, and the precipitation of $\mathrm{Fe}$ (III) hydroxide due to the oxidation of $\mathrm{Fe}$ (II) by the access of air. Less common examples are precipitation of sparingly soluble sulfides by reaction of group VIIIA elements with $\mathrm{H}_{2} \mathrm{~S}$ or of sulfates by reaction of group II elements with $\mathrm{SO}_{4}^{2-}$ ions or precipitation of U(IV) hydroxide by reduction of $\mathrm{UO}_{2}^{2+}$ ions. Depending on the conditions and the properties of the compounds, the process of precipitation may stop at an intermediate stage with the formation of a colloid. Examples are sols of colloidal Fe(III) hydroxide in water. Formation of colloids is also possible for other sparingly soluble compounds, if further growth of the particles is hindered by protective coatings. Precipitation of radionuclides may be stopped by adsorption of the intermediates (e.g. polynuclear complexes) on the surface of natural colloids. On the other hand, colloids may be precipitated by increase of salt concentration, as has been mentioned in section 4.3 .

In the first place those elements are involved in these precipitation reactions that are present in sufficiently high concentrations in natural waters, so that the solubility limits are exceeded. For trace elements this condition is in most cases not fulfilled. However, solubility limits may be exceeded even for trace elements, if compounds of extremely low solubility, e.g. hydroxides, sulfides or phosphates are formed. A practical example is the deposition of U(IV) in zones of low redox potential [170]. Precipitation of sparingly soluble hydroxides has been studied as function of $\mathrm{pH}$ by use of paper chromatography for Th hydroxide and Fe(III) hydroxide $[92,171]$.

If low concentrations of radionuclides are considered, coprecipitation is, in general, the most important process. Two mechanisms of coprecipitation of radionuclides have been proposed by Hahn [172], isomorphous substitution or adsorption. In the first case solid solutions (mixed crystals) are formed in which the microcomponents replace the macrocomponent in its normal lattice by syncrystallization (cocrystallization). In the second case, the microcomponents are incorporated as impurities during formation of amorphous precipitates or crystal growth, respectively. They may be given off again, at least partly, in the course of recrystallization of crystalline compounds or in the course of ageing.

Coprecipitation with sparingly soluble hydroxides, preferably $\mathrm{Fe}$ (III) hydroxide, is frequently used in analytical chemistry for separation of trace elements [173]. The amorphous intermediates that are formed by condensation of mononuclear to polynuclear hydroxo complexes offer a high specific surface area with hydroxyl groups as reactive sorption sites for many species of trace elements or radionuclides, respectively, in particular cationic hydroxo complexes of metals in the oxidation states +3 and +4 , like $\mathrm{MOH}^{2+}, \mathrm{MOH}^{3+}, \mathrm{M}(\mathrm{OH})_{2}^{+}, \mathrm{M}(\mathrm{OH})_{2}^{2+}$ and others, and anions, like $\mathrm{HPO}_{4}^{2-}, \mathrm{MoO}_{4}^{2-}$ and others. Coprecipitation of trace elements with $\mathrm{Fe}(\mathrm{III})$ hydroxide or $\mathrm{Fe}$ (III) phosphate, respectively, is often used as an effective procedure in the preparation of drinking water [174].

Actinides(IV) and actinides(III) are very effectively coprecipitated with $\mathrm{BaSO}_{4}$ [175-177], although they do not form compounds that are isomorphous with $\mathrm{BaSO}_{4}$. Detailed investigation showed that by coprecipitation of Th and $\mathrm{U}(\mathrm{IV})$ with $\mathrm{BaSO}_{4}$ anomalous solid solutions are formed in which in the lattice of $\mathrm{BaSO}_{4} 3 \mathrm{Ba}^{2+}$ ions are substituted by $2 \mathrm{~K}^{+}$and $1 \mathrm{Th}^{4+}$ or $1 \mathrm{U}^{4+}$, respectively $[178,179]$. Coprecipitation of actinides(IV) with $\mathrm{SrSO}_{4}$ is taking place in a similar way by formation of anomalous solid solutions [180]. The results show that even if the microcomponent and the macrocomponent have different stoichiometry and do not form isomorphous crystals, if considered separately, the microcomponent may be coprecipitated very effectively by lattice substitution. Generally, coprecipitation of microcomponents is to be expected, if these would also be precipitated under the given conditions, provided they would be present in higher concentrations. This rule must also be extended in the case of coprecipitation of actinides(IV) with $\mathrm{BaSO}_{4}$ or $\mathrm{SrSO}_{4}$, because the sulfates of actinides(IV) do not exhibit low, but medium solubility. Furthermore, so far formation of solid solutions has only be observed, if the ionic radii of the substituting and the substituted ions do not differ by more than $15 \%$. But this limit is appreciably exceeded in case of formation of anomalous 
solid solutions of $\mathrm{Th}^{4+}$ with $\mathrm{BaSO}_{4}$, where the ionic radius of $\mathrm{Th}^{4+}$ is about $24 \%$ smaller than that of $\mathrm{Ba}^{2+}$.

As a result it can be concluded that coprecipitation may considerably influence the fate of radionuclides in natural waters, in particular that of actinides.

\section{Interaction of radionuclides with solid components of the geosphere}

\subsection{General aspects}

The migration behaviour of radionuclides in the geosphere is strongly influenced by the interaction of the species present in the aqueous system with the surrounding solids. This is of special interest in case of long-lived radionuclides [3, 147, 181-183] the transport of which may be appreciably retarded or even stopped, if the interaction is strong, particularly if the radionuclides are incorporated into the solids. Therefore, sorption of radionuclides on solids has been investigated extensively for materials in the neighbourhood of planned high-active waste repositories [3, 184].

Sorption of radionuclides on solids may be due to various kinds of interactions [185-187]: Fixation by predominantly ionic bonds (ion exchange), by mainly covalent bonds (chemisorption), by weak (van der Waals) bonds (physisorption); sorption on the outer surface of the solids (substantial quantity: outer surface area), sorption on inner surfaces (substantial quantity: inner surface area), sorption by ion exchange at positions within the solids, sorption by precipitation, coprecipitation, or incorporation (one directional processes). In all cases the surface and exchange properties of the solids, in particular the quality of the sorption and exchange sites, are important, as well as the knowledge of the species of the radionuclides in the aqueous system $[137,185,188-197]$, in order to understand the migration behaviour of radionuclides.

The following main groups of interactions of radionuclides with solids can be distinguished:

a) Reactions of hydroxo complexes or anionic forms of radionuclides with hydroxyl groups at the surface of solids $(>\mathrm{SiOH},>\mathrm{AlOH}$ or $>\mathrm{FeOH})$, e.g.

$$
\begin{aligned}
\searrow \mathrm{SiOH}(\mathrm{s}) & +\mathrm{HO}-\mathrm{M}^{(n-1)+}(\mathrm{aq}) \\
& \rightleftharpoons \\
& \geqslant \mathrm{Si}-\mathrm{O}-\mathrm{M}^{(n-1)+}(\mathrm{s})+\mathrm{H}_{2} \mathrm{O} .
\end{aligned}
$$

(Additional water molecules are omitted.) The complex of $\mathrm{M}$ in solution is converted to a complex at the surface of the sorbent ("surface complex") with a partly changed coordination sphere. Reaction (6) is equivalent to reaction (3) in section 4.1. It has first been described in detail by Kautsky [140] who studied the interaction of $\mathrm{Th}^{4+}$ with hydrous silicon dioxide and the subsequent reaction with phosphate. As already mentioned in section 4.4 , this type of reaction has been characterized by the term "hydrolytic adsorption" in the literature [139-142]. It is very common and has been used in analytical chemistry for selective separations [141, 142]. By this group of interactions, bonds of predominantly covalent nature are formed. Reaction (6) is often described as an ion exchange

$$
\begin{aligned}
\searrow \mathrm{SiOH}(\mathrm{s}) & +\mathrm{M}^{n+}(\mathrm{aq}) \\
& \rightleftharpoons \\
\rightleftharpoons & \mathrm{Si}-\mathrm{O}-\mathrm{M}^{(n-1)+}(\mathrm{s})+\mathrm{H}^{+},
\end{aligned}
$$

although the presence of hydroxo complexes of $M$ is a prerequisite of the reaction and contribution of ionic bonding in $-\mathrm{SiOH}$ is extremely small. Sorption of the anion ${ }^{99} \mathrm{MoO}_{4}^{2-}$ on hydrous aluminium oxide is applied in the commercial ${ }^{99} \mathrm{Mo} /{ }^{99 \mathrm{~m}} \mathrm{Tc}$ radionuclide generators.

b) Exchange of non-hydrolyzed cationic species of radionuclides at the outer surface or within the layer structure of solids. This type of reactions plays an important role in case of the non-hydrolyzing ions ${ }^{137} \mathrm{Cs}^{+}$, ${ }^{90} \mathrm{Sr}^{2+}$ and ${ }^{226} \mathrm{Ra}^{2+}$ and is very effective, if clay minerals are present that exhibit a high exchange capacity [137]. The predominant type of interaction is ion exchange. Exchange of cationic or anionic species of radionuclides on the surface of ionic compounds may also contribute to sorption, in particular, if the radionuclides are incorporated in the course of recrystallization.

c) Adsorption of complexes of radionuclides with various inorganic ligands (besides hydroxo complexes) or with organic ligands, and adsorption of colloidal species of radionuclides. This group of reactions comprises a great variety of radionuclide species and of sorption equilibria. Adsorption of organic complexes of radionuclides, particularly complexes with humic acids, and adsorption of colloids are important examples. The predominant kind of interaction is physical adsorption with formation of relatively weak (van der Waals) bonds.

The investigation of radioactive disequilibria in natural systems [3, 198] gives valuable information about solid/solution interactions and their influence on the migration behaviour of radionuclides.

The presence of colloids may influence the sorption ratios observed in natural systems appreciably $[199,200]$, and the large variations of sorption ratios that have been measured in the same systems could be explained by the formation of colloids.

The sorption behaviour of radionuclides in various natural systems have been studied in great detail [e.g. $3,84,85,90,93,138,184,186,187,201-215]$, and it has been found in all investigations that sorption and migration may vary considerably. They depend on the properties and the dispersal of the radionuclide species present in solution, the nature of the sorption sites, the surface area of the solids and the interference and the competition, respectively, of other species. Again, knowledge about the behaviour of trace elements in aquatic systems $[96,103,106,108,160-163,216]$ is of great practical importance.

The solids in the geosphere are of very different kind and composition. As already mentioned, the surface properties are of special interest with respect to the interaction with radioactive species. Keeping this 
aspect in mind, the following main components of the geosphere can be distinguished:

- Consolidated rocks (magmatic rocks, like basalt, granite, feldspar, quartz, olivines, plagioclases, pyroxenes, and sedimentary rocks, like sandstone, limestone or dolomite);

- unconsolidated rocks (more or less loose-packed material, consisting mainly of glacial deposits of gravel, sand and clay;

- sediments in rivers, lakes and oceans;

- soils (mainly sand, clay, humus with plant residues, little animals and plenty of microorganisms).

Besides the main components, many other minerals have to be taken into account:

- Oxides and hydroxides (e.g. hydrargillite, diaspor, corundum, spinels, hematite, magnetite, perowskites);

- halides (e.g. rock salt, cryolite, carnallite);

- sulfides (e.g. pyrite);

- sulfates (e.g. gypsum, anhydrite, alum);

- phosphates (e.g. apatites, monazites - some phosphates contain exchangeable protons);

- carbon and carboniferous material.

Of special significance with respect to their properties as sorbents are the clay minerals (e.g. kaolinite, montmorillonite, illite, chlorite), mainly due to their high exchange capacity. They exhibit the three main groups of interactions a), b) and c) mentioned above. In the case of clay minerals with layer structure, sorption by ion exchange proceeds into the inner parts of the particles, and the term "adsorption" is not appropriate.

\subsection{Consolidated rocks}

The surfaces of silicate rocks are altering in the course of time. Cations, like $\mathrm{Na}^{+}, \mathrm{K}^{+}, \mathrm{Mg}^{2+}, \mathrm{Ca}^{2+}$, that are integrated parts of the silicates, are leached out and hydroxyl groups are formed at the surface which may add or give off protons, depending on the $\mathrm{pH}$. The resulting sorption sites are of different nature and quality. $\geqslant \mathrm{SiOH},>\mathrm{AlOH},>\mathrm{FeOH}$ groups are found most frequently. They are binding hydroxo complexes or divalent oxoanions by formation of surface complexes, as described in section 5.1. A review on anion adsorption is given in the literature [217].

Most investigations with consolidated rocks have been made with granites, because these are possible host rocks for high-active waste repositories [3, 44, 218-228]. Qualitatively, the interactions of radionuclides with various natural materials are comparable with the interactions in chromatographic columns, filled with $\mathrm{SiO}_{2} \cdot x \mathrm{H}_{2} \mathrm{O}, \mathrm{Al}_{2} \mathrm{O}_{3} \cdot x \mathrm{H}_{2} \mathrm{O}$, or $\mathrm{Fe}_{2} \mathrm{O}_{3} \cdot x \mathrm{H}_{2} \mathrm{O}$. The specific surface area of silicate rocks, however, is relatively low. In neutral media preferably those radionuclides are sorbed that are present as hydroxo complexes or as divalent anions. Other stable complexes with inorganic or organic ligands as well as colloids show only weak interactions. The competition with other components of the aqueous system for the sorption sites must also be considered in discussion the sorption equilibria.

With sedimentary rocks radionuclides may also interact in various ways. They are sorbed on sandstone, limestone and other sedimentary rocks [3, 229-232]. In addition to reactions with hydroxyl groups, heterogeneous exchange reactions may contribute to the sorption [233, 234]. Examples are: Exchange of $\mathrm{H}^{14} \mathrm{CO}_{3}^{-}$(aq) for ${ }^{12} \mathrm{CO}_{3}^{2-}(\mathrm{s})$ or exchange of ${ }^{90} \mathrm{Sr}^{2+}(\mathrm{aq})$ for $\mathrm{Ca}^{2+}(\mathrm{s})$ at the surface of calcite, limestone or dolomite. These exchange reactions have a certain energy of activation, but they may lead to a considerable decrease of the concentration of radionuclides, like ${ }^{14} \mathrm{C}$, ${ }^{90} \mathrm{Sr},{ }^{210} \mathrm{~Pb}$ or ${ }^{226} \mathrm{Ra}$, while the water is moving slowly along the surfaces of these kinds of rocks. In addition, incorporation into the inner parts of the crystals due to recrystallization and formation of solid solutions may take place.

Interaction of radionuclides with consolidated volcanic tuffs has been investigated intensively [3, 235239], because the deposits at the Yucca Mountains, USA, have been found to be suitable as repositories for high-active waste.

\subsection{Unconsolidated rocks}

The loose-packed material of unconsolidated rocks consists mainly of sand and clay. Clay minerals are the most important components, because of their high sorption capacity that has already been mentioned in section 5.1. Compared with clay minerals, sand is a rather poor sorbent, although particles of crystalline hydrated silica exhibit also exchange properties [240], due to the presence of $\searrow \mathrm{SiOH}$ groups.

The exchange properties of clay minerals have been investigated in great detail [137, 195, 241-249]. On the one hand, sorption and exchange sites, respectively, are available at the outer surfaces, similar to those present at the surface of alumosilicates $(\Longrightarrow \mathrm{SiOH}$ and $\mathrm{AlOH}$ groups). On the other hand, clay minerals with layer structure (e.g. montmorillonite, vermiculite) are able to exchange cations (mainly $\mathrm{Na}^{+}, \mathrm{K}^{+}, \mathrm{Mg}^{2+}$, $\mathrm{Ca}^{2+}$ ) in positions between the layers. Due to the high specific surface area and the large number of exchange sites, the exchange capacity goes up to values of about 1 to $2 \mathrm{meq} / \mathrm{g}$ clay. The ion exchange equilibria depend on the charge density of the clays and the valence of the exchangeable ions. Clay minerals with high charge densities, like illite and micas, exhibit a high preference for monovalent cations $\left(\mathrm{Cs}^{+}>\mathrm{Rb}^{+}>\mathrm{K}^{+}\right)$which are bound more or less irreversibly. Divalent cations $\left(\mathrm{Ra}^{2+}>\mathrm{Ba}^{2+}>\mathrm{Sr}^{2+}\right)$ are also firmly bound.

These highly charged, mica-type clay minerals play an important role in nature, because they are present in all fertile soils and capable of binding monoand divalent cations. They exhibit a high tendency to form colloids and affect strongly the behaviour of ra- 
dionuclides in the geosphere. ${ }^{137} \mathrm{Cs},{ }^{90} \mathrm{Sr}$ and ${ }^{226} \mathrm{Ra}$ are fixed in positions between the layers in partly irreversible form. They are set free again only in presence of relatively high concentrations of competing ions. The hydroxo complexes of lanthanides and actinides are mainly bound at the outer surfaces by interaction with $\geqslant \mathrm{SiOH}$ and $>\mathrm{AlOH}$ groups. In addition, complexes, in particular those with organic ligands, are bound at the outer surfaces rather effectively, due to the large specific surface area of the clay minerals.

Often compounds present in relatively low concentration play a decisive role for the sorption behaviour of natural solids. Examples are: Small amounts of clay besides large amounts of sand in case of sorption of ${ }^{137} \mathrm{Cs}$ [138] and small amounts of carboniferous materials besides large amounts of sand and clay in case of sorption of ${ }^{129} \mathrm{I}$ [85].

As the layers above the salt dome at Gorleben, Germany, consist of unconsolidated rocks, they have been investigated in great detail with respect to the migration behaviour of radionuclides [3]. In other countries, clay is discussed as host for high-active waste repositories, because of the favorable sorption properties of clay minerals.

\subsection{Isotopic and non-isotopic exchange on minerals}

Heterogeneous exchange on carbonates has already been mentioned in the previous section. Such exchange reactions are also taking place at the surface of other sparingly soluble compounds and minerals (e.g. halides, sulfates, phosphates). They may lead to rather selective separations [196, 233, 234, 250-261]. Following the exchange at the surface, ions may be incorporated into the solids in the course of recrystallization which is a very slow but continuous process. The rate of recrystallization increases with decreasing size and increasing imperfection of the crystals. The uptake of foreign ions is not only observed, if these have the same charge, but anomalous solid solutions with radionuclides of different charge may also be formed [180].

\subsection{Sediments in rivers, lakes and oceans}

The sediments in rivers, lakes and in the oceans are worth special consideration, because sediments are present in all surface waters and radionuclides disposed at the surface of the earth (compartment 1 , section 3.2) will sooner or later come into contact with these sediments.

Aquatic sediments are formed by settling down of coarse and fine inorganic and organic particles. Radionuclides may enter river, lake or ocean sediments in different ways: By sorption of molecular-dispersed species (ions, molecules) on the sediments, by precipitation or coprecipitation of originally molecular-dispersed species, by coagulation and sedimentation of colloids, in particular carrier colloids (e.g. by increase of the ionic strength in estuaries) or by sedimentation of coarse particles (suspended matter). By desorption, the radionuclides may by remobilized and released again into the water.

The main components of these sediments are similar to the sediments that have been formed in former geological times: sand and clay minerals. However, river and lake sediments contain also relatively great amounts of organic material and of living things, in particular microorganisms.

Due to the importance of river, lake and ocean sediments with respect to the migration behaviour of radionuclides, many authors have investigated the interactions of radionuclides or trace elements with these sediments [3, 262-278]. In many cases, appreciable fixation and retention, respectively, of radionuclides have been found. It is difficult, however, to distinguish the influences of the various processes, mentioned above, and to correlate the fixation in the sediments to certain components. As far as the inorganic components are concerned, the interaction with clay minerals plays the most important role.

\subsection{Soils}

With respect to the components and the chemistry, soils are even more complex than river or lake sediments. On the other hand, large areas of the continents are covered with soils of various composition, and therefore the interest in the behaviour of trace elements or radionuclides, respectively, in soils is justified [3, 279-306]. Above that, radionuclides are easily transferred from soils to plants and animals, and in this way they may enter the biosphere and the food chain.

The main components of soils are sand, clay and humus. Whereas interaction of radionuclides with sand is rather weak, as in the case of sediments, sorption by clay minerals and reactions with the organic compounds in humus are most important for the migration behaviour of radionuclides. The following statements can be made for some relevant radionuclides: ${ }^{137} \mathrm{Cs}^{+}$ ions are rather strongly bound on clay particles, as already mentioned in section $5.3 .{ }^{90} \mathrm{Sr}^{2+},{ }^{226} \mathrm{Ra}^{2+}$ and ${ }^{210} \mathrm{~Pb}^{2+}$ are also retained by clay particles or bound on chalky soil by precipitation or ion exchange. ${ }^{129} \mathrm{I}^{-}$is oxidized and reacts easily with organic compounds, and these take part in the metabolism of microorganisms. Lanthanides and actinides are either present as hydroxo complexes or as organic complexes. These species are rather strongly bound on the components of the soils, but the organic complexes may also stay in solution, possibly in form of colloids. ${ }^{99} \mathrm{TcO}_{4}^{-}$reacts easily with proteins [122] and ${ }^{99} \mathrm{Tc}$ may thus be incorporated into organic matter.

Besides the composition of the soils, other factors are also of major influence on the migration of radionuclides: rainfall, thickness of the soil layers and their permeability to water, and nature of the layers under- 
neath. For instance, ${ }^{137} \mathrm{Cs}$ will be washed down quickly through layers of sand, but stay in layers of clay. ${ }^{239} \mathrm{Pu}$ will be sorbed by clay more strongly than by sand and may stay in soils for rather long times, if it is not dissolved by complexation or displaced by other compounds.

\subsection{Modelling}

Because of the great practical importance of the interactions between radionuclides and solids, particularly with respect to safety aspects of high-active waste repositories, attempts have been made to model these interactions with the aim to describe the influence of sorption quantitatively by a theoretical concept and characteristic data.

The first approach was the " $K_{d}$-concept", i.e. the determination of distribution coefficients $K_{d}$ for the calculation of sorption and retardation of radionuclides in an aquatic solid/solution system [307]. In this concept it is assumed that an equilibrium distribution of a certain radionuclide $\mathrm{X}$ exists between solution and solid: $\mathrm{X}$ (solution) $\rightleftharpoons \mathrm{X}$ (solid). It was found, however, that the $K_{d}$ values or sorption ratios $R_{s}$, respectively, may vary in a range of several orders of magnitude in the same solid/solution systems $[83,84,138,187$, 207]. Every measured sorption ratio is valid only for a certain species and for a special set of conditions, including the kind and the composition of the solid, Eh, $\mathrm{pH}$, temperature, concentrations of all possible complexing agents, concentration of other components in the water, particularly those competing for the sorption sites, colloid formation, volume to mass ratio, agitation, time of contact between water and solid, filtration effects. Furthermore, equilibrium conditions are generally not given, e.g. if colloids are involved. Sorption data without detailed description of the species and the conditions for which they have been measured, are not useable for quantitative statements. If the influence of only one parameter has been overlooked, the results may be useless. Therefore, the concept that sorption of radionuclides in natural multicomponent systems may be described by one (or possibly two) distribution coefficients (" $K_{c l}$ concept") must fail, because of the complexity of the systems and because equilibrium conditions are, in general, not fulfilled.

Another concept is the surface complexation model [3, 193, 308-316]. In this concept, it is assumed that the species of the radionuclides react with certain groups at the surface of solids (primarily hydroxyl groups, e.g. $>\mathrm{SiOH},>\mathrm{AlOH}$, or $>\mathrm{FeOH}$ groups) by formation of surface complexes, as indicated in Eq. (6). Various approaches with respect to the formulation of surface complexation are described in the literature [309-316], but the common feature is the reaction of metal ions $\mathrm{M}^{n+}$ with hydroxyl groups $\mathrm{SOH}$ at the surface of solids

$$
\begin{aligned}
& \mathrm{SOH}+\mathrm{M}^{n+} \rightleftharpoons \mathrm{SOM}^{(n-1)+}+\mathrm{H}^{+} . \\
& \text {(equilibrium constant } K_{\mathrm{M}} \text { ) }
\end{aligned}
$$

This equation is equivalent to Eq. (7) in section 5.1.

By the surface complexation model reactions of type a) in section 5.1 are taken into account, and in application of this model the same general problems are encountered as in the case of the " $K_{d}$-concept". If one process of sorption (i.e. one species of $M$ and one kind of sorption sites) is dominating, if the concentration of the sorption sites is known, and if the sorption properties are not changed by the sorption of other cations or anions, sorption may be described by equilibrium constants, such as $K_{\mathrm{M}}$ in Eq. (8). If several radionuclide species and/or several kinds of sorption sites are involved, however, several equilibria have to be taken into account.

Sorption by ion exchange is not considered in Eq. (8), and uptake of radionuclides by precipitation, coprecipitation or recrystallization, or adsorption of colloids are not taken into consideration in the surface complexation model. Therefore, it is unavoidable to investigate all possible interactions in every given system very carefully.

\section{References}

1. Becquerel, H.: Sur les Radiations Invisibles Émises par les Corps Phosphorescents, C. R. Acad. Sci. Paris 122, 501 (1896).

2. See textbooks on Nuclear and Radiochemistry, e.g. Friedlander, G., Kennedy, G. W., Macias, E. S., Miller, J. M.: Nuclear and Radiochemistry, 3rd. ed., Wiley, New York 1981; Lieser, K. H.: Einführung in die Kernchemie, 3rd. ed., VCH-Verlag, Weinheim 1991; Choppin, G. R., Liljenzin, J.-O., Rydberg, J.: Radiochemistry and Nuclear Chemistry, 2nd ed. Butterworth-Heinemann Ltd., Oxford 1995; Adloff, J.-P., Guillaumont, R.: Fundamentals of Radiochemistry, CRC Press, Boca Raton, FLA, 1993.

3. Chemistry and Migration Behaviour of Actinides and Fission Products in the Geosphere, Proceedings of the International Conference Munich 1987, Radiochim. Acta 44/45 (1988); Proceedings of the Second International Conference Monterey, CAL., 1989, Radiochim. Acta 52/53 (1990); Proceedings of the Third International Conference, Jerez de la Frontera, Spain, 1991, Radiochim. Acta 58/59 (1992); Proceedings of the Fourth International Conference Charleston, SC, 1993, Radiochim. Acta 66/67 (1994).

4. Browne, E., Firestone, R. B. (Ed. Shirley, V. S.), Table of Radioactive Isotopes, Wiley, New York 1986.

5. Seelmann-Eggebert, W., Pfennig, G., Münzel, H., KleweNebenius, H.: Chart of the Nuclides, Kernforschungszentrum Karlsruhe, 5th ed. 1981.

6. Allard, B., Torstenfeld, B.: Actinide Solubilities and Speciation in a Repository Environment, NAGRA-NTB-85-18, Nagra, Baden, Switzerland 1985.

7. Nitsche, H., Edelstein, N. M.: Solubilities and Speciation of Selected Transuranium Ions, Radiochim. Acta 39, 23 (1985).

8. Felmy, A. R., Rai, Dhanpat, Schramke, J. A., Ryab, R. L.: The Solubility of Plutonium Hydroxide in Dilute Solution and in High-Ionic Strength Chloride Brines, Radiochim. Acta 48, 29 (1989).

9. Felmy, A. R., Rai, Dhanpat, Fulton, R. W.: The Solubility of $\mathrm{AmOHCO}_{3}$ (c) and the Aqueous Thermodynamics of the System $\mathrm{Na}^{+}-\mathrm{Am}^{3+}-\mathrm{HCO}_{3}^{-}-\mathrm{OH}^{-}-\mathrm{H}_{2} \mathrm{O}$, Radiochim. Acta 50, 193 (1990).

10. Nitsche, H., Müller, A., Standifer, E. M., Deinhammer, R. S., Becraft, K., Prussin, T., Gatti, R. C.: Dependence of Actinide Solubility and Speciation on Carbonate Concen- 
tration and Ionic Strength in Groundwater, Radiochim. Acta 58/59, 27 (1992).

11. Lemire, R. J., Garisto, F.: The Effect of Ionic Strength, Groundwater Composition and Temperature on Calculated Radionuclide Solubilities, Radiochim. Acta 58/59, 37 (1992).

12. Lieser, K. H.: Radiochemische Messung der Löslichkeit von Silberhalogeniden in Wasser und in Natriumhalogenidlösungen und die Komplexbildung der Silberhalogenide mit Halogenidionen, Z. Anorg. Allg. Chem. 292, 97 (1957).

13. Lieser, K. H.: Radiochemische Bestimmung der Löslichkeit von Erdalkalisulfaten in Wasser und in Natriumsulfatlösungen, Z. Anorg. Allg. Chem. 335, 225 (1965).

14. Lieser, K. H., Beyer, G., Lakatos, E.: Radiochemische Messung der Löslichkeit von Bleisulfat, Z. Anorg. Allg. Chem. 339, 208 (1965).

15. Coetzee, P. P., Förster, M., Lieser, K. H.: Solubility of AgI in Saturated $\mathrm{NaCl}$ Solution, Radiochim. Acta 37, 159 (1984).

16. Lieser, K. H., Mühlenweg, U., Sipos-Galiba, I.: Dissolution of Neptunium Dioxide in Aqueous Solutions under Various Conditions, Radiochim. Acta 39, 35 (1985).

17. Lieser, K. H., Bauscher, Ch., Nakashima, T.: Dissolution of $\mathrm{TcO}_{2}$ in Aqueous Solutions under Various Conditions, Radiochim. Acta 42, 191 (1987).

18. Oeser, H.: Radiochemische Messung der partiellen Löslichkeit von Strontiumsulfat und Bariumsulfat im System $\mathrm{SrSO}_{4} / \mathrm{BaSO}_{4}$ und der Löslichkeit von Strontiumsulfat in Abhängigkeit von der Sulfatkonzentration, Diplomarbeit T. H. Darmstadt 1961.

19. Lieser, K. H.: unpublished results.

20. Eisenbund, M.: Environmental Radioactivity, Academic Press, New York 1973.

21. Kathren, R. L.: Radioactivity in the Environment; Sources, Distribution and Surveillance, Harwood Acad. Publ., Chur 1984.

22. Durrance, E. M.: Radioactivity in Geology, Principles and Applications, Ellis Horwood, Chichester 1986.

23. Stein, L.: The Chemistry of Radon, Radiochim. Acta 32, 163 (1983).

24. Hopke, P. K. (Ed.): Radon and its Decay Products: Occurrence, Properties and Health Effects, Amer. Chem. Soc., Washington D.C. 1987.

25. Crameri, R., Burkart, W.: The Radon Problem, Radiat. Phys. Chem. 34, 251 (1989).

26. Semkow, T. M.: Recoil Emanation Theory Applied to Radon Release from Mineral Grains, Geochim. Cosmochim. Acta 54, 425 (1989)

27. Tieh, T. T., Ledger, E. B., Rowe, M. W.: Release of Uranium from Granitic Rocks during in Situ Weathering and Initial Erosion (Central Texas), Chem. Geol. 29, 227 (1980)

28. Benes, P., Obdrzalek, M., Cejchanova, M.: The Physicochemical Forms of Traces of Radium in Aqueous Solutions Containing Chlorides, Sulphates and Carbonates, Radiochem. Radioanal. Lett. 50, 227 (1982).

29. Benes, P., Sebesta, F., Sedlacek, J., John, J., Sandrik, R.: Particulate Forms of Radium and Barium in Uranium Mine Waste Waters and Receiving River Waters, Water Res. 17, 619 (1983)

30. The Environmental Behaviour of Radium, International Atomic Energy, Vienna 1990.

31. Grosse, A. V., Johnston, W. M., Wolfgang, R. L., Libby, W. F.: Science 113, 1 (1951)

32. Fireman, E. L.: Phys. Rev. 91, 922 (1953).

33. Fireman, E. L., Schwarze, D.: Phys. Rev. 94, 385 (1954).

34. Kaufman, S., Libby, W. F.: Phys. Rev. 93, 1337 (1954).

35. Andersen, E. C., Libby, W. F., Weinhouse, S., Reid, A. F., Kirschenbaum, A. D., Grosse, A. V.: Science 105, 576 (1947); Phys. Rev. 72, 931 (1947).

36. Momoshima, N., Okai, T., Kaji, T., Takashima, Y.: Distribution and Transformation of Various Chemical Forms of
Tritium in the Environment, Radiochim Acta 54, 129 (1991).

37. Chamberlain, A. C.: Radioactive Aerosols, Cambridge Environmental Chemistry Series 3, Cambridge University Press, Cambridge 1991.

38. Tadmor, J.: Radioactivity from Coal-fired Power Plants, J, Environ. Radioact. 4, 177 (1986).

39. Pigford, T. H.: Environmental Aspects of Nuclear Energy Production, Ann. Rev. Nucl. Sci. 24, 515 (1974)

40. Aurand, K. (Ed.): Kernenergie und Umwelt, Erich Schmidt Verlag, Berlin 1976.

41. Farmer, F. R.: Nuclear Reactor Safety, Academic Press, New York 1977.

42. The Environmental Impacts of Production and Use of Energy, UNEP Energy Report Series 2-79, Nairobi 1979.

43. Brookins, D. G.: Geochemical Aspects of Radioactive Waste Disposal, Springer Verlag, New York, Berlin, Heidelberg, Tokyo 1984.

44. Barney, G. S., Navratil, J. D., Schulz, W. W. (Eds.): Geochemical Behaviour of Disposed Radioactive Waste, Amer. Chem. Soc. Symp. Series 246, Seattle 1984.

45. Lieser, K. H.: Technetium und Neptunium im Kernbrennstoff-Kreislauf, Chem. Ztg. 110, 215 (1986).

46. Lieser, K. H.: Technetium in the Nuclear Fuel Cycle, in Medicine and in the Environment, Radiochim. Acta 63, 5 (1993).

47. Lieser, K. H., Coetzee, P. P., Förster, M.: Liberation of Iodine from AgI during Radiolysis, Radiochim. Acta 38, 33 (1985)

48. Summary Report on the Post-Accident Review Meeting on the Chernobyl Accident, Safety Series No. 75 - INSAG 1, IAEA, Vienna 1986.

49. WHO Assesses Chernobyl Radiation in Europe, Nucl. Europe 6, 29 (1986)

50. Symposium Chemical Phenomena Associated with Radioactivity Releases During Severe Nuclear Plant Accidents, Amer. Chem. Soc., New York 1986

51. Radionuclides from the Chernobyl Accident, Special Issue, Radiochim. Acta 41 (no. 4), 131-201 (1987).

52. Rogers, J. T. (Ed.): Fission Product Transport Processes in Reactor Accidents, Hemisphere Publishing 1990.

53. Proceedings Seminar on Comparative Assessment of the Environmental Impact of Radionuclides Released during three Major Nuclear Accidents: Kyshtym, Windscale, Chernobyl, EUR 13574, Commission of the European Communities, Luxembourg 1990.

54. Sandalls, F. J., Segal, M. G., Victorova, N.: Hot Particles from Chernobyl: A Review, J. Environ. Radioact. 18, 5 (1993).

55. Cains, P. W., Yewer, K. C., Waring, S.: Volatilization of Ruthenium, Caesium and Technetium from Nitrate Systems in Nuclear Fuel Processing and Waste Solidification, Radiochim. Acta 56, 99 (1992).

56. Ure, A. M., Davidson, C. M. (Eds.): Chemical Speciation in the Environment, Chapman and Hall, London 1994.

57. von Gunten, H. R., Benes, P.: Speciation of Radionuclides in the Environment, PSI-Bericht Nr. 94-03, Februar 1994, ISSN 1019-0643.

58. Paneth, F. A.: Akad. Wiss. Wien, Abt. IIa 121, 2193 (1912); 122, 1079 (1913).

59. Zsigmondy, R.: Kolloid-Z. 6, 304 (1913).

60. Hahn, O., Imre, L.: Z. Phys. Chem. A 144, 161 (1929)

61. Haissinsky, M.: Les Radiocolloides, Hermann, Paris 1934.

62. Straik, I.: Z. Phys. Chem. A 157, 269 (1951).

63. Ramsay, J. D. F.: The Role of Colloids in the Release of Radionuclides from Nuclear Waste, Radiochim. Acta 44/ 45, 165 (1988).

64. Maiti, C. T., Smith, M. R., Saul, J. C.: Colloid Formation Study of $\mathrm{U}, \mathrm{Th}, \mathrm{Ra}, \mathrm{Pb}, \mathrm{Sr}, \mathrm{Rb}$ and $\mathrm{Cs}$ in Briny Groundwaters, Nucl. Technol. 84, 82 (1989).

65. Lieser, K. H., Ament, A., Hill, R., Singh, R. N., Stingl, U., Thybusch, B.: Colloids in Groundwater and Their Influence on Migration of Trace Elements and Radionuclides, Radiochim. Acta 49, 83 (1990). 
66. Kim, J. I.: Actinide Colloid Generation in Groundwater, Radiochim. Acta 52/53, 71 (1991).

67. See Textbooks and Handbooks on Inorganic Chemistry.

68. Keller, C.: The Chemistry of the Transuranium Elements, Verlag Chemie, Weinheim 1971.

69. Katz, J. J., Seaborg, G. T., Morss, L. R. (Eds.): The Chemistry of Actinide Elements, 2nd ed., Chapman and Hall, London 1986.

70. Cleveland, J. M.: The Chemistry of Plutonium, Gordon and Breach, New York 1971.

71. Hagemann, R., Roth, E.: Relevance of the Studies of the Oklo Natural Reactors to the Storage of Radioactive Wastes, Radiochim. Acta 25, 241 (1978).

72. The Oklo Phenomenon, IAEA Symposium, Vienna 1975.

73. Natural Fission Reactors, IAEA Tech. Commun., Vienna 1978.

74. Guillaumont, R., Adloff, J. P., Peneloux, A., Delamoye, P.: Sub-tracer Scale Behaviour of Radionuclides. Application to Actinide Chemistry, Radiochim. Acta 54, 1 (1991).

75. Guillaumont, R., Adloff, J. P.: Behaviour of Environmental Plutonium at very Low Concentration, Radiochim. Acta 58/59, 53 (1992).

76. Adloff, J. P.: Chemical Behaviour of Matter at very Low Concentration, to appear in Pure Appl. Chem.

77. Allard, B., Kipatsi, H., Liljenzin, J. O.: Expected Species of Uranium, Neptunium and Plutonium in Neutral Aqueous Solutions, J. Inorg. Nucl. Chem, 42, 1015 (1980).

78. Edelstein, N. M. (Ed.): Actinides in Perspective, Pergamon Press, Oxford 1982.

79. Carnall, W. T., Choppin, G. R. (Eds.): Plutonium Chemistry, Amer. Chem. Soc. Symp. Series 216, Washington, D.C., 1983.

80. Choppin, G. R.: Solution Chemistry of the Actinides, Radiochim. Acta 32, 43 (1983)

81. Bulman, R. A., Cooper, J. R. (Eds.): Speciation of Fission and Activation Products in the Environment, Elsevier, Amsterdam 1985.

82. Kim, J. I.: Chemical Behaviour of Transuranic Elements in Natural Aquatic Systems, in: Handbook on the Physics and Chemistry of Actinides, Vol. 4 (Freeman, A. J., Keller, C., (Eds.), p. 413, Elsevier, Amsterdam 1986.

83. Lieser, K. H., Bauscher, Ch.: Technetium in the Hydrosphere and in the Geosphere, I. Chemistry of Technetium and Iron in Natural Waters and Influence of the Redox Potential on the Sorption of Technetium, Radiochim. Acta 42, 213 (1987).

84. Lieser, K. H., Mühlenweg, U.: Neptunium in the Hydrosphere and in the Geosphere. I. Chemistry of Neptunium in the Hydrosphere and Sorption of Neptunium from Groundwater on Sediments under Aerobic Conditions, Radiochim. Acta 43, 27 (1988).

85. Lieser, K. H., Steinkopff, Th.: Chemistry of Radioactive Iodine in the Hydrosphere and in the Geosphere, Radiochim. Acta 46, 49 (1988).

86. Nelson, D. M., Orlandini, K. A., Penrose, W. R.: Oxidation States of Plutonium in Carbonate-rich Natural Waters, J. Environ. Radioact. 9, 189 (1989).

87. Caceci, M. S.: Environmental Chemistry of the Actinide Elements, in: Metal Speciation in the Environment (Broekart, J. A. C., Gücer, S., Adams, F., Eds.) NATO ASI Series, Vol. G 23, Springer Verlag, Berlin, Heidelberg, New York 1990.

88. Guillaumont, R., Peneloux, A.: Radiochemistry and Actinide Chemistry, J. Radioanal. Nucl. Chem. 143, 275 (1990).

89. Ahrland, S.: Hydrolysis of the Actinide Ions, in: Handbook on the Physics and Chemistry of the Actinides, Vol. 9 (Eds. Freeman, A., Keller, C.), p. 471, Elsevier, Amsterdam 1991.

90. Lieser, K. H., Hill, R., Mühlenweg, U., Singh, R. N., Tu Shude, Steinkopff, Th.: Actinides in the Environment, J. Radioanal. Nucl. Chem. 147, 117 (1991).
91. Dozol, M., Hagemann, R.: Radionuclide Migration in Groundwaters: Review of the Behaviour of Actinides, Pure Appl. Chem. 65, 1081 (1993).

92. Lieser, K. H., Hill, R.: Hydrolysis and Colloid Formation of Thorium in Water and Consequences for its Migration Behaviour - Comparison with Uranium, Radiochim. Acta 56, 37 (1992).

93. Lieser, K. H., Hill, R.: Chemistry of Thorium in the Hydrosphere and in the Geosphere, Radiochim. Acta 56, 141 (1992).

94. Proc. Intern. Symp. on Radioecology: Chemical Speciation - Hot Particles, Commission European Communities, Znojmo 1992.

95. Lieser, K. H., Ament, A.: Radiochemical Investigation of the Behaviour of Lead in Groundwaters, Radiochim. Acta 57, 45 (1992).

96. Förstner, U., Müller, G.: Schwermetalle in Flüssen und Seen, Springer Verlag, Berlin, Heidelberg 1974.

97. Stumm, W., Brauner, P. A.: Chemical Speciation, in: Chemical Oceanography, 2nd Ed. (Riley, J. P., Skirow, G., Eds.), p. 173, Academic Press, New York 1975.

98. Benes, P., Steinnes, E.: On the Use of Radionuclides in the Study of Behaviour and Physico-chemical State of Trace Elements in Natural Waters, Int. J. Environ. Anal. Chem. 4, 263 (1976).

99. Lerman, A. (Ed.): Lakes Chemistry, Geology, Physics. Marcel Dekker, New York 1978.

100. Bowen, H. J. M., Page, E., Valente, I., Wade, R. J.: Radiotracer Methods for Studying Speciation in Natural Waters, J. Radioanal. Chem. 48, 9 (1979).

101. Benes, P., Majer, V.: Trace Chemistry in Aqueous Solutions, Elsevier, Amsterdam 1980.

102. Florence, T. M., Batley, G. E.: Chemical Speciation in Natural Waters, CRC Crit. Rev. Anal. Chem. 9, 219 (1980).

103. Stumm, W., Morgan, J. J.: Aquatic Chemistry, 2nd Ed., Wiley, New York 1981.

104. Wong, C. S., Boyle, E., Bruland, K. W., Burton, J. D., Goldberg, E. D. (Eds.): Trace Metals in Sea Water, Plenum Press, New York 1983

105. Leppard, G. G. (Ed.): Trace Element Speciation in Surface Waters and Its Ecological Implications, Plenum Press, New York 1983.

106. Salomons, W., Förstner, U.: Metals in the Hydrocycle, Springer Verlag, Berlin 1984.

107. Bernhard, M., Brinckman, F. E., Sadler, P. J. (Eds.): The Importance of Chemical Speciation in Environmental Processes, Springer Verlag, Berlin 1986.

108. Stumm, W.: Aquatic Surface Chemistry, Wiley, New York 1987.

109. Glück-Macholdt, C., Lieser, K. H.: Untersuchung des Verhaltens von $\mathrm{Zn}, \mathrm{Cd}$. $\mathrm{Hg}$ and $\mathrm{Pb}$ in Wasser ohne und mit Zusatz von Schwebstoffen und Komplexbildnem sowie in Rheinwasser mit Hilfe der Radionuklidtechnik, Vom Wasser 69, 183 (1987).

110. Mizuike, A.: Recent Developments in Trace Metal Speciation in Fresh Waters, Pure Appl. Chem. 59, 555 (1987).

111. L. Landner (Ed.): Speciation of Metals in Water, Sediment and Soil Systems, Springer Verlag, Berlin 1987.

112. Kramer, J. R., Allen, H. E. (Eds.): Metal Speciation, Theory, Analysis and Application, Lewis Publishers 1988.

113. Batley, G. E. (Ed.): Trace Element Speciation: Analytical Methods and Problems, CRC Press, Boca Raton, FLA, 1989.

114. Lieser, K. H.: Speziation: Eine Herausforderung für die Analytische Chemie, GIT Fachz. Lab. 33, 293 (1992).

115. Salbu, B., Steinnes, E. (Eds.): Trace Elements in Natural Waters, CRC, in press.

116. Bidoglio, G., Stumm, W. (Eds.): Chemistry of Aquatic Systems: Local and Global Perspectives, Kluwer Academic Publishers, 1994.

117. Pourbaix, M.: Atlas of Electrochemical Equilibrium Aqueous Solutions, Pergamon Press, Oxford 1966.

118. Brookins, D. C.: Eh-pH Diagrams for Geochemistry, Springer Verlag, Berlin, Heidelberg 1988. 
119. Beaucaire, C., Poalhoat, P.: Redox Chemistry of Uranium and Iron, Radium Geochemistry, and Uranium Isotopes in the Groundwaters of the Lodève Basin, Massif Central, France, Appl. Geochem. 2, 417 (1987).

120. Büppelmann, K., Kim, J. I., Lierse, Ch.: The Redox Behaviour of Plutonium in Saline Solutions under Radiolysis Effects, Radiochim. Acta 44/45, 65 (1988).

121. Grenthe, I., Stumm, W., Laaksuharju, M., Nilsson, A.-C., Wikberg, P.: Redox Potentials and Redox Reactions in Deep Groundwater Systems, Chem. Geol. 98, 131 (1992).

122. Desmet, G., Myttenaere, C. (Eds.): Technetium in the Environment, Elsevier, London, New York 1986.

123. Baes Jr., C. F., Mesmer, R.: The Hydrolysis of Cations, Wiley, New York 1976

124. Smith, R. M., Martell, A. E.: Critical Stability Constants, Plenum Press, New York 1976.

125. Pashalidis, I., Kim, J. I., Lierse, Ch., Sullivan, J. C.: The Hydrolysis of $\mathrm{Pu}(\mathrm{VI})$ and Time-dependent Nucleation Reactions, Radiochim. Acta 61, 29 (1993).

126. Buffle, J.: Complexation Reactions in Aquatic Systems: An Analytical Approach, Ellis Horwood 1988.

127. Means, J. L., Crerar, D. A., Duguid, J. O.: Migration of Radioactive Wastes: Radionuclide Mobilization by Complexing Agents, Science 200, 1477 (1978).

128. Smith, R. M., Martell, A. E.: Critical Stability Constants, Plenum Press, Oxford 1976.

129. Newton, T. W., Sullivan, J. C.: Actinide Carbonate Complexes in Aqueous Solution, in: Handbook on the Physics and Chemistry of the Actinides, Vol. 3 (Eds. Freeman, A. J., Keller, C.), p. 387, Elsevier, Amsterdam 1985.

130. Ho, C. H., Miller, N. H.: Chemistry of Uranium Colloids in Groundwater Environment, in: Proc. 2. Intern. Conf. on Radioactive Waste Management, Canadian Nucl. Soc., Toronto 1986.

131. Buddemeier, R. W., Hunt, J. R.: Transport of Colloidal Contaminants in Groundwater: Radionuclide Migration at the Nevada Test Site, Appl. Geochem. 3, 535 (1988).

132. von Gunten, H. R., Krähenbühl, U.: The Reactor Accident at Chernobyl: A Possibility to test Colloid-controlled Transport of Radionuclides in a Shallow Aquifer, J. Contaminant Hydrol. 2, 237 (1988).

133. Ramsay, J. D. F.: The Role of Colloids in the Release of Radionuclides from Nuclear Waste, Radiochim. Acta 44/ 45, 165 (1988).

134. Dearlove, J. P. L., Longworth, G., Ivanovich, M., Kim, J. I., Delakowitz, B., Zeh, P.: Study of Groundwater Colloids and their Geochemical Interactions with Natural Radionuclides in Gorleben Aquifer Systems, Radiochim. Acta 52/53, 83 (1991).

135. Lieser, K. H.: Kolloide in der Analytischen Chemie, GIT Fachz. Lab. 33, 583 (1991).

136. Kim, J. I., Zeh, P., Delakowitz, B.: Chemical Interactions of Actinide Ions with Groundwater Colloids in Gorleben Aquifer Systems, Radiochim. Acta 58/59, 147 (1992).

137. Amphlett, C. B.: Inorganic Ion Exchangers, Elsevier, Amsterdam 1964.

138. Lieser, K. H., Steinkopff, Th.: Chemistry of Radioactive Cesium in the Hydrosphere and in the Geosphere, Radiochim. Acta 46, 39 (1988).

139. Fricke, R., Schmäh, H.: Z. Anorg. Chem. 255, 253 (1948).

140. Kautsky, H., Weßlau, H.: Z. Naturforsch. 9b, 569 (1954).

141. Kohlschütter, H. W., Getrost, H., Miedtank, S.: Z. Anorg. Allg. Chem. 308, 190 (1961).

142. Kohlschütter, H. W., Miedtank, S., Getrost, H.: Fresenius Z. Anal. Chem. 192, 381 (1963).

143. See Textbooks on Colloid Chemistry.

144. Calmano, W., Lieser, K. H.: Austauschvorgänge von Spurenelementen an Schwebstoffen, Naturwissenschaften 68 , 264 (1981)

145. Calmano, W., Lieser, K. H.: Untersuchung der Austauschvorgänge von Spurenelementen an Schwebstoffen mit Hilfe der Radionuklidtechnik, Fresenius Z. Anal. Chem. 307, 356 (1981).
146. Choppin, G. R., Allard, B.: Complexes of Actinides with Naturally Occurring Organic Compounds, in: Handbook on the Physics and Chemistry of the Actinides, Vol. 3 (Eds. Freeman, A. J., Keller, C.), p. 407, Elsevier, Amsterdam 1985.

147. Environmental Migration of Long-lived Radionuclides, IAEA, Vienna 1982.

148. Wallace, G. T.: The Association of Copper, Mercury and Lead with Surface-active Organic Matter in Coastal Seawater, Mar. Chem. 11, 379 (1982).

149. Boggs, S. Jr., Livermore, D., Seitz, M. G.: Humic Substances in Natural Waters and their Complexation with Trace Metals and Radionuclides: A Review, Argonne National Laboratory ANL-84-78, Argonne, ILL, 1985.

150. Giesy, J. P., Geiger, R. A., Kevern, N. R., Alberts, J. J.: $\mathrm{UO}_{2}^{2+}$-Humate Interactions in Soft, Acid, Humate-rich Waters, J. Environ. Radioact. 4, 39 (1986).

151. Sparkes, S. T., Sanders, T. W., Long, S. E.: A Literature Survey of the Organic Speciation of Radionuclides, AERE R-12487, Harwell 1987.

152. Choppin, G. R.: Humics and Radionuclide Migration, Radiochim. Acta 44/45, 23 (1988).

153. Choppin, G. R.: Chemistry of Actinides in the Environment, Radiochim. Acta 43, 82 (1988).

154. Bidoglio, G., De Plano, A.: Interactions and Transport of Plutonium-Humic acid Particles in Groundwater Environments, in: Proc. Conf. Scientific Basis for Nuclear Waste Management XII, p. 823, Materials Research Society, 1989.

155. Kim, J. I., Buckau, G., Bryant, E., Klenze, R.: Complexation of Americium(III) with Humic Acid, Radiochim. Acta 48, 135 (1989).

156. Berry, J. A., Baston, G. M., Bond, K. A., Linklater, C., Pilkington, N. J.: Studies on the Effects of Degradation Products on the Sorption of Tin and Radium, Mat. Res. Soc. Symp. Proc. 212, 577 (1991).

157. Choppin, G. R.: J. Radioanal. Nucl. Chem. 147, 109 (1991).

158. Kim, J. I., Wimmer, H., Klenze, R.: A Study of Curium(III) Humate Complexation by Time-resolved Laser Fluorescence, Spectroscopy (TRLFS), Radiochim. Acta 54, 35 (1991)

159. Choppin, G. R.: The Role of Natural Organics in Radionuclide Migration in Natural Aquifer Systems, Radiochim. Acta 58/59, 113 (1992).

160. Burton, J. D., Liss, P. S. (Eds.): Estuarine Chemistry, Academic Press, London, New York 1976.

161. Kavanough, M. C., Leckie, J. O. (Eds.): Particulates in Water, Amer. Chem. Soc., Advances in Chemistry Series 189, Washington, D.C., 1980.

162. Förstner, U., Wittmann, G. T. W.: Metal Pollution in the Aquatic Environment, 2nd Ed., Springer Verlag, Berlin, Heidelberg, New York 1981.

163. Morel, F. M. N.: Principles of Aquatic Chemistry, Wiley, New York 1983.

164. Duursma, E. K., Dawson, H. J.: Marine Organic Chemistry, Elsevier, Amsterdam 1981.

165. Glück, C., Lieser, K. H.: Microautoradiography of Trace Elements in Suspended Matter, Naturwissenschaften 69, 391 (1982).

166. Glück-Macholdt, C., Lieser, K. H.: Untersuchung der Sorption von Schwermetallen an Schwebstoffen des Rheins mit Hilfe der Mikroautoradiographie, Vom Wasser 70, 255 (1988).

167. Pedersen, K., Albinsson, Y.: Possible Effects of Bacteria on Trace Element Migration in Crystalline Bed-rock, Radiochim. Acta 58/59, 365 (1992).

168. Nielsen, A. E.: Kinetics of Precipitation, Pergamon Press, Oxford 1964.

169. Lieser, K. H.: Steps in Precipitation Reactions, Angew. Chem., Int. Ed. 8, 188 (1969).

170. Deutsch, W. J., Serne, R. J.: Uranium Mobility in the Natural Environment. Evidence from Sedimentary Roll-Front 
Deposits, in: Geochemical Behaviour of Disposed Radioactive Waste (Eds. Barney, G. S., Navratil, J. D., Schulz, W. W.), ACS Symposium Series 246, Amer. Chem. Soc., Washington, D.C., 1984.

171. Fabrikanos, A., Lieser, K. H.: Papierchromatographische Trennung während der Hydroxidfällung, Z. Phys. Chem. Neue Folge 51, 130 (1966).

172. Hahn, O.: Applied Radiochemistry, Cornell University Press, Ithaca, N. Y., 1936.

173. See textbooks on Analytical Chemistry.

174. Dyck, W., Lieser, K. H.: Mitfällung von $\mathrm{Cu}, \mathrm{Zn}, \mathrm{As}, \mathrm{Ag}$, $\mathrm{Cd}$ und $\mathrm{Pb}$ bei der Eisenhydroxid- und der Eisenphosphatfällung, Vom Wasser 56, 183 (1981).

175. Sill, C. W., Willis, C. P.: Anal. Chem. 36, 622 (1964).

176. Sill, C. W., Willis, C. P.: Anal. Chem. 38, 97 (1966).

177. Sill, C. W., Williams, R. L.: Anal. Chem. 41, 1624 (1969).

178. Ambe, S., Lieser, K. H.: Coprecipitation of Thorium with Barium Sulfate, Radiochim. Acta 25, 93 (1978).

179. Lieser, K. H., Bachtanian, S.: Coprecipitation of U(IV) with Barium Sulfate, Radiochim. Acta 68, 121 (1995).

180. Lieser, K. H., Medert, K.: Coprecipitation of Th with $\mathrm{SrSO}_{4}$ and Uptake of Th by $\mathrm{SrSO}_{4}$, Radiochim. Acta 68 191-195 (1995).

181. Paul, A. C., Pillai, K. C.: Transfer and Uptake of Radium in a Natural and Technologically Modified Radiation Environment, J. Environ. Radioact. 3, 55 (1986).

182. Coughtrey, P. J., Thorne, M. C.: Radionuclide Distribution and Transport in Terrestrial and Aquatic Ecosystems. A Critical Review of Data, Vol. 1-4, Balkema 1984.

183. Desmet, G., Nassimbeni, P., Belli, M.: Transfer of Radionuclides in Natural and Semi-Natural Environments, Elsevier, Amsterdam 1990.

184. Proc. Conf. Scientific Basis for Nuclear Waste Management, North Holland, Amsterdam (e.g. VI, 1982, VI, 1983 , VII, 1984).

185. Lieser, K. H.: Sorption Mechanisms, in: Sorption and Filtration for Gas and Water Purification (Ed. BonnevieSvendsen, M.), NATO Advanced Study Institutes Series, Noordhoff-Leyden 1975.

186. Lieser, K. H., Gleitsmann, B., Steinkopff, Th.: Sorption of Trace Elements or Radionuclides in Natural Systems Containing Groundwater and Sediments, Radiochim. Acta 40, 33 (1986).

187. Lieser, K. H., Steinkopff, Th.: Sorption Equilibria of Radionuclides or Trace Elements in Multicomponent Systems, Radiochim. Acta 47, 55 (1989).

188. Gregg, S. J., Sing, K. S. W.: Adsorption, Surface Area and Porosity, Academic Press, London, New York 1965.

189. Gould, R. F.: Adsorption from Aqueous Solutions, Advances in Chemistry Series No. 79, Amer. Chem. Soc. Washington, D.C., 1968.

190. Hauffe, K., Morrison, S. R.: Adsorption, Walter de Gruyter, Berlin, New York 1974

191. Lieser, K. H., Quandt, S., Gleitsmann, B.: Abtrennung von Schwermetallen aus natürlichen Wässern an anorganischen Sorbentien $\left(\mathrm{TiO}_{2}, \mathrm{ZrO}_{2}, \mathrm{Al}_{2} \mathrm{O}_{3}\right)$, Fresenius $\mathrm{Z}$. Anal. Chem. 298, 378 (1979).

192. Sipos-Galiba, I., Lieser, K. H.: Comparison of the Properties of Inorganic Ion Exchangers with Respect to the Separation of the Fission Products Cesium and Strontium, Radiochem. Radioanal. Lett. 42, 329 (1980).

193. Anderson, M. A., Rubin, A. J. (Eds.): Adsorption of Inorganics at Solid-Liquid Interfaces, Ann Arbor Sciences, Ann Arbor 1981.

194. Clearfield, A.: Inorganic Ion Exchange Materials, CRC Press, Boca Raton, FLA, 1982.

195. Weiß, A., Sextl, E.: Clay Minerals as Ion Exchangers, in: Ion Exchangers (Ed. Dorfner, K.), p. 492, Walter de Gruyter, Berlin, New York 1991.

196. Lieser, K. H.: Non-Siliceous Inorganic Ion Exchangers, in: Ion Exchangers (Ed. Dorfner, K.), p. 519, Walter de Gruyter, Berlin, New York 1991
197. Lieser, K. H., Quandt-Klenk, S., Thybusch, B.: Sorption of Uranyl Ions on Hydrous Silicon Dioxide, Radiochim. Acta 57, 45 (1992).

198. Ivanovich, M., Harmon, R. S.: Uranium Series Disequilibrium: Applications to Earth, Marine, and Environmental, Sciences, Oxford Sciences Publ., Oxford 1992.

199. Lieser, K. H., Peschke, S., Gleitsmann, B.: Sorption Equilibria in Colloid Systems and their Influence on Distribution Ratios of Trace Elements, Fresenius Z. Anal. Chem. 321, 119 (1985).

200. Lieser, K. H., Gleitsmann, B., Peschke, S., Steinkopff, Th.: Colloid Formation and Sorption of Radionuclides in Natural Systems, Radiochim. Acta 40, 39 (1986).

201. Langmuir, D., Herman, J. S.: The Mobility of Thorium in Natural Waters at Low Temperatures, Geochim. Cosmochim. Acta 44, 1753 (1980)

202. Lieser, K. H., Peschke, S.: The Geochemistry of Fission Products (Cs, I, Tc, Sr, Zr, Sm), OECD Workshop on Geochemistry and Radioactive Waste Disposal, Paris 1982.

203. Ames, L. L., McGarrah, J. E., Walker, B. A.: Sorption of Uranium and Radium by Biotite, Muscovite and Phlogopite, Clays Clay Miner. 31, 343 (1983).

204. Grütter, A., von Gunten, H. R., Rössler, E.: Sorption, Desorption and Isotope Exchange of Caesium $\left(10^{-9}-10^{-3} \mathrm{M}\right)$ on Chlorite, Clays Clay Miner. 34, 677 (1986).

205. Lieser, K. H., Bauscher, Ch.: Technetium in the Hydrosphere and in the Geosphere, II. Influence of $\mathrm{pH}$, of Complexing Agents and of Some Minerals on the Sorption of Technetium, Radiochim. Acta 44/45, 125 (1988).

206. Lieser, K. H., Mühlenweg, U.: Neptunium in the Hydrosphere and in the Geosphere, II. Column Experiments with Neptunium, Radiochim. Acta 44/45, 129 (1988).

207. Lieser, K. H., Steinkopff, Th.: Chemistry of Radioactive Cerium in the Hydrosphere and in the Geosphere, Radiochim. Acta 48, 79 (1989).

208. Mahara, Y., Matsuzuru, H.: Mobile and Immobile Plutonium in Groundwater Environment, Water Res. 23, 43 (1989).

209. Grütter, A., von Gunten, H. R., Kohler, M., Rössler, E.: Sorption, Desorption and Exchange of Caesium on Glaciofluvial Deposits, Radiochim. Acta 50, 177 (1990).

210. Hobart, D. E.: Actinides in the Environment, in: Proc. of Robert A. Welch Foundation Conf. on Chemical Research XXXIV, Fifty Years with Transuranium Elements, Houston, TX, 1990, p. 379.

211. Sheppard, S. C., Sheppard, M. I., Evenden, W. G.: A Novel Method Used to examine Variation in Tc Sorption among 34 Soils, Aerated and Anoxic, J. Environ. Radioact. 11, 215 (1990)

212. Ivanovich, M., Froehlich, K., Hendry, M.: Uranium-Series Radionuclides in Fluids and Solids, Milk River Aquifer, Alberta, Canada, Appl. Geochem. 6, 405 (1991).

213. Silva, R. J.: Mechanism for the Retardation of Uranium(VI) Migration, Mat. Res. Soc. Symp. Proc. 257, 323 (1992).

214. Baston, G. M. N., Berry, J. A., Linklater, C. M.: Factors Influencing the Sorption of Radium onto Geological Materials, Anal. Proc. 30, 194 (1993).

215. Ticknor, K. V.: Uranium Sorption on Geological Materials, Radiochim. Acta 64, 229 (1994).

216. Schindler, P.: Surface Complexes at Oxide-Water Interfaces, in: Adsorption of Inorganics at Solid-Liquid Interfaces (Eds. Anderson, M. A., Rubin, A. J.), Ann Arbor Science, Ann Arbor 1981

217. Hingston, F. J.: A Review of Anion Adsorption, in: $A d$ sorption of Inorganics at Solid-Liquid Interfaces (Eds. Anderson, M. A., Rubin, A. J.) Ann Arbor Science, Ann Arbor 1981

218. Ames, L. L., McGarrah, J. E., Walker, B. A.: Sorption of Trace Constituents from Aqueous Solutions onto Secondary Minerals, I. Uranium, Clays Clay Miner. 31, 321 (1983); II. Radium, Clays Clay Miner. 31, 335 (1983). 
219. Gascoyne, M., Cramer, J. J.: History of Actinide and Minor Element Mobility in an Archean Granitic Batholith in Manitoba, Canada, Appl. Geochem. 2, 37 (1987).

220. Torstenfeld, B., Rundberg, R. S.: Actinide Sorption on Granites and Minerals as a Function of $\mathrm{pH}$ and Colloids/ Pseudocolloids, Radiochim. Acta 44/45, 111 (1988).

221. Hochella Jr., M. F., White, A. F. (Eds.): Mineral-Water Interface Geochemistry, Reviews in Mineralogy, Vol. 23, Mineralogical Society of America, Washington, D.C., 1990.

222. Gauthrie, V. A., Hart, K. P., Levins, D. M., Seatonberry, B. W.: Geochemical Interactions between Leachants from Actinide-Doped Synroc and three Australian Granites, Radiochim. Acta 52/53, 159 (1990).

223. Gutierrez, M. G., Bidoglio, G., Avogadro, A., Mingarro, E., d'Alessandro, M.: Experimental Investigations of Radionuclide Transport through Cored Granite Samples, Radiochim. Acta 52/53, 213 (1990).

224. Mecherri, O. M., Budiman-Sastrowardoyo, P., Kamal, L., Rouchaud, J.-C., Fedoroff, M.: Study of the Sorption of Neodymium on Granite Minerals, Radiochim. Acta 58/59, 267 (1992).

225. Gutierrez, M. G., Bidoglio, G., Avogadro, A., Yllera de Llano, A.: Studies on Hydro-Geochemical Controls of Neptunium and Selenium Migration in Granite Columns, Radiochim. Acta 58/59, 277 (1992).

226. Gascoyne, M., Barber, J. H.: The Mobility of U, Ra and $\mathrm{Rn}$ in a Granite Batholith on the Canadian Shield, Radiochim. Acta 58/59, 277 (1992).

227. Hölttä, P., Hautojärvi, A., Hakanen, M.: Transport and Retardation on Non-Sorbing Radionuclides in Crystalline Rock Fractures, Radiochim. Acta 58/U5, 285 (1992).

228. Griffault, L. Y., Gascoyne, M., Kaminenir, C., Kerrich, R., Vandergraaf, T. T.: Actinide and Rare Earth Element Characteristics of Deep Fracture Zones in the Lac du Bonnet Granitic Batholith, Manitoba, Canada, Geochim. Cosmochim. Acta 57, 1181 (1993).

229. Berry, J. A., Bourke, P. J., Coates, H. A., Green, A., Jefferies, N. L., Littleboy, A. K., Hooper, A. J.: Sorption of Radionuclides on Sandstones and Mudstones, Radiochim. Acta 44/45, 135 (1988)

230. Liu, Wen-Chung, Lo, Jiunn-Guang, Tsai, Chao-Ming: Sorption of Cs, Sr and Co on Andesite and Coral Limestone, Radiochim. Acta 52/53, 169 (1990).

231. Carroll, S. A., Bruno, J., Petit, J.-C., Dran, J.-C.: Interaction of U(VI), Nd and Th(IV) at the Calcite-Solution Interface, Radiochim. Acta 58/59, 245 (1992).

232. Winkler, A., Brühl, H., Trapp, Ch., Bock, W.-D.: Mobility of Technetium in Various Rocks and Defined Combinations of Natural Minerals, Radiochim. Acta 44/45, 183 (1988).

233. Lieser, K. H., Hild, W.: Principles and Applications of Heterogeneous Isotopic and Non-Isotopic Ion Exchange on the Surface of Ionic Crystals, Radioisotopes in the Physical Sciences and Industry, IAEA, Vienna 1962, p. 338.

234. Lieser, K. H.: Radiochemische Messung des heterogenen Austausches von isotopen und nicht-isotopen Ionen an der Oberfläche von Erdalkalicarbonaten, Radiochim. Acta 3, 93 (1964).

235. Triay, I. R., Meijer, A., Cisneros, M. R., Miller, G. G., Mitchell, A. J., Ott, M. A., Hobart, D. E., Palmer, P. D., Perrin, R. E., Aguilar, R. D.: Sorption of Americium in Tuff and Pure Minerals Using Synthetic and Natural Groundwaters, Radiochim. Acta 52/53, 139 (1990).

236. Rundberg, R. S., Triay, I. R., Ott, M. A., Mitchell, A. J.: Observation of Time Dependent Dispersion in Laboratory Experiments with Intact Tuff, Radiochim. Acta 52/53, 219 (1990)

237. Thompson, J. L., Gilmore, J. S.: Migration of Fission Products at the Nevada Test Site: Detection with an Isotopic Tracer, Radiochim. Acta 52/53, 229 (1990).

238. Buddemeier, R. W., Finkel, R. C., Marsh, K. V., Ruggieri, M. R., Rego, J. H., Silva, R. J.: Hydrology and Radio- nuclide Migration at the Nevada Test Site, Radiochim. Acta 52/53, 275 (1990).

239. Thompson, J. L.: Studies of Fission Product Movement in Tuffaceous Media, Radiochim. Acta 58/59, 273 (1992).

240. Iler, R. K.: Ion Exchange Properties of Crystalline Hydrated Silica, J. Colloid Sci. 19, 648 (1964).

241. Hofmann, U., Giese, K.: Cation Exchange by Clay Minerals, Kolloid-Z. 87, 21 (1939).

242. Weiß, A., Hofmann, U.: Batavite, Z. Naturforsch. 6b, 405 (1951).

243. Weiß, A.: Cation Exchange Ability of Clay Minerals, 1 . Comparison of Investigations, Z. Anorg. Allg. Chem. 297, 232 (1958); II. Cation Exchange in Minerals of the Mica, Vermiculite and Montmorillonite Groups, Z. Anorg. Allg. Chem. 297, 257 (1958).

244. Weiß, A., Mehler, A., Koch, G., Hofmann, U.: Anion Exchange in Clays, Z. Anorg. Allg. Chem. 284, 247 (1956).

245. Boehm, H.-P., Lieser, K. H.: Radiochemische Bestimmung des Kationenaustauschvermögens von Tonmineralen, $\mathrm{Z}$. Anorg. Allg. Chem. 304, 207 (1960).

246. Halevy, E.: Exchangeability of Hydroxyl Groups in Kaolinite, Geochim. Cosmochim. Acta 28, 1139 (1964).

247. Weiß, A.: in: Ullmanns Enzyklopädie der Technischen Chemie (Ed. W. Foerst), Urban und Schwarzenberg, München, Berlin, Wien 1966, p. 583; 1964, p. 697.

248. von Olphen, H.: An Introduction to Clay Colloid Chemistry; Wiley, New York 1977.

249. Hafez, M. B., Abdelrasoul, A. A., Algasmi, R.: Fixation of Radioelements on Illite and Bentonite, Isotopenpraxis 18, 321 (1982).

250. Lieser, K. H., Hild, W.: Zur Abtrennung von Strontium-90 aus Lösungen, Naturwissenschaften 46, 599 (1959).

251. Lieser, K. H., Hild, W.: Selektive Abtrennung von radioaktivem Strontium, Naturwissenschaften 47, 494 (1960).

252. Lieser, K. H., Hild, W.: Heterogener Austausch isotoper und nicht-isotoper Ionen an Erdalkalisulfaten, I. Untersuchungsmethode und Isotopenaustausch mit Strontium90, Z. Anorg. Allg. Chem. 320, 117 (1963); II. Austauschgleichgewichte an der Oberfläche der Erdalkalisulfate, Z. Anorg. Allg. Chem. 331, 133 (1964).

253. Lieser, K. H., Gütlich, Ph., Rosenbaum, I.: Kinetics and Mechanism of Heterogeneous Exchange Reactions on the Surface of Ionic Crystals, Proc. Exchange Reactions, IAEA, Vienna 1965 , p. 375.

254. Lieser, K. H., Gütlich, Ph., Hild, W., Hecker, A., Rosenbaum, I.: Exchange Equilibria on the Surface of Ionic Crystals, Proc. Exchange Reactions, IAEA, Vienna 1965, p. 385 .

255. Lieser, K. H.: Kinetik heterogener Isotopenaustauschreaktionen, Monatsh. Chem. 101, 1630 (1970).

256. Mager, H., Lieser, K. H.: Rekristallisation und Alterung von Strontiumsulfat, I. Z. Phys. Chem. Neue Folge 79, 288 (1972); II. Z. Phys. Chem. Neue Folge 81, 81 (1972); III. Z. Phys. Chem. Neue Folge 81, 89 (1972).

257. Lang, G., Lieser, K. H.: Heterogener Isotopenaustausch, Kristallwachstum und Auflösung von Ionenkristallen am Beispiel Bleisulfat, Z. Phys. Chem. Neue Folge 86, 143 (1973).

258. Lieser, K. H., Braun, H., Mager, H.: Selective Separations via Recrystallization, J. Radioanal. Chem. 32, 367 (1976).

259. Lieser, K. H., Pallikaris, G.: Investigation of the Mechanism of Recrystallization, Faraday Discuss, Chem. Soc. 61, 149 (1976).

260. Lieser, K. H., Mager, H., Pallikaris, G.: Mechanism of Recrystallization of Ionic Crystals under Solution, Z. Phys. Chem. Neue Folge 105, 35 (1977).

261. Lieser, K. H.: Dynamic Behaviour of Solid Surfaces, in: Reactivity of Solids (Eds. Wood, J., Lindqvist, O., Helgesson, C., Vannerberg, N.-G.), Plenum Press, New York 1977.

262. Shearer Jr., S. D., Lee, G. F.: Leachability of Radium-226 from Uranium Mill Solids and River Sediments, Health Phys. 10, 217 (1964). 
263. Edgington, D. N., Alberts, J. J., Wahlgren, N. A., Karttunen, J. O., Reeve, C. A.: Plutonium and Americium in Lake Michigan Sediments, in: Transuranic Nuclides in the Environment, p. 493, IAEA, Vienna 1981.

264. Aston, S. R., Assinder, D. J., Stanners, D. A., Rae, J. E.: Plutonium Occurrence and Phase Distribution in Sediments of the Wyre Estuary, Northwest England, Mar. Pollut. Bull. 12, 308 (1981).

265. Mahara, Y., Kudo, A.: Fixation and Mobilization of ${ }^{60} \mathrm{Co}$ on Sediments in Coastal Environments, Health Phys. 41, 645 (1981).

266. Foerstner, U., Schoer, J.: Some Typical Examples of the Importance of the Role of Sediments in the Propagation and Accumulation of Pollutants, in: Sediments and Pollution in Waterways. General Considerations, p. 137. Techn. Doc. 302, IAEA, Vienna 1982.

267. Pimpl, M., Schüttelkopf, H.: The Plutonium Contamination of the Altrhein River. The Plutonium Contamination as a Function of Sediment Particle Diameter (in German), KfK-3074, Kernforschungszentrum Karlsruhe 1982.

268. Evans, D. W., Alberts, J. J., Clark, R. A.: Reversible IonExchange of Cesium-137 Leading to Mobilization from Reservoir Sediments, Geochim. Cosmochim. Acta 47, 1041 (1983).

269. Azevedo, H. L., Schüttelkopf, H.: Studies on the Retention of $\mathrm{Ra}-226$ and $\mathrm{Pb}-210$ by Sediments from the Receiving River of the Waste Waters of an Uranium Prospection in Menzenschwand, West Germany, Kernforschungszentrum Karlsruhe 1984.

270. Foerstner, U., Schoer, J.: Diagenesis of Chemical Associations of ${ }^{137} \mathrm{Cs}$ and other Artificial Radionuclides in River Sediments, Environ. Technol. Lett. 5, 295 (1984).

271. Joshi, L. U., Zingde, M. D., Desai, B. N.: Studies on ${ }^{226}$ Ra and ${ }^{210} \mathrm{~Pb}$ Activities and the Concentration Factors of ${ }^{226} \mathrm{Ra}$ in the Surface Organic Layers of the Estuarine Sediments of Mindola and Purna Rivers in India, J. Radioanal. Nucl. Chem. 82, 369 (1984).

272. Schoer, J., Foerstner, U.: Chemical Forms of Artificial Radionuclides and their Stable Counterparts in Sediments, in: Environmental Contamination, Internat. Conf., London, July 1984, p. 738, CEP Consultants, Edinburgh 1984.

273. McKay, W. A., Baxter, M. S.: The Partitioning of Sellafield-Derived Radio-Caesium in Scottish Coastal Sediments, J. Environ. Radioact. 2, 93 (1985).

274. Benes, P., Strejc, P.: Interaction of Radium with Freshwater Sediments and their Mineral Components. IV. Waste Water and Riverbed Sediments, J. Radioanal. Nucl. Chem. 99, 407 (1986).

275. Terada, K., Hamano, M., Natsumoto, K.: The Distribution and Characterization of ${ }^{1.37} \mathrm{Cs}$ in Shallow Water Sediments, Bull. Chem. Soc. Japan 59, 1863 (1986).

276. Azevedo, H. L., Amaral, E. C. S., Godoy, J. M.: Evaluation of the ${ }^{226} \mathrm{Ra}$ Transport by River Sediments Surrounding the Brasilian Uranium Mining and Milling Facilities, Environ. Pollut. 51, 259 (1988).

277. Benes, P., Lam Ramos, P., Poliak, R.: Factors Affecting Interaction of Radiocesium with Freshwater Solids, I. pH, Composition of Water and Solids, J. Radioanal. Nucl. Chem. 133, 359 (1989)

278. Milton, G. M., Cornett, R. J., Kramers, S. J.: The Transfer of Iodine and Technetium from Surface Waters to Sediments, Radiochim. Acta 58/59, 291 (1992).

279. Raja, M. E., Babcock, K. L.: On the Soil Chemistry of Radio-Iodine, Soil Sci. 91, 1 (1961).

280. Squire, H. M., Middleton, L. J.: Behaviour of ${ }^{137} \mathrm{Cs}$ in Soils and Pastures. A Long Term Experiment, Radiat. Bot. 6, 413 (1966).

281. Wada, K., Harward, M. E.: Amorphous Clay Constituents of Soils. Adv. Agron. 26, 211 (1974).

282. Whitehead, D. C.: The Sorption of Iodide by Soil Components, J. Sci. Food Agric. 25, 73 (1974).

283. Nriagu, J. O. (Ed.): The Biochemistry of Lead in the Environment, Elsevier, Amsterdam 1978.
284. Means, J. L., Crerar, D. A., Borcsik, M. P., Duguid, J. O.: Adsorption of $\mathrm{Co}$ and Selected Actinides by $\mathrm{Mn}$ and $\mathrm{Fe}$ Oxides in Soils and Sediments, Geochim. Cosmochim. Acta 42, 1763 (1978).

285. Bohn, H. L., McNeal, B. L., O’Connor, G. A.: Soil Chemistry, Wiley, New York 1979.

286. Lindsay, W. L.: Chemical Equilibria in Soils, Wiley, New York 1979.

287. Benes, J.: Concentration Dependence of Iodine Ion Sorption by Soils, Jad. Energ. 25, 344 (1979).

288. Davies, B. E. (Ed.): Applied Soil Trace Elements, Wiley, New York 1980.

289. Yamamoto, M., Yamamori, S., Komura, K., Sakanoue, K.: Behaviour of Plutonium and Americium in Soils, J. Radiat. Res. 21, 204 (1980).

290. Hanson, W. C. (Ed.): Transuranic Elements in the Environment, US Department of Energy, Technical Information Center, Washington, D.C., 1980.

291. Fowler, E. B., Essington, E. H., Polzer, W. L.: The Interaction of Low Level Liquid Radioactive Waste with Soils: I. Behaviour of Radionuclides in Soil-Waste Systems, Soil Sci. 132, 2 (1981).

292. Yamamoto, M., Tanii, T., Sakanoue, M.: Characteristics of Fall-out Plutonium in Soil, J. Radiat. Res. 22, 134 (1981).

293. Bachhuber, H., Bunzl, K., Schimmack, W., Gaus, I.: The Migration of ${ }^{137} \mathrm{Cs}$ and ${ }^{90} \mathrm{Sr}$ in Multilayered Soils: Results from Batch, Column and Fallout Investigations, Nucl. Technol. 59, 291 (1982).

294. Cook, G. T., Baxter, M. S., Duncan, H. J., Malcolmson, R.: Geochemical Associations of Plutonium and Gammaemitting Radionuclides in Caithness Soils and Marine Particulates, J. Environ. Radioact. 1, 119 (1984).

295. Sposito, G.: The Surface Chemistry of Soils, Oxford University Press, Oxford 1984.

296. Spalding, B. P.: Extraction of Radiostrontium Coprecipitated with Calcium Carbonate in Soil, Soil Sci. Soc. Am. J. 49, 69 (1985).

297. Bors, J., Martens, B.: Studies on the Significance of Organic Soil Components on the Immobilization of Radioiodine, in: Proc. 4th Internat. Symp. Radioecology. The Impact of Nuclear Origin Accidents on Environment, p. D142, Cadarache 1988.

298. Livens, F. R., Rimmer, D. L.: Physico-chemical Controls of Artificial Radionuclides in Soil, Soil Use Manag. 4, 63 (1988).

299. Livens, F. R., Baxter, M. S.: Particle Size and Radionuclide Levels in Some West Cumbrian Soils, Sci. Total Environ. 70, 1 (1988).

300. Robens, E., Hauschild, J., Aumann, D. C.: Iodine-129 in the Environment of a Nuclear Fuel Reprocessing Plant: IV. ${ }^{129} \mathrm{I}$ and ${ }^{127} \mathrm{I}$ in Undisturbed Surface Soils, J. Environ. Radioact. 9, 17 (1989).

301. Sposito, G.: The Chemistry of Soils, Oxford 1989.

302. Rauret, G., Llaurado, M., Vidal, M.: Solid Speciation of Radiocaesium in Soils, in: Proc. Workshop Transfer of Radionuclides in Natural and Semi-Natural Environments (Eds. Desmet, P., Nassimbeni, P., Belli, M.), p. 538, Elsevier, Amsterdam 1990.

303. Bors, J., Erten, H., Martens, R.: Sorption Studies of Radioiodine in Soils with Special References to Soil Microbial Biomass, Radiochim. Acta 52/53, 317 (1991).

304. Assimakopoulos, P., Ioannides, K. G., Karamanis, D. T., Pakou, A. A., Stamoulis, K. C., Vayonakis, A., Veltsos, E.: Radiocaesium Aging in Surface Soils, in: Proc. Internat. Symp. Radioecology, Znojmo, Commission of European Communities 1992.

305. Oughton, D. H., Salbu, B., Riise, G., Lien, H., Oestby, G., Noeren, A.: Radionuclide Mobility and Bioavailability in Norwegian and Soviet Soils, Analyst 117, 481 (1992).

306. Arapis, G., Voutsinas, M., Martinez, A., Millan, R., Gutierrez, J.: Behaviour of Cesium in Contaminated Soils with and without Agricultural Practices, Radiochim. Acta 58/ 59, 309 (1992). 
307. Cremers, A., Maes, A.: Radionuclide Partitioning in Environmental Systems: A Critical Analysis, in: Application of Distribution Coefficients in Radiological Assessment Models (Eds. Sibley, T. H., Myttenaere, C.), Elsevier Applied Science, London 1985.

308. Stumm, W. (Ed.): Equilibria Concepts in Natural Water Systems, Amer. Chem. Soc., Adv. Chem. Series 67, Washington, D.C., 1967.

309. Schindler, P. W., Fürst, B., Dick, R., Wolf, P. U.: Ligand Properties of Surface Silanol Groups: Surface Complex Formation with $\mathrm{Fe}^{3+}, \mathrm{Cu}^{2+}, \mathrm{Cd}^{2+}$ and $\mathrm{Pb}^{2+}$, J. Colloid Interface Sci. 55, 469 (1976)

310. Davis, J. A., Leckie, J. O.: Effect of Adsorbed Complexing Ligands on Trace Metal Uptake by Hydroxides, Environ. Sci. Technol. 12, 1309 (1978).

311. Davis, J. A., James, R. O., Leckie, J. O.: Surface Ionization and Complexation at the Oxide-Water Interface. I. Computation of Electrical Double Layer Properties in Simple Electrolytes, J. Colloid Interface Sci. 63, 480 (1978).
312. Davis, J. A., Leckie, J. O.: Surface Ionization and Complexation at the Oxide-Water Interface. II. Surface Properties of Amorphous Iron Oxyhydroxide and Adsorption on Metal Ions, J. Colloid Interface Sci. 67, 90 (1978).

313. Jenne, E. A.: Chemical Modelling in Aqueous Systems, Amer. Chem. Soc. Symp. Series 93, Washington, D.C., 1979.

314. Stumm, W., Kummert, R., Sigg, L.: A Ligand Exchange Model for the Adsorption of Inorganic and Organic Ligands at Hydrous Oxide Surfaces, Croat. Chim. Acta 530, 291 (1980).

315. Westall, J., Hohl, H.: A Comparison of Electrostatic Models for the Oxide-Solution Interface, Adv. Colloid Interface Sci. 12, 265 (1980).

316. Schindler, P. W.: Surface Complexes at Oxide-Water Interfaces, in: Adsorption of Inorganics at Solid-Liquid Interfaces (Eds. Anderson, M. A., Rubin, A.), Ann Arbor Science, Ann Arbor 1981. 



\title{
Actinide Environmental Chemistry
}

\author{
By R. J. Silva and H. Nitsche ${ }^{1, *}$ \\ San Jose State University, San Jose, CA 95102, USA \\ ${ }^{1}$ Institut für Radiochemie, Forschungszentrum Rossendorf e.V., P. O. Box 510119, D-01314 Dresden, Germany
}

(Received September 18, 1995)

\section{Actinides / Chemistry / Environment / Migration}

\begin{abstract}
Summary
In order to predict release and transport rates, as well as design cleanup and containment methods, it is essential to understand the chemical reactions and forms of the actinides under aqueous environmental conditions. Four important processes that can occur with the actinide cations are: precipitation, complexation, sorption and colloid formation. Precipitation of a solid phase will limit the amount of actinide in solution near the solid phase and have a retarding effect on release and transport rates. Complexation increases the amount of actinide in solution and tends to increase release and migration rates. Actinides can sorb on to mineral or rock surfaces which tends to retard migration. Actinide ions can form or become associated with colloidal sized particles which can, depending on the nature of the colloid and the solution conditions, enhance or retard migration of the actinide. The degree to which these four processes progress is strongly dependent on the oxidation state of the actinide and tends to be similar for actinides in the same oxidation state.

In order to obtain information on the speciation of actinides in solution, i.e., oxidation state, complexation form, dissolved or colloidal forms, the use of absorption spectroscopy has become a method of choice. The advent of the ultrasensitive, laser induced photothermal and fluorescence spectroscopies has made possible the detection and study of actinide ions at the parts per billion level. With the availability of third generation synchrotrons and the development of new fluorescence detectors, X-ray absorption spectroscopy (XAS) is becoming a powerful technique to study the speciation of actinides in the environment, particularly for reactions at the solid/solution interfaces.
\end{abstract}

\section{Introduction}

Due to nuclear testing, reentry and disintegration of nuclear powered satellites, nuclear reactor accidents, uranium mining and nuclear weapons production, actinides have been introduced into the environment. Proposed disposal of high-level radioactive waste in mined repositories in geologic formations as well as the storage and disposal of uranium and plutonium from weapons dismantlement are further possible sources for actinide releases to the environment. In order to design methods for the cleanup of contaminated sites, predict the transport behavior in the environment, perform safety assessment studies to determine the ability of repositories to adequately contain them, and design ways to retard their release and migration rates, it is essential to understand the chemical behavior and forms of actinides under environmental con-

\footnotetext{
* Corresponding author.
}

ditions. Because aqueous transport is the most likely scenario for wide-spread actinide intrusion into the biosphere, one needs to know the aqueous chemistry of actinides under environmental conditions and how that chemistry controls the interactions of the actinides with the surrounding geologic media and thus the actinide transport behavior.

The amounts and half-lives of the actinides produced in nuclear explosions and spent reactor fuel need to be considered to decide which actinide isotopes are of most concern from a radiological hazards points of view. The half-lives of selected long-lived isotopes of the actinides are given in Table 1 [1]. The actinides that have long-lived isotopes with large production amounts, and thus are the major contributors to the present contamination and possible future contaminations, are $\mathrm{U}, \mathrm{Np}, \mathrm{Pu}$ and $\mathrm{Am}$. For example, a few hundred years after enriched uranium spent fuel has been removed from boiling and pressurized water reactors, the actinides $U$ through Am account for more than 98 percent of the radioactivity in the fuel $[2,3]$. In Figure 1, the distribution of curies per metric ton of heavy metal is shown as a function of time after removal from a typical BWR with 30,000 megawatt-day burnup as calculated using the ORIGEN computer code $[2,3]$.

\section{Reactions in the environment}

If one wants to model or predict the release or transport rates of actinides under aqueous environmental conditions, several processes that control the amounts and forms of the actinide in solution should be considered. Four important processes that can occur with actinide cations are: (1) precipitation, (2) complexation, (3) sorption and (4) colloid formation.

Precipitation can occur if there is sufficient concentration of the actinide in solution to exceed the solubility product constant for the formation of a solid phase. This effect will limit the amount of the actinide in solution in the vicinity of the solid phase at any given time and thus will tend to have a retarding effect on release and migration rates.

A number of inorganic and organic ligands that can form complexes with the actinide ions in solution may be present in groundwaters. The charge of the solution complex can vary widely. Complexation increases the 
Table 1. Nuclear properties of selected actinide isotopes [1]

\begin{tabular}{|c|c|c|c|c|}
\hline Nuclide & Mode of decay & Half-life & Availability & Source \\
\hline Th-227 & $\alpha$ & $18.7 \mathrm{~d}$ & trace & nature \\
\hline Th-228 & $a$ & $1.9 \mathrm{y}$ & trace & nature \\
\hline Th-229 & $\alpha$ & $7.3 \times 10^{3} \mathrm{y}$ & g & ${ }^{233} \mathrm{U}$ daughter \\
\hline Th-230 & $\alpha$ & $8.0 \times 10^{4} y$ & $\mathrm{~g}$ & nature \\
\hline \multirow[t]{2}{*}{ Th-232 } & $a$ & $1.41 \times 10^{10} y$ & $\mathrm{~kg}$ & nature \\
\hline & SF & $>1 \times 10^{21} \mathrm{y}$ & & \\
\hline Th-234 & $\beta^{-}$ & $24.10 \mathrm{~d}$ & trace & nature \\
\hline $\mathrm{Pa}-231$ & $\alpha$ & $3.28 \times 10^{4} \mathrm{y}$ & $\mathrm{g}$ & nature \\
\hline $\mathrm{Pa}-233$ & $\beta^{-}$ & $27.0 \mathrm{~d}$ & $\mathrm{~g}$ & $\begin{array}{l}{ }^{233} \mathrm{Th} \text { daughter } \\
{ }^{237} \mathrm{~Np} \text { daughter }\end{array}$ \\
\hline \multirow{2}{*}{$\begin{array}{c}\mathrm{Pa}-234 \\
\mathrm{U}-232\end{array}$} & $\beta^{-}$ & $6.75 \mathrm{~h}$ & trace & nature \\
\hline & $\begin{array}{c}\alpha \\
S F\end{array}$ & $\begin{array}{c}68.9 y \\
8 \times 10^{13} y\end{array}$ & $\mathrm{~g}$ & ${ }^{232} \mathrm{Th}$ daughter \\
\hline \multirow[t]{2}{*}{$\mathrm{U}-233$} & $\alpha$ & $1.59 \times 10^{5} \mathrm{y}$ & $\mathrm{kg}$ & ${ }^{233} \mathrm{~Pa}$ daughter \\
\hline & SF & $1.2 \times 10^{17} \mathrm{y}$ & & \\
\hline \multirow{2}{*}{ U-234 } & $a$ & $2.45 \times 10^{5} \mathrm{y}$ & $\mathrm{g}$ & nature \\
\hline & SF & $2 \times 10^{16} \mathrm{y}$ & & \\
\hline \multirow[t]{2}{*}{ U-235 } & $a$ & $7.0 \times 10^{8} y$ & $\mathrm{~kg}$ & nature \\
\hline & SF & $3.5 \times 10^{17} \mathrm{y}$ & & \\
\hline \multirow[t]{2}{*}{ U-238 } & $\alpha$ & $4.47 \times 10^{9} \mathrm{y}$ & $\mathrm{kg}$ & nature \\
\hline & SF & $8.19 \times 10^{15} \mathrm{y}$ & & \\
\hline $\mathrm{Np}-237$ & $\stackrel{\alpha}{S F}$ & $\begin{array}{l}2.14 \times 10^{6} \mathrm{y} \\
>1 \times 10^{18} \mathrm{y}\end{array}$ & $\mathrm{kg}$ & $\begin{array}{c}\text { nature(?) } \\
{ }^{237} \mathrm{U} \text { daughter } \\
{ }^{241} \mathrm{Am} \text { daughter }\end{array}$ \\
\hline \multirow{2}{*}{$\begin{array}{l}\mathrm{Np}-238 \\
\mathrm{~Np}-239\end{array}$} & $\beta^{-}$ & $2.1 \mathrm{~d}$ & trace & ${ }^{237} \mathrm{~Np}(\mathrm{n}, \gamma)$ \\
\hline & $\beta^{-}$ & $2.35 \mathrm{~d}$ & $\mu \mathrm{g}$ & $\begin{array}{c}\text { nature(?) } \\
{ }^{243} \mathrm{Am} \text { daughter } \\
{ }^{239} \mathrm{U} \text { daughter }\end{array}$ \\
\hline \multirow[t]{2}{*}{ Pu-238 } & $\alpha$ & $87.7 \mathrm{y}$ & $\mathrm{kg}$ & ${ }^{242} \mathrm{Cm}$ daughter \\
\hline & SF & $4.8 \times 10^{10} y$ & & ${ }^{238} \mathrm{~Np}$ daughter \\
\hline \multirow[t]{2}{*}{ Pu-239 } & $\alpha$ & $2.41 \times 10^{4} \mathrm{y}$ & $\mathrm{kg}$ & nature(?) \\
\hline & SF & $5.5 \times 10^{15} \mathrm{y}$ & & $\begin{array}{c}{ }^{239} \mathrm{~Np} \text { daughter } \\
\text { n capture }\end{array}$ \\
\hline \multirow[t]{2}{*}{$\mathrm{Pu}-240$} & $\alpha$ & $6.56 \times 10^{3} \mathrm{y}$ & g & multi $n$ capture \\
\hline & SF & $1.34 \times 10^{11} \mathrm{y}$ & $\mathrm{g}$ & \\
\hline $\mathrm{Pu}-241$ & $\beta^{-}(>99 \%)$ & $14.4 \mathrm{y}$ & $\mathrm{g}$ & multi n capture \\
\hline \multirow[t]{2}{*}{$\mathrm{Pu}-242$} & $\begin{array}{c}\alpha(<0.002 \%) \\
\alpha\end{array}$ & $3.76 \times 10^{5} y$ & g & multi n capture \\
\hline & SF & $6.8 \times 10^{10} \mathrm{y}$ & B & \\
\hline \multirow{2}{*}{ Pu-244 } & $\alpha$ & $8.26 \times 10^{7} \mathrm{y}$ & $\mathrm{g}$ & nature(?) \\
\hline & SF & $6.6 \times 10^{10} \mathrm{y}$ & & multi n capture \\
\hline \multirow{2}{*}{ Am-241 } & $\alpha$ & $432.7 \mathrm{y}$ & $\mathrm{kg}$ & ${ }^{241} \mathrm{Pu}$ daughter \\
\hline & SF & $1.15 \times 10^{14} \mathrm{y}$ & & multi n capture \\
\hline Am-242 & $\beta^{-}(82.7 \%)$ & $16.01 \mathrm{~h}$ & $\mathrm{~g}$ & ${ }^{241} \mathrm{Am}(\mathrm{n}, \gamma)$ \\
\hline$A m-242 m$ & $\begin{array}{l}\mathrm{EC}(17.3 \%) \\
\mathrm{IT}(99.5 \%)\end{array}$ & $141 \mathrm{y}$ & g & ${ }^{241} \mathrm{Am}(\mathrm{n}, \gamma)$ \\
\hline & $\begin{array}{c}\alpha(0.48 \%) \\
S F(0.02 \%)\end{array}$ & $9.5 \times 10^{11} \mathrm{y}$ & & \\
\hline Am-243 & $\begin{array}{c}\alpha \\
\alpha\end{array}$ & $7.38 \times 10^{3} \mathrm{y}$ & kg & multi n capture \\
\hline & SF & $2.0 \times 10^{14} \mathrm{y}$ & & \\
\hline $\mathrm{Cm}-242$ & $a$ & $162.9 \mathrm{~d}$ & $\mathrm{~g}$ & ${ }^{239} \mathrm{Pu}(\alpha, \mathrm{n})$ \\
\hline & SF & $6.1 \times 10^{6} \mathrm{y}$ & & ${ }^{242} \mathrm{Am}$ daughter \\
\hline $\mathrm{Cm}-244$ & $\alpha$ & $18.11 \mathrm{y}$ & kg & multi n capture \\
\hline & SF & $1.35 \times 10^{7} \mathrm{y}$ & & ${ }^{244} \mathrm{Am}$ daughter \\
\hline $\mathrm{Cm}-245$ & $\alpha$ & $8.5 \times 10^{3} \mathrm{y}$ & $\mathrm{g}$ & multi $n$ capture \\
\hline $\mathrm{Cm}-246$ & $a$ & $4.73 \times 10^{3} \mathrm{y}$ & $\begin{array}{l}\mathrm{b} \\
\mathrm{g}\end{array}$ & multi n capture \\
\hline & $\mathrm{SF}$ & $1.8 \times 10^{7} \mathrm{y}$ & & \\
\hline $\mathrm{Cm}-247$ & $\alpha$ & $1.56 \times 10^{7} \mathrm{y}$ & $\mathrm{g}$ & multi n capture \\
\hline $\mathrm{Cm}-248$ & $\alpha(91.74 \%)$ & $3.4 \times 10^{5} y$ & $\mathrm{~g}$ & multi n capture \\
\hline Bk-249 & $\begin{array}{l}\mathrm{SF}(8.26 \%) \\
\beta^{-}(>99 \%)\end{array}$ & $320 \mathrm{~d}$ & $\mathrm{mg}$ & multi $n$ capture \\
\hline & $\alpha(<0.002 \%)$ & & & \\
\hline Bk-250 & $\beta^{-}$ & $3.217 \mathrm{~h}$ & trace & ${ }^{254}$ Es daughter \\
\hline Cf-249 & $\alpha$ & 351 y & $\mathrm{mg}$ & ${ }^{249} \mathrm{Bk}$ daughter \\
\hline & SF & $6.9 \times 1010 y$ & & \\
\hline Cf-252 & $\alpha(96.91 \%)$ & $2.645 \mathrm{y}$ & $\mathrm{mg}$ & multi n capture \\
\hline Es-253 & SF $(3.09 \%)$ & $20.47 \mathrm{~d}$ & $\mu \mathrm{g}$ & multi n capture \\
\hline & SF & $6.3 \times 10^{5} \mathrm{y}$ & & \\
\hline Es-245g & $\alpha$ & $275.7 \mathrm{~d}$ & $\mu \mathrm{g}$ & multi n capture \\
\hline & SF & $>2.5 \times 10^{7} \mathrm{y}$ & & \\
\hline Es-254m & $\begin{array}{l}\beta^{-}(99.6 \%) \\
S F(0.33 \%)\end{array}$ & $39.3 \mathrm{~h}$ & $\mu \mathrm{g}$ & ${ }^{253} \operatorname{Es}(\mathrm{n}, \gamma)$ \\
\hline Es-255 & $\begin{array}{l}\text { SF }(0.33 \%) \\
B^{-}(92.0 \%)\end{array}$ & $>1 \times 10^{5} \mathrm{y}$ & trace & multi n canture \\
\hline & $\begin{array}{c}\rho(8.0 \%) \\
\alpha(8.0 \%)\end{array}$ & & & multi n capture \\
\hline & $\mathrm{SF}\left(4 \times 10^{-3} \%\right)$ & & & \\
\hline
\end{tabular}




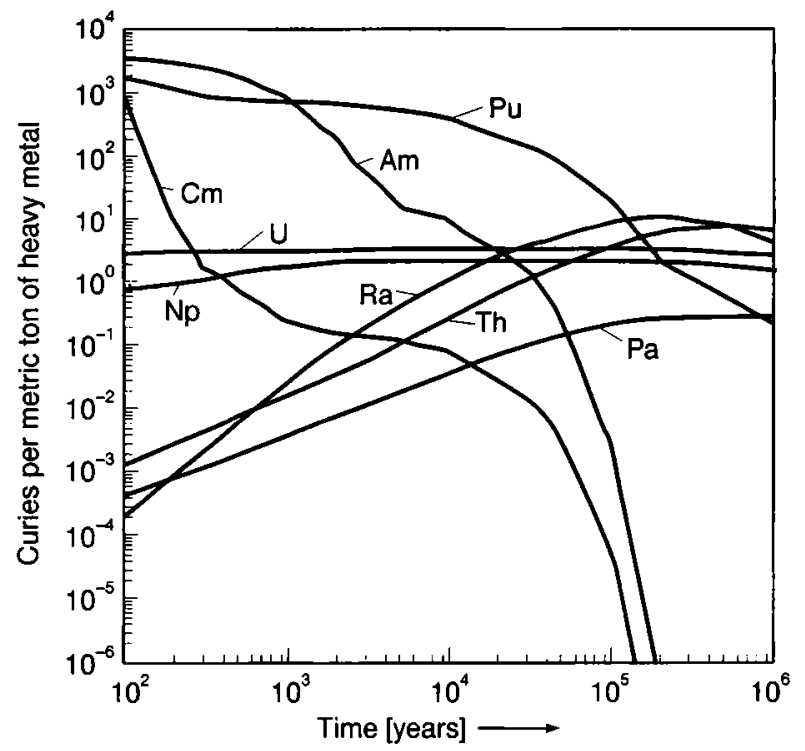

Fig. 1. The distribution of actinide curies per metric ton of heavy metal fuel as a function of time after removal from a typical Boiling Water Reactor with 30,000 megawatt-day burnup as calculated using the ORIGEN code.

amount of the actinide in solution and thus tends to increase release and migrations rates.

The actinide ions may attach themselves to mineral or rock surfaces in contact with the aqueous phase. This process is analogous to the precipitation process since it removes actinide ions from solution. Thus, this process tends to reduce the amount of actinide ion in solution and produce a retarding effect on the migration process.

Finally, the actinide ions can form or become associated with colloidal sized particles. Actinides in this form will not behave like a dissolved species and may exhibit a considerably different migration behavior than the dissolved species. Depending on the nature of the colloid and the solution conditions, this process may enhance or retard migration of the actinide.

All four processes must be considered if one wants to understand and predict the chemical behavior and transport properties of actinides in the environment. Detailed knowledge of the actinide species and charges are essential because the nature and extent of precipitation, complexation, sorption and colloid formation are strongly dependent on them. In addition, because these processes are not independent of one another, they need to be considered simultaneously. These four processes for the actinides $\mathrm{U}, \mathrm{Np}, \mathrm{Pu}$ and $\mathrm{Am}$ will be discussed.

\section{General actinide chemistry}

The actinide series of elements, actinium through lawrencium, results from the filling of the $5 f$ electron shell. The chemical similarity to the $4 f$ lanthanide series was recognized nearly 50 years ago $[4,5]$ and provided the frame work for the design of chemical meth- ods for the isolation and identification of the heavier actinides [6]. Table 2 gives the electronic configurations of the lanthanide and actinide atoms and ions. While the trivalent oxidation state prevails throughout the lanthanide series, higher oxidations states are found to be the most stable in the early members of the actinide series [7]. The conversion from one oxidation state to another in aqueous solution is determined by the magnitude of the energy required to remove an electron from the gaseous ion (ionization energy) and the energy released when the gaseous ion combines with water to form the aqueous ion (hydration energy). There exists a large binding energy difference between the $4 f$ electrons and the $5 d, 6 s$ electrons for the lanthanide elements and the trivalent state owes its stability to a fortuitous combination of ionization and hydration energies [8]. There is not sufficient hydration energy gain over the ionization energy for the $4 f$ electrons to produce oxidation states above $3+$ as the most stable in aqueous solution. However, other oxidations states can be produced under oxidizing [Ce(IV), $\mathrm{Tb}(\mathrm{IV})]$ and reducing conditions [Eu(II), $\mathrm{Yb}(\mathrm{II})]$ due to the special stability of the $4 f^{0}, 4 f^{7}$ and the $4 f^{14}$ electronic configurations [8]. In contrast, the $5 f$ electrons are shielded to a larger extent from the nucleus of the atom than are the $4 f$ electrons. This results in a smaller energy difference between the $5 f, 6 d$ and $7 s$ electrons than in the lanthanide series [7] and a wider range of oxidation states are possible. The oxidation states that have been observed are given in Table 3 . Not all of these oxidation states are possible under environmental conditions as will be discussed later.

While the charge remains $3+$, the ionic radii of the lanthanides decrease slightly across the series (the lanthanide contraction) [8]. Many chemical reactions of an ionic nature are correlated with the ratio of the charge to volume of the ions, the charge density [9]. The change of the charge density across the series is sufficiently small that the chemical properties are nearly identical. The lanthanide contraction is essentially parallel among the di, tri and tetravalent ions [10]. The trivalent $5 f$ elements exhibit a similar decrease in ionic radii across the series (the actinide contraction) and actinides in the $3+$ state tend also to exhibit similar chemical properties $[7,11]$. Further, trivalent actinides tend to exhibit similar chemical properties to trivalent lanthanides of the same ionic radius [7], e.g., $\mathrm{Nd}^{3+}$ and $\mathrm{Am}^{3+}$ form isostructural oxides of similar solubilities [12] and elute in similar positions from ion-exchange resin columns using $\alpha$-hydroxyisobutyrate as eluant [13]. Also trivalent actinides and trivalent lanthanides have similar hydrolysis constants [14]. There are many other such examples. The radii of the tetravalent actinides exhibit the same regular contraction with atomic number [11]. Because of the similarities and the fact that actinide ions in the same oxidation state have essentially the same core structure, actinides in the same oxidation state will tend to have similar chemical properties. This has certainly been found to be true 
Table 2. Electronic configurations of $f$-block atoms and ions ${ }^{a}$ [7]

\begin{tabular}{|c|c|c|c|c|c|c|c|c|}
\hline \multicolumn{3}{|c|}{ Lanthanide series } & \multicolumn{6}{|c|}{ Actinide series } \\
\hline Element & $\begin{array}{l}\text { Gaseous } \\
\text { atom }\end{array}$ & $\mathrm{M}^{3+}(\mathrm{g})$ & Element & $\begin{array}{l}\text { Gaseous } \\
\text { atom }\end{array}$ & $\mathrm{M}^{+}(\mathrm{g})$ & $\mathrm{M}^{2+}(\mathrm{g})$ & $\mathrm{M}^{3+}(\mathrm{g})$ & $\mathrm{M}^{4+}(\mathrm{g})$ \\
\hline $\mathrm{La}$ & $5 d 6 s^{2}$ & & Ac & $6 d 7 s^{2}$ & $7 s^{2}$ & $7 s$ & & \\
\hline $\mathrm{Ce}$ & $4 f 5 d 6 s^{2}$ & $4 f$ & Th & $6 d^{2} 7 s^{2}$ & $6 d 7 s^{2}$ & $5 f 6 d$ & $5 f$ & \\
\hline $\operatorname{Pr}$ & $4 f^{3} 6 s^{2}$ & $4 f^{2}$ & $\mathrm{~Pa}$ & $5 f^{2} 6 d 7 s^{2}$ & $5 f^{2} 7 s^{2}$ & $5 f^{2} 6 d$ & $5 f^{2}$ & $5 f$ \\
\hline $\mathrm{Nd}$ & $4 f^{4} 6 s^{2}$ & $4 f^{3}$ & $\mathrm{U}$ & $5 f^{3} 6 d 7 s^{2}$ & $5 f^{3} 7 s^{2}$ & $5 f^{3} 6 d ?$ & $5 f^{3}$ & $5 f^{2}$ \\
\hline $\mathrm{Pm}$ & $4 f^{5} 6 s^{2}$ & $4 f^{4}$ & $\mathrm{~Np}$ & $5 f^{4} 6 d 7 s^{2}$ & $5 f^{5} 7 s ?$ & $5 f^{5} ?$ & $5 f^{4}$ & $5 f^{3}$ \\
\hline $\mathrm{Sm}$ & $4 f^{x} 6 s^{2}$ & $4 f^{5}$ & $\mathrm{Pu}$ & $5 f^{6} 7 s^{2}$ & $5 f^{57} 7 s$ & $5 f^{6}$ & $5 f^{5}$ & $5 f^{4}$ \\
\hline $\mathrm{Eu}$ & $4 f^{7} 6 s^{2}$ & $4 f^{6}$ & $\mathrm{Am}$ & $5 f 7 s^{2}$ & $5 f^{7} 7 s$ & $5 f^{7}$ & $5 f^{6}$ & $5 f^{5}$ \\
\hline $\mathrm{Gd}$ & $4 f^{7} 5 d 6 s^{2}$ & $4 f^{7}$ & $\mathrm{Cm}$ & $5 f^{7} 6 d 7 s^{2}$ & $5 f^{7} 7 s^{2}$ & $5 f^{\star}$ & $5 f^{7}$ & $5 f^{6}$ \\
\hline $\mathrm{Tb}$ & $4 f^{9} 6 s^{2}$ & $4 f^{\circ}$ & $\mathrm{Bk}$ & $5 f^{9} 7 s^{2}$ & $5 f^{9} 7 s$ & $5 f^{9}$ & $5 f^{8}$ & $5 f^{7}$ \\
\hline Dy & $4 f^{116} 6 s^{2}$ & $4 f^{9}$ & $\mathrm{Cf}$ & $5 f^{10} 7 s^{2}$ & $5 f^{10} 7 s$ & $5 f^{10}$ & $5 f^{9}$ & $5 f^{x}$ \\
\hline $\mathrm{Ho}$ & $4 f^{11} 6 s^{2}$ & $4 f^{10}$ & Es & $5 f^{11} 7 s^{2}$ & $5 f^{117} s$ & $5 f^{11}$ & $5 f^{10}$ & $\left(5 f^{9}\right)$ \\
\hline Er & $4 f^{12} 6 s^{2}$ & $4 f^{\prime \prime}$ & Fm & $5 f^{12} 7 s^{2}$ & $\left(5 f^{12} 7 s\right)$ & $\left(5 f^{12}\right)$ & $\left(5 f^{\prime 1}\right)$ & $\left(5 f^{16}\right)$ \\
\hline $\mathrm{Tm}$ & $4 f^{13} 6 s^{2}$ & $4 f^{12}$ & $\mathrm{Md}$ & $\left(5 f^{13} 7 s^{2}\right)$ & $\left(5 f^{13} 7 s\right)$ & $\left(5 f^{13}\right)$ & $\left(5 f^{12}\right)$ & $\left(5 f^{11}\right)$ \\
\hline $\mathrm{Yb}$ & $4 f^{14} 6 s^{2}$ & $4 f^{1.3}$ & No & $\left(5 f^{34} 7 s^{2}\right)$ & $\left(5 f^{14} 7 s\right)$ & $\left(5 f^{14}\right)$ & $\left(5 f^{13}\right)$ & $\left(5 f^{12}\right)$ \\
\hline \multirow[t]{3}{*}{$\mathrm{Lu}$} & $4 f^{14} 5 d 6 s^{2}$ & $4 f^{14}$ & $\mathrm{Lr}$ & $\left(5 f^{14} 6 d 7 s^{2}\right.$ & $\left(5 f^{14} 7 s^{2}\right)$ & $\left(5 f^{14} 7 s\right)$ & $\left(5 f^{14}\right)$ & $\left(5 f^{13}\right)$ \\
\hline & & & & or & & & & \\
\hline & & & $\mathrm{Rf}$ & $\begin{array}{l}\left.5 f^{14} 7 s^{2} 7 p\right) \\
\left(5 f^{14} 6 d^{2} 7 s^{2}\right)\end{array}$ & & & & $\left(5 f^{14}\right)$ \\
\hline
\end{tabular}

"Predicted configurations in parentheses.

Table 3. The oxidation states of the actinide elements [7]

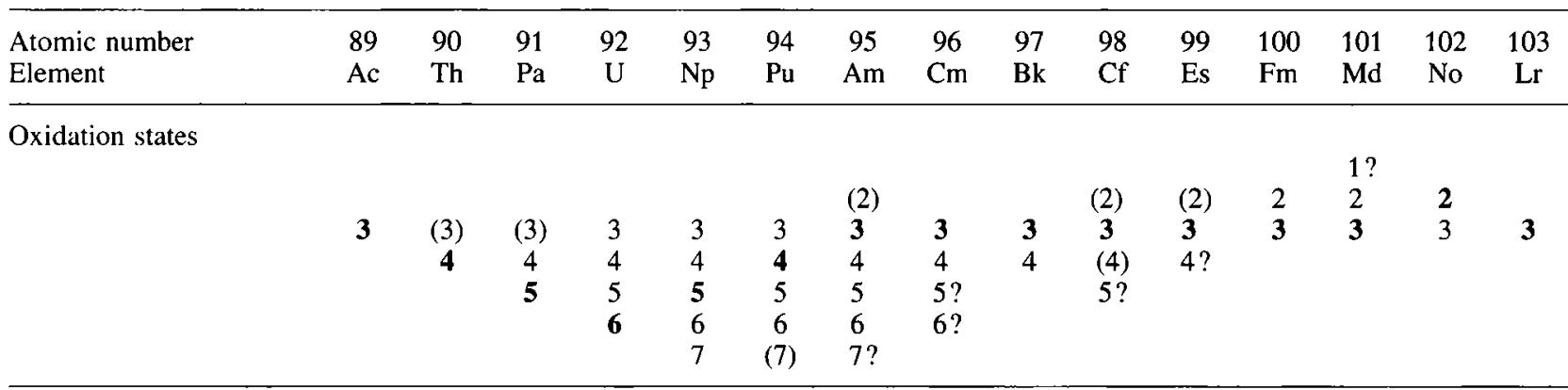

Bold type $=$ most stable; ()$=$ unstable; ? = claimed but not substantiated.

for the solubilities of many compounds and for the formation constants for many complexes.

Actinide ions in the trivalent and tetravalent states in acidic solutions are in the form of the simple hydrated ions $\mathrm{An}^{3+}$ and $\mathrm{An}^{4+}$. Actinides in higher oxidation states form oxygenated species in solution called actinyl ions [7]. They have a symmetric and nearly linear structure. The actinyl ions $\mathrm{AnO}_{2}^{+}$and $\mathrm{AnO}_{2}^{2+}$ are extremely stable and act as a unit in chemical reactions. However, this structure decreases the effective charge on the central actinide ion, e.g., values of +3.2 and +2.2 have been reported for the effective charge on the $\mathrm{Pu}$ atom in the $\mathrm{PuO}_{2}^{2+}$ and $\mathrm{PuO}_{2}^{+}$ions, respectively [15].

\section{Environmental actinide chemistry}

\subsection{Oxidation states}

The single most important property of an actinide ion is its oxidation state because precipitation, complexation, sorption and colloid formation behavior dif- fer considerably from one oxidation state to another. Water has an important oxidation-reduction chemistry that puts limits on the oxidation states that actinides can have in aqueous solutions. The oxidizing and reducing reactions of water (relative to the standard hydrogen electrode) are [16]:

In acid solution

$$
\begin{aligned}
& \mathrm{H}^{+}+e^{-}=1 / 2 \mathrm{H}_{2} \quad E_{f}=0.00 \mathrm{~V} . \\
& 1 / 4 \mathrm{O}_{2}+\mathrm{H}^{+}+e^{-}=1 / 2 \mathrm{H}_{2} \mathrm{O} \quad E_{f}=1.23 \mathrm{~V}
\end{aligned}
$$

In basic solution

$$
\begin{aligned}
& \mathrm{H}_{2} \mathrm{O}+e^{-}=1 / 2 \mathrm{H}_{2}+\mathrm{OH}^{-} \\
& E_{f}^{\mathrm{b}}=-0.826 \mathrm{~V} . \\
& 1 / 4 \mathrm{O}_{2}+1 / 2 \mathrm{H}_{2} \mathrm{O}+e^{-}=\mathrm{OH}^{-} \\
& E_{f}^{\mathrm{b}}=0.404 \mathrm{~V} .
\end{aligned}
$$

The formal electrode potentials, $E_{f}$, refer to standard conditions of an ideal one molal solution of ions and one bar gaseous pressure. The way in which these po- 


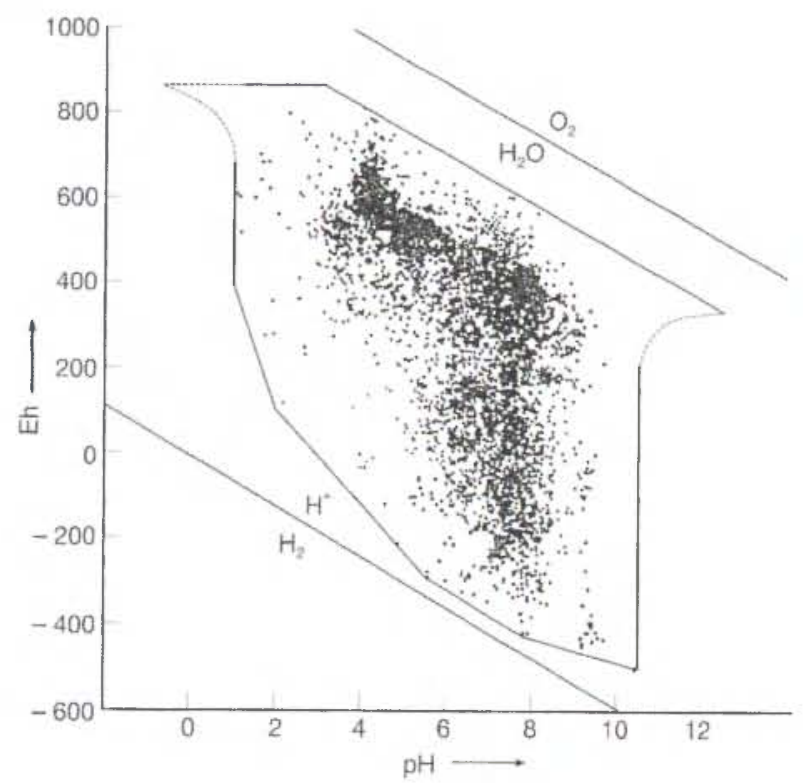

Fig. 2. Eh-pH range found in waters in the natural environment. Heavy solid line represent the stability of water (reprinted with permission from [17], Copyright 1960, The University of Chicago Press).

tentials vary with $\mathrm{pH}$ is given by the solid lines in Figure 2. The points shown in Figure 2 are values obtained from Eh and $\mathrm{pH}$ measurements on natural waters from hundreds of different sources around the world [17] and illustrate the wide range in Eh and $\mathrm{pH}$ values. The points in the upper half of the diagram represent samples taken from environments in contact with the atmosphere. They range from around $\mathrm{pH} 4$ for mine waters, tô $\mathrm{pH} 6$ for rain and streams, to $\mathrm{pH} 8$ for normal sea water and 10 for aerated saline residues. The points in the lower half of the Eh-pH diagram are for waters that were isolated from the atmosphere. They range from about $\mathrm{pH} 5$ for water-logged soils to $\mathrm{pH} 10$ for organic saline waters. Any half-reaction with a potential between the two lines of $\mathrm{H}_{2} \mathrm{O}$ is stable with respect to oxidation or reduction by water. Of the many oxidation states that have been found for the actinides, only those with potentials that lie between the limits of water stability will persist in natural aquatic environments. In addition to oxygen, a few other elements $(\mathrm{C}, \mathrm{N}, \mathrm{O}, \mathrm{S}, \mathrm{Fe}, \mathrm{Mn})$ participate in redox reactions that are responsible for establishing the Eh of groundwater [16].

Figure 3 shows the reported redox potentials for the actinide ions at $\mathrm{pH}=0$ and $\mathrm{pH}=14$ [7]. Comparisons of these values with the limits set by the stability of water given in reactions 1 through 4 above indicate that $\mathrm{U}(4+, 5+, 6+), \mathrm{Np}(3+, 4+, 5+, 6+), \mathrm{Pu}(3+$, $4+, 5+, 6+)$ and Am (3+) would be expected to be stable in natural aqueous environments.

The potential for other than standard conditions is given by the Nernst equation [18]:

$$
\begin{aligned}
& E=E^{0}+(R T / n F) \ln ([\mathrm{ox}] /[\mathrm{red}]) \\
& =E^{0}+(0.059 / n) \log ([\mathrm{ox}] /[\mathrm{red}])
\end{aligned}
$$

where $R=$ the gas constant, $T=$ degrees Kelvin, $n=$ number of electrons involved, $F=$ the Faraday constant, $[\mathrm{ox}]=$ the concentration of the oxidized species, and [red] $=$ the concentration of the reduced species. While the redox reaction between the $3+$ and $4+$ states as well as the $5+$ and $6+$ states are $\mathrm{pH}$ independent, oxidation or reduction reactions between either of the two lower oxidation states and either of the two upper oxidation states will be $\mathrm{pH}$ dependent because of the formation of the actinyl ion. For example:

$$
\begin{aligned}
& \mathrm{Pu}^{3+}=\mathrm{Pu}^{4+}+e^{-} \\
& \mathrm{Pu}^{4+}+2 \mathrm{H}_{2} \mathrm{O}=\mathrm{PuO}_{?}^{+}+4 \mathrm{H}^{+}+e^{-} \\
& \mathrm{PuO}_{2}^{+}=\mathrm{PuO}_{3}^{2+}+e^{-} .
\end{aligned}
$$

Low $\mathrm{pH}$ values tend to favor the lower oxidation states while the higher oxidation states become more accessible as the $\mathrm{pH}$ is increased, e.g., in acid solutions $(\mathrm{pH}$ $<1$ ) in contact with air, $\mathrm{Pu}^{4+}$ is the most stable oxidation state while $\mathrm{PuO}_{2}^{+}$is the more stable at neutral $\mathrm{pH}$ [19].

Strong complexation of one member of a redox pair can significantly shift the potential in favor of its formation. Therefore, in order to calculate the exact Eh value where oxidation state conversions occurs for $\mathrm{U}, \mathrm{Np}, \mathrm{Pu}$ and $\mathrm{Am}$, all of the significant reactions of the actinide ions in solution would need to be included. For a solution of low ionic strength $(0.01 \mathrm{M}$ $\mathrm{NaCl}$ ), exposed to atmospheric $\mathrm{CO}_{2}$ and at a pH of 7 . the concentrations of different oxidations states for $\mathrm{U}$, $\mathrm{Np}, \mathrm{Pu}$ and Am were calculated as a function of Eh using the thermodynamic data base for the formation of actinide complexes with hydroxide and carbonate given in references [20], [21] and [22] and the reduction potentials given in Figure 3 . The calculation was performed using the speciation computer code HYDRAQL [23]. The results are shown in Figure 4. In a mined repository open to the air with such a dilute groundwater, the oxidation states in solution one would expect to be dominant are: $\mathrm{UO}_{2}^{+}, \mathrm{NpO}_{2}^{+}, \mathrm{PuO}_{2}^{+}$ and $\mathrm{PuO}_{2}^{2+}$, and $\mathrm{Am}^{3+}$. However, the oxidation of $\mathrm{Am}^{3+}$ to $\mathrm{AmO}_{2}^{-}$in brine solutions with $\mathrm{pH}>8$ and $\mathrm{NaCl}$ concentrations $>3 \mathrm{M}$ has been observed [24]. This is due to the formation of oxidizing forms of chlorine produced by the alpha radiation of the Am.

\subsection{Precipitation}

Precipitation can limit the amount of actinide in solution and thus can be the first step in the retardation process. The common anions in groundwaters are hydroxide, carbonate, sulfate, phosphate, fluoride, chloride, nitrate and silicate. In Table 4, the composition of water from a number of sources are shown [1]. Hydroxide, carbonate, sulfate, phosphate and fluoride form insoluble compounds with the actinides while chloride and nitrate compounds are quite soluble [25]. The silicate compounds have not been investigated to any great extent, however, uranium forms very insoluble compounds with silica, e.g., uranophane, sodium 

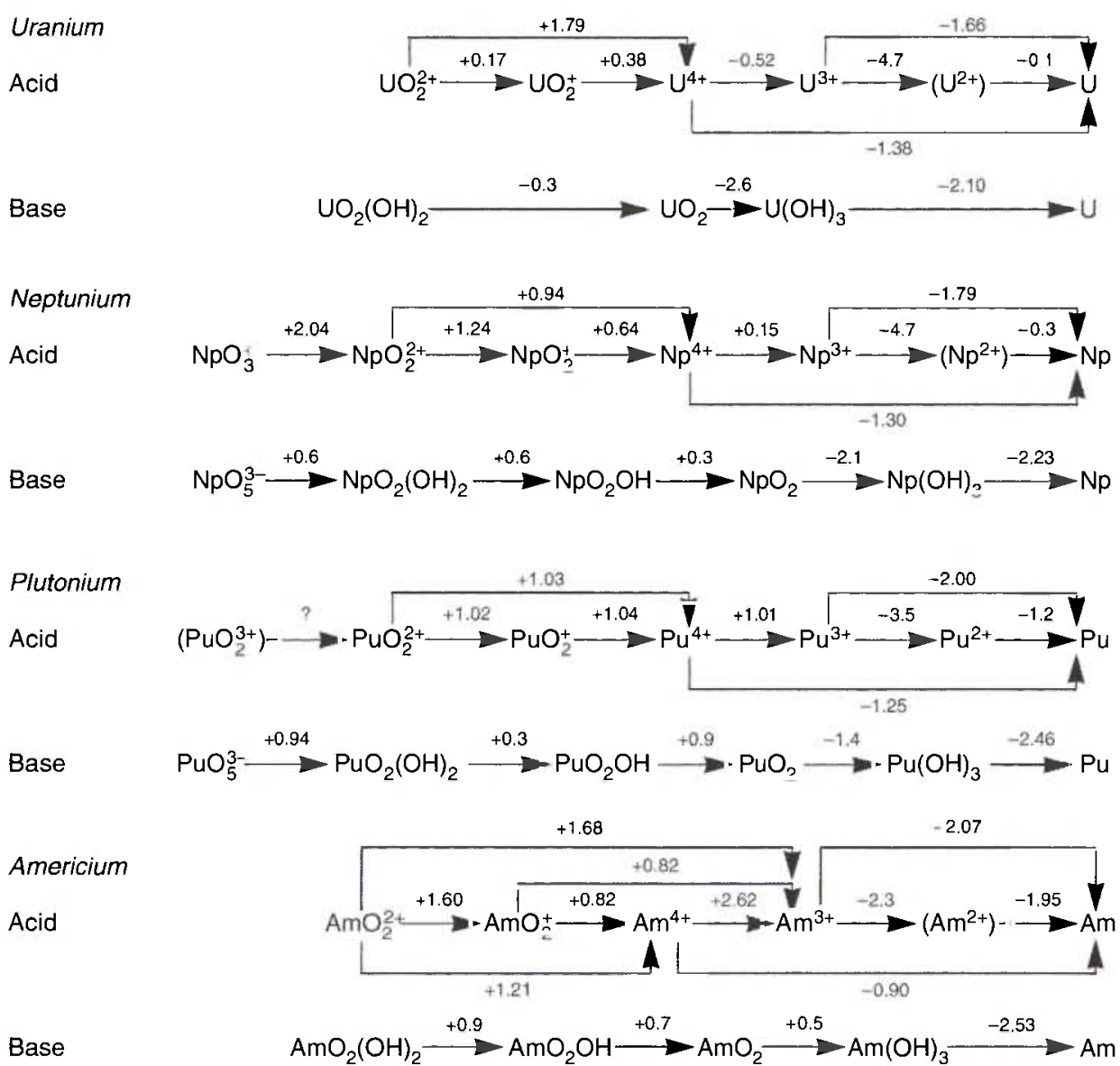

Fig. 3. Standard reduction potentials (volts vs. standard hydrogen electrode) of uranium, neptunium, plutonium and americium in 3znacidic ( $\mathrm{pH} 0$ ) and basic ( $\mathrm{pH} \mathrm{14)}$ aqueous solution. (From Ref. [7].)

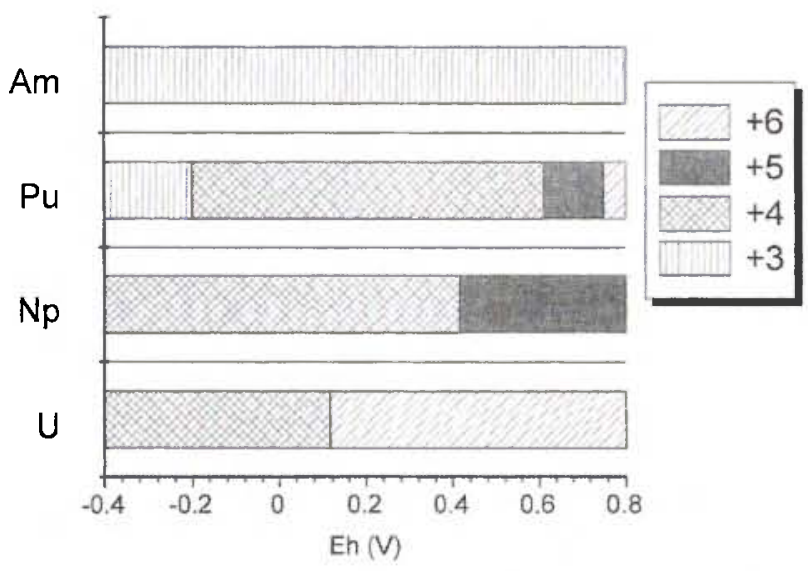

Fig. 4. The calculated distribution in oxidation states of uranium, neptunium, plutonium and americium as function of the Eh of an aqueous solution of $0.01 \mathrm{M} \mathrm{NaCl}$ exposed to atmospheric $\mathrm{CO}_{2}$ at a $\mathrm{pH}$ of 7 .

boltwoodite, coffinite, soddyite sodium weeksite [26]. The solubilities and solid phases exhibited by $\mathrm{U}, \mathrm{Np}$, $\mathrm{Pu}$ and $\mathrm{Am}$ in all the oxidation states possible under environmental conditions have not been measured. Therefore, we will assume that different actinide elements in the same oxidation state will exhibit similar chemical properties and consider existing thermodynamic data in a general way. Hydroxide and carbonate are the dominant anions in dilute ground waters [25]. Solubility and speciation experiments with U(VI), $\mathrm{Np}(\mathrm{V}), \mathrm{Pu}(\mathrm{IV})$ and $\mathrm{Am}(\mathrm{III})$ in dilute ground waters or simulated ground waters have indicated that oxide, hydroxide, carbonate or mixed hydroxycarbonate compounds are the dominant solid phases $[21,22,25,27-$ 30]. Possible reactions for the $3+, 4+, 5+$ and $6+$ oxidation states are shown in Table 5. The nature and solubility of solid phases that form in a solution open to air at a $\mathrm{pH}$ of 7 for the four different oxidation states, represented by data for $\mathrm{Am}^{3+}, \mathrm{Pu}^{4+}, \mathrm{NpO}_{2}^{+}$and $\mathrm{UO}_{2}^{2+}$ are given in Figure $5[21,22,25,27-30]$.

\subsection{Complexation}

\subsubsection{Inorganic complexes}

The inorganic ligands in ground water responsible for the complexation of the actinides are the same ones discussed under precipitation, i.e., hydroxide, carbonate, sulfate, phosphate, chloride, fluoride, nitrate and silicate. Complexation can occur with more than one ligand or actinide ion so several species may be associated with a given ligand. The expression that describes the complexation reaction is:

$$
a \mathrm{An}^{x}+b \mathrm{~L}^{y}=\left(\mathrm{An}_{a} \mathrm{~L}_{b}\right)^{a x+b y}
$$


Table 4. Characteristics of natural waters [1]

\begin{tabular}{|c|c|c|c|c|c|c|c|}
\hline Analysis & Rainwater & $\begin{array}{l}\text { Surface water } \\
\text { (a) }\end{array}$ & $\begin{array}{l}\text { Bedrock water } \\
\text { (b) }\end{array}$ & $\begin{array}{c}\text { YMP (f) } \\
\text { J-13 } \\
\text { water }\end{array}$ & $\begin{array}{l}\text { YMP (f) } \\
\text { UE-25p\#1 } \\
\text { water }\end{array}$ & Ocean & $\begin{array}{c}\text { Mono } \\
\text { lake } \\
\text { brine }\end{array}$ \\
\hline Depth (meters) & 0 & 0.50 & $\leq 500$ & & & $0-20$ & \\
\hline Age (years) & 0 & $\leq 10$ & $\geq 100$ & & & & \\
\hline $\mathrm{pH}$ & $4-6$ & $7.3-8.4(7.9)$ & $7-10$ & 6.9 & 6.7 & 8.1 & \\
\hline Eh (Volts) & 0.9 & $0.0-0.3$ & -0.05 & 0.1 & 0.36 & 0.8 & \\
\hline $\mathrm{O}_{2}(\mathrm{mg} /$ liter $)(\mathrm{c})$ & 10 & $1-10$ & $<0.1$ & 5.7 & & $\leq 9$ & \\
\hline $\mathrm{Na}^{+}$ & $0.3-20$ & $1-20(12)$ & $10-100(d)$ & 45 & 171 & 10,766 & 22,000 \\
\hline $\mathrm{K}^{+}$ & $0.1-4$ & $0.3-8(4)$ & $1-5$ & 5.3 & 13.4 & 399 & \\
\hline $\mathrm{Ca}^{2+}$ & $0.5-5$ & $2-100(25)$ & $20-60$ & 11.5 & 87.8 & 413 & \\
\hline $\mathrm{Mg}^{2+}$ & $0.1-0.5$ & $3-30(10)$ & $15-30$ & 1.76 & 31.9 & 1292 & \\
\hline $\mathrm{Fe}$ (total) & & $0.1-1$ & $5-30$ & 0.04 & $<0.1$ & $<0.02$ & 1 \\
\hline $\mathbf{F}^{-}$ & & $\leq 0.1$ & $0.5-2$ & 2.1 & 3.5 & 1.4 & 48 \\
\hline $\mathrm{Cl}^{-}$ & $0.1-20$ & $0.5-90(10)$ & $5-50(d)$ & 6.4 & 37 & 19.353 & \\
\hline $\mathrm{Br}^{-}$ & & & & & & 67 & \\
\hline $\mathrm{CO}_{3}^{2-}$ (total) (d) & $\leq 1$ & $60-200$ & $5-400$ & $118-143$ & 960 & $\sim 140$ & 28,300 \\
\hline $\mathrm{NO}_{3}^{-}$ & $0.1-4$ & $\leq 10$ & $<1$ & 10.1 & $<0.1$ & $<0.7$ & \\
\hline $\mathrm{PO}_{4}^{3-}$ (total) & 0 & $\leq 0.1$ & $\leq 0.1$ & & & $\leq 0.1$ & 20 \\
\hline $\mathrm{SO}_{4}^{2-}$ (total) & $\leq 20(1-5)$ & $3-300(20)$ & $1-15$ & 18.1 & 129 & 2712 & 8300 \\
\hline $\mathrm{SiO}_{2}$ (total) & 0 & $3-15$ & $5-30$ & 66 & 66 & $0.01-7$ & \\
\hline $\mathrm{SH}^{-}(\mathrm{e})$ & 0 & 0 & $<1$ & & & & \\
\hline $\mathrm{NH}_{3}(\mathrm{e})$ & $<0.5$ & $<0.1$ & $<0.5$ & & & $<0.05$ & \\
\hline Organic carbon & & $1-50$ & $<1$ & 0.15 & & $\sim 1$ & \\
\hline
\end{tabular}

(a) Lakes, rivers, and shallow wells; typical values within parenthesis, (b) Swedish granite, (c) all concentrations in $\mathrm{mg} /$ liter, (d) Mainly as $\mathrm{HCO}_{3}^{-}$, (e) $\mathrm{SH}^{-}$and $\mathrm{NH}_{3}$ only occur in reducing waters $(\mathrm{Eh}<0)$, except for surface waters in industrial areas, (f) Yucca Mountain, Nevada wells.

Table 5. Solids

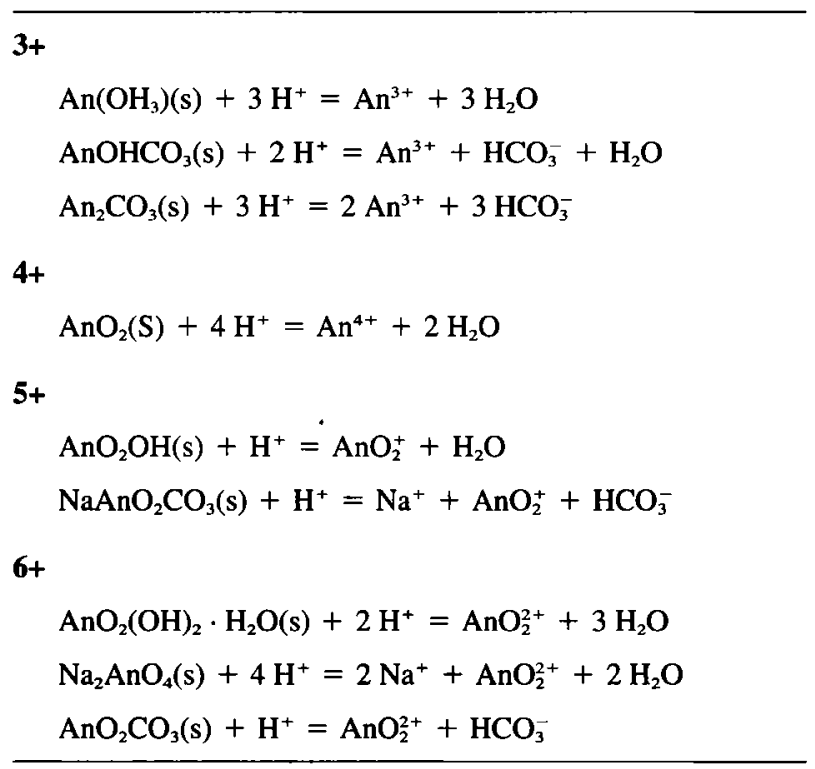

and the thermodynamic constant governing the reaction:

$$
\beta_{a, b}=\left[\mathrm{An}_{a} \mathrm{~L}_{b}\right] /[\mathrm{An}]^{a}[\mathrm{~L}]^{b}
$$

where the quantities in brackets, [ ], represents concentrations for equilibrium quotients or activities for equilibrium constants. One can compare the relative strengths of different ligands for complexing actinides in different oxidation states by comparing the complex formation constants [31]. This comparison is made in Figure 6 which shows a plot of the formation constants

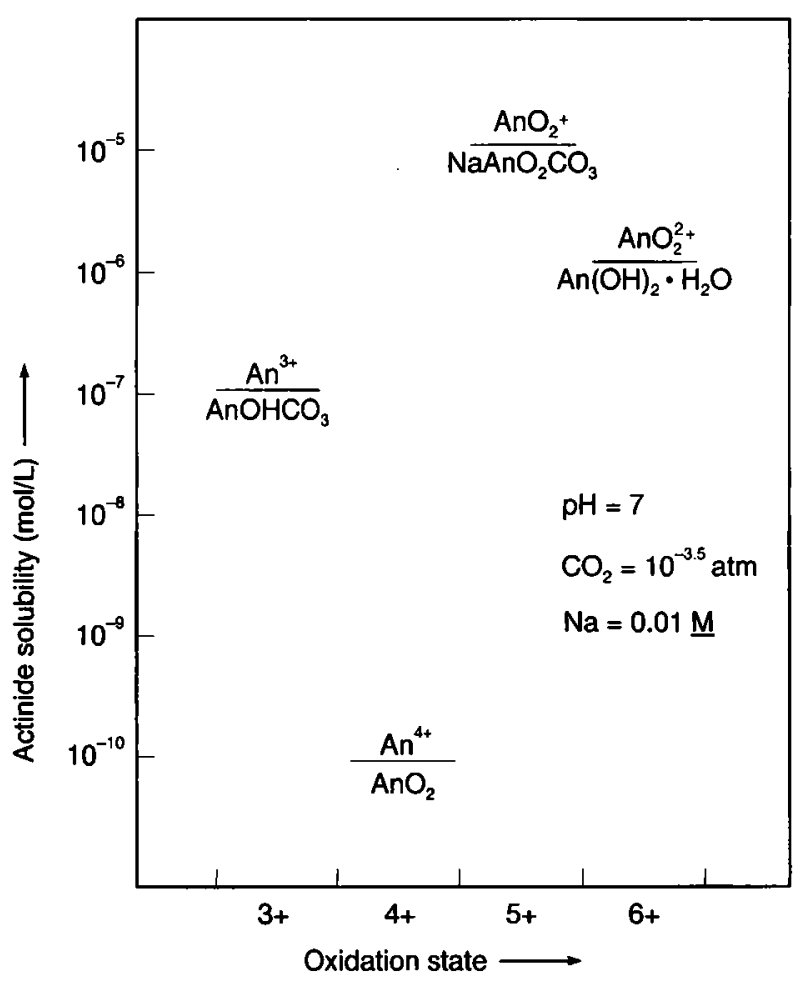

Fig. 5. Solid phases and solubilities of actinides expected for a $0.01 \mathrm{M}$ solution exposed to atmospheric $\mathrm{CO}_{2}$ at a pH of 7 .

for the different ligands, $\beta_{1,1}$, as a function of oxidation state number. The values for the constants were taken from references [20], [21] and [22]. When a complex formation constant was known for more than one actinide in the given oxidation state, an average value was 


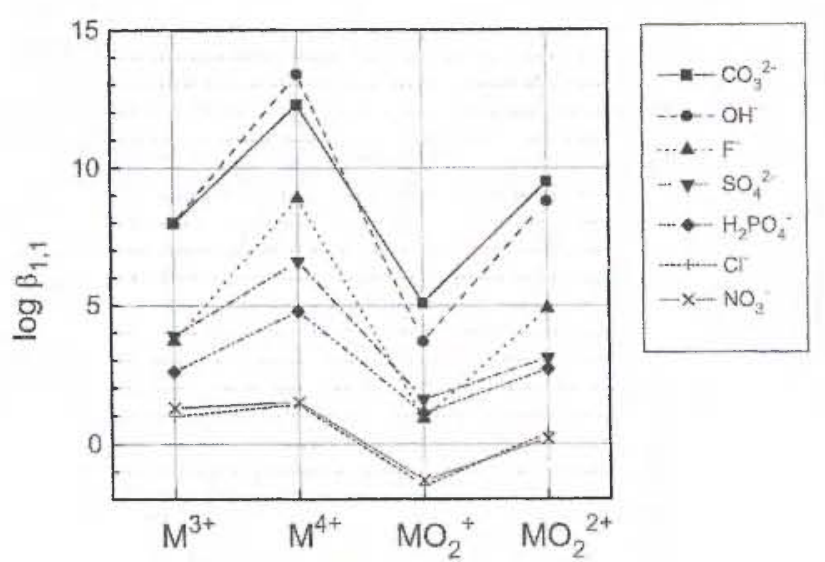

Fig. 6. Average complex formation constants of groundwater ligands versus the oxidation state of the actinide.

Table 6. Calculated concentrations $(\mathrm{M})^{*}$ of ligand required to produce more than $10 \%$ complexation

\begin{tabular}{lrrrc}
\hline Actinide & $\mathrm{Cl}^{-}$ & $\mathrm{NO}_{3}^{-}$ & $\mathrm{F}^{-}$ & $\mathrm{SO}_{4}^{2-}$ \\
\hline $\mathrm{UO}_{5}^{-+}$ & $>1$ & $>1$ & 0.1 & $>1$ \\
$\mathrm{NpO}^{\prime}$ & $>1$ & $>1$ & 0.1 & 0.1 \\
$\mathrm{Pu}^{4+}$ & $>1$ & $>1$ & 0.1 & 1 \\
$\mathrm{Am}^{3+}$ & 1 & $>1$ & 0.01 & 0.01 \\
\hline
\end{tabular}

* Aqueous solution of $\mathrm{pH} 8$ in contact with atmospheric $\mathrm{CO}_{2}$.

used in the plots. The values of the constants tend to fall into three groups for a given oxidation state. The trend in strengths of complexation of the various ligands are:

$$
\mathrm{OH}^{-}, \mathrm{CO}_{3}^{2-}>\mathrm{F}^{-}, \mathrm{HPO}_{4}^{2-}, \mathrm{SO}_{4}^{2-}>\mathrm{Cl}^{-}, \mathrm{NO}_{3}^{-} \text {. }
$$

Another obvious trend is in the strength of complexation of a given ligand for actinides in different oxidation states. This trend is:

$$
4+>3+\approx 6+>5+\text {. }
$$

In order to compare the complexation of $\mathrm{Cl}^{-}, \mathrm{NO}_{3}^{-}$, $\mathrm{F}^{-}$and $\mathrm{SO}_{4}^{-}$with carbonate complexation and hydrolysis, calculation were made varying the amounts, individually, of the four ligands in a solution of $\mathrm{pH}=$ 8 in contact with atmospheric $\mathrm{CO}_{2}$. The concentrations of the four ligands that were necessary to produce better than $10 \%$ complexation by that ligand are given in Table 6 for $\mathrm{UO}_{2}^{2+}, \mathrm{NpO}_{2}^{+}, \mathrm{Pu}^{4+}$ and $\mathrm{Am}^{3+}$.

In Figures 7, 8, 9 and 10 are shown the calculated speciation of $\mathrm{UO}_{2}^{2+}, \mathrm{NpO}_{2}^{+}, \mathrm{Pu}^{4+}$ and $\mathrm{Am}^{3+}$ in a dilute sodium chloride solution in contact with atmospheric $\mathrm{CO}$, as a function of $\mathrm{pH}$ using HYDRAQL. At the low $\mathrm{pH}$ values, hydrolysis dominates the speciation but above neutral $\mathrm{pH}$ there is sufficient carbonate in solution to make $\mathrm{CO}_{3}^{2-}$ the dominant ligand. The development of negatively charged species, carbonate and hydroxide, is responsible for the increase in solubility of these elements as the $\mathrm{pH}$ increases above the neutral region, thus giving rise to the frequently observed Ushaped solubility curves.

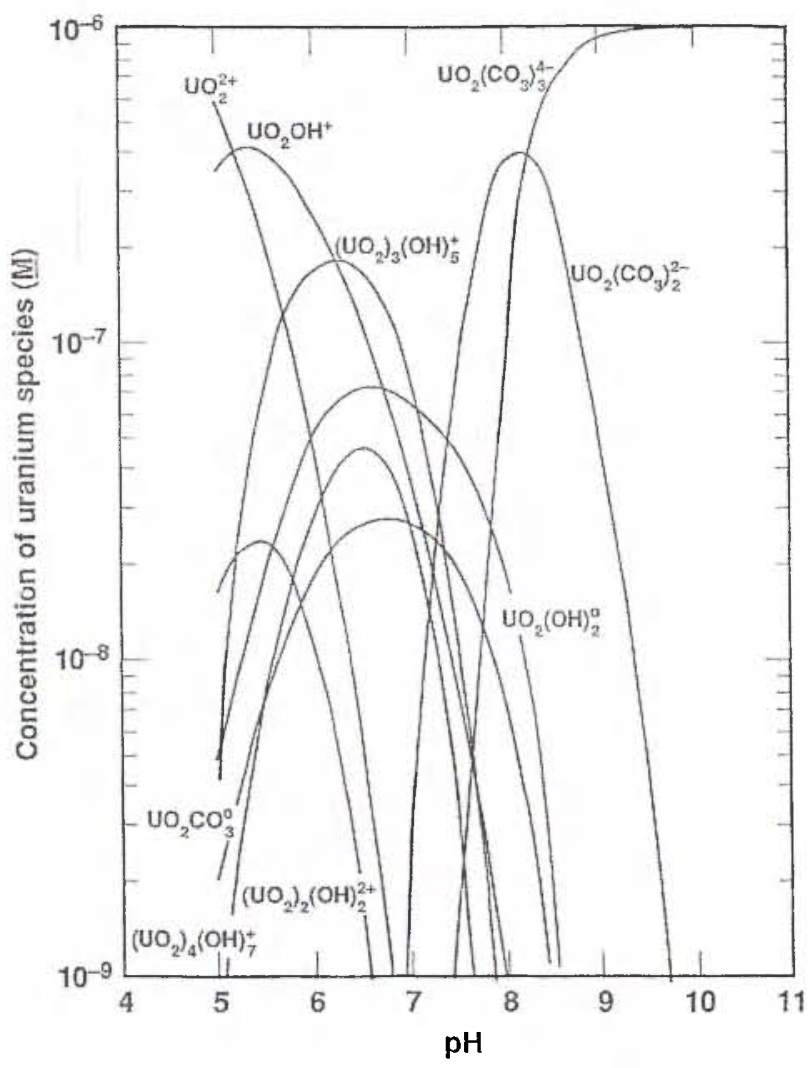

Fig. 7. Calculated speciation of $\mathrm{UO}_{2}^{2+}$ as a function of $\mathrm{pH}$ for a $10^{-6} \mathrm{M}$ solution of $U$ in $0.01 \mathrm{M} \mathrm{NaCl}$ exposed to atmospheric $\mathrm{CO}_{2}$.

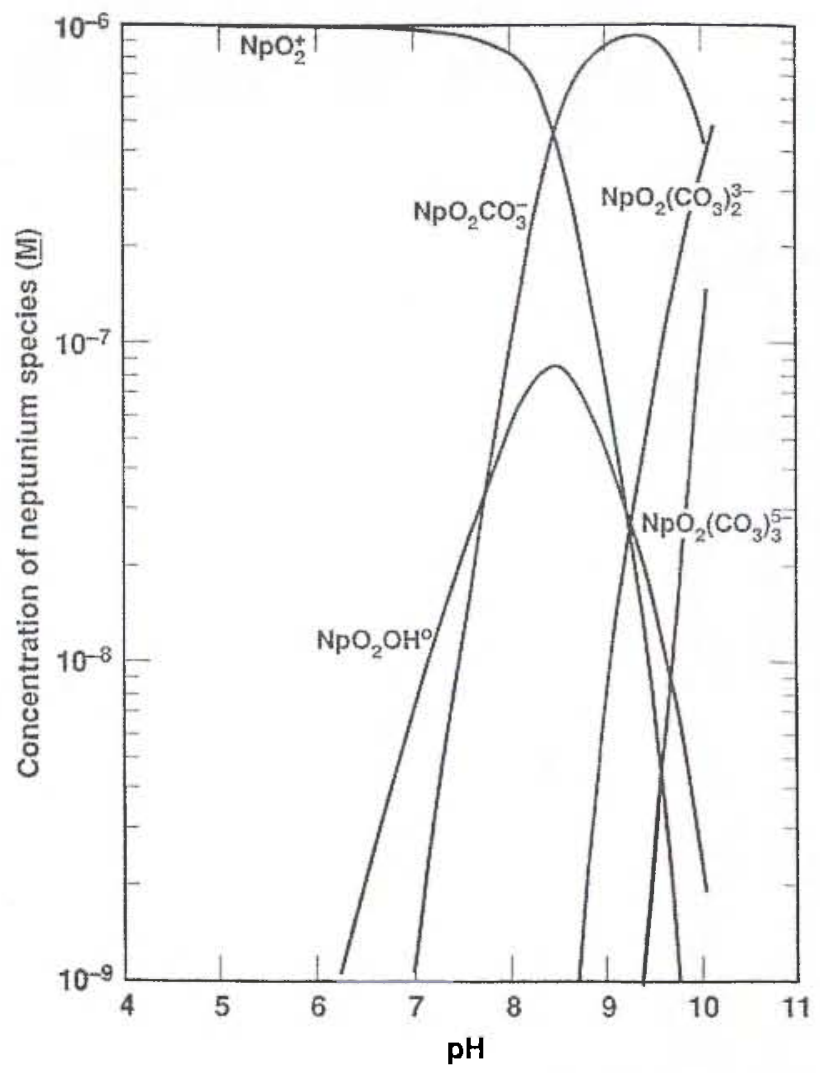

Fig. 8. Calculated speciation of $\mathrm{NpO}_{2}^{+}$as a function of $\mathrm{pH}$ for a $10^{-6} \mathrm{M}$ solution of $\mathrm{Np}$ in $0.01 \mathrm{M} \mathrm{NaCl}$ exposed to atmospheric $\mathrm{CO}_{2}$. 


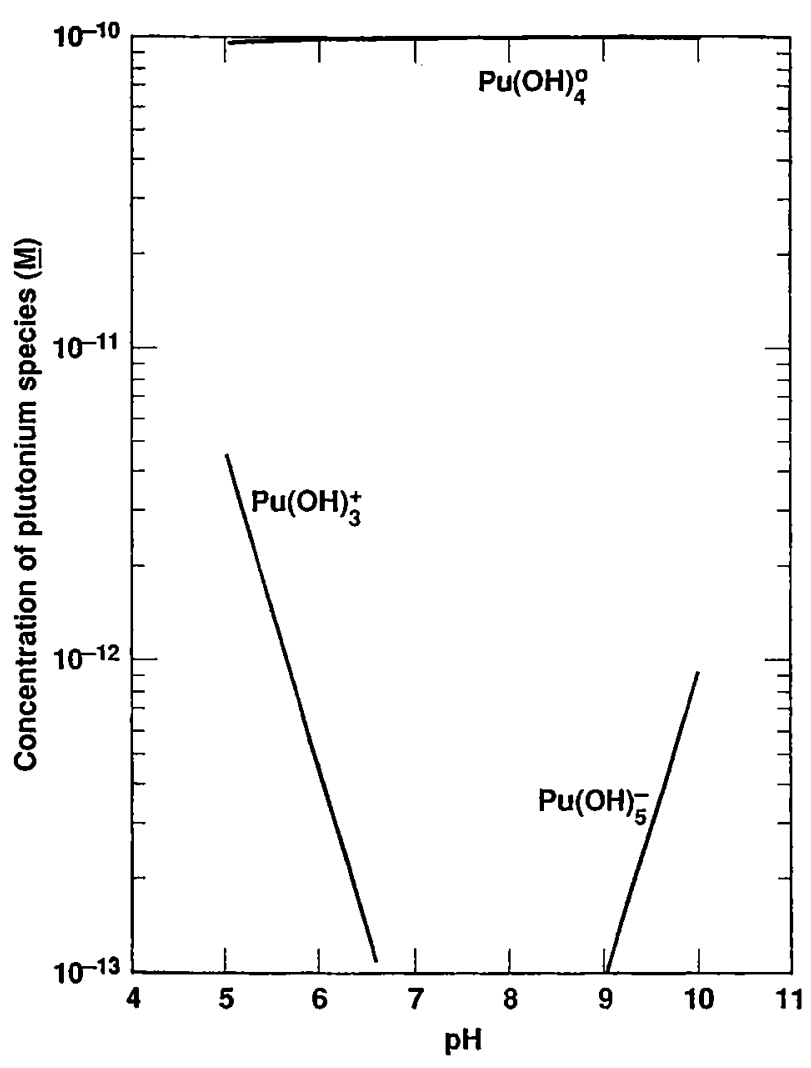

Fig. 9. Calculated speciation of $\mathrm{Pu}^{4+}$ as a function of $\mathrm{pH}$ for a $10^{-6} \mathrm{M}$ solution of $\mathrm{Pu}$ in $0.01 \mathrm{M} \mathrm{NaCl}$ exposed to atmospheric $\mathrm{CO}_{2}$.

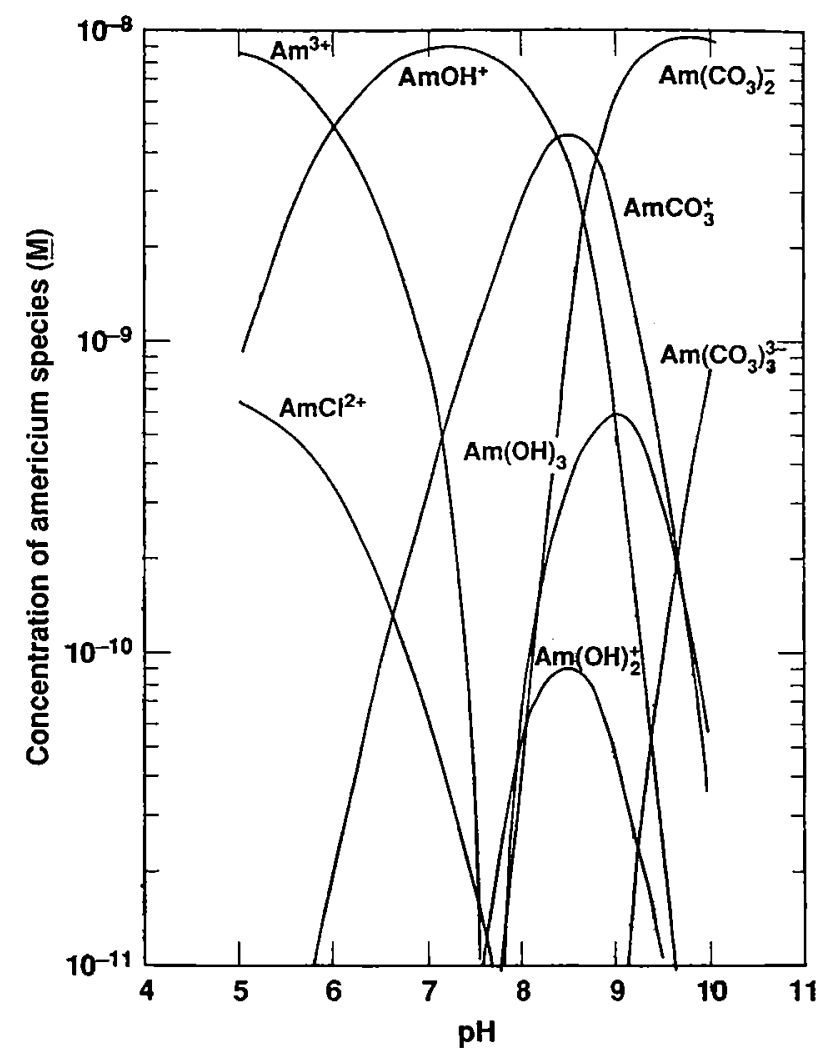

Fig. 10. Calculated speciation of $\mathrm{Am}^{3+}$ as a function of $\mathrm{pH}$ for a $10^{-6} \mathrm{M}$ solution of $\mathrm{Am}$ in $0.01 \mathrm{M} \mathrm{NaCl}$ exposed to atmospheric $\mathrm{CO}_{2}$.

\subsubsection{Organic complexes}

In addition to the inorganic ligands in ground waters, there are naturally occurring organic ligands that can complex the actinides rather strongly and could effect actinide transport. The most important natural ligands are humic and fulvic acids [32]. These polyelectrolytes tend to be ubiquitous in natural waters, giving rise to a brownish color at sufficient concentration, but vary in concentration and composition depending on their source. It is, therefore, not possible to give a precise value for the actinide complexation constants since they depends on the exact structure. A proposed general structure is shown in Figure 11 [33]. In addition to the phenolic, amine and alcoholic hydroxyl groups that form rather weak complexes, the carbonate groups are numerous and probably account for the strong actinide complex formation.

The humic material in ground waters comes from the decay of natural organic products. Average surface water (no color) is about $5 \mathrm{ppm}$, the surface of the ocean is about $1 \mathrm{ppm}$, and the dark swamp waters are about $50 \mathrm{ppm}$ [34]. The names humic and fluvic arise from their method of isolation [32]. Dissolution of the humic substance in $\mathrm{NaOH}$ is the first step. The remaining material that is not soluble in the aqueous solution is termed humin. Acidification of the alkaline solution to a $\mathrm{pH}$ of 2 with $\mathrm{HCl}$, by definition, precipitates the humic acid fraction. That which remains in solution is the fulvic acid fraction. Fulvic acid molecular weights range from 500 to 2000 amu while the humic acids can be from 1000 to more than $10,000 \mathrm{amu}$ [35] and can attain colloidal dimensions [36].

In addition to the source, the values of the actinide complexation constants depend on the degree of ionization of the humic and fulvic acids and, thus, on $\mathrm{pH}$. The constants tend to increase with $\mathrm{pH}$ until about $\mathrm{pH}=7$ where the acids are completely ionized. Figure 12 [34] shows the variation of the humic acid complex formation constants for $\mathrm{Th}^{4+}, \mathrm{Am}^{3+}$ and $\mathrm{UO}_{2}^{2+}$ as a function of $\mathrm{pH}$ and degree of ionization, $\alpha$. The logarithmic values of humic acid complex formations constants for $\mathrm{Am}^{3+}, \mathrm{Pu}^{4+}, \mathrm{NpO}_{2}^{+}$and $\mathrm{UO}_{2}^{2+}$ are estimated to be $12,16,5$ and 8 , respectively, at a $\mathrm{pH}$ of 7 using the equations given in reference [34]. These values are about 100 times larger than the carbonate values shown in Figure 6 and humic acid could be an important source of complex formation at concentrations even less than one ppm.

\subsection{Adsorption}

\subsubsection{Adsorption processes}

Actinide or other metal ions in ground waters can attach themselves reversibly or irreversibly onto rock or mineral surfaces. According to Stumm and Morgan [37], this adsorption process may result from shortrange chemical forces, e.g., covalent bonding, hydrophobic bonding and hydrogen bridges. These chemi- 


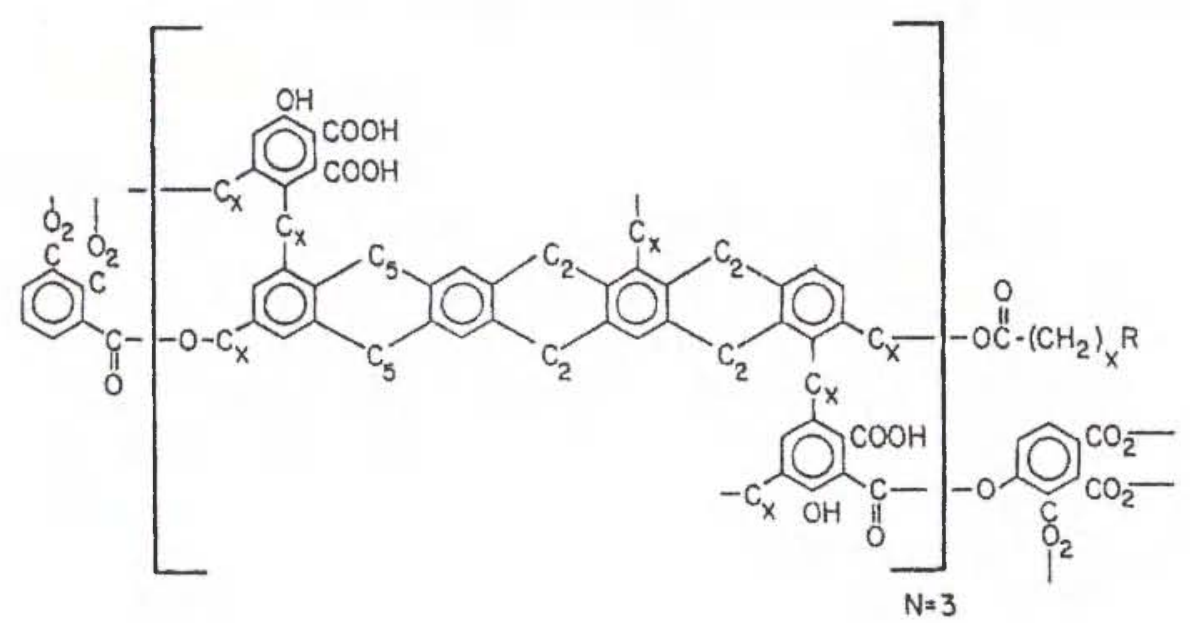

Fig. 11. Hypothetical structural relationships in aqueous humic material based on degradation products of permanganate (reprinted with permission from [32], Copyright 1989, American Chemical Society).

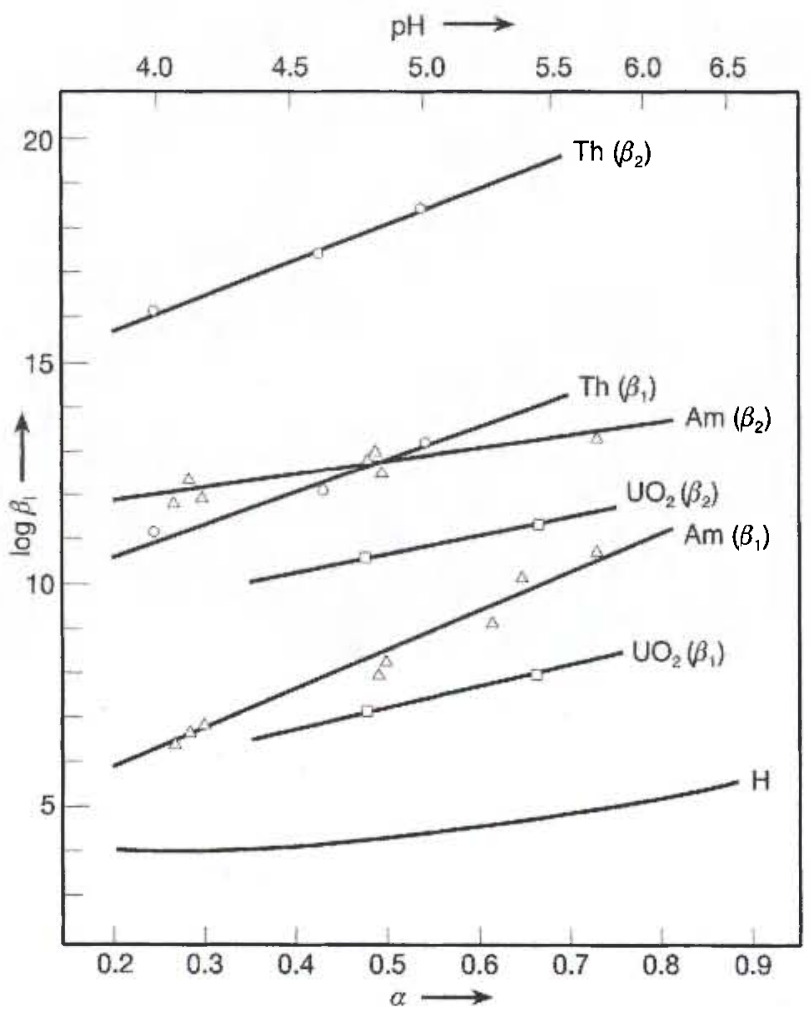

Fig. 12. Complex formation constants of several actinides with humic acid as a function of the degree of ionization $(\alpha)$ and $\mathrm{pH}$ (reprinted with permission from [34], Copyright 1985, Elsevier Science Publishers B. V.).

sorption processes are frequently irreversible. Sorption may also result from long-range forces, i.e., electrostatic and van der Waals attraction. Electrostatic adsorption is frequently rapid and reversible, e.g., ionexchange reactions.

The adsorption of a hydrated ion, $M\left(\mathrm{H}_{2} \mathrm{O}\right)_{n}$, onto a hydrated surface, $S\left(\mathrm{H}_{2} \mathrm{O}\right)_{m}$, can be thought of as a multistep process that involves the dehydration of $M$, the adsorption of dehydrated $\mathbf{M}$ on the hydrated surface and the hydration of the adsorption product [37]. The over all reaction is:

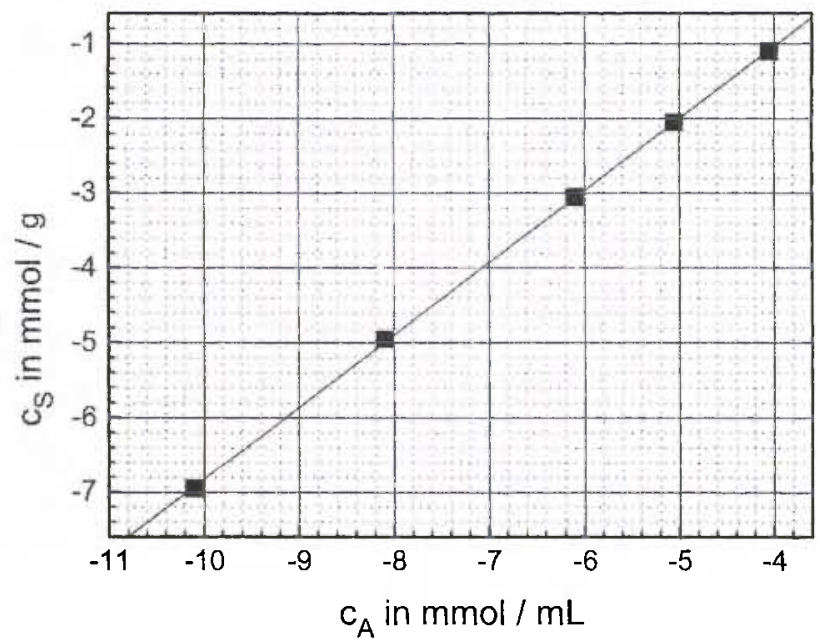

Fig. 13. Isotherm of the adsorption of Cs onto Belle Fourche clay.

$$
\begin{aligned}
& S\left(\mathrm{H}_{2} \mathrm{O}\right)_{m}+M\left(\mathrm{H}_{2} \mathrm{O}\right)_{n} \\
& =S M\left(\mathrm{H}_{2} \mathrm{O}\right)_{p}+(m+n-p) \mathrm{H}_{2} \mathrm{O} .
\end{aligned}
$$

Adsorption is usually described quantitatively by adsorption isotherms [37], i.e., by plots of the concentration of the solute in the solid phase versus the concentration of solute in the aqueous phase. An isotherm describing the measured adsorption of cesium on to Belle Fourche clay (montmorillonite) from a solution of $\mathrm{pH} 7$ and $0.01 \mathrm{M} \mathrm{NaCl}$ is given in Figure 13 [38]. Several models, e.g., Gibbs, Freundlich and Langmuir have been used to describe the distribution of a solute between solid and liquid phases [37, 39]. A good empirical description of single-solute equilibrium is provided by the Freundlich model [39]. The equation is:

$$
K_{d}^{1 / n}=C_{s} / C_{a}
$$

where $C_{s}$ and $C_{a}$ are the equilibrium solid-phase and liquid-phase solute concentrations. The concentrations are usually expressed in units directly connected to the amounts of solute (e.g., moles, disintegrations/minute for radioactive isotopes, etc.) per gram of solid and 
amounts of solute per ml of solution. Thus, the distribution coefficient, $K_{d}$, has the units $\mathrm{ml} / \mathrm{g}$. The thermodynamic equilibrium distribution coefficient is given by:

$$
K_{d}^{0}=a_{s} / a_{c}=\gamma_{s} C_{s} / \gamma_{a} C_{a} .
$$

Because the activities, particularly for the solute in the solid phase, are difficult to obtain or estimate, measured concentrations are used in expression 12 and the constant is frequently refered to as the distribution ratio, $R_{d}$. Some average distribution ratios for 12 different minerals and 4 rock types for actinides in the 4 different oxidation states $[40,41]$ are in the ratio $\mathrm{An}^{4+}-500: \mathrm{An}^{3+}-50: \mathrm{AnO}_{2}^{2+}-5: \mathrm{AnO}_{2}^{+}-1$. Again, as with precipitation and complexation, there are substantial differences between oxidation states. The trend in $R_{d}$ values is $4+>3+>6+>5+$.

\subsubsection{Source of surface charge}

The surface of solids in natural water are electrically charged and, depending on their nature, they may be either positively or negatively charged. For electrical neutrality, there is an equivalent opposite charge of counter ions diffusely distributed in the liquid near the surface. The fixed charge of the surface and the diffuse charge of the liquid are refered to as the electrical double layer [42]. In the simplest model, the charged surface consists of two layers, one on the surface and the other in the solution (Helmholtz model). If the charges in solution are allowed to move due to thermal forces, a balance between the thermal and electrostatic forces is attained and a diffuse layer in solution is formed (Gouy-Chapman diffuse charge model). Stern divided the near surface region into two parts, a layer of ions adsorbed from solution onto the surface (Stern layer) and a diffuse layer (Gouy layer). Integration over the surface layers sum to zero charge. The various models are discussed in detail in reference [42].

There are three main ways for the surface charge to originate [42]:

(1) Ionizable functional groups, e.g., $-\mathrm{OH},-\mathrm{COOH}$, $-\mathrm{OPO}_{3} \mathrm{H}_{2}$, etc., that depend on the mineral phase. The charge depends on the degree of ionization of the groups and therefore on the $\mathrm{pH}$. The behavior is much like a weak acid.

(2) Lattice imperfections at the solid surface or isomorphous replacement within the lattice, e.g., replacement of $\mathrm{Si}^{4+}$ ions in the $\mathrm{SiO}_{2}$ tetrahedra with $\mathrm{Al}^{3+}$ ions generates negatively charged sites.

(3) Adsorption of surfactants via van der Waals interactions, or by hydrogen or hydrophobic bonding, e.g., adsorption of an organic coating onto an inorganic surface.

\subsubsection{Surface complexation model}

Most metal, metal oxide and metal hydroxide surfaces, e.g., $\mathrm{Si}, \mathrm{Al}, \mathrm{Fe}$, exhibit an amphoteric behavior [42-
Table 7. Zero point of charge (reprinted with permission from [42], Copyright 1981, John Wiley \& Sons, Inc.)

\begin{tabular}{lc}
\hline Material & $\mathrm{pH}_{\text {zpr }}$ \\
\hline$\alpha-\mathrm{Al}_{2} \mathrm{O}_{3}$ & 9.1 \\
$\alpha-\mathrm{Al}(\mathrm{OH})_{3}$ & 5.0 \\
$\gamma-\mathrm{AlOOH}$ & 8.2 \\
$\mathrm{CuO}$ & 9.5 \\
$\mathrm{Fe}_{3} \mathrm{O}_{4}$ & 6.5 \\
$\alpha-\mathrm{FeOOH}$ & 7.8 \\
$\gamma-\mathrm{Fe} \mathrm{O}_{3}$ & 6.7 \\
"Fe(OH) $)_{3}($ amorph $)$ & 8.5 \\
$\mathrm{MgO} \mathrm{MnO}_{2}$ & 12.4 \\
$\beta-\mathrm{MnO}_{2}$ & 2.8 \\
$\mathrm{SiO}_{2}$ & 7.2 \\
$\mathrm{ZrSiO}_{4}$ & 2.0 \\
Feldspars & 5 \\
$\mathrm{Kaolinite}$ & $2-2.4$ \\
Montmorillonite & 4.6 \\
Albite & 2.5 \\
Chrysotile & 2.0 \\
\hline
\end{tabular}

44], i.e., the surface hydroxyl group may undergo protonation and deprotonation as follows:

$$
\mathrm{S}-\mathrm{OH}_{2}^{+} \stackrel{k_{1}}{=} \mathrm{S}-\mathrm{OH} \stackrel{k_{2}}{=} \mathrm{S}-\mathrm{O}^{-}
$$

Where $S$ represents the surface, and $k_{1}$ and $k_{2}$ are the intrinsic acid constants for the two deprotonation reactions. The positively charged species dominate at low $\mathrm{pH}$ while the negatively charged species dominate at high $\mathrm{pH}$. The surface charge will go from positive to zero to negative as the $\mathrm{pH}$ changes from low to high values. At some $\mathrm{pH}$, which varies from one type of surface to another, the charge integrated over the surface is zero, denoted the point of zero charge (PZC). The $\mathrm{pH}_{\mathrm{pzc}}=1 / 2\left[p k_{1}+p k_{2}\right]$ [42]. These constants are obtained from acid-base titrations of aqueous suspensions of the finely divided material [42-44]. Because the surface charge is generated by $\mathrm{H}^{+}$and $\mathrm{OH}^{-}$, they are referred to as the potential determining ions. For other than oxide surfaces, in addition to $\mathrm{H}^{+}$and $\mathrm{OH}^{-}$, other ions in solution may contribute to determining the potential, e.g., for carbonate solids, $\mathrm{H}_{2} \mathrm{CO}_{3}$, $\mathrm{HCO}_{3}^{-}$and $\mathrm{CO}_{3}^{2-}$ may be potential determining as well [42]. In these cases, the solution composition must be specified along with the $\mathrm{pH}_{\mathrm{pzc}}$. In Table 7, the PZC's for a number of geologic materials are given [42].

The surface groups can interact with solute ions. For example, depending on the surface site speciation, the ions of $\mathrm{NaCl}$ can interact as follows [45]:

$$
\begin{aligned}
& \mathrm{S}-\mathrm{OH}_{2}^{+}+\mathrm{Cl}^{-}=\mathrm{S}-\mathrm{OH}_{2} \mathrm{Cl} \\
& \mathrm{S}-\mathrm{O}^{-}+\mathrm{Na}^{+}=\mathrm{S}-\mathrm{ONa}
\end{aligned}
$$

negatively charged solution species being adsorbed at the lower $\mathrm{pH}$ values and positively charge solution species at higher $\mathrm{pH}$ values. In the double layer, one type of counter ion can be exchanged for another, e.g., the ion exchange reaction

$$
\mathrm{S}-\mathrm{ONa}+\mathrm{Mg}^{2+}=\mathrm{S}-\mathrm{OMg}^{+}+\mathrm{Na}^{+}
$$




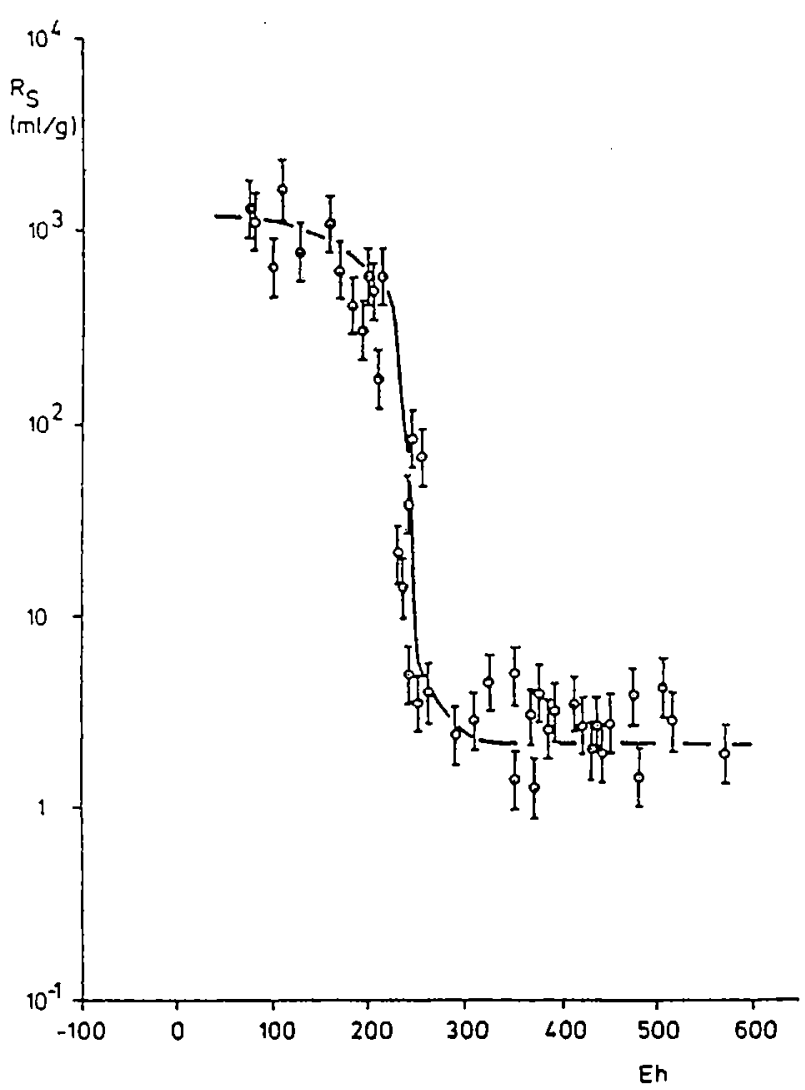

Fig. 14. Neptunium adsorption ratios measured in various systems at $\mathrm{pH} 7$ as a function of the redox potential (reprinted with permission from [31], Copyright 1988, Oldenbourg Verlag $\mathrm{GmbH})$.

or

$$
2 \mathrm{~S}-\mathrm{ONa}+\mathrm{Mg}^{2+}=2 \mathrm{SO}-\mathrm{Mg}+2 \mathrm{Na}^{+} \text {. }
$$

Other solution complexes may also be exchanged, e.g.,

$$
\mathrm{S}-\mathrm{ONa}+\mathrm{Mg}(\mathrm{OH})^{+}=\mathrm{S}-\mathrm{OMg}(\mathrm{OH})+\mathrm{Na}^{+} \text {. }
$$

The double-layer theory predicts [45] that higher valence ion are generally prefered over lower valence ions, the trend observed for the actinides. The dependence of the adsorption coefficient with oxidation state can be seen dramatically in the measured $R_{d}$ for $\mathrm{Np}$ as a function of solution Eh reported by Lieser et al. [31] and shown in Figure 14. The distribution ratio decreases dramatically at the Eh corresponding to the oxidation of $\mathrm{Np}^{4+}$ to $\mathrm{NpO}_{2}^{+}$.

The $R_{d}$ approach ignores the chemical properties of absorbent and absorbate, and is valid for a single solution composition and adsorbate concentration. An alternative to the $R_{d}$ approach is the so-called surface complexation or site-binding model $[43,44,46,47]$. In this model, the adsorption reactions of aqueous solute species, i.e., hydrated ions, hydrolysis products or other complexed species, with the solid surface are considered as surface complexation reactions. The various solution and surface reactions are allowed to compete for the solute ions. Because the surface adsorption reactions are described in the same form as the solution reactions, the modelling calculations can

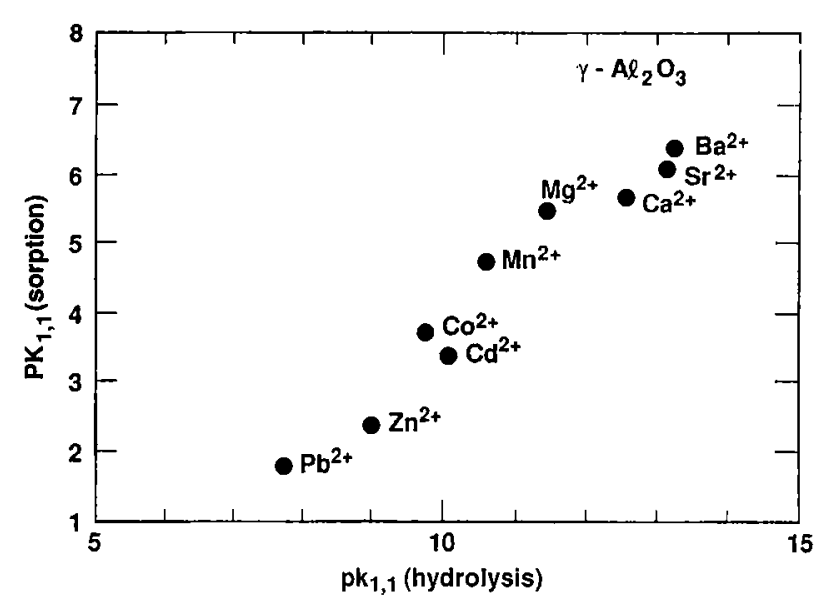

Fig. 15. Correlation of the reaction constants for the adsorption of several metals on to aluminum oxide vs. their first hydrolysis constants.

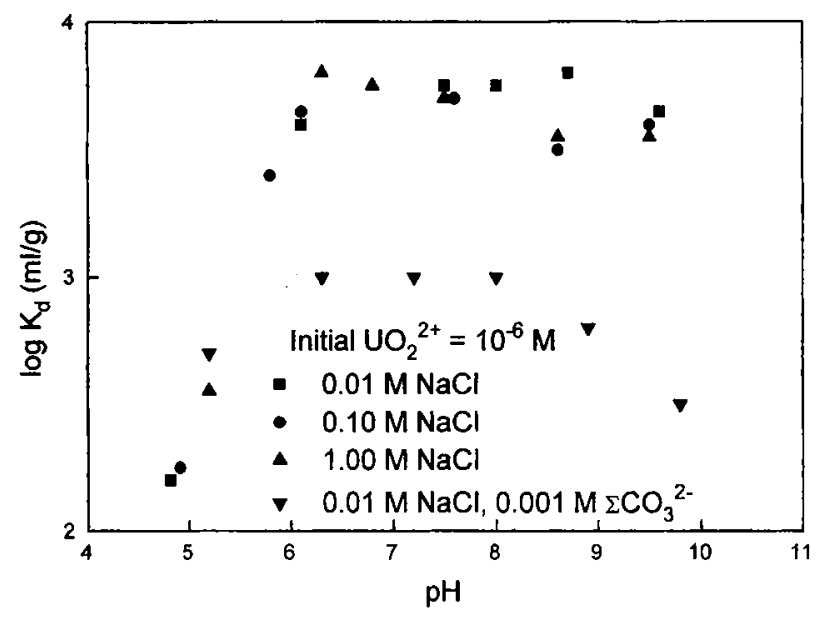

Fig. 16. Distribution coefficients for $\mathrm{UO}_{2}^{2+}$ adsorption on to silica in the presents of carbonate and without carbonate.

consider all reactions simultaneously. This model has been used to predict reasonably well the adsorption of many metals on a variety of surfaces [43, 48-50]. The disadvantage of the surface complexation model is the difficulty in the experimental determination of the model parameters and surface reaction constants. However, it has been suggested $[42,51]$ that there may be correlations between the tendency of given ligands to form complexes in solution and the tendency of that functional group to form surface complexes, e.g., hydrolysis constants of an ion in solution and complexation by surface hydroxide groups. Such a correlation is shown for adsorption of various cations onto aluminum oxide in Figure 15. Possible surface complexation reactions with several actinides and their surface reaction constants are given in references [30] and [43].

In Figure 16, the results of the competition between the two complexation reactions, surface and solution, on the measured adsorption of $\mathrm{UO}_{2}^{2+}$ is readily seen. The figure shows the results of measurements of the adsorption of $\mathrm{UO}_{2}^{2+}$ as a function of $\mathrm{pH}$ by silica 
in $\mathrm{NaCl}$ solutions with and without the presence of carbonate [34]. Due to the formation of carbonate complexes of $\mathrm{UO}_{2}^{2+}$ that are not adsorbed or adsorbed to a much lesser extent than the hydrated ion, the distribution ratio is reduced by a factor of about 500 when changing from solutions of $\mathrm{NaCl}$ without carbonate present to solutions that contain millimolar amounts of carbonate. The addition of strong actinide complexing agents normally decreases actinide adsorption.

\subsection{Colloids}

The role of colloids in facilitating actinide transport is far from clear, however, greatly enhanced transport of americium and plutonium associated with colloids over that predicted for ionic species has been observed at a liquid seepage site at Los Alamos. At another site at Los Alamos, plutonium and americium were detected in monitoring wells over a mile away from a liquid waste source and found by ultracentrifugation to be present as colloids [52].

Depending on their size and charge relative to the surrounding porous media, colloids can move more rapidly or more slowly than the average groundwater velocity $[53,54]$. The sign and magnitude of the electrical charge of a colloid, the zeta potential, generally is a function of the $\mathrm{pH}$ of the solution and there is a specific $\mathrm{pH}$ where they are uncharged. When uncharged particles pass through a porous media or thin fracture, they are usually transported without retention by convection and diffusion due to Brownian motion. The water velocity distribution is generally parabolic, the maximum velocity at the center being about two times the average velocity of the water $[53,54]$. Particles will randomly sample this velocity variation but will not reach the walls due to their size. Therefore, their average velocity will be greater than the average groundwater velocity; the larger colloids will travel more rapidly than the smaller ones. If the colloids have the same charge as the surrounding media, repulsion will tend to increase the colloids relative velocity even more as they are kept even further away from the walls and will tend to inhibit wall adsorption. In addition, colloid particles that are larger than some pore diameters will be excluded from passage through them and experience a shorter overall path length (size exclusion) and, again, an apparent higher velocity than the average water velocity. If the particles have a charge that is opposite to the surrounding surfaces, retention mechanisms (wall absorption) will decrease the particle velocity relative to that of the ground water. Failure to account for colloid formation and transport could lead to serious underestimations of the rate of transport of actinide contaminants.

\subsubsection{Nature of colloids}

Colloid systems are usually defined as systems containing particles whose diameters range from one nanometer to one micrometer [54-57]. Colloid systems in aqueous media are divided into two types, lyophilic and lyophobic. The term lyophilic is used to describe colloids produced by the dissolution of macromolecules in the solvent while lyophobic describes colloids formed by dispersion of solid particles in the solvent. A characteristic feature of colloidal dispersions is the large area-to-volume ratio of the particles. The colloids formed by inorganic cations, like the actinide elements, are classified as lyophobic.

Two mechanisms have been proposed to explain the formation of colloids containing actinides in ground waters $[36,54,57,58]$. The first describes the particles of the colloid as being composed primarily of an actinide and formed by condensation of actinide molecules or ions by a hydrolytic or precipitation process. This type of colloid might be expected to exhibit chemical properties similar to the assumed compound in macroamounts [54]. Such colloids have been called at various times "real", "pure", "eigen", "true" or "intrinsic" colloids.

The other mechanism pictures the formation of actinide containing colloids as the result of the adsorption of trace amounts of actinides onto colloids of impurity or other foreign materials in the aqueous phase. The chemical properties of these colloids would be similar to that of the impurity rather than the actinide. These types of colloids have been called "pseudo", "fremd", or "associative" colloids. There is ample evidence for the formation of both of these types of actinide bearing colloids $[15,36,58-60]$.

Many of the important properties of colloids, such as stability and coagulation, are determined by the electric charge on the particles, the zeta potential [60]. The larger the surface charge, the more the particles tend to repell each other, the less likely they are to coagulate, and the more stable the colloid system [61]. For oxides and hydroxides, as the $\mathrm{pH}$ changes from acidic to basic conditions, the surface charge on oxide surfaces changes from highly positive to neutral to negative, gradually [61]. The further the $\mathrm{pH}$ of the solution is from the $\mathrm{pH}_{\mathrm{pzc}}$ of the colloid, the larger the surface charge and the more stable is the colloidal system. For example, the pzc for $\mathrm{Pu}(\mathrm{IV})$ oxide is around $\mathrm{pH} 8$ [62]. Thus, it is not surprising that the $\mathrm{Pu}(\mathrm{IV})$ colloid is very stable at low $\mathrm{pH}$ values, i.e., $1-$ 4 , but tends to coagulate and precipitate at near neutral $\mathrm{pH}$ values [63].

The main effect of increasing electrolyte concentration is to reduce the double layer potential [64]. Therefore, the stability of a colloidal system normally decreases with increasing electrolyte concentration, and coagulation and precipitation are enhanced. The critical electrolyte concentration needed for coagulation varies as $(1 / z)^{6}[64]$. Thus, the higher the charge on the electrolyte ions, the more effective that electrolyte is in inducing coagulation. Adsorption and surface charge neutralization by species of opposite charge to the colloid promote coagulation at low concentrations but can restabilize colloids at higher concentrations 
due to reversal of the charge of the colloidal particles [65]. Such behavior has been observed with Pu(IV) colloid in solutions of varying nitrate concentrations [66].

\subsubsection{Actinide intrinsic colloids}

Kim has given the order in the tendency of actinides to form intrinsic colloids as $\mathrm{M}^{4+}>\mathrm{MO}_{2}^{2+}>\mathrm{M}^{3+}>$ $\mathrm{MO}_{2}^{+}$[58]. This is the order of decreasing charge on the central ion. The mechanisms for the nucleation and growth of intrinsic colloids are thought to be similar to those of precipitation $[54,55,67,68]$. Thus, the process assumes that the concentration of the actinide is sufficiently large so as to exceed the solubility product constant for the formation of a solid phase $[54,68$, 69]. Because actinide oxides and hydroxides are very insoluble, they are frequently the source of intrinsic colloids. The route is generally believed to proceed by a gradual transition from ions to hydrolyzed ions to hydrolytic polymers to colloidal-size solid-phase particles. However, other very insoluble compounds of actinides could conceivably be the basis for colloids in natural systems, e.g., carbonates, hydroxycarbonates or phosphates. From this picture, one would not expect intrinsic colloids to form unless the actinide ion solution concentration exceeded the solubility product for the formation of a solid phase.

The colloid of $\mathrm{Pu}(\mathrm{IV})$ is the only actinide intrinsic colloid that has been studied in any great detail. The colloid can be easily produced by neutralization of acid solutions of Pu(IV) ion, can remain stable for years, and can be purified by ion-exchange column methods [70]. It exhibits an absorption spectrum distinctly different from those of the other Pu species [70]. The colloid can be precipitated from solution by a variety of anions and it resembles the precipitation of slightly soluble metal salts [66]. While Pu(IV) colloids were once thought to be due to polymer formation from hydrolysis products, Lloyd and Haire have shown that the colloid consists of very discrete particles, which can be amorphous or crystalline, of hydrated plutonium dioxide [71]. The particles become more crystalline with aging. The possible formation of a hydrolytic polymer would be only a step in the colloid formation process.

Silver has estimated the free energy of formation of $\mathrm{Pu}(\mathrm{IV})$ colloid [72]. From this number, he has calculated a value of $2.5 \times 10^{-56}$ for the solubility product constant. This value is close to that measured for $\mathrm{Pu}(\mathrm{OH})_{4}[73,74]$. The solubility of the colloid appears to be between that of amorphous $\mathrm{Pu}(\mathrm{OH})_{4}$ and $\mathrm{PuO}_{2}$, however, the exact value depends on the degree of aging, i.e., crystallinity [75]. Interestingly, the predominant solution species in equilibrium with the colloid under oxidizing conditions was found to be $\mathrm{Pu}(\mathrm{V})$ [76]. Rai and Serne found that, if the Pu solution concentration at a given $\mathrm{pH}$ falls above the $\mathrm{Pu}(\mathrm{OH})_{4}$ solubility line, Pu(IV) colloid can form. If the Pu concentration falls below this line, the colloid or $\mathrm{Pu}(\mathrm{OH})_{4}$ will

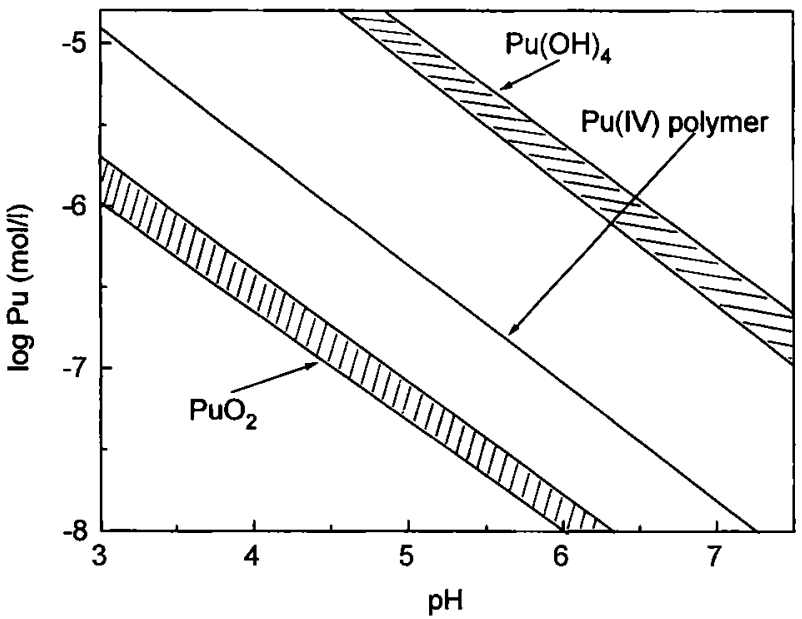

Fig. 17. Solubility curves for $\mathrm{Pu}(\mathrm{OH})_{4}, \mathrm{PuO}_{2}$ and $\mathrm{Pu}(\mathrm{IV})$ colloids as a function of $\mathrm{pH}[76]$.

not form [77]. The $\mathrm{pH}$ dependent solubility curves for the oxide, hydroxide and colloid are shown in Figure 17 [77]. From these curves, it should be possible to estimate the concentration of $\mathrm{Pu}$ required for intrinsic colloid formation.

The size of the Pu(IV) intrinsic colloids have been studied by ultracentrifugation [78] and autocorrelation photon spectroscopy $[79,80]$. They can vary in size from one to several hundred nanometers. The distribution is not uniform and depends on aging. The fraction of large particles increases with time. Rundberg, et al., found the density to be near but slightly lower than the estimated density of crystalline plutonium dioxide [80].

Plutonium(IV) colloid can form in solutions of $\mathrm{Pu}(\mathrm{V})$ and $\mathrm{Pu}(\mathrm{VI})$ following reduction of the latter by the effects of alpha radiation [81]. Conversely, the $\mathrm{Pu}(\mathrm{IV})$ in the intrinsic colloid is electroactive and the colloid can be broken down and oxidized to soluble $\mathrm{Pu}$ (VI) by cerium(IV) [82]. Under oxidizing environmental conditions, the major solution species to form in equilibrium with the colloid is $\mathrm{Pu}(\mathrm{V})[76,83]$, i.e., $\mathrm{Pu}(\mathrm{IV})$ colloid will dissolve to produce $\mathrm{Pu}(\mathrm{V})$ in solution. Strong complexing agents may inhibit formation or enhance the dissolution of the Pu(IV) colloid [84].

There is indiction that U(IV) forms colloids similar to $\mathrm{Pu}$ (IV) [85], however, it has not been studied to any extent. It would be expected to form under reducing conditions where the U(IV) ion is stable. The solubility curve for $\mathrm{U}(\mathrm{IV})$, i.e. concentration versus $\mathrm{pH}$, would be the best way to predict the conditions for possible colloid formation.

There is some evidence for the formation of Am(III) $[36,58,59,67,86]$ and U(VI) $[58,59,67$, $85]$ intrinsic colloids but not for $\mathrm{Np}(\mathrm{V})[58,59,67]$. By analogy with $\mathrm{Pu}(\mathrm{IV})$, an estimate of the solution concentration necessary for the formation of intrinsic colloids of actinides in the III, V, and VI oxidation states could be made from their solubility curves. The solubility of $\mathrm{Am}(\mathrm{OH})_{3}$ [12], $\mathrm{UO}_{2}(\mathrm{OH})_{2}$ [29] and $\mathrm{NpO}_{2}(\mathrm{OH})$ [87] have been reported in the literature. 
However, in groundwater, carbonate or other complexation of the solution species can change these solubilities. Compared to Pu(IV), it would seem less likely that one would exceed the solubility products of Am(III) and U(VI) at low $\mathrm{pH}$ values where the colloids would be the most stable. $\mathrm{Np}(\mathrm{V})$ is very soluble at the low $\mathrm{pH}$ values and does not reach a minimum until a pH close to 11 [87]. Conditions for $\mathrm{Np}(\mathrm{V}) \mathrm{col}-$ loid formation in environmental waters would usually not be achieved.

\subsubsection{Actinide association colloids}

Natural colloids are in all groundwaters to some extent. The amount and nature will depend on the associated geologic structure. Colloid particles are commonly composed of materials produced by the disintegration and weathering of rocks and minerals, e.g., clays, silica, aluminum oxide minerals, as well as hydroxides or hydrated oxides of metal, e.g., iron [36, 52, 54, 88-90]. Organic colloids (humic substances) and inorganic particles that are covered with organics may also be present. Groundwater concentrations may vary from as few as $<10^{6}$ particles per liter at the Nevada Test Site to $10^{17}$ particles per liter at the Gorleben Site in Germany. The adsorption processes for the adsorption of actinides is similar to those discussed for mineral surfaces in section 4.4 and many of the techniques and conclusions are the same.

\section{Optical absorption spectroscopy}

Because the oxidation state, degree of complexation and solution form (dissolved or colloidal) have a strong influence on the chemical behavior of an actinides in the environment, the determination of the solution speciation of actinides is nearly as important as a measurement of the amount for predicting migration rates or planning clean-up techniques. While nuclear counting methods provide a sensitive method for determining the amounts, it gives no information about the nature of the solution species. Absorption spectroscopy methods are considered to be one of the most reliable techniques for the detection and characterization of solution species [91, 92] and have been widely used for the characterization of actinides in solutions [93, 94]. The optical absorption spectra of actinides (and lanthanides) show peaks due to the excitation of $f-f$ electron transitions [93]. These peaks are quite narrow, usually less than a few nanometers wide (full-width-at-half-maximum height), and the wave length of the absorption peaks are uniquely characteristic of the actinide element and its oxidation state. For example, spectra are shown in Figure 18 for $\mathrm{Pu}^{3+}, \mathrm{Pu}^{4+}, \mathrm{PuO}_{2}^{+}$and $\mathrm{PuO}_{2}^{2+}$ [93]. The major absorption peak wave lengths for $\mathrm{U}, \mathrm{Np}, \mathrm{Pu}$ and $\mathrm{Am}$ in the oxidation states of environmental importance are given in Table 8. In addition to the identification, the quan- tity of the solution species can be obtained from the measured absorption peaks through the use of Beer's law [95]:

$$
A=\varepsilon \times C \times L
$$

where $A$ is the measured absorbance (peak height or peak area), $\varepsilon$ is the molar absorptivity constant, $C$ is the concentration and $L$ is the light path length in the solution. The reported molar absorptivities of the major absorption peaks of $\mathrm{U}, \mathrm{Np}, \mathrm{Pu}$ and $\mathrm{Am}$ in different oxidation states are given in Table 8.

Complexation or colloid formation produces changes in the absorption spectra that can frequently be used to identify the complex species or detect colloid formation. In Figure 19, the absorption spectra of $\mathrm{Pu}^{4+}$, both uncomplexed and carbonate complexed, are shown [96]. The absorption wave length of the uncomplexed hydrated ion is shifted from $470 \mathrm{~nm}$ to $486 \mathrm{~nm}$ due to formation of a carbonate complexes. Because the concentrations of both complexed and uncomplexed species can frequently be obtained from an analysis of the absorption spectra, this method has been used to measure the complex formation constants for a number of actinide complexes [97-99]. The spectra of dissolved $\mathrm{Am}^{3+}$ and of $\mathrm{Am}^{3+}$ absorbed onto colloid particles are shown in Figure 20 [87]. The formation of colloids degrades and nearly eliminates the absorption peak of Am at $508 \mathrm{~nm}$.

Unfortunately, conventional absorption spectrometers have detection limits of between 0.01 and 1 millimolar for the actinides [100], depending on their molar absorptivities, while the solubilities of actinides in aqueous solutions of near neutral $\mathrm{pH}$ are generally two or more orders of magnitude less (see section 4.2). With the advent of high powered, pulsed lasers in recent years, new laser based techniques have been developed for measuring very weak sample absorbance [101]. These techniques, photoacoustic (PAS) [102], photothermal deflection (PDS) [103] and thermal lensing (TLS) [104], are referred to as photothermal spectroscopies and are potentially three orders of magnitude more sensitive than absorption spectroscopy using conventional spectrometers while supplying the same information [105]. Laser induced fluorescence spectroscopy can be even more sensitive for those actinides that deexcite by the fluorescence process, e.g., $\mathrm{U}, \mathrm{Cm}$, and to a lesser extent, Am [106-108]. Unlike conventional spectroscopy, where the absorption is measured as the difference between the intensity of light passing in and out of the absorption cell, photothermal spectroscopies measure directly the amount of energy absorbed by the solute ions in the path of the laser light. The detection limits obtained by PAS for $\mathrm{U}, \mathrm{Np}, \mathrm{Pu}$ and $\mathrm{Am}$ in the oxidation states of environmental importance are given in Table 8. In principle, it is possible to increase the sensitivity a factor of ten using TLS [104], however, the experimental arrangement is difficult to set-up and maintain. The use of photothermal spectroscopies coupled with optical fibers for remote measurements of actinides in aqueous 

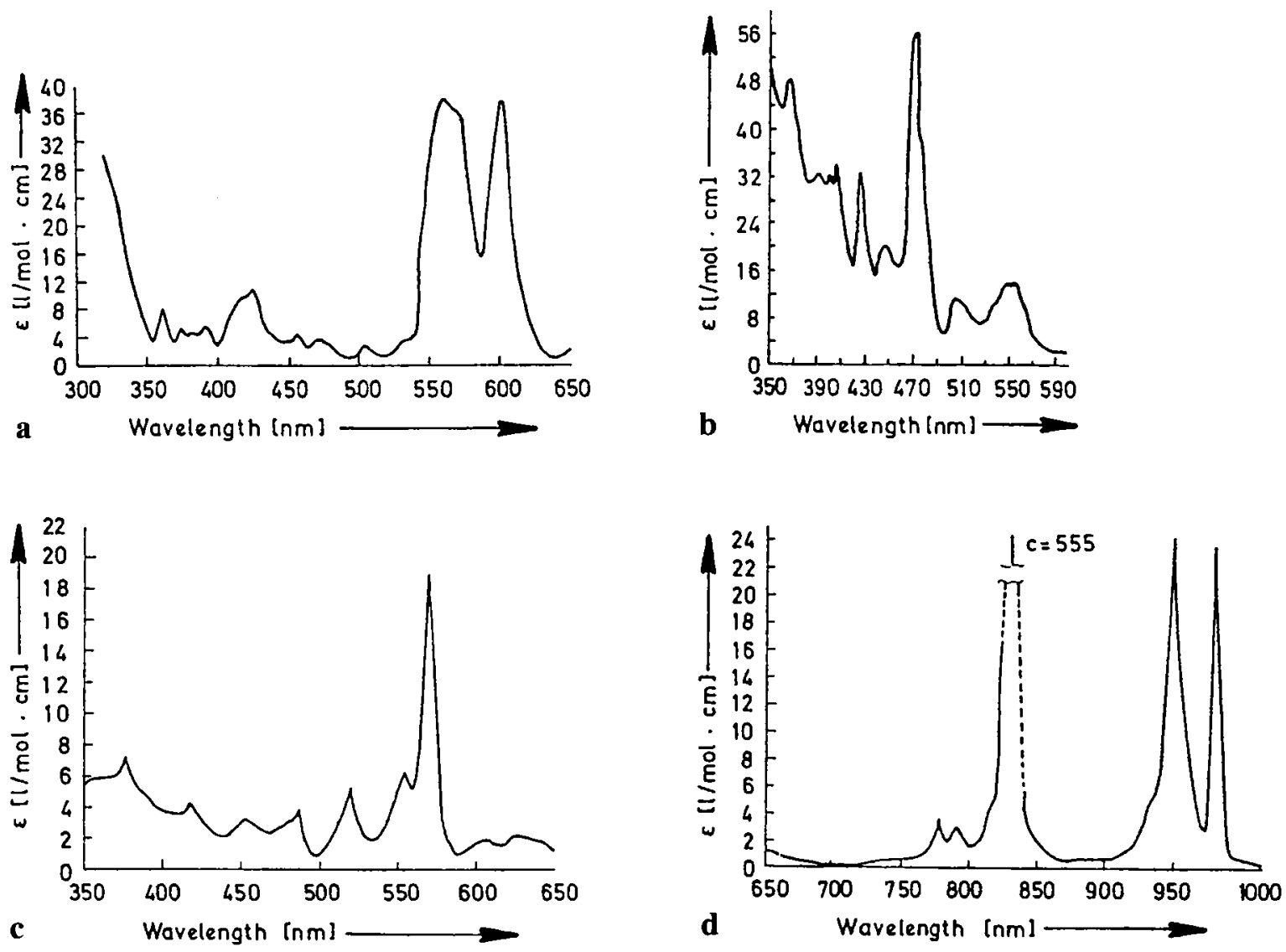

Fig. 18. Absorption spectra for $\mathrm{Pu}^{3+}$ (a), $\mathrm{Pu}^{4+}$ (b), $\mathrm{PuO}_{2}^{+}$(c), and $\mathrm{PuO}_{2}^{2+}$ (d) [93].

Table 8. Photoacoustic spectroscopy

\begin{tabular}{lcrcc}
\hline Ion & $\begin{array}{c}\text { Abs. } \\
\text { wavelength } \\
\text { nm }\end{array}$ & $\begin{array}{c}\text { Molar } \\
\text { Abs. } \\
\mathrm{M}^{-1} \mathrm{~cm}^{-1}\end{array}$ & \multicolumn{2}{c}{ Conc. sensitivity } \\
\cline { 5 - 6 } & 503 & 380 & $1 \times 10^{-8}$ & ppm \\
\hline $\mathrm{Am}(3+)$ & 50.003 \\
$\mathrm{Pu}(3+)$ & 600 & 38 & $1 \times 10^{-7}$ & 0.03 \\
$\mathrm{Pu}(4+)$ & 470 & 55 & $1 \times 10^{-7}$ & 0.03 \\
$\mathrm{Pu}(5+)$ & 568 & 19 & $5 \times 10^{-7}$ & 0.10 \\
$\mathrm{Pu}(6+)$ & 830 & 550 & $1 \times 10^{-7}$ & 0.03 \\
$\mathrm{~Np}(5+)$ & 980 & 395 & $1 \times 10^{-7}$ & 0.03 \\
$\mathrm{U}(4+)$ & 650 & 58 & $1 \times 10^{-7}$ & 0.03 \\
$\mathrm{U}(6+)$ & 415 & 8 & $1 \times 10^{-6}$ & 0.20 \\
\hline
\end{tabular}

solution at the parts per billion level [110] has increased rapidly over the last few years. Present systems are usually composed of a Nd-YAG or EXIMER pumped dye lasers $[110,111]$. With this system, it is necessary to change dyes several times in order to cover the visible and near infrared region. However, the very recent development of optical parametric oscillator systems using ultrapure barium borate crystals in place of the dye lasers has made continuous spectrum scanning from ultraviolet to the near infrared regions possible [112].

\section{X-ray absorption spectroscopy}

With the availability of third generation synchrotrons [113] and the development of new fluorescence detectors [114] that can process high count rates, X-ray absorption spectroscopy (XAS) is becoming a powerful technique to study the speciation of actinides in the environment $[115,116]$. XAS is particularly useful for investigating non-crystalline and polymeric actinide compounds that can not be identified by $\mathrm{X}$-ray diffraction analysis.

X-ray Absorption Near Edge Spectroscopy (XANES), usually within $40 \mathrm{eV}$ of the adsorption edge, can provide information about the local structure and oxidation state of an actinide in solution, solid or at a solution/solid interface. For example, uranium $\mathrm{L}_{\text {III }}$ XANES spectra of U(IV) in $\mathrm{UO}_{2}, \mathrm{U}(\mathrm{VI})$ in $\mathrm{UO}_{3}$ and a $50 / 50$ mixture are given in Figure 20 [116]. The peak shift in the spectra with oxidation state is easily detected. This technique has recently been used to show that U(VI) was reduced to U(IV) by cultures of the bacterium Clostridium sp. and that uranium in wastes can be stabilized by the action of this anaerobic bacteria [117]. This technique has also been used recently to investigate uranium speciation in soils and sediments from two former U.S. Department of Energy uranium processing facilities [116]. 

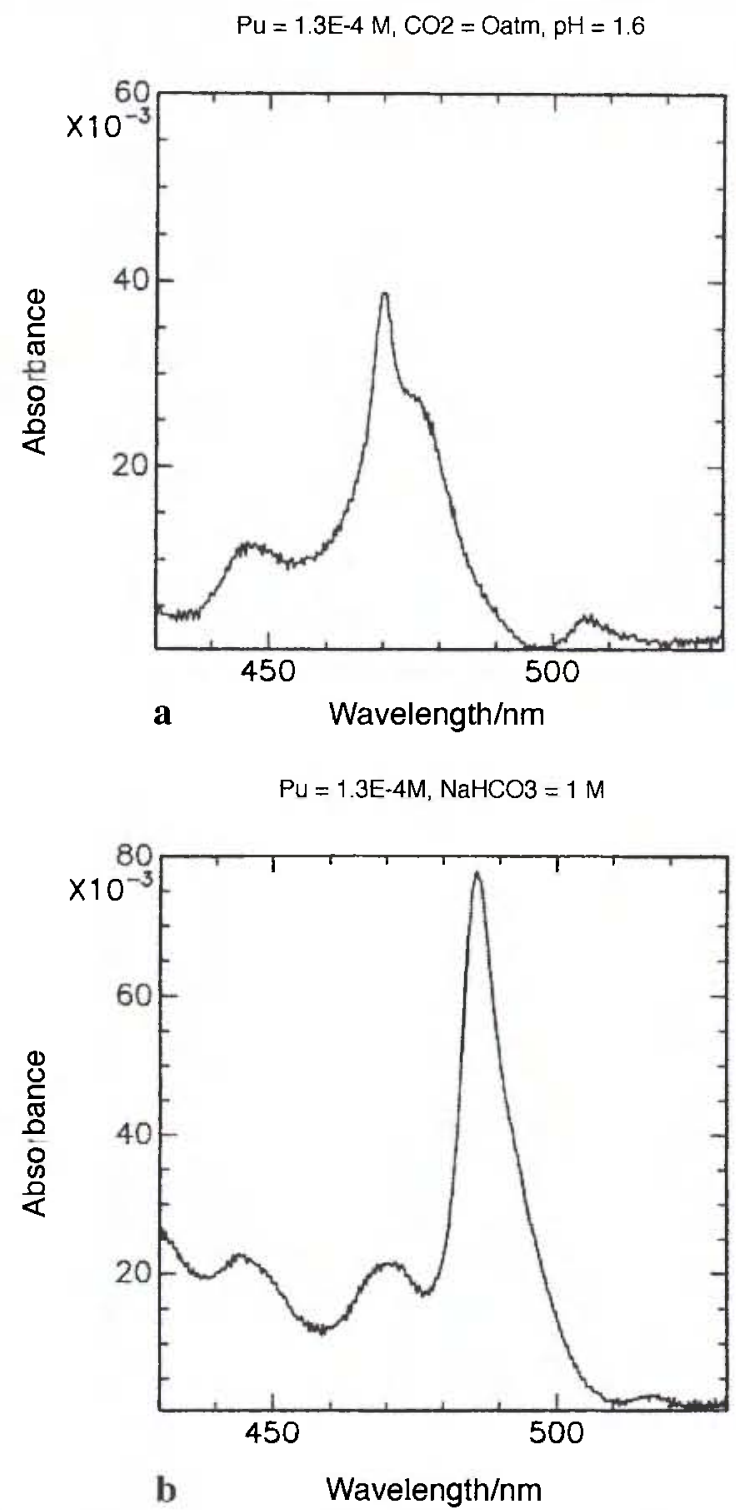

Fig. 19. Absorption spectra for $\mathrm{Pu}^{4+}$ (a) in perchloric acid and $\mathrm{Pu}^{4+}\left(\right.$ b) in $1 \mathrm{M} \mathrm{Na}_{2} \mathrm{CO}_{3}$.

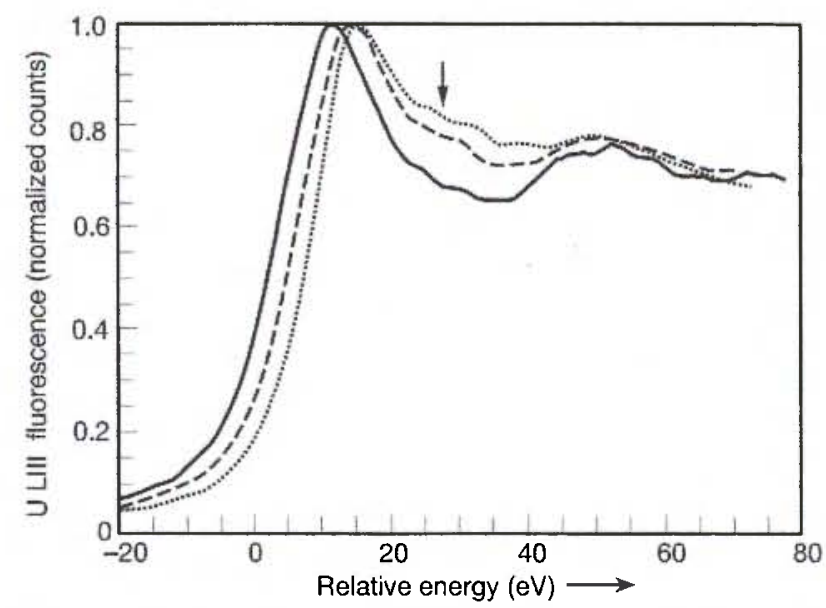

Fig. 20. Uranium $L_{\text {III }}$ XANES spectra of pure $U(I V) \mathrm{O}_{2}$ (solid line), $\mathrm{U}(\mathrm{VI}) \mathrm{O}_{3}$ (dotted line) and a $50 / 50$ mixture of the two (dashed line), (reprinted with permission from [116], Copyright 1994, American Chemical Society).
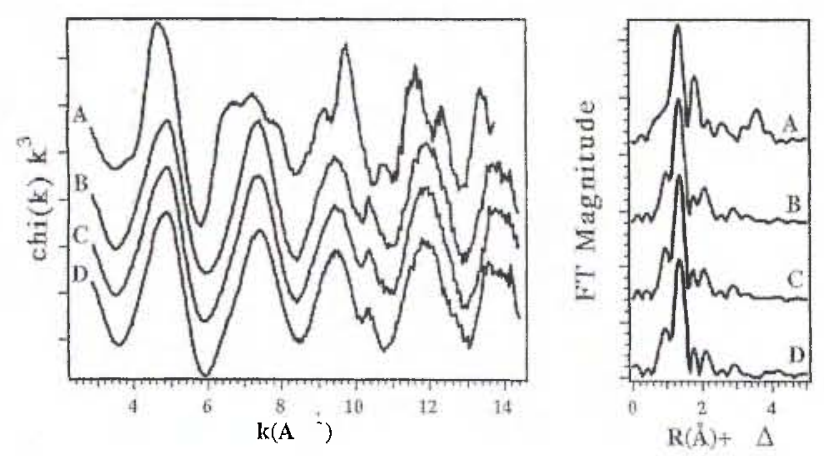

Fig. 21. Uranium $L_{\mathrm{tI}}$ edge EXAFS spectra of uranyl orthosilicate (A), uranyl adsorbed from a $0.01 \mathrm{M}$ uranyl solution onto silicic acid (B), uranyl adsorbed from a $0.05 \mathrm{M}$ uranyl solution onto silicic acid (C), and uranyl adsorbed from a $0.05 \mathrm{M}$ uranyl solution onto silica gel (D). Right panel shows the Fourier-transformed EXAFS of samples A through C.

Extended X-ray Absorption Fine Structure Spectroscopy (EXAFS) gives additional knowledge on coordination numbers and bond lengths to first, second and even more distant neighbor atoms [115]. This information is very useful for understanding the chemical state and bonding of actinide related to (a) speciation and complexation studies in aqueous and nonaqueous solutions, (b) adsorption processes at solidsolution interfaces involving minerals, mineral assemblies, rocks and soils and (c) adsorption and incorporation of radionuclides in microorganisms and other biological materials. The fine structure in absorption spectra above the $\mathrm{L}_{\text {III }}$ edge comes from interferences between outgoing photoelectron waves and backscattered waves from neighboring atoms. When EXAFS spectra are converted to momentum space (k), the fine structure is directly related to the sum of sinusoidal oscillations for each shell of neighboring atoms. The amplitude of the EXAFS oscillation depends on the number and type of near-neighbor atoms. For example, EXAFS spectra of uranyl orthosilicate and uranium(VI) adsorbed onto precipitated silicic acid and silica gel are shown in Figure 21 [118]. The Fourier-transformed EXAFS of these samples are included in the right panel. From fitting the EXAFS spectrum of the uranium orthosilicate, the following distances for the first four coordination shells of uranium were determined: $\mathrm{U}-\mathrm{O}_{\mathrm{axial}}=1.79 \hat{\mathrm{A}}, \mathrm{U}-\mathrm{O}_{\text {equatonal }}=2.39 \hat{\mathrm{A}}, \mathrm{U}-$ $\mathrm{Si}=3.16 \AA$, and $\mathrm{U}-\mathrm{U}=3.88 \AA$. The EXAFS spectra of uranyl species adsorbed onto silicic acid and silica gel at $\mathrm{pH} 4$ are identical indicating similar uranyl coordination. The main characteristic of the surface species are two well-separated oxygen coordination shells in the equatorial uranyl plane at 2.27 and $2.50 \hat{\mathrm{A}}$. The results of the analysis favored the interpretation of the uranyl surface species as an innersphere, mononuclear, bidentate complex. A number of papers describing investigations of uranyl(VI) and neptunyl(V) adsorption using EXAFS have appeared recently in the literature [119-122].

The handling of actinides at large synchrotron facilities is very difficult and highly restricted because 
of the toxicity and radiation properties of the actinides. Therefore, only a few studies have been conducted using elements of higher atomic number than uranium and neptunium. However, proposed facilities of special design for the handling and irradiation of plutonium and beyond at high concentration levels are being constructed at the European Synchrotron Radiation Facility at Grenoble, France [115].

\section{References}

1. Hobart, D. E.: Actinides in the Environment, Proc. of the Robert A. Welch Foundation Conference on Chemical Research: XXXIV Fifty Years with Transuranium Elements, Houston, TX, 1990, pp. 379-436.

2. Bell, M. J.: Origen - The ORNL Isotope Generation and Depletion Code, ORNL Report-4628, Oak Ridge National Laboratory, Oak Ridge, TN, 1973.

3. Croff, A. G.: Origen2-A, Revised and Updated Version of the Oak Ridge Isotope Generation and Depletion Code, ORNL Report-5621, Oak Ridge National Laboratory, Oak Ridge, TN, 1980

4. Seaborg, G. T., Katz, J. J.: The Actinide Elements, Natl. Nucl. Energy Ser., Div. IV, 14A, McGraw-Hill, New York 1954.

5. Seaborg, G. T., Katz, J. J., Manning, W. M.: The Transuranium Elements: Research Papers, Natl. Nucl. Energy Ser., Div. IV, 14B, McGraw-Hill, New York 1949.

6. Seaborg, G. T.: Elements Beyond 100, Present Status and Future Prospects, Ann. Rev. Nucl. Sci. 18, 59 (1968).

7. Katz, J. J., Seaborg, G. T., Morss, L. R.: The Chemistry of the Actinide Elements, 2nd ed., vol. 2, Chapman and Hall, New York 1986, pp. 1133-1146.

8. Durrant, P. J., Durrant, B.: Introduction to Advanced Inorganic Chemistry, Chapter 28, Longman Grp. Ltd., London 1970, pp. 1197-1212.

9. Larsen, E. M.: Transitional elements, W. A. Benjamin, Inc., New York 1965, p. 104

10. Moeller, T.: The Chemistry of the Lanthanides, Reinhold Publ. Corp., New York 1963, p. 21

11. Katz, J. J., Seaborg, G. T., Morss, L. R.: The Chemistry of the Actinide Elements, 2nd ed., vol. 2, Chapman and Hall, New York 1986, pp. 1164-1165.

12. Silva, R. J.: Thermodynamic Properties of Chemical Species in Nuclear Waste: The Solubilities of Crystalline Neodymium and Americium Trioxides, LBL Report-15055, Lawrence Berkeley Laboratory, Berkeley, CA, 1982.

13. Katz, J. J., Seaborg, G. T., Morss, L. R.: The Chemistry of the Actinide Elements, 2nd ed., vol. 2, Chapman and Hall, New York 1986, pp. 1131-1132.

14. Baes, C. F., Mesmer, R. E.: The Hydrolysis of Cations, Krieger Publ. Co., John Wiley and Son, New York 1976.

15. Choppin, G. R.: Chemistry of Actinides in the Environment, Radiochim. Acta 43, 82-83 (1988).

16. Stumm, W., Morgan, J. J.: Aquatic Chemistry, 2nd. ed., John Wiley and Sons, New York 1981, pp. 418-428.

17. Baas Becking, L. G. M., Kaplan, I. R., Moore, D.: Limits of the Natural Environment in Terms of $\mathrm{pH}$ and Oxidationreduction Potentials, J. Geol. 68, 243-284 (1960).

18. Stumm, W., Morgan, J. J.: Aquatic Chemistry, 2nd ed., Wiley-Interscience, New York 1981, p. 436.

19. Choppin, G. R., in: Plutonium Chemistry (W. T. Camall and G. R. Choppin, eds.), ACS Symposium Series 216, Am. Chem. Soc., Washington, D. C., 1983, p. 214.

20. Grenthe, I., chairman: Chemical Thermodynamics of Uranium, North-Holland, Amsterdam 1992.

21. Nitsche, H.: Basic Research for Assessment of Geologic Nuclear Waste Repositories: What Solubility and Speciation Studies of Transuranium Elements Can Tell Us, Mat. Res. Soc. Symp. Proc. 212, 517-529 (1991).
22. Silva, R. J., chairman: Chemical Thermodynamics of Americium, North Holland, Amsterdam 1995 (in press).

23. Papelis, C., Hayes, K. F., Leckie, J. O.: HYDRAQL: Aprogram for the Computation of Chemical Equilibrium Composition of Aqueous Batch Systems Including Surface-Complexation Modeling of Ion Absorption at the Oxide/Solution Interface, Tech. Rpt. No. 306, Environmental Engineering and Science, Dept. of Civil Engineering, Stanford University, Stanford, CA 1988.

24. Kim, J. I., Apostolidis, Ch., Büppelmann, K., Kanellakopulos, B., Klenze, R., Lierse, Ch., Magirius, S.: Chemisches Verhalten von Np, Pu und Am in Salzlösungen: Radiolyse, Löslichkeit, Hydrolyse, Chloridkomplexierung und Speziation, TUM Rpt-RCM 00187, Institut für Radiochemie, Technische Universität München, Garching, Germany 1987 , p. 15

25. Allard, B.: Solubilities of Actinides in Neutral or Basic Solutions, Proc. of the Actinide-1989 Conf., Pacific Grove, CA 1981, pp. 553-580.

26. Nguyen, S. N., Silva, R. J., Weed, H. C., Andrews, J. E.: Standard Gibbs Free Energies of Formation at the Temperature $303.15 \mathrm{~K}$ of Four Uranyl Silicates: Soddyite, Uranophane, Sodium Boltwoodite, and Sodium Weeksite, J. Chem. Thermodyn. 24, 359-376 (1992).

27. Nitsche, H.: Solubility Studies of Transuranium Elements for Nuclear Waste Disposal: Principles and Overview, Radiochim. Acta 52/53, 3-8 (1991).

28. Silva, R. J.: The Behavior of Americium in Aqueous Carbonate Systems, Mat. Res. Soc. Symp. Proc. 26, 875-881 (1984).

29. Meinrath, G., Kim, J. I.: Solubility Products of Different Am(III) and Nd(III) Carbonates, Eur. J. Solid State Inorg. Chem. 28, 383-388 (1991).

30. Silva, R. J.: Mechanisms for the Retardation of Uranium(VI) Migration, Mat. Res. Soc. Symp. Proc. 257, 323-330 (1992).

31. Lieser, K. H., Mühlenweg, U.: Neptunium in the Hydrosphere and in the Geosphere, Radiochim. Acta 43, 27-35 (1988).

32. McCarthy, P., in: Aquatic Humic Substances, Adv. Chem. Ser. 219, Am. Chem. Soc., Washington, D. C., 1989, pp. xvii-xxx.

33. Sonnenberg, L. B., Johnson, J. D., Christman, R. F., in: Aquatic Humic Substances, Adv. Chem. Ser. 219, Am. Chem. Soc., Washington, D. C., 1989, pp. 3-23.

34. Choppin, G. R., Allard, B.: Handbook on the Physics and Chemistry of the Actinides, A. J. Freeman, C. Keller, eds., Elsevier Sci. Publ., Amsterdam 1985 pp. 407-429.

35. Kaastrup, E., Halmo, T. M., in: Aquatic Humic Substances, Adv. Chem. Ser. 219, Am. Chem. Soc., Washington, D. C., 1989 , p. 698.

36. Kim, J. I., in: Handbook on the Physics and Chemistry of the Actinides, A. J. Freeman and C. Keller, eds., Elsevier Science Publ., Amsterdam 1985, pp. 413-455.

37. Stumm, W., Morgan, J. J.: Aquatic Chemistry, 2nd ed., John Wiley and Sons, New York 1981, pp. 599-647.

38. Silva, R. J., Yee, A. W., White, A. X.: Waste Isolation Safety Assessment Program: Annual Progress Report October 1, 1979-September 30, 1980, LBL Rpt. 9945, Lawrence Berkeley Laboratory, Berkeley, CA 1980.

39. Massoud, P., Ravindran, V., Wong, S.-P., Stevens, M. R., in: Aquatic Humic Substances, Adv. Chem. Ser. 219, Am. Chem. Soc., Washington, D. C., 1989, p. 558.

40. Serne, R. J., Relyea, J. F.: The Status of Radionuclide Sorption-Desorption Studies Performed by the WRIT Program, PNL Rpt.-SA-9787, Battelle Pacific Northwest Laboratory, Richland, WA 1981.

41. Moody, J. B.: Radionuclide Migration/Retardation: Research and Development Technology Status Report, ONWI-321, Office of Nuclear Waste Isolation, Battelle Memorial Institute, Columbus, $\mathrm{OH} 1982$.

42. Stumm, W., Morgan, J. J.: Aquatic Chemistry, 2nd. ed., John Wiley and Sons, New York 1981, pp. 610-640. 
43. Kent, D. B., Tripathi, V. S., Ball, N. B., Leckie, J. O.: Surface-complexation Modeling of Radionuclide Adsorption in Sub-surface Environments, Tech. Rpt. No. 294, Environmental Engineering and Science, Department of Civil Engineering, Stanford University, Stanford, CA 1986.

44. Hayes, K. F., Redden, G. Ela, W., Leckie, J. O.: Application of Surface Complexation Models for Radionuclide Adsorption, PNL Rpt.-7239, Pacific Northwest Laboratory, Richland, WA 1989.

45. Stumm, W., Morgan, J. J.: Aquatic Chemistry, 2nd. ed., John Wiley and Sons, New York 1981, pp. 640-647.

46. Davis, J. A., James, R. O., Leckie, J. O.: Surface Ionization and Complexation of the Oxide/Water Interface, J. Colloid Interface Sci. 63(3), 480-499 (1978).

47. Yates, D. E., Levine, S., Healy, T. W.: Site Binding Model of the Electrical Double Layer at the Oxide/Water Interface, J. Chem. Soc. Faraday Trans. I, 170, 1807-1818 (1974).

48. Davis, J. A., Leckie, J. O.: Surface Ionization and Complexation at the Oxide/Water Interface. II. Surface properties of Amorphous Iron Oxyhydroxide and Adsorption of Metal Ions, J. Colloid Interface Sci. 67, 90-107 (1978).

49. James, R. O., Healy, T. W.: Adsorption of Hydrolyzable Metal Ions at the Oxide-Water Interface, J. Colloid Interface Sci. 40, 42-52 (1972).

50. Silva, R. J., Benson, L. V., Yee, A. W., Parks, G. A.: Waste Isolation Safety Assessment Program. Task 4: Collection and Generation of Transport Data Theoretical and Experimental Evaluation of Waste Transport in Selected Rocks, LBL Rpt.-9945, Lawrence Berkeley Laboratory, Berkeley, CA 1979.

51. Silva, R. J.: An Integrated View of Solubilities, Speciation, Sorption and Migration from a Chemist's Point of View, 3rd, Inter. Conf. on the Chemistry and Migration Behavior of Actinides and Fission Products in the Geosphere, Jerez de la Frontera, October 21-25, 1991.

52. McCarthy, J. F., Zachara, J. M.: Subsurface Transport of Contaminants, Environ. Sci. Technol. 23(5), 496-502 (1989).

53. Avogadro, A., DeMarsily, G.: The Role of Colloids in Nuclear Waste Disposal, Mat. Res. Soc. Symp. Proc. 26, 495-505 (1984)

54. Ramsay, D. A.: The Role of Colloids in the Release of Radionuclides from Nuclear Waste, Radiochim. Acta 44/ 45, 165-170 (1988).

55. Sheludko, A.: Colloid Chemistry, Elsevier Publ. Co., New York 1966, pp. 1-2.

56. Shaw, D. J.: Colloid and Surface Chemistry, 4th Ed., Butterworth-Heinemann Ltd., Oxford 1992, pp. 1-7.

57. Bênes, P., Majer, V.: Trace Chemistry of Aqueous Solutions, Elsevier Sci. Publ. Co., New York 1980, p. 62.

58. Kim, J. I.: Actinide Colloid Generation in Groundwater, Radiochim. Acta 52/53, 71-81 (1991).

59. Thompson, J. L.: Actinide Behavior on Crushed Rock Columns, J. Radioanal. Nucl. Chem. 130, 353-364 (1989).

60. Lieser, K. M., Gleitsmann, B., Peschke, S., Steinkopff, T.: Colloid Formation and Sorption of Radionuclides in Natural Systems, Radiochim. Acta 40, 39-47 (1988).

61. Yariv, S., Cross, H.: Geochemistry of Colloidal Systems, Springer-Verlag, Berlin 1979, pp. 343-349.

62. Bênes, P., Majer, V.: Trace Chemistry of Aqueous Solutions, Elsevier Sci. Publ. Co., New York 1980, p. 101.

63. Rai, D., Swanson, J. L.: Properties of Plutonium(IV) Polymer of Environmental Importance, Nucl. Technol. 54, $107-112$ (1981)

64. Stumm, W., Morgan, J. J.: Aquatic Chemistry, 2nd ed., John Wiley and Sons, New York 1981, pp. 647-664.

65. Kaastrup, E., Halmo, T. M., in: Aquatic Humic Substances, Adv. Chem. Ser. 219, Am. Chem. Soc., Washington, D. C., 1989, pp. 393-395.

66. Bell, J. T., Coleman, C. F., Costanzo, D. A., Biggers, R. E.: Plutonium Polymerization - III. The Nitrate Precipitation of Pu(IV) Polymer, J. Inorg. Nucl. Chem. 35, 629632 (1973).
67. Olofsson, U., Allard, B., Anderson, K., Torstenfelt, B. Formation and Properties of Actinide Colloids, SKBF/ KBS Tech. Rpt.-TR 83-08, Swedish Nucl. Fuel and Waste Management Co., Stockholm 1983.

68. Kepak, F.: Adsorption and Colloidal Properties of Radioactive Elements in Trace Concentrations, Chem. Rev. 71(4), 357-369 (1971).

69. Silver, G. L.: Formation of Plutonium(IV) Colloid from Plutonyl Cations, J. Radioanal. Nucl. Chem. Lett. 126, 429-433 (1988)

70. Costanzo, D. A., Biggers, R. E., Bell, J. T.: Plutonium Polymerization-I. A Spectrophotometric study of the Polymerization of Plutonium(IV), J. Inorg. Nucl. Chem. 34, 609-622 (1973).

71. Lloyd, M. H., Haire, R. G.: The Chemistry of Plutonium in Sol-Gel Processes, Radiochim. Acta 25, 139-148 (1978)

72. Silver, G. L.: Free Energy of Plutonium Polymer Formation, J. Less-Common Met. 91, 317-320 (1983).

73. Rai, D.: Solubility Product of Pu(IV) Hydrous Oxide and Equilibrium Constants of $\mathrm{Pu}(\mathrm{IV}) / \mathrm{Pu}(\mathrm{V}), \mathrm{Pu}(\mathrm{IV}) / \mathrm{Pu}(\mathrm{VI})$ and $\mathrm{Pu}(\mathrm{V}) / \mathrm{Pu}(\mathrm{VI})$ Couples, Radiochim. Acta 35, 97-106 (1984).

74. Kim, J. I., Kanellakopulos, B.: Solubility products of Plutonium(IV) Oxide and Hydroxide, Radiochim. Acta 48 , 145-150 (1989).

75. Rai, D., Ryan, J. L.: Crystallinity and Solubility of Pu(IV) Oxide and Hydrous Oxide in Aged Aqueous Suspensions, Radiochim. Acta 30, 213-216 (1982).

76. Rai, D., Serne, R. J., Swanson, J. L.: Solution Species of Plutonium in the Environment, J. Environ. Qual. 9, 417$420(1980)$

77. Rai, D., Serne, R. J.: Solution Species of Pu-239 in Oxidizing Environments: I. Polymeric Pu(IV), PNL Rpt.-SA6994, Pacific Northwest Laboratory, Hanford, WA, 1979. pp. 1-9.

78. Ichikawa, F., Sato, T.: On the Particle Size Distribution of Hydrolyzed Plutonium(IV) Polymer, J. Radioanal. Nucl Chem. 84, 269-275 (1984).

79. Triay, I. R., Hobart, D. E., Mitchell, A. J., Newton, T. W., Ott, M. A., Palmer, P. D., Rundberg, R. S., Thompson, J. L.: Size Determinations of Plutonium Colloids Using Autocorrelation Photon Spectroscopy, Radiochim. Acta 52/ 53, 127-131 (1991).

80. Rundberg, R. S., Mitchell, A. J., Triay, I. R., Torstenfelt, J. B.: Size and Density of a Pu-242 Colloid, Mat. Res. Soc. Proc. 112, 269-275 (1988).

81. Newton, T. W., Hobart, D. E., Palmer, P. D.: The Formation of Pu(IV)-Colloid by the Alpha-Reduction of $\mathrm{Pu}(\mathrm{V})$ or $\mathrm{Pu}(\mathrm{VI})$ in Aqueous Solutions, Radiochim. Acta 39 139-147 (1986).

82. Savage, D. J., Kyffin, T. W.: Oxidation Breakdown of Polymeric Plutonium(IV) Hydroxide by Cerium(IV), Polyhedron 5(3), 743-752 (1986).

83. Silver, G. L.: The Ratio Pu(V)/Pu(IV) in Natural Water, J. Radioanal. Nucl. Chem. Lett. 137, 75-78 (1989).

84. Cleveland, J. M. in: Geochemical Modeling in Aqueous Systems, ACS Sym. Ser., American Chemical Society, Washington, D.C., 1979, pp. 321-338.

85. Kraus, K. A.: Hydrolytic Behavior of the Heavy Elements, Proc. Intern. Conf. on the Peaceful Uses of Atomic Energy, Geneva, Switzerland, 7, 245-257 (1956).

86. Buckau, G., Stumpe, R., Kim, J. I.: Americium Colloid Generation in Groundwaters and Its Speciation by LaserInduced Photoacoustic Spectroscopy, J. Less-Common Met. 122, 555-562 (1986).

87. Lierse, Ch., Treiber, W., Kim, J. I.: Hydrolysis Reactions of Neptunium(V), Radiochim. Acta 38, 27-28 (1985).

88. Kim, J. I.: Actinide Colloid Generation in Groundwater, 2nd Int. Conf. on the Chemistry and Migration Behavior of Actinides and Fission Products in the Geosphere, Monterey, CA 1989.

89. Triay, I., Simmons, A., Levy, S., Nelson, S., Nuttall, H., Robinson, B., Steinkampf, W., Viani, B.: Colloid-Facili- 
tated Radionuclide Transport at Yucca Mountain, LA Rpt.12779-MS, Los Alamos National Laboratory, Los Alamos, NM 1995.

90. Yariv, S., Cross, H.: Geochemistry of Colloidal Systems, Springer-Verlag, Berlin 1979, p. 23.

91. Rossotti, F. J. C., Rossotti, H. S.: The Determination of Stability Constants, McGraw-Hill, New York 1961.

92. Baumann, R. P.: Absorption Spectroscopy, John Wiley and Sons, New York 1962, pp. 19-20.

93. Keller, C.: The Chemistry of the Transuranium Elements, Verlag Chemie Weinheim, Germany 1971, pp. 94-115.

94. Katz, J. J, Seaborg, G. T., Morss, L. R.: The Chemistry of the Actinide Elements, 2nd ed., vol. 2, Chapman and Hall, New York 1986, pp. 1257-1277.

95. Bauman, R. P.: Adsorption Spectroscopy, John Wiley and Sons, New York 1962, pp. 368-369.

96. Nitsche, H., Standifer, E. M., Silva, R. J.: Neptunium(V) Complexation with Carbonate, Lanth. and Act. Res. 3, 203-211 (1990).

97. Nitsche, H., Standifer, E. M., Silva, R. J.: Am(III) Carbonate Complexation in Aqueous Perchlorate Solutions, Radiochim. Acta 46, 185-189 (1989).

98. Bennett, D. A., Hoffman, D., Nitsche, H., Russo, R. E., Torres, R. A., Baisden, P. A., Andrews, J. E., Palmer, C. E. A., Silva, R. J.: Hydrolysis and Carbonate Complexation of Dioxoplutonium(V), Radiochim. Acta 56, 15-19 (1992)

100. Cetorelli, J. J., Winefordner, J. D.: Estimation of the Minimum Detectable Concentration and Optimum Instrumental Conditions in Precision Absorption Spectrophotometry of Substances in the Condensed Phase, Talanta 14, 705-713 (1967).

101. Swafford, R. L., in: Lasers in Chemical Analysis, G. M. Hieftje, J. C. Travis, F. E. Lytle, eds., Humana Press, West Lafayette, Indiana 1981, pp. 143-156.

102. Tam, A. C.: Applications of Photoacoustic Sensing Techniques, Rev. Mod. Phys. 58, 381-486 (1986).

103. Jackson, W. B., Amer, N. M., Boccara, A. C., Fournier, D.: Photothermal Deflection Spectroscopy and Detection, Appl. Opt. 20, 1333-1344 (1981).

104. Fang, H. L., Swafford, R. L., in: Ultrasensitive Laser Spectroscopy, D. S. Kliger, Ed., Academic Press, New York 1983, pp. 175-180.

105. Torres, R. A., Palmer, C. A., Baisden, P. A., Russo, R. E., Silva, R. J.: Comparison of Photoacoustic Spectroscopy, Conventional Absorption Spectroscopy, and Potentiometry as Probes of Lanthanide Speciation, Anal. Chem. 62(3), 298-303 (1990).

106. Klenze, R., Kim, J. I., Wimmer, H.: Speciation of Aquatic Actinide Ions by Pulsed Laser Spectroscopy, Radiochim. Acta 52/53, 97-103 (1991).

107. Beitz, J. V., Bowers, D. L., Doxtader, M. M., Maroni, V. A., Reed, D. T.: Detection and Speciation of Transuranium Elements in Synthetic Groundwater via Pulsed-Laser Excitation, Radiochim. Acta 44/45, 87-93 (1988).

108. Moulin, C., Decambox, P., Mauchien, P., Moulin, V., Theyssier, M.: On the Use of Laser-Induced Time-Resolved Spectrofluorometry for Interaction Studies between Organic Matter and Actinides: Application to Curium, Radiochim. Acta 52/53, 119-125 (1991).
109. Russo, R. E., Rojas, D., Robouch, P., Silva, R. J.: Remote Photoacoustic Measurements in Aqueous Solutions Using an Optical Fiber, Rev. Sci. Instrum 61(12), 3729-3732 (1990).

110. Klenze, R., Kim, J. I.: Direct Speciation of Transuranium Element in Natural Aquatic Systems by Laser-Induced Photoacoustic Spectroscopy, Radiochim. Acta 44/45, 7785 (1988).

111. European Synchrotron Radiation Facility (ESRF): Beam Line Handbook, Grenoble, France (1994).

112. Mollenauer, L. F., White, J. C., Pollock, C. R., eds.: Tunable Lasers, Topics in Applied Physics, Springer-Verlag, New York 1993.

113. Konigsberger, D. C., Prins, R.: X-ray Absorption, Principles, Application, Techniques of EXAFS, SEXAFS and XANES, Wiley and Sons, New York 1988.

114. Bucher, J. J., Allen, P. G., Edelstein, N. M., Shuh, D. K., Madden, N., Pehl, D., Cork, C., Malone, D.: A Quad-pixel Monolithic Ge Fluorescence Detector. Stanford Synchrotron Radiation Laboratory (SSRL), Stanford, CA, USA, Annual Users Meeting, Poster Session (1994).

115. Nitsche, H.: Synchrotron X-ray Absorption Spectroscopy: A New Tool for Actinide and Lanthanide Speciation in Solids and Solution, J. Alloys and Compounds 223, 274279 (1995).

116. Bertsch, P. M., Hunter, D. B., Sutton, S. R., Bajt, S., Rivers, M. L.: In Situ Chemical Speciation of Uranium in Soils and Sediments by Micro X-ray Absorption Spectroscopy. Environ. Sci. Technol. 28, 980-984 (1994).

117. Francis, A. J., Dodge, C. J., Lu, F., Halada, G. P., Clayton, C. R.: XPS and XANES Studies of Uranium Reduction by Clostridium sp., Environ. Sci. Technol. 28, 636-639 (1994).

118. Reich, T., Moll, H., Denecke, M. A., Geipel, G., Bernhard, G., Nitsche, H., Allen, P. G., Kaltsoyannis, N., Bucher, J. J., Edelstein, N. M., Shuh, D. K.: Characterization of Hydrous Uranyl Silicate by EXAFS Analysis. Fifth International Conference on Migration of Actinides and Fission Products in the Geosphere, Saint-Malo (1995).

119. Chisholm-Brause, C., Conradson, S. D., Buscher, C. T., Eller, P. G., Morris, D. E.: Speciation of Uranyl Sorbed at Multiple Binding Sites on Montmorillonite. Geochim. Cosmochim. Acta 58(17), 3625-3631 (1994).

120. Chisholm-Brause, C., Conradson, S. D., Eller, P. G., Morris, D. E.: Changes in U(VI) Speciation Upon Sorption onto Montmorillonite from Aqueous and Organic Solutions. MRS Sci. Basis for Nuclear Waste Management, XV, 315-322 (1992).

121. Dent, A. J., Ramsay, J. D. F., Swanton, S. W.: An EXAFS Study of Uranyl Ion in Solution and Sorbed onto Silica and Montmorillonite Clay Colloids. J. Colloid Interface Sci. 150, No. 1, 45-60 (1992).

122. Combes, J., Chisholm-Brause, D., Brown, Jr., G. E., Parks, G. A., Conradson, S. D., Eller, P. G., Triay, I. R., Hobart, D. E., Meijer, A.: EXAFS Spectroscopic Study of Neptunium(V) Sorption at the $\alpha$-FeOOH/Water Interface. Environ. Sci. Technol. 26, No. 2, 376-383 (1992). 


\title{
Radioactivity and Fission Energy
}

\author{
By L. Koch \\ European Commission, Joint Research Centre, European Institute for Transuranium Elements, \\ P.O. Box 2340, 76125 Karlsruhe, Federal Republic of Germany
}

(Received August 23, 1995)

Radioacitvity / Nuclear energy / Transmutation / Fission

\begin{abstract}
Anthropogenic radioactivity stems mainly from nuclear energy generation. The contents are given for fission and radioactivation products in a typical LWR and for global accumulation including transuranium elements. The transmutation of radiotoxicity in fast reactors is described.
\end{abstract}

\section{Introduction}

Similar to the $\mathrm{CO}_{2}$ emissions from the burning of fossile fuels enhancing the greenhouse effect, fission energy generates also an unwanted by-product: artificial radioactivity. Nevertheless fissiogenic radioactivity occurs in nature, too. In 1972, H. Bouzigues observed in natural uranium an odd isotopic abundance for ${ }^{235} \mathrm{U}$ of $0.711 \pm 0.0007 \%$, which led to the discovery of a precambrian natural fission energy source in Oklo, Gabon. The uranium ore that Becquerel held in his hands also must have contained radioactivity that stemmed from fission - spontaneous or induced by cosmic rays. During early times on earth, when the ${ }^{235} U$ abundance was above $2.1 \%$, natural light water boiling reactors were still possible so that the Oklo phenomenon was not a singularity. The Oklo reactors, however, operated only with a power of $1-10 \mathrm{~kW}$ during about 1 million years. So, present nuclear power stations cannot simply be regarded as atavisms, although they generate about the same energy. Their power density and hence the accumulation of short-lived fission products is larger by $10^{6}$. A high degree of safety technology is required to contain the accumulated radioactivity in the core of the reactor. In case of a sudden release, as during the Chernobyl catastrophe, a devastating contamination of the environment is the unavoidable consequence. Already before this event, when fission energy became a military weapon in 1945, it turned the public against fission energy use. The following atomic bomb tests in the atmosphere led to a wide-spread contamination by long-living radioactive fission products of which some accumulated in the food chain, which further sensibilized the public, so that now the final disposal of long-living radio- toxic nuclides has become the major acceptance problem of fission energy use.

Nevertheless, it is more or less common belief that mankind cannot do without the energy generated by fission as long as no reasonable substitute is found. Consequently, it ought to be the greatest challenge to the scientific and technical community to develop feasible solutions that will make fission energy acceptable in reducing and containing the artificial radioactivity to such an extent that accidental releases to the environment cannot pose a major hazard to life.

\section{Formation of radioactivity by fission energy}

The radioactivity building up during fission energy generation can be described by:

$$
\frac{d N}{d t}=\sum\left(f \sigma^{*} \phi+z \lambda^{*}\right) N^{*}-(\sigma \phi+\lambda) N
$$

With $N$ as the radioactive nuclide considered that is formed by $\Sigma$ routes from different nuclides $N^{*}$ with the reaction constants $f \sigma^{*} \phi$ (neutron induced) and $z \lambda^{*}$ of possible decay modes ( $\phi$ is the neutron flux). The second term of the equation describes the nuclide's depletion by the same type of reactions.

The primary nuclear reaction is the neutron induced fission of ${ }^{235} \mathrm{U}$, which is the only fissile nuclide in accessible quantities on earth to sustain a nuclear chain reaction.

$$
{ }^{235} \mathrm{U}+n=f p+v n+E
$$

For the fission of one ${ }^{235} \mathrm{U}$ atom induced by one thermal neutron $n$, there are released fission products $f p$, of varying masses - as described below - together with an average yield of $v=2.423$ neutrons and of average released energy $E=193.6$ [MeV].

\section{Radioactivity by fission}

Following Eq. (1), the formation of a fission product mass $N$ is described by:

$$
f \sigma \phi \equiv f y \frac{\sigma_{f}}{\sigma_{a}} \phi
$$



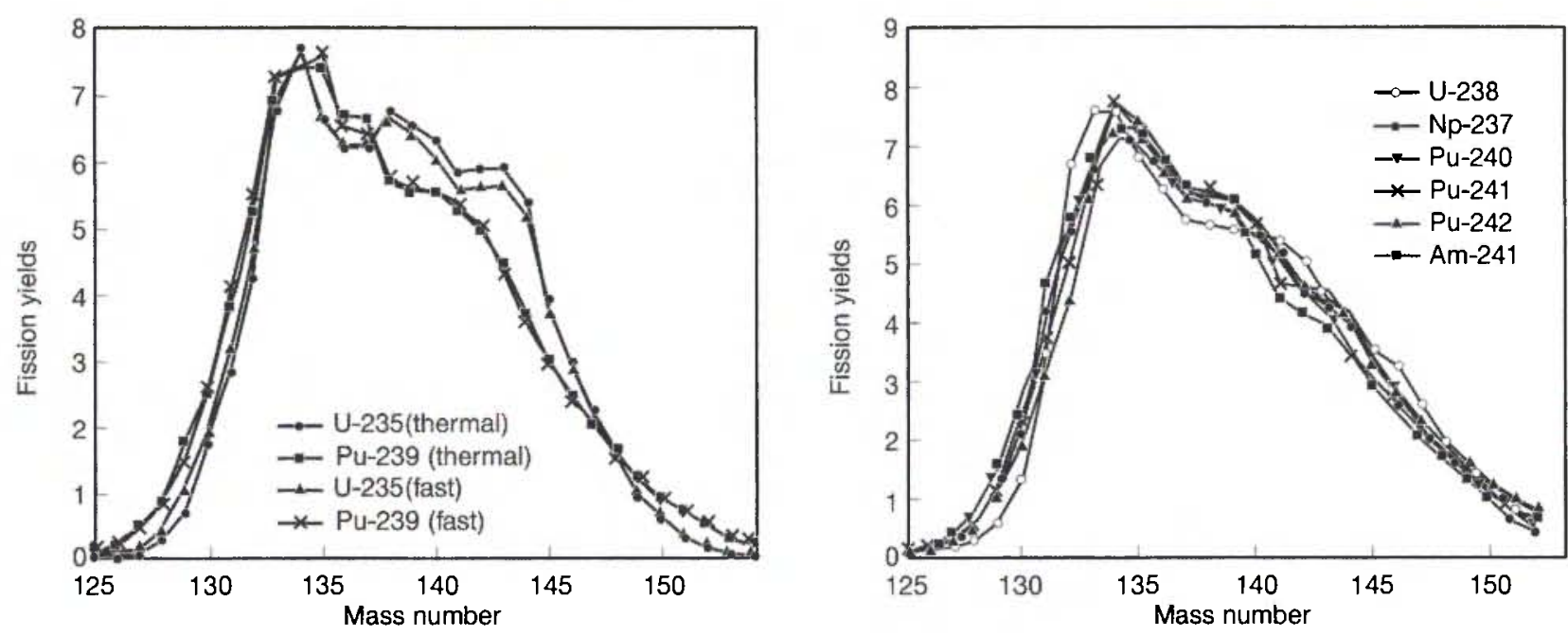

Fig. 1. Isobaric yields of heavier fission products: influence of neutron energy for ${ }^{235} \mathrm{U}$ and ${ }^{239} \mathrm{Pu}$ (left curve), influence of higher masses of fission sources $\left({ }^{237} \mathrm{~Np},{ }^{238} \mathrm{U},{ }^{240} \mathrm{Pu},{ }^{241} \mathrm{Pu},{ }^{241} \mathrm{Am},{ }^{242} \mathrm{Pu}\right)[1,2]$.

where the fission yield $f y$, as well as the relative fission cross section $\sigma_{f} / \sigma_{a}$ varies with the energy spectrum of the neutron flux $\phi$. The lighter masses distribution of the asymmetric fission changes little. The heavier fission product distribution reflects the higher masses of the fission sources. With increasing energy of the neutron inducing fission, the symmetric fission increases only slightly (Fig. 1 ), but the $\sigma_{f} / \sigma_{a}$ varies strongly, due to so-called resonances in the epithermal neutron energy spectrum $\left(\sigma_{a}\right.$ is the total absorption cross section $\sigma_{a}=\sigma_{f}+\sigma_{c}$ ).

The (independently by fission) formed nuclide $N$ decays by $\beta^{-}$with the reaction constant $\lambda$ into another radioactive or stable nuclide. During reactor operation, the short-lived radionuclides determine the total radioactivity which is about $10^{20} \mathrm{~Bq}$ for a typical LWR at the time of a reactor shut down. After ten thousand years, the remaining radioactivity is governed by a few radionuclides.

\section{Radioactivity by neutron capture}

The neutrons (Eq. (2)) in excess $(v-1)$ to maintain the chain reaction are captured in reactor materials. According to Eq. (1), the build-up is governed by

$$
f \sigma^{*} \phi \equiv \frac{\sigma_{c}}{\sigma_{a}} \phi
$$

with $\sigma_{c}$ the cross section for neutron capture $\left(\sigma_{a}=\right.$ $\left.\sigma_{f}+\sigma_{c}\right)$. The radiative neutron capture reaction $(\mathrm{n}, \gamma)$ dominates other possible reactions $(n, 2 n),(n, 3 n)$, $(n, p),(n, \alpha)$. Although for absorbers of excess reactivity and for structural materials elements are chosen such as $\mathrm{B}, \mathrm{Gd}, \mathrm{Zr}$ with small radioactivation, the radioactivity of reactor material is considerable (Table 1).

Of more relevance is the built up radioactivity by activation in the fuel itself. Certain fission products limit the fuel use because of parasitic neutron capture which leads in some cases to the build-up of new radionuclides that are not formed by fission and subsequent $\beta^{-}$decay, because they are shielded in the decay chain by stable nuclides. (Among them are: ${ }^{110} \mathrm{Ag}$, ${ }^{134} \mathrm{Cs}$ and ${ }^{154} \mathrm{Eu}$ ). The neutron capture reactions change the fission product distribution in Light Water Reactors for highly burnt fuels considerably, so that it deviates from the original mass distribution.

The reactivity of a reactor fuel is prolonged by the formation of TU nuclides which are partially fissile, but all are highly radiotoxic. The main reaction is the (multiple) radiative neutron capture $(n, \gamma)$ followed by $\beta^{-}-$and $\alpha$-decay which determine the pattern of the reaction path (Fig. 2) leading to the build-up of actinides in measurable quantities up to californium. In Table 2 is given the concentration for the actinide nuclides contained in $1 \mathrm{t} \mathrm{HM}$ of spent fuel at the time of discharge.

Although the ${ }^{238} \mathrm{Pu}(\mathrm{n}, 3 \mathrm{n}){ }^{236} \mathrm{Pu}$ and ${ }^{234} \mathrm{U}(\mathrm{n}, 3 n){ }^{232} \mathrm{U}$ reactions have a low probability, they nevertheless contribute substantially, e.g. at discharge of PWR fuel to the formation of the ${ }^{236} \mathrm{Pu}\left(10^{10} \mathrm{~Bq} / \mathrm{t} \mathrm{HM}\right)$ and ${ }^{232} \mathrm{U}$ $\left(10^{8} \mathrm{~Bq} / \mathrm{t} \mathrm{HM}\right)$, which fall into the natural $4 \mathrm{n}$ chain of ${ }^{232} \mathrm{Th}$ [5]. It is the build-up of ${ }^{208} \mathrm{~T} 1$, which emits a $2.6 \mathrm{MeV}$ hard $\gamma$-radiation that limits the reuse of recovered uranium from reprocessed LWR fuel, because - during the re-enrichment process with present shielding in the facilities - the acceptable occupational radiation dose would be soon exceeded.

The ${ }^{238} \mathrm{U}(\mathrm{n}, 2 \mathrm{n})^{237} \mathrm{U} \stackrel{\beta^{-}}{\longrightarrow}{ }^{237} \mathrm{~Np}$ reaction resurrects the extinct $(4 n+1)$ decay chain (Fig. 3). Since ${ }^{237} \mathrm{~Np}$ is being produced in the ton scale, it will testify far 
Table 1. Radioactivity of fission products ( $\mathrm{Bq} / \mathrm{t} \mathrm{HM}$ ) from typical PWR fuel and radioactivation in reactor material at discharge and $10000 \mathrm{a}$ [3]

\begin{tabular}{|c|c|c|}
\hline \multicolumn{3}{|c|}{ Fission product radioactivity $[\mathrm{Bq}]$} \\
\hline Radionuclide & Discharge & $10000 \mathrm{a}$ \\
\hline${ }^{3} \mathrm{H}$ & $2 \cdot 10^{13}$ & - \\
\hline${ }^{79} \mathrm{Se}$ & $1 \cdot 10^{10}$ & $1 \cdot 10^{10}$ \\
\hline${ }^{85} \mathrm{Kr}$ & $3 \cdot 10^{14}$ & - \\
\hline${ }^{86} \mathrm{Rb}$ & $7 \cdot 10^{13}$ & - \\
\hline${ }^{89} \mathrm{Sr}$ & $3 \cdot 10^{16}$ & - \\
\hline${ }^{90} \mathrm{Sr}$ & $3 \cdot 10^{15}$ & - \\
\hline${ }^{90} \mathrm{Y}$ & $3 \cdot 10^{15}$ & - \\
\hline${ }^{91} \mathrm{Y}$ & $4 \cdot 10^{16}$ & - \\
\hline${ }^{93} \mathrm{Zr}$ & $7 \cdot 10^{10}$ & $7 \cdot 10^{10}$ \\
\hline${ }^{95} \mathrm{Zr}$ & $5 \cdot 10^{16}$ & - \\
\hline${ }^{93 m} \mathrm{Nb}$ & $5 \cdot 10^{9}$ & $6 \cdot 10^{10}$ \\
\hline${ }^{95} \mathrm{Nb}$ & $5 \cdot 10^{16}$ & - \\
\hline${ }^{95 m} \mathrm{Nb}$ & $4 \cdot 10^{14}$ & - \\
\hline${ }^{90} \mathrm{Tc}$ & $5 \cdot 10^{11}$ & $5 \cdot 10^{11}$ \\
\hline${ }^{103} \mathrm{Ru}$ & $6 \cdot 10^{16}$ & - \\
\hline${ }^{106} \mathrm{Ru}$ & $2 \cdot 10^{16}$ & - \\
\hline${ }^{103 m} \mathrm{Rh}$ & $5 \cdot 10^{16}$ & - \\
\hline${ }^{106} \mathrm{Rh}$ & $2 \cdot 10^{16}$ & - \\
\hline${ }^{107} \mathrm{Pd}$ & $4 \cdot 10^{9}$ & $4 \cdot 10^{9}$ \\
\hline${ }^{110} \mathrm{Ag}$ & $5 \cdot 10^{15}$ & - \\
\hline${ }^{110 \mathrm{~m}} \mathrm{Ag}$ & $1 \cdot 10^{14}$ & - \\
\hline${ }^{113 \mathrm{~m}} \mathrm{Cd}$ & $1 \cdot 10^{12}$ & - \\
\hline${ }^{115 m} \mathrm{Cd}$ & $3 \cdot 10^{13}$ & - \\
\hline${ }^{114} \mathrm{In}$ & $9 \cdot 10^{10}$ & - \\
\hline${ }^{114 m} \mathrm{In}$ & $7 \cdot 10^{10}$ & - \\
\hline${ }^{119 m} \mathrm{Sn}$ & $4 \cdot 10^{12}$ & - \\
\hline${ }^{121 \mathrm{~m}} \mathrm{Sn}$ & $6 \cdot 10^{9}$ & - \\
\hline${ }^{123} \mathrm{Sn}$ & $7 \cdot 10^{13}$ & - \\
\hline${ }^{126} \mathrm{Sn}$ & $2 \cdot 10^{10}$ & $2 \cdot 10^{10}$ \\
\hline${ }^{124} \mathrm{Sb}$ & $2 \cdot 10^{13}$ & - \\
\hline${ }^{125} \mathrm{Sb}$ & $3 \cdot 10^{14}$ & - \\
\hline${ }^{126} \mathrm{Sb}$ & $3 \cdot 10^{13}$ & $3 \cdot 10^{9}$ \\
\hline${ }^{126 \mathrm{~m}} \mathrm{Sb}$ & $2 \cdot 10^{13}$ & $2 \cdot 10^{10}$ \\
\hline${ }^{123 \mathrm{~m}} \mathrm{Te}$ & $3 \cdot 10^{11}$ & - \\
\hline${ }^{125 \mathrm{~m}} \mathrm{Te}$ & $7 \cdot 10^{13}$ & - \\
\hline${ }^{127} \mathrm{Te}$ & $3 \cdot 10^{15}$ & - \\
\hline${ }^{127 \mathrm{~m}} \mathrm{Te}$ & $4 \cdot 10^{14}$ & - \\
\hline${ }^{129} \mathrm{Te}$ & $1 \cdot 10^{16}$ & - \\
\hline${ }^{129 m} \mathrm{Te}$ & $2 \cdot 10^{15}$ & - \\
\hline${ }^{129} \mathbf{I}$ & $1 \cdot 10^{9}$ & $1 \cdot 10^{9}$ \\
\hline${ }^{134} \mathrm{Cs}$ & $6 \cdot 10^{15}$ & - \\
\hline${ }^{135} \mathrm{Cs}$ & $1 \cdot 10^{10}$ & $1 \cdot 10^{10}$ \\
\hline${ }^{137} \mathrm{Cs}$ & $4 \cdot 10^{15}$ & - \\
\hline${ }^{137 m} \mathrm{Ba}$ & $4 \cdot 10^{15}$ & - \\
\hline${ }^{140} \mathrm{Ba}$ & $6 \cdot 10^{16}$ & - \\
\hline${ }^{140} \mathrm{La}$ & $6 \cdot 10^{16}$ & - \\
\hline${ }^{141} \mathrm{Ce}$ & $5 \cdot 10^{16}$ & - \\
\hline${ }^{144} \mathrm{Ce}$ & $4 \cdot 10^{16}$ & - \\
\hline${ }^{143} \mathrm{Pr}$ & $5 \cdot 10^{16}$ & - \\
\hline${ }^{144} \mathrm{Pr}$ & $4 \cdot 10^{16}$ & - \\
\hline${ }^{144 \mathrm{~m}} \mathrm{Pr}$ & $5 \cdot 10^{14}$ & - \\
\hline${ }^{147} \mathrm{Pm}$ & $6 \cdot 10^{15}$ & - \\
\hline${ }^{148} \mathrm{Pm}$ & $6 \cdot 10^{15}$ & - \\
\hline${ }^{148 m} \mathrm{Pm}$ & $1 \cdot 10^{15}$ & - \\
\hline${ }^{151} \mathrm{Sm}$ & $1 \cdot 10^{13}$ & - \\
\hline${ }^{152} \mathrm{Eu}$ & $2 \cdot 10^{11}$ & - \\
\hline${ }^{154} \mathrm{Eu}$ & $5 \cdot 10^{14}$ & - \\
\hline${ }^{155} \mathrm{Eu}$ & $3 \cdot 10^{14}$ & - \\
\hline${ }^{156} \mathrm{Eu}$ & $8 \cdot 10^{15}$ & - \\
\hline${ }^{153} \mathrm{Gd}$ & $7 \cdot 10^{11}$ & - \\
\hline${ }^{100} \mathrm{~Tb}$ & $3 \cdot 10^{13}$ & - \\
\hline Total & $7 \cdot 10^{17}$ & $7 \cdot 10^{11}$ \\
\hline
\end{tabular}

Table 1. Continuation.

\begin{tabular}{|c|c|c|}
\hline \multicolumn{3}{|c|}{ Radioactivation products [Bq] } \\
\hline Radionuclide & Discharge & $10000 \mathrm{a}$ \\
\hline${ }^{3} \mathrm{H}$ & $6 \cdot 10^{7}$ & - \\
\hline${ }^{14} \mathrm{C}$ & $5 \cdot 10^{9}$ & $2 \cdot 10^{9}$ \\
\hline${ }^{33} \mathrm{P}$ & $2 \cdot 10^{13}$ & - \\
\hline${ }^{35} \mathrm{~S}$ & $3 \cdot 10^{11}$ & - \\
\hline${ }^{45} \mathrm{Ca}$ & $8 \cdot 10^{9}$ & - \\
\hline${ }^{46} \mathrm{Sc}$ & $1 \cdot 10^{12}$ & - \\
\hline${ }^{5} \mathrm{Cr}$ & $7 \cdot 10^{15}$ & - \\
\hline${ }^{54} \mathrm{Mn}$ & $3 \cdot 10^{14}$ & - \\
\hline${ }^{55} \mathrm{Fe}$ & $2 \cdot 10^{15}$ & - \\
\hline${ }^{59} \mathrm{Fe}$ & $2 \cdot 10^{14}$ & - \\
\hline${ }^{58} \mathrm{Co}$ & $1 \cdot 10^{15}$ & - \\
\hline${ }^{60} \mathrm{Co}$ & $8 \cdot 10^{14}$ & - \\
\hline${ }^{59} \mathrm{Ni}$ & $6 \cdot 10^{11}$ & $6 \cdot 10^{11}$ \\
\hline${ }^{63} \mathrm{Ni}$ & $9 \cdot 10^{13}$ & - \\
\hline${ }^{65} \mathrm{Zn}$ & $9 \cdot 10^{9}$ & - \\
\hline${ }^{89} \mathrm{Sr}$ & $3 \cdot 10^{12}$ & - \\
\hline${ }^{90} \mathrm{Sr}$ & $8 \cdot 10^{7}$ & - \\
\hline${ }^{90} \mathrm{Y}$ & $1 \cdot 10^{14}$ & - \\
\hline${ }^{91} \mathrm{Y}$ & $7 \cdot 10^{12}$ & - \\
\hline${ }^{93} \mathrm{Zr}$ & $7 \cdot 10^{9}$ & $7 \cdot 10^{9}$ \\
\hline${ }^{95} \mathrm{Zr}$ & $2 \cdot 10^{15}$ & - \\
\hline${ }^{93 \mathrm{~m}} \mathrm{Nb}$ & $4 \cdot 10^{8}$ & $6 \cdot 10^{9}$ \\
\hline${ }^{94} \mathrm{Nb}$ & $4 \cdot 10^{10}$ & $3 \cdot 10^{10}$ \\
\hline${ }^{95} \mathrm{Nb}$ & $2 \cdot 10^{15}$ & - \\
\hline${ }^{93} \mathrm{Mo}$ & $3 \cdot 10^{9}$ & $4 \cdot 10^{8}$ \\
\hline${ }^{99} \mathrm{Tc}$ & $4 \cdot 10^{8}$ & $4 \cdot 10^{8}$ \\
\hline${ }^{119 m} \mathrm{Sn}$ & $4 \cdot 10^{14}$ & - \\
\hline${ }^{121} \mathrm{~m} \mathrm{Sn}$ & $3 \cdot 10^{10}$ & - \\
\hline${ }^{123} \mathrm{Sn}$ & $3 \cdot 10^{10}$ & - \\
\hline${ }^{124} \mathrm{Sb}$ & $5 \cdot 10^{11}$ & - \\
\hline${ }^{125} \mathrm{Sb}$ & $3 \cdot 10^{12}$ & - \\
\hline${ }^{125 \mathrm{~m}} \mathrm{Te}$ & $6 \cdot 10^{11}$ & - \\
\hline${ }^{182} \mathrm{Ta}$ & $7 \cdot 10^{15}$ & - \\
\hline${ }^{185} \mathrm{~W}$ & $2 \cdot 10^{10}$ & - \\
\hline Total & $2 \cdot 10^{16}$ & $6 \cdot 10^{11}$ \\
\hline
\end{tabular}

into the future that nuclear energy was once used on earth.

The reactions ${ }^{17} \mathrm{O}(\mathrm{n}, \alpha)$ and ${ }^{14} \mathrm{~N}(\mathrm{n}, \mathrm{p})$ also with low probability lead to the build-up of significant ${ }^{14} \mathrm{C}$ radioactivity (Table 1 ).

Table 1 specifies the content of fission and radioactivation products and Table 2 the contribution of actinides in one ton Heavy Metal, HM, of a typical LWR.

\section{Accumulation of radioactivity}

There exist several computer programmes that calculate according Eq. (1) for a given operation time the radioactivity accumulated in a nuclear reactor $[3,6,7]$. The abundance of a radionuclide in a spent nuclear fuel depends on the neutron fluence and neutron spectrum. The latter is determined by the moderator $/ \mathrm{cool}$ ant, as can be read from Table 2, where the long-living transuranium nuclides from a typical spent PWR fuel $(33 \mathrm{GWd} / \mathrm{t})$ are compared to a heavy water moderated power station fuelled with natural uranium $(6 \mathrm{GWd} / \mathrm{t})$. 


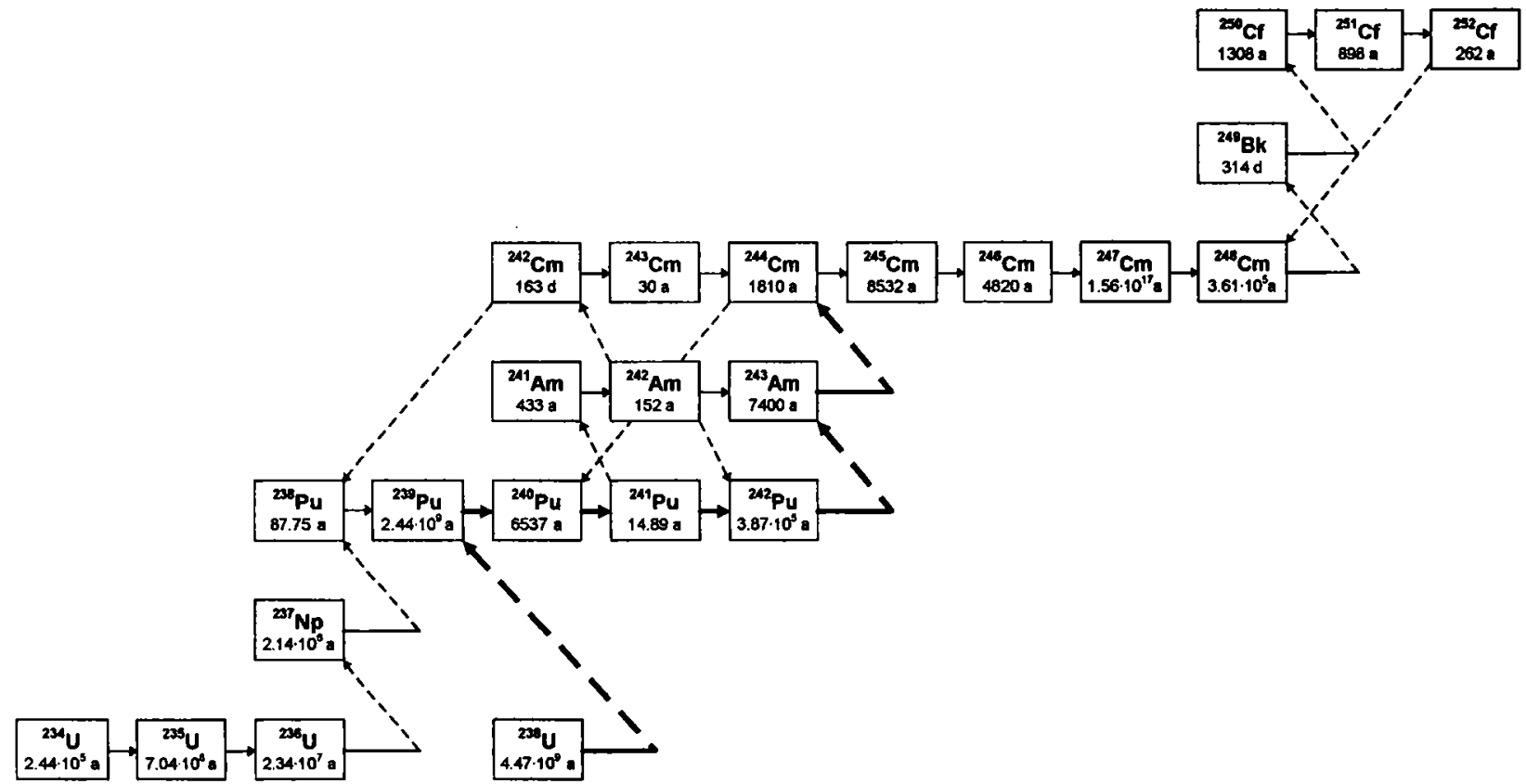

Fig. 2. Build-up chain of long-lived actinides in nuclear fuels with major (bold arrows) and minor (thin arrows) pathways (dashed lines symbolise short-lived radioactive decay) [4].

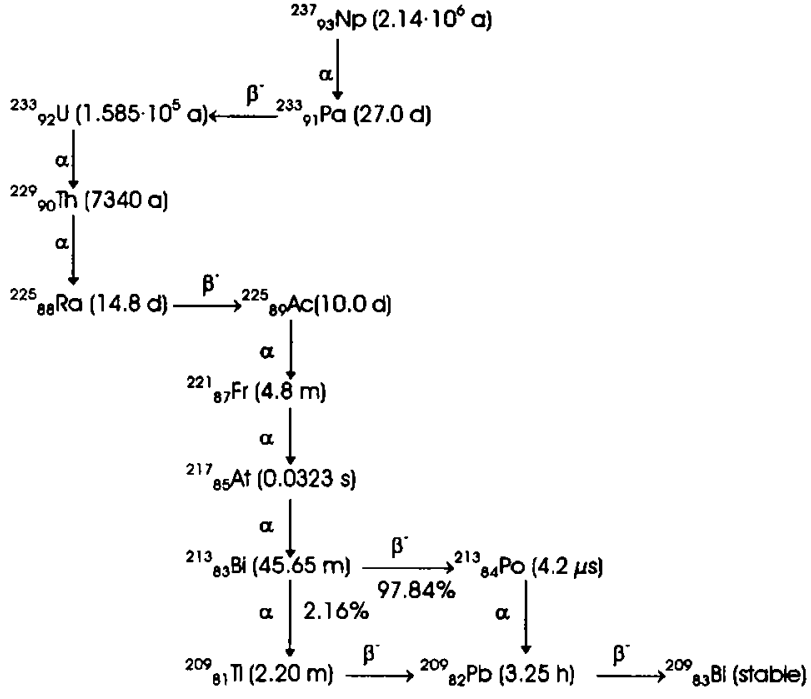

Fig. 3. Extinct decay chain: $4 n+1$.

There is a variety of reactor types in operation worldwide (Fig. 4), from which the so far accumulated artificial radioactivity can be estimated. To do so, either the produced energy or the discharged fuel with its declared burn-up has to be known. Unfortunately the published figures are not detailed enough. From the total generated electricity, the produced plutonium has now been estimated to be about $750 \mathrm{t}$ (to which about $200 \mathrm{t} \mathrm{Pu}$ from the military sector have to be added). The average $\mathrm{Pu}$ concentration contained in the $165000 \mathrm{t}$ of spent fuel produced so far amounts to $4.5 \mathrm{~kg} / \mathrm{t} \mathrm{HM}$, which is a rather low value compared to that in present spent fuel, but in accordance with the estimated average burn-up of $15-20 \mathrm{MWd} / \mathrm{t} \mathrm{HM}$.
Table 2. Radioactivity [Bq] of built up actinides in $1 \mathrm{t}$ of $\mathrm{HM}$ of a typical PWR fuel and HWR fuel at discharge and 10000 a

\begin{tabular}{ccccc}
\hline Radionuclide & $\begin{array}{c}\text { Discharge } \\
\text { PWR }\end{array}$ & $\begin{array}{c}\text { Discharge } \\
\text { HWR }\end{array}$ & $\begin{array}{c}10000 \text { a } \\
\text { PWR }\end{array}$ & $\begin{array}{c}10000 \text { a } \\
\text { HWR }\end{array}$ \\
\hline${ }^{236} \mathrm{U}$ & $1 \cdot 10^{10}$ & $2 \cdot 10^{9}$ & $1 \cdot 10^{10}$ & $3 \cdot 10^{9}$ \\
${ }^{237} \mathrm{~Np}$ & $1 \cdot 10^{10}$ & $2 \cdot 10^{8}$ & $5 \cdot 10^{10}$ & $4 \cdot 10^{9}$ \\
${ }^{238} \mathrm{Pu}$ & $\mathbf{8} \cdot 10^{13}$ & $5 \cdot 10^{11}$ & - & - \\
${ }^{239} \mathrm{Pu}$ & $1 \cdot 10^{13}$ & $6 \cdot 10^{12}$ & $1 \cdot 10^{13}$ & $4 \cdot 10^{12}$ \\
${ }^{240} \mathrm{Pu}$ & $2 \cdot 10^{13}$ & $7 \cdot 10^{12}$ & $7 \cdot 10^{12}$ & $2 \cdot 10^{12}$ \\
${ }^{241} \mathrm{Pu}$ & $5 \cdot 10^{15}$ & $5 \cdot 10^{14}$ & $3 \cdot 10^{9}$ & $1 \cdot 10^{6}$ \\
${ }^{242} \mathrm{Pu}$ & $7 \cdot 10^{10}$ & $4 \cdot 10^{9}$ & $8 \cdot 10^{10}$ & $4 \cdot 10^{9}$ \\
${ }^{241} \mathrm{Am}$ & $5 \cdot 10^{12}$ & $3 \cdot 10^{11}$ & $3 \cdot 10^{9}$ & $3 \cdot 10^{6}$ \\
${ }^{242 \mathrm{~m}} \mathrm{Am}$ & $1 \cdot 10^{11}$ & $6 \cdot 10^{9}$ & - & - \\
${ }^{243} \mathrm{Am}$ & $6 \cdot 10^{11}$ & $5 \cdot 10^{9}$ & $3 \cdot 10^{11}$ & $2 \cdot 10^{9}$ \\
${ }^{242} \mathrm{Cm}$ & $2 \cdot 10^{15}$ & $2 \cdot 10^{13}$ & - & - \\
${ }^{243} \mathrm{Cm}$ & $6 \cdot 10^{11}$ & $4 \cdot 10^{9}$ & - & - \\
${ }^{244} \mathrm{Cm}$ & $7 \cdot 10^{13}$ & $1 \cdot 10^{11}$ & - & - \\
\hline Total & $6 \cdot 10^{15}$ & $6 \cdot 10^{14}$ & $2 \cdot 10^{13}$ & $7 \cdot 10^{12}$ \\
\hline
\end{tabular}

Table 3. Present accumulated actinide radioactivity [Bq] for major abundant, long-living nuclides

\begin{tabular}{lccccc}
\hline Nuclide & ${ }^{237} \mathrm{~Np}$ & ${ }^{239} \mathrm{Pu}$ & ${ }^{240} \mathrm{Pu}$ & ${ }^{241} \mathrm{Am}$ & ${ }^{243} \mathrm{Am}$ \\
\hline Radioactivity & $6 \cdot 10^{14}$ & $2 \cdot 10^{18}$ & $1 \cdot 10^{18}$ & $4 \cdot 10^{17}$ & $2 \cdot 10^{16}$ \\
\hline
\end{tabular}

The accumulated radioactivity by fission products - including the military sector - follows directly from the produced energy or the mass of plutonium and amounts to about $5 \cdot 10^{16} \mathrm{~Bq}$ after a cooling time of 1000 a (i.e. mainly ${ }^{99} \mathrm{Tc}$ ). The radioactivity of transuranium nuclides - as described above - increases exponentially with discharge burn-up of the fuel. The 


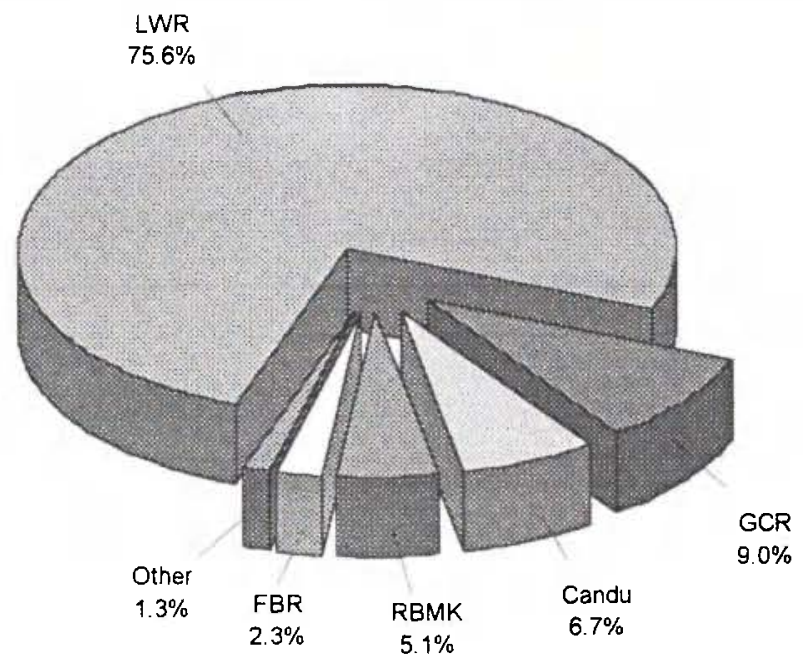

Fig. 4. Share of reactor types in worldwide fission energy generation (1992), $343 \mathrm{GWe}$ (433 units) [8].

latter value is often not accessible, therefore the estimates of the worldwide accumulation of radioactivity can be uncertain by a factor of 2 .

\section{Disposal of radioactivity}

The option to send the radioactive waste into outer space is presently not considered as a realistic possibility. Hence, all radioactivity has to be stored in the country where the energy was produced. Due to fission energy generation, about $10000 \mathrm{t} \mathrm{HM}$ of spent fuel are discharged annually worldwide giving an estimated cumulated total of over $165000 \mathrm{t} \mathrm{HM}$. Of this, about $105000 \mathrm{t} \mathrm{HM}$ are currently being stored. The present reprocessing capacity of $4000 \mathrm{t}$ per year is projected to increase in ten years to $7700 \mathrm{t} / \mathrm{a}$ [9]. Consequently, the arisings of spent fuel exceed their possible reprocessing.

Several countries with major nuclear energy generating capacities, like Canada, Sweden and USA have decided to dispose of the fuel directly without reprocessing into a geological repository. Others follow both the routes: Finland, Germany, Russian Federation, Spain, Ukraine.

The total amount of commercial spent fuel reprocessed up to 1994 was about $47300 \mathrm{t}$ HM with $34300 \mathrm{t}$ HM stemming from GCR and only $13000 \mathrm{t} \mathrm{HM}$ discharged from LWR. From the extracted Pu, about $98 \mathrm{t}$ are stored. Between 2 and $7 \mathrm{t} \mathrm{Pu}$ have been used annually in LWRs and FBRs. $40 \mathrm{t} \mathrm{HM}$ of the fuel from the latter reactor type have also been reprocessed [9]. As mentioned above, about $200 \mathrm{t} \mathrm{Pu}$ have been produced in the military sector.

In the high level waste (HLW) resulting from fuel reprocessing are contained most of the fission products and actinides other than uranium and plutonium. Little waste has been vitrified and most is still stored in liquid form. The radioactivity of the spent fuel and high level waste generate in the first years too much

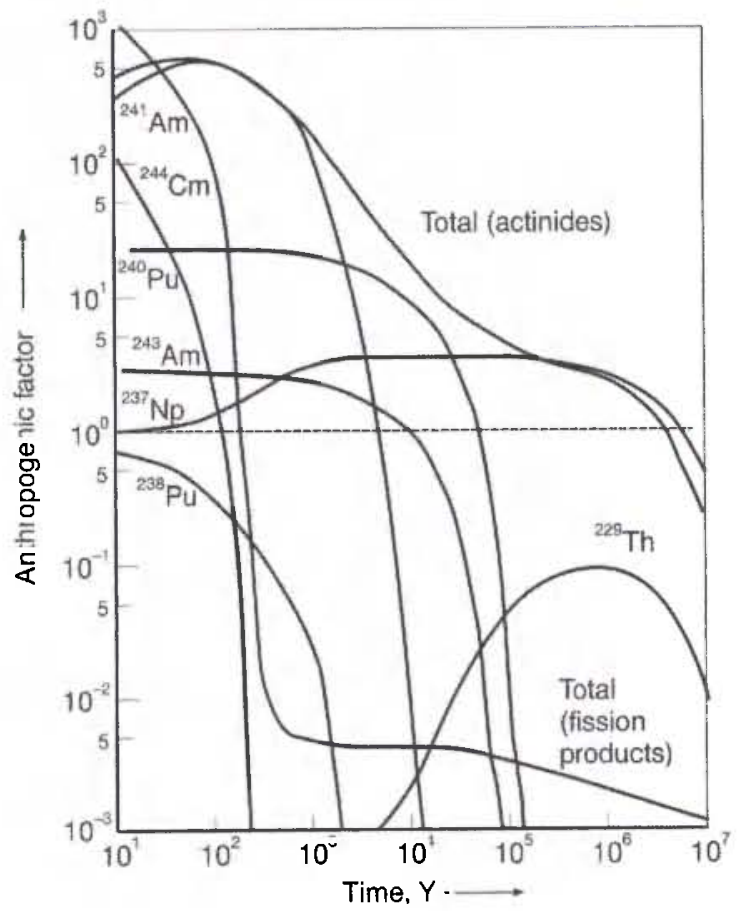

Fig. 5. Time-dependence of radiotoxicity in a spent LWR fuel of $33 \mathrm{GWid} / \mathrm{t}$ normalized to the radiotoxicity of the uranium ore (dashed line) mined to produce the fuel [4].

heat $(1.5 \mathrm{~kW} / \mathrm{t} \mathrm{HM})$, to be brought underground. Therefore, an intermediate storage for tens of years is needed to have the radioactivity decayed to acceptable heat levels. During this period, the radiotoxic nuclides still remain accessible for further treatment.

The time dependence of the radiological risk of the radioactivity by fission energy in a waste repository is for a given nuclide $N$ according to Eq. (5)

$$
\frac{d N}{d t}=z \lambda^{*} N^{*}-\lambda N
$$

with $N^{*}$ being its parent nuclide with $z \lambda^{*}$ decay modes. This has to be expressed in terms of its radiotoxicity as assessed by the ICRP and expressed in annual limits of intake of radionuclides [10]. In order to make the radiological risk comprehensible, one should normalize the radiotoxicity of a certain nuclide to that of the uranium ore which is needed to fabricate the fuel. After use of the fuel, the induced enhanced radioactivity is illustrated in Figure 5 as a function of time.

The radiotoxicity of fission products decreases within a few hundred years to below that of the uranium ore mined to produce the fresh fuel. The accumulated transuranium elements will decay over much longer periods. Hence, their transmutation into shortlived or stable nuclides would reduce the radiotoxic hazard for future generations. This view looks only at the source of the radiotoxic hazard as it is posed by the spent fuel. If stored in a geological repository, the leaching of the fuel and the eventual migration of nuclides back to the biosphere is a more relevant description of the imminent danger. Also fission product nu- 
Table 4. List of long-lived radionuclides considered as candidates for nuclear transmutation [11]

\begin{tabular}{ll}
\hline Nuclide & $T_{1 / 2}[\mathrm{a}]$ \\
\hline${ }^{14} \mathrm{C}$ & $5.7 \cdot 10^{3}$ \\
${ }^{36} \mathrm{Cl}$ & $3.0 \cdot 10^{5}$ \\
${ }^{129} \mathrm{I}$ & $1.6 \cdot 10^{7}$ \\
${ }^{135} \mathrm{Cs}$ & $2.0 \cdot 10^{7}$ \\
${ }^{79} \mathrm{Se}$ & $6.5 \cdot 10^{4}$ \\
${ }^{93} \mathrm{Zr}$ & $1.5 \cdot 10^{6}$ \\
${ }^{90} \mathrm{Sr}$ & $2.9 \cdot 10^{1}$ \\
${ }^{121} \mathrm{Sn}$ & $5.0 \cdot 10^{1}$ \\
${ }^{126} \mathrm{Sn}$ & $1.0 \cdot 10^{5}$ \\
${ }^{137} \mathrm{Cs}$ & $3.0 \cdot 10^{1}$ \\
${ }^{99} \mathrm{Tc}$ & $2.1 \cdot 10^{5}$ \\
\hline
\end{tabular}

Table 5. Half-lifes [a] of actinides by natural decay and transmutation in a fast reactor [12]

\begin{tabular}{ccc}
\hline Actinide & Natural decay & Decay in FR \\
\hline${ }^{237} \mathrm{~Np}$ & $2 \cdot 10^{6}$ & 2.5 \\
${ }^{238} \mathrm{Pu}$ & 88 & 2.0 \\
${ }^{239} \mathrm{Pu}$ & $2 \cdot 10^{4}$ & 1.5 \\
${ }^{240} \mathrm{Pu}$ & $6 \cdot 10^{3}$ & 3.1 \\
${ }^{241} \mathrm{Pu}$ & 15 & 1.2 \\
${ }^{242} \mathrm{Pu}$ & $4 \cdot 10^{5}$ & 3.4 \\
${ }^{241} \mathrm{Am}$ & 433 & 2.1 \\
${ }^{242 \mathrm{~m}} \mathrm{Am}$ & 152 & 1.2 \\
${ }^{243} \mathrm{Am}$ & $7 \cdot 10^{3}$ & 2.9 \\
${ }^{242} \mathrm{Cm}$ & 0.45 & 0.36 \\
${ }^{243} \mathrm{Cm}$ & 30 & 1.3 \\
${ }^{244} \mathrm{Cm}$ & 18 & 2.5 \\
${ }^{245} \mathrm{Cm}$ & $8 \cdot 10^{3}$ & 1.5 \\
\hline
\end{tabular}

clides, even if being of lower quantities, could pose a problem if they accumulate in the biosphere.

So far, no common criteria have been accepted which would allow the identification of hazardous nuclides and the extent to which they ought to be partitioned and transmuted. The IAEA has started a coordinated research programme (CRP on Evaluation of the Safety, Environmental and Non-Proliferation Aspects of Partitioning and Transmutation of Actinides and Fission Products) aimed at the definition of criteria to determine the radiological hazard posed by the numerous anthropogenic radionuclides (Table 4). Not yet knowing the outcome of this co-ordinated research programme, one can assume that the largest hazard is posed by the transuranium nuclides as well as ${ }^{99} \mathrm{Tc}$ which have no natural diluent, unlike e.g. ${ }^{135} \mathrm{Cs}$, which will be diluted by natural caesium.

Such radionuclides could be destroyed by nuclear reactions faster than by decay, if in Eq. (1)

$$
\sigma a \phi>\lambda \text {. }
$$

Several possibilities exist: The transmutation by photon-induced reactions or by charged particles seem to have technical difficulties. Therefore, the most promising would be the transmutation by neutron capture or neutron induced fission. For this purpose, existing power stations could be used, but also newly-devel- oped dedicated burner reactors which could be driven by accelerators.

The transmutation of transuranium elements was successfully demonstrated in an irradiation experiment in PHENIX fast reactor in 1985 [11]. Since then, several research programmes have started implying the use of existing nuclear reactors or advanced burner reactors in Russia, Japan, USA and Europe.

With increasing energy of the neutron, the $\sigma_{f} / \sigma_{c}$ ratio is growing. Consequently, in LWR the build-up of higher actinides is substantially larger than in FR, which not only complicates the fuel handling, but increases the void coefficient of the LWR such that, for reactor safety reasons, a repeated recycling in LWR is excluded. In the fast reactor PHENIX, the transmutation half-life $\ln 2 / \sigma a \phi$ is about two years for all actinides which compares favourably, e.g. for ${ }^{237} \mathrm{~Np}$ with its natural decay half-life of $2 \cdot 10^{6}$ a (Table 5).

To achieve a convincingly 100 -fold reduction of the radiotoxicity (including also plutonium for warheads), the partitioning and transmutation losses have to be as low as $0.3 \%$, because of the repetitive recycling.

Since worldwide research on partitioning and transmutation has just begun, it would be premature to draw conclusions on technical feasibility and cost/ benefit of the different concepts. Moreover, the development status of the various approaches does not yet allow a meaningful comparison. It should be pointed out that spent nuclear fuel has to be stored for tens of years. Also decades will be needed to disassemble nuclear warheads and the recovered Pu has to be stored intermediately, because of the lack of facilities in the US and Russia to feed the Pu into the commercial fuel cycle. Therefore, partitioning and transmutation if feasible - could offer to the next generation an option to reduce the radioactivity generated by fission energy.

\section{References}

1. Cunninghame, J. G.: IAEA-213, vol. 1, p. 351 (1977).

2. Koch, L., et al.: EUR 6738e (1981).

3. Fischer, U., Wiese, H. W.: KfK 3014 (1983).

4. Koch, L.: Handbook on the Physics and Chemistry of the Actinides, Vol. 4, p. 457-490 (1986).

5. Koch, L., Molinet, R., Wellum, R.: Tagungsbericht Jahrestagung Kerntechnik, p. 472 (1983).

6. Bell, M. J.: Report ORNL-4628 (Oak Ridge National Laboratory) (1973).

7. Croff, A. G., McAdoo, J. W., Bjerke, M. A.: ORNL/TM7176/R1 (Oak Ridge National Laboratory) (1983).

8. World Nuclear Industry Handbook 1993, ISSN 0029-5507, p. 10 (1993).

9. IAEA Yearbook 1994, ISBN 92-0-102394-4 (1994).

10. Annual Limits of Intake of Radionuclides by Workers Based on the 1990 Recommendations, Annals of the ICRP (1990).

11. Koch, L.: Status of Transmutation, IAEA Specialists' Meeting on Use of FBRs for Actinide Transmutation, Obninsk (1992).

12. Koch, L., Cottone, G., Cricchio, A.: Transplutonium 1975, Proceedings of the 4th Transplutonium Element Symposium, p. 461 (1976). 


\title{
Radioactivity and Fusion Energy
}

\author{
By Hiroshi Kudo \\ Department of Chemistry, Graduate School of Science, Tohoku University, Sendai 980-77, Japan
}

(Received June 8, 1995)

\section{Radioactivity / Tritium / Thermonuclear fusion / Muon catalyzed fusion / Fusion neutrons}

\begin{abstract}
Summary
Nuclear fusion is expected to give an ultimate solution to energy problems over the long term. From recent progress in developing technology for fusion reactors, we can anticipate a prototype fusion reactor by 2030 . This review article describes the present status of nuclear fusion research, including muon catalyzed fusion $(\mu \mathrm{CF})$ which attracts quite new physical interest. Tritium is an essential component of fusion reactors, because the first-stage fusion reactors will utilize a mixture of deuterium and tritium as their fuel. The knowledge about tritium as well as the fusionneutron induced radioactivity is summarized in terms of nuclear fusion research.
\end{abstract}

\section{Introduction}

It has passed one hundred years, since the discovery of radioactivity by Becquerel in 1896 . In the past century, we have experienced the great progress in science and technology. Big changes are also seen in our daily life. In these days, we consume huge amounts of energy in food production, transportation, communication, heating and cooling buildings, materials processing and manufacturing, and virtually all aspects of modern life.

The world total of power demands was about $8 \mathrm{TW}$ in 1975, and estimates of the growth of populations and per-capita energy consumption rates indicates that the world energy demands in 2000 and 2025 will be around $18 \mathrm{TW}$ and $50 \mathrm{TW}$, respectively [1]. Renewable energy sources, such as solar, geothermal, biomass, hydroelectric, wind, wave, and tidal power, are limited by the usable power they provide. Although the solar and geothermal power flows are large, the useful fractions are small. An additional problem to be solved is restriction of fossil fuel consumption to prevent the increasing atmospheric $\mathrm{CO}_{2}$ concentrations. Nonrenewable fossil and nuclear fuel are limited by the total amount they can provide.

Utilization of nuclear fusion energy is envisaged to give an ultimate solution to energy problems over the long term. The enormous power is radiated from the sun and stars as the results of nuclear fusion of hydrogen atoms. The most important sequence is the PPI chain [2]:

$$
\begin{aligned}
& \mathrm{H}+\mathrm{H} \rightarrow \mathrm{D}+\mathrm{e}^{+}+v \\
& \mathrm{D}+\mathrm{H} \rightarrow{ }^{3} \mathrm{He}+\gamma \\
& { }^{3} \mathrm{He}+{ }^{3} \mathrm{He} \rightarrow{ }^{4} \mathrm{He}+2 \mathrm{H} .
\end{aligned}
$$

Since middle of the 1950's, continuous efforts have been made to develop technology for nuclear fusion reactors or controlled thermonuclear reactors (CTR). First-stage fusion reactors, which will be constructed in the early 2000 's, likely utilize the deuterium and tritium as fuel. One gram of fusion fuel a mixture of deuterium and tritium gas - produces the same amount of energy as eight tons of oil. The energy in one gram of fusion fuel is five times greater than the energy liberated from nuclear fission of one gram of ${ }^{235} \mathrm{U}$, which is the fuel of current nuclear reactors. Although the natural abundance of deuterium $(0.0153 \%)$ would ensure a sufficient supply of this isotope for the fueling of $\mathrm{D}-\mathrm{T}$ fusion reactors, tritium with negligible abundance (some $10^{-18}$ of natural hydrogen) is to be artificially produced and a practical fusion reactor should breed at least as much tritium as it consumes. The amount of tritium needed for a fusion reactor is estimated to be more than $3 \mathrm{~kg}$ or $\sim 10^{18} \mathrm{~Bq}$ [3], and precautions are needed to minimize the release of radioactive tritium into the environments.

The 14-MeV neutrons emitted from the $\mathrm{D}-\mathrm{T}$ reaction would cause severe radiation damage and make the reactor materials radioactive. Nevertheless, a fusion reactor is envisaged to be a clean nuclear energy source, because a fusion reactor does not seem to generate so large amounts of long-lived radioactive waste as current fission reactors do.

This review article describes the present status of nuclear fusion research as well as the radioactivity related to fusion energy. Tritium is an essential component of a fusion reactor, and in developing a clean fusion reactor, it is important to understand a variety of problems concerned with tritium and the fusionneutron induced radioactivity.

\section{Nuclear fusion energy}

Our experience of nuclear fusion energy on earth started with thermonuclear weapons in the early 1950's. A series of nuclear tests scattered large amounts of radioactive materials as well as tritium in the environments. The incidents were undesirable, but we realized that really enormous power was released from nuclear fusion.

Fusion research for peaceful use began in middle of the 1950's, with hopes of developing a fusion reactor or controlled thermonuclear reactor. During the first international conference on the peaceful use of 


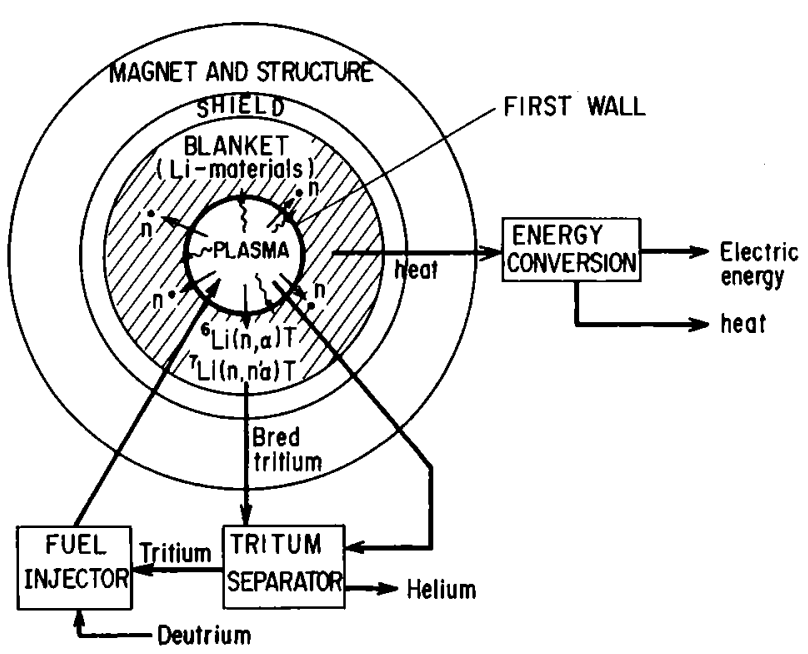

Fig. 1. A schematic drawing of $D-T$ tokamak fusion reactor.

atomic energy, held in Geneva in 1955, the chairman reportedly said that fusion technology would be developed within 20 years. However, nobody at that time understood the difficulty of confining high temperature plasmas which would be the key to nuclear fusion. The difficulty of fusion lies in joining two nuclei. Coulomb repulsion between nuclei with positive charges prevents them from coming close enough to each other. If the temperature in a fusion reactor is raised to 100 million degrees, fuel nuclei become plasmas in which nuclei and electrons move independently at a speed of $1000 \mathrm{~km} \mathrm{~s}^{-1}$, overcoming the repulsive forces of nuclei.

Nuclear fusion experiments fall into two general categories; magnetic confinement and inertia confinement [1]. Magnetic confinement employs strong magnetic fields to provide thermal insulation between the plasma and the chamber walls. Inertia confinement allows free plasma expansion and cooling, but relies on an extremely high density to attain the reaction conditions in the short expansion time (typically a few $\mathrm{ns})$. The high density is attained by compressing a solid fuel pellet to over 1000 times of its initial density, using laser beams or ion beams. Major experimental programs in inertia confinement fusion (ICF) were initiated in the 1970's.

In the early 1970's many nations shifted experimental emphasis to tokamak-type plasma confinement devices, following the Soviet experimental success in the 1960's. The name "tokamak" stands for Russian words meaning "Toroidal Chamber with Magnet Coils". Tokamaks consist of a doughnut-shaped toroidal magnetic field produced by external coils, a poloidal field produced by a strong plasma current, and a weak vertical field component needed for confining plasma. The plasma must be confined inside a magnetic field so that its particles and energy will not be lost. Figure 1 illustrates a schematic drawing of a magnetic confinement fusion power plant.

In a $\mathrm{D}-\mathrm{T}$ tokamak fusion reactor, the thermonuclear reaction takes place in the plasma confined in the vacuum vessel, as shown in Fig. 1. The energy produced by the $\mathrm{D}-\mathrm{T}$ reaction is partly transported by the 14-MeV neutron. In addition, electromagnetic radiation and particles (neutrals and ions) with kinetic energies up to the $\mathrm{keV}$ range leave the plasma zone. The "first wall", which separates the vacuum zone from a blanket, would receive a heavy energy load of the 14$\mathrm{MeV}$ neutrons $\left(10^{14}-10^{15} \mathrm{~cm}^{2} \mathrm{~s}^{-1}\right)$ and energetic particles $\left(\sim 10^{16} \mathrm{~cm}^{2} \mathrm{~s}^{-1}\right)$. The blanket is designed to play the following important roles; (1) heat generation, (2) tritium breeding and (3) radiation shields for superconducting magnets outermost. The fast neutrons reaching the blanket lose their energy and produce new tritium through the ${ }^{7} \mathrm{Li}\left(\mathrm{n}, \mathrm{n}^{\prime} \alpha\right) \mathrm{T}$ and ${ }^{6} \mathrm{Li}(\mathrm{n}, \alpha) \mathrm{T}$ reactions. The generated heat will be removed and eventually converted into electric power.

The progress of plasma confinement technology attained in the past decade with large tokamak devices such as JET (EU), TFTR (US) and JT-60 (Japan) is shown in Fig. 2. The D-T plasma burning experiment using small amounts of tritium $(0.2 \mathrm{~g})$ was performed in the Joint European Torus (JET) for the first time in November 1991 [4]. Since December 1993, the high power D-T experimental program with $20-30 \mathrm{~g}$ of tritium has been continued on the Tokamak Fusion Test Reactor (TFTR) [5, 6]. Although remarkable progress has been made in creating high temperature plasmas, further progress is required not only in plasma physics, but also in materials science as well as fuel-cycle technology.

To accelerate fusion research and development, the US, Russia, the European Union (EU) and Japan jointly set up in 1988 the International Thermonuclear Experimental Reactor (ITER) project under the auspices of the International Atomic Energy Agency (IAEA). Since 1992, the four parties have been jointly engaged in both conceptual designing for ITER and experiments to collect technical data needed for fully integrating its engineering design. They are aiming at constructing one prototype fusion reactor by 2030 . A commercial fusion reactor will hopefully be constructed by around 2050 .

\section{Nuclear fusion reactions and the fuel cycle}

Although there are many possible nuclear fusion reactions as listed in Table 1 [7], the nuclear reactions of prime interest for man-made controlled thermonuclear reactors (CTR) are as follows:

$$
\begin{aligned}
& \mathrm{D}+\mathrm{T} \rightarrow{ }^{4} \mathrm{He}+\mathrm{n}+17.58 \mathrm{MeV} \\
& \mathrm{D}+\mathrm{D} \rightarrow{ }^{3} \mathrm{He}+\mathrm{n}+3.27 \mathrm{MeV} \\
& \mathrm{D}+\mathrm{D} \rightarrow \mathrm{T}+\mathrm{H}+4.04 \mathrm{MeV} \\
& \mathrm{D}+{ }^{3} \mathrm{He} \rightarrow{ }^{4} \mathrm{He}+\mathrm{H}+18.34 \mathrm{MeV} \\
& \mathrm{H}+{ }^{6} \mathrm{Li} \rightarrow{ }^{4} \mathrm{He}+{ }^{3} \mathrm{He}+4.02 \mathrm{MeV} \\
& \mathrm{H}+{ }^{11} \mathrm{~B} \rightarrow 3^{4} \mathrm{He}+8.68 \mathrm{MeV}
\end{aligned}
$$




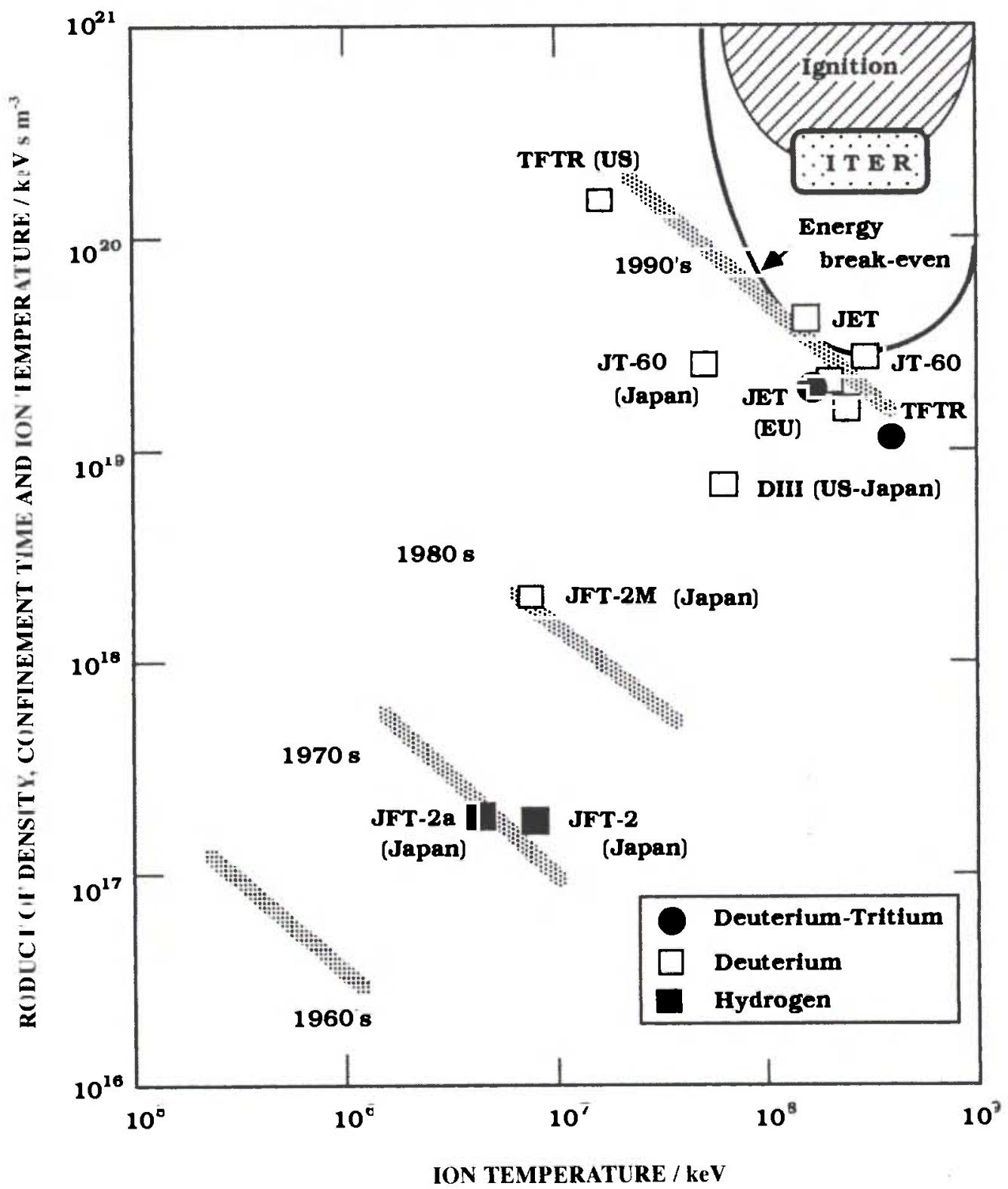

Fig. 2. Progress of tokamak plasma experiments in the world.

Figure 3 shows reaction rate parameters as a function of the plasma temperature [8]. The parameter $\langle\sigma v\rangle$ is the product of the cross section and the relative velocity, averaged over the respective Maxwellian velocity distributions of the plasma.

Of these fusion reactions, deuterium-tritium (D$\mathrm{T})$ reaction which gives rise to $14.06-\mathrm{MeV}$ neutrons and $3.52-\mathrm{MeV} \alpha$ particle is the most plausible for practical CTR to be constructed in the near future, because a self-sustaining plasma may be realized at the lowest plasma temperatures $T>5 \mathrm{keV}$. The optimum plasma temperature is about $15 \mathrm{keV}[9,10]$. In this case, it is necessary to breed tritium by bombarding lithium with the fusion neutrons, because tritium does not occur in natural sources. This type is referred to as $\mathrm{D}-\mathrm{T}-\mathrm{Li}$ fuel cycle. Concern for the environmental impacts of $\mathrm{D}-\mathrm{T}$ reactors is based on the radioactive nature of the primary fuel constituent, the copious activation and radiation damage of materials by $14-\mathrm{MeV}$ neutrons. In addition, a D-T-Li tokamak reactor may need several hundred tons of lithium in the blanket.

The D-D fusion reaction of Eq. (5) is attractive because the primary fuel is only naturally abundant deuterium. It requires no fuel breeding. However, a higher temperature $T>20 \mathrm{keV}$ is required for a selfsustaining deuterium plasma to overcome bremsstrahlung and synchrotron radiation; the optimum temperature is about $40 \mathrm{keV}$. Practically, the D-D reaction of Eq. (5) occurs in nearly the same probability as Eq. (6), which produces tritium as the reaction product. We cannot avoid tritium problems, but the amounts of tritium would largely be reduced. A plasma temperature may be lowered to around $35 \mathrm{keV}$ if the fusion products, $\mathrm{T}$ and ${ }^{3} \mathrm{He}$, are recirculated; a scenario referred to as catalyzed D-D cycle. In this cycle, unburned tritium and ${ }^{3} \mathrm{He}$ are recycled into the plasma 
Table 1. Thermonuclear reactions in which $\mathrm{Z}$ is smaller than about 10 and the cross section is more than one millibarns at energies less than $10 \mathrm{MeV}$ [7]

\begin{tabular}{|c|c|c|c|}
\hline Reaction & $\begin{array}{c}Q \text { value } \\
\mathrm{MeV}\end{array}$ & $\begin{array}{c}\sigma_{\max } \\
\mathrm{mb}\end{array}$ & $\begin{array}{c}\varepsilon_{\max } \\
\mathrm{MeV}\end{array}$ \\
\hline $\mathrm{D}(\mathrm{p}, \mathrm{pn}) \mathrm{H}$ & -2.2 & $>400$ & $>5.5$ \\
\hline $\mathrm{D}(\mathbf{d}, \mathbf{n})^{3} \mathrm{He}$ & 3.27 & 105 & 1.9 \\
\hline$D(d, p) T$ & 4.03 & 90 & 2.0 \\
\hline $\mathrm{T}(\mathrm{p}, \mathrm{n})^{3} \mathrm{He}$ & -0.76 & 500 & 3.0 \\
\hline$T(d, n p) T$ & -2.2 & $>700$ & $>6.0$ \\
\hline $\mathrm{T}(\mathrm{d}, 2 \mathrm{n})^{3} \mathrm{He}$ & -3.0 & $?>1200$ & $>6.5$ \\
\hline $\mathrm{T}(\mathrm{d}, \mathrm{n})^{4} \mathrm{He}$ & 17.6 & 5000 & 0.108 \\
\hline $\mathrm{T}(\mathrm{t}, \mathrm{n})^{5} \mathrm{He}(\mathrm{n})^{4} \mathrm{He}$ & & & \\
\hline $\mathrm{T}(\mathrm{t}, 2 \mathrm{n})^{4} \mathrm{He}$ & 11.4 & & \\
\hline $\mathrm{T}(\mathrm{t}, \mathrm{n})^{5} \mathrm{He}^{*}(\mathrm{n})^{4} \mathrm{He}$ & & & \\
\hline${ }^{3} \mathrm{He}(\mathrm{d}, \mathrm{np})^{3} \mathrm{He}$ & -2.2 & $>70$ & $>1.0$ \\
\hline${ }^{3} \mathrm{He}(\mathrm{d}, \mathrm{p})^{4} \mathrm{He}$ & 18.4 & 700 & 0.4 \\
\hline${ }^{3} \mathrm{He}(\mathrm{t}, \mathrm{d}){ }^{4} \mathrm{He}$ & 14.3 & & \\
\hline${ }^{3} \mathrm{He}(\mathrm{t}, \mathrm{p})^{5} \mathrm{He}(\mathrm{n})^{4} \mathrm{He}$ & $11.3+1.0$ & & $\sim 10$ \\
\hline${ }^{3} \mathrm{He}(\mathrm{t}, \mathrm{np}){ }^{4} \mathrm{He}$ & 12.1 & $\sim 50$ & $\sim 1.0$ \\
\hline${ }^{3} \mathrm{He}(\mathrm{t}, \mathrm{n})^{5} \mathrm{Li}(\mathrm{p})^{4} \mathrm{He}$ & $10.3+1.8$ & & \\
\hline${ }^{3} \mathrm{He}\left({ }^{3} \mathrm{He}, \mathrm{p}\right)^{5} \mathrm{Li}(\mathrm{p})^{4} \mathrm{He}$ & $11.0+1.8$ & & \\
\hline${ }^{3} \mathrm{He}\left({ }^{3} \mathrm{He}, 2 \mathrm{p}\right){ }^{4} \mathrm{He}$ & 12.8 & $>30$ & $>0.8$ \\
\hline${ }^{4} \mathrm{He}(\mathrm{d}, \mathrm{np}){ }^{4} \mathrm{He}$ & -2.2 & $>240$ & $>6$ \\
\hline${ }^{6} \mathrm{Li}\left(\mathrm{p},{ }^{3} \mathrm{He}\right){ }^{4} \mathrm{He}$ & 4.02 & $\sim 200$ & 1.8 \\
\hline${ }^{6} \mathrm{Li}(\mathrm{d}, \mathrm{n}){ }^{3} \mathrm{He}+{ }^{4} \mathrm{He}$ & 1.72 & $>600$ & $>50$ \\
\hline${ }^{6} \mathrm{Li}(\mathrm{d}, \mathrm{n})^{7} \mathrm{Be}\left(\mathrm{e}_{\mathrm{K}}\right)^{7} \mathrm{Li}$ & 3.34 & $\geq 600$ & $>5.0$ \\
\hline${ }^{6} \mathrm{Li}(\mathrm{d}, \mathrm{p})^{7} \mathrm{Li}$ & 5.02 & & \\
\hline${ }^{6} \mathrm{Li}\left(\mathrm{d}, \mathrm{p}^{\prime}\right)^{7} \mathrm{Li}^{*}(\gamma)^{7} \mathrm{Li}$ & $4.54+0.45$ & 100 & 1.2 \\
\hline${ }^{6} \mathrm{Li}(\mathrm{d}, \mathrm{t})^{5} \mathrm{Li}(\mathrm{p})^{4} \mathrm{He}$ & $0.9+1.6$ & $>300$ & $>4.0$ \\
\hline${ }^{6} \mathrm{Li}(\mathrm{d}, \alpha)^{4} \mathrm{He}$ & 22.4 & 30 & 3.7 \\
\hline${ }^{6} \mathrm{Li}(\mathrm{t}, \mathrm{d})^{7} \mathrm{Li}$ & 0.995 & & \\
\hline${ }^{6} \mathrm{Li}\left(\mathrm{t}, \mathrm{d}^{\prime}\right)^{7} \mathrm{Li} *(\gamma)^{7} \mathrm{Li}$ & $0.509+0.45$ & & \\
\hline${ }^{6} \mathrm{Li}(\mathrm{t}, \mathrm{p})^{8} \mathrm{Li}(\beta)^{8} \mathrm{Be}(\alpha)^{4} \mathrm{He}$ & 0.800 & $>320$ & $>2.1$ \\
\hline${ }^{6} \mathrm{Li}(\mathrm{t}, \mathrm{n})^{\mathrm{x}} \mathrm{Be}^{*}$ or $2^{4} \mathrm{He}$ & 16.0 & & \\
\hline${ }^{6} \mathrm{Li}\left({ }^{3} \mathrm{He}, \mathrm{p}\right){ }^{8} \mathrm{Be}(\alpha)^{4} \mathrm{He}$ & 16.8 & 30 & $\sim 5$ \\
\hline${ }^{6} \mathrm{Li}\left({ }^{3} \mathrm{He}, \mathrm{p}\right)^{8} \mathrm{Be}^{*}(\alpha \gamma){ }^{4} \mathrm{He}$ & $13.9+2.9$ & $>60$ & $>5$ \\
\hline${ }^{7} \mathrm{Li}(\mathrm{p}, \mathrm{n})^{7} \mathbf{B e}$ & -1.63 & $>800$ & $>7$ \\
\hline${ }^{7} \mathrm{Li}(\mathrm{p}, \alpha){ }^{4} \mathrm{He}$ & 17.5 & 65 & 3 \\
\hline${ }^{7} \mathrm{Li}(\mathrm{d}, \mathrm{n})^{8} \mathrm{Be}(\alpha)^{4} \mathrm{He}$ & 15.0 & $>1000$ & $>5$ \\
\hline${ }^{7} \mathrm{Li}(\mathrm{d}, \mathrm{p})^{8} \mathrm{Li}(\beta)^{8} \mathrm{Be}(\alpha)^{4} \mathrm{He}$ & $-0.26+16.0$ & $? 160$ & 3 \\
\hline${ }^{7} \mathrm{Li}(\mathrm{d}, \mathrm{t})^{6} \mathrm{Li}$ & -0.995 & $>150$ & $>4$ \\
\hline${ }^{7} \mathrm{Li}(\mathrm{t}, 2 \mathrm{n} \alpha)^{4} \mathrm{He}$ & 8.88 & & \\
\hline${ }^{7} \mathrm{Li}(t, n)^{9} \mathrm{Be}$ & 10.52 & & \\
\hline${ }^{7} \mathrm{Li}(\mathrm{t}, 2 \mathrm{n})^{8} \mathrm{Be}(\alpha)^{4} \mathrm{He}$ & 8.83 & $>1300$ & $>2.1$ \\
\hline${ }^{7} \mathrm{Li}(\mathrm{t}, 2 \mathrm{n} \alpha)^{4} \mathrm{He}$ & 8.85 & & \\
\hline${ }^{7} \mathrm{Li}(\mathrm{t}, \mathrm{n} \alpha)^{5} \mathrm{He}(\mathrm{n}){ }^{4} \mathrm{He}$ & $8.08+1.0$ & & \\
\hline${ }^{7} \mathrm{Li}(\mathrm{t}, \alpha)^{6} \mathrm{He},{ }^{6} \mathrm{He}^{*}$ & 9.83 & $>40$ & $>1.8$ \\
\hline${ }^{7} \mathrm{Li}\left({ }^{3} \mathrm{He}, \mathrm{p}\right)^{9} \mathrm{~B}(\mathrm{p})^{8} \mathrm{Be}(\alpha)^{4} \mathrm{He}$ & $9.3+0.3$ & & \\
\hline${ }^{7} \mathrm{Li}\left({ }^{3} \mathrm{He}, \mathrm{np}\right)^{8} \mathrm{Be}(\alpha)^{4} \mathrm{He}$ & $9.5+0.1$ & $>600$ & $>1.4$ \\
\hline $\begin{array}{l}{ }^{7} \mathrm{Li}\left({ }^{3} \mathrm{He}, \mathrm{p}\right)^{9} \mathrm{~B} \\
{ }^{7} \mathrm{Li}\left({ }^{3} \mathrm{He}, \mathrm{d}\right)^{8} \mathrm{Be}(\alpha)^{4} \mathrm{He}\end{array}$ & 11.2 & & \\
\hline${ }^{7} \mathrm{Li}\left({ }^{3} \mathrm{He}, \mathrm{d}\right)^{8} \mathrm{Be}(\alpha){ }^{4} \mathrm{He}$ & $11.7+0.1$ & & \\
\hline
\end{tabular}

$\sigma_{\text {max }}:$ maximum value of the cross section.

$\varepsilon_{\max }$ : energy at which $\sigma_{\max }$ is obtained.

*: excited nucleus.

such that the burnup rate of these fuels is equal to their production rate [11]. The fusion energy yield comes principally from the $\mathrm{D}-\mathrm{T}, \mathrm{D}-\mathrm{D}$ and $\mathrm{D}-{ }^{3} \mathrm{He}$ reactions. The absence of a breeding blanket is an advantage.

The fusion reaction of Eq. (7) also takes place at higher temperatures, $T \geq 30 \mathrm{keV}$, but this reaction provides a relatively "clean" sequence, because little tritium and few neutrons are produced. This $\mathrm{D}-{ }^{3} \mathrm{He}$ fuel cycle can achieve a reduced level of activation in reactor structures, yielding a low inventory of radioactivity

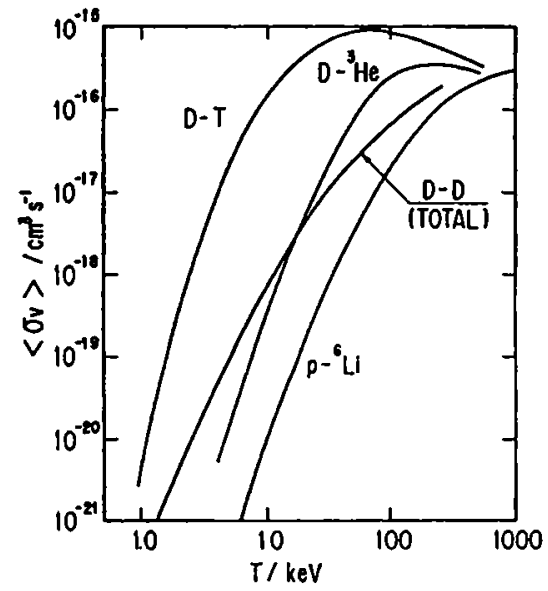

Fig. 3. Plot of fusion reaction rate parameter $\langle\sigma n\rangle$ as a function of the plasma temperature [8]

in the fuel system [12]. A principal disadvantage is the lack of a ${ }^{3} \mathrm{He}$ source on earth. Apparently it is abundant on the moon, and a proposal has been made to mine the moon to collect ${ }^{3} \mathrm{He}$ [13].

The $\mathrm{D}-{ }^{6} \mathrm{Li}$ fuel cycle is extremely complicated, having two $\mathrm{D}-\mathrm{D}$ branches, five $\mathrm{D}-{ }^{6} \mathrm{Li}$ branches and six ${ }^{6} \mathrm{Li}-{ }^{6} \mathrm{Li}$ branches, all of which are exothermic [12]. Although there are slight advantages of $\mathrm{D}-{ }^{-6} \mathrm{Li}$ over $\mathrm{D}-\mathrm{D}$ reactors, $\mathrm{D}-{ }^{6} \mathrm{Li}$ is less reactive than $\mathrm{D}-\mathrm{T}$, $\mathrm{D}-\mathrm{D}$ and $\mathrm{D}-{ }^{3} \mathrm{He}$.

The $\mathrm{p}^{-11} \mathrm{~B}$ fuel cycle is the only proton-based fuel cycle with adequate reactivity for serious consideration. Although neutron production is the lowest in this fuel cycle of the four cycles considered here, condensable and radioactive ash deposition could introduce both technological and radiological problems in the vacuum systems. The ignition prospects appear good for bremsstrahlung losses and $\alpha$ removal [14], but no steady-state burn has yet been projected for this fuel cycle.

\section{Muon catalyzed fusion ( $\mu$ CF)}

Muon catalyzed fusion $(\mu \mathrm{CF})$ is an intramolecular nuclear fusion which was first predicted by Sakharov in 1948 , several years before any concepts of thermonuclear fusion were suggested. The idea of energy applications was discarded for a long time because no ways were recognized of efficient use of muon within its lifetime $(2.2 \mu \mathrm{s})$, but a discovery of the resonance mechanism of muonic dd $\mu$ and $d t \mu$ molecule formation has shed light on the $\mu \mathrm{CF}$ study again. In recent experiments at LAMPF (USA), PSI (Switzerland) and UT-MSL/KEK (Japan), fusion yields exceeding 100 per muon were observed for the liquid deuterium-tritium system. The $\mu \mathrm{CF}$ research has attracted quite new physical interest and is rapidly developing in theories, experiments and future applications [15].

Nuclear fusion reactions occur when two nuclei are within a few $\mathrm{fm}\left(10^{-15} \mathrm{~m}\right)$. Under moderate conditions, however, nuclei with positive charge hardly approach 


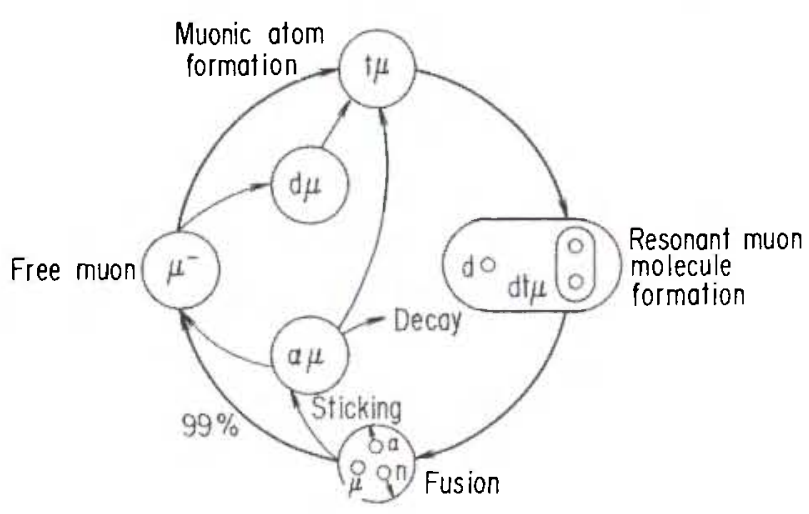

Fig. 4. Schematic expression of a muon catalyzed fusion $(\mu \mathrm{CF})$ cycle in $\mathrm{D}-\mathrm{T}$ mixtures.

each other because of the strong Coulomb repulsion. In $D_{2}$ molecules, for example, the equilibrium internuclear distance is $74 \mathrm{pm}$, and in this case the fusion rate is as low as $10^{-70}$ to $10^{-60} \mathrm{~s}^{-1}$. As described in the previous section, we usually use high temperature plasmas to make the nuclear fusion occur. When a negative muon $\left(\mu^{-}\right)$is replaced for the electron in the deuterium atom, the diameter of the neutralized muonic atom is reduced to about $1 / 200$ of normal deuterium atom, because the mass of muon is 207 times as heavy as electrons. In the muonic DT molecule $(\mathrm{dt} \mu)$ with the internuclear distance of about $500 \mathrm{fm}$, the fusion rate is enhanced to approximately $10^{12} \mathrm{~s}^{-1}$. Although the lifetime of muon is $2.2 \mu \mathrm{s}$, the fusion yields exceeding 100 per one muon have been experimentally observed for liquid deuterium-tritium systems in several laboratories [16-20].

The muon is one of the cosmic rays. For laboratory use, we can obtain intense muon beams from highenergy accelerators. Namely, bombardment of protons or heavy ions with kinetic energy of $300 \mathrm{MeV}$ or more on targets such as beryllium and graphite generates pions $\left(\pi^{ \pm}\right)$. The pions with the lifetime of 26 ns decay to muons $\left(\mu^{-}\right)$. The negative muon $\left(\mu^{-}\right)$is obtained only through the decay of negative pion $\left(\pi^{-}\right)$in a vacuum. Figure 4 shows a $\mu \mathrm{CF}$ cycle in a deuterium-tritium mixture. A negative muon from an accelerator thermalizes in the D-T mixture and quickly forms a ground-state muonic $\mathrm{d} \mu$ atom within $10^{-10} \mathrm{~s}$. The muonic atom is tiny and neutral. Since the groundstate energy level of $t \mu$ is deeper by $48 \mathrm{eV}$ than that of $\mathrm{d} \mu$, the $\mathrm{d} \mu$ transfers to $t \mu$ at the rate of $10^{-8} \mathrm{~s}^{-1}$, colliding with the surrounding DT and $\mathrm{T}_{2}$ molecules.

The neutral t $\mu$ easily penetrates into $\mathrm{D}_{2}$ or DT molecules and interacts with the deuterium nucleus to form a muonic $d t \mu$ molecule. Binding energies of muonic hydrogen atoms are typically of several $100 \mathrm{eV}$, so that the normal process of $\mathrm{dt} \mu$ formation proceeds via the Auger mechanism. Unfortunately, however, the rate of Auger process $\left(\sim 5 \times 10^{4} \mathrm{~s}^{-1}\right)$ is rather small compared with the decay rate of muon $\left(\lambda_{0}=4.5 \times 10^{5} \mathrm{~s}^{-1}\right)$. In the late 1950 's this led to a disappointing disbelief of $\mu \mathrm{CF}$ for energy production. In 1967, however, Vesman suggested a resonance

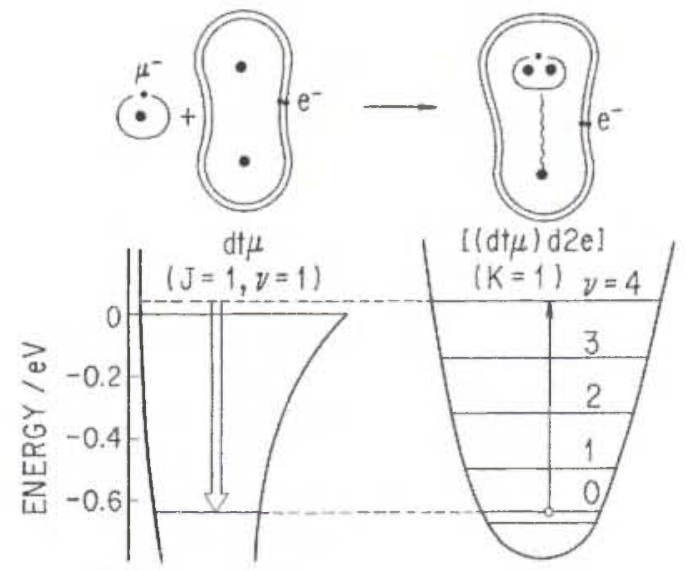

Fig. 5. Level schemes of resonant $\mathrm{dt} \mu$ formation.

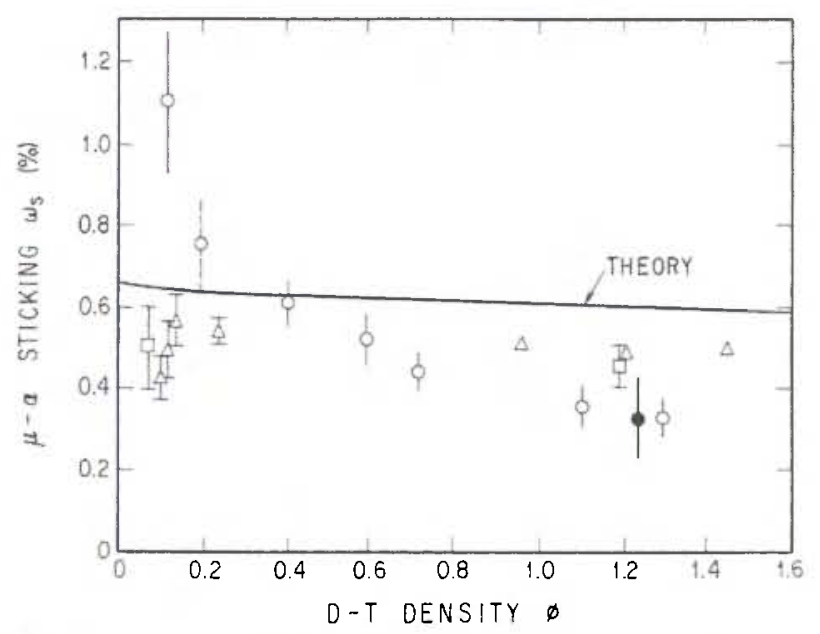

Fig. 6. Observed $\alpha$-sticking probabilities $\left(\omega_{\mathrm{s}}\right)$ plotted against the density of D-T mixtures: $\bigcirc$ LAMPF $[16,17], \square$ and $\triangle$ PSI $[18,19]$, and UT-MSL/KEK [20]. The curve is derived from theories.

mechanism which could greatly enhance the $\mathrm{dt} \mu$ formation rate $[21,22]$. The resonance mechanism is possible due to a weakly bound energy level $(-0.64 \mathrm{eV})$ of the $\mathrm{dt} \mu$ molecule as depicted in Fig. 5. The excess of energy released by the $\mathrm{dt} \mu$ formation is given to the electronic excitation of the resonant molecule $[(\mathrm{d} t \mu) \mathrm{d} 2 \mathrm{e}]$. The rate of this process, called "Vesman mechanism", is a few 10 to 100 times higher than $\lambda_{0}$.

Once the muonic dt $\mu$ molecule is formed, the intramolecular D-T fusion occurs at the rate of $10^{12} \mathrm{~s}^{-1}$, giving rise to a neutron and an $\alpha$ particle. The negative muon $\mu^{-}$is liberated from the molecule in the fusion reaction, and then forms the t $\mu$ atom again. Thus, the $\mu \mathrm{CF}$ cycle continues within the lifetime of the muon $(2.2 \mu \mathrm{s})$. The number of $\mu \mathrm{CF}$ cycle depends mainly upon the $\mu^{-}$sticking on $\alpha$ particles. Determination of the $\alpha$-sticking probability $\left(\omega_{\mathrm{s}}\right)$ is essential in evaluating the energy production possibility with the muon catalyzed fusion process. A number of theoretical and experimental studies have been carried out on this subject [16-27]. Figure 6 shows the $\alpha$-sticking probabilities observed by several research groups. Re- 
Table 2. Physical properties of tritium

\begin{tabular}{ll}
\hline Mass & $3.016049 \mathrm{u}$ \\
Nuclear spin & $1 / 2$ \\
Magnetic moment & $1.50461 \cdot 10^{-26} \mathrm{Am}^{2}$ \\
Ionization energy & $13.55 \mathrm{eV}$ \\
Dissociation energy $\left(\mathrm{T}_{2} \rightarrow 2 \mathrm{~T}\right)$ & $4.59 \mathrm{eV}$ \\
& \\
$\beta^{-}$decay & $100 \%$ \\
Half-life & $12.3 \mathrm{y}$ \\
Maximum $\beta^{-}$energy & $18.6 \mathrm{keV}$ \\
Average $\beta^{-}$energy & $5.7 \mathrm{keV}$ \\
Decay heat & $91.1 \mathrm{aW} / \mathrm{Bq}$ \\
Specific activity of $\mathrm{T}_{2}$ & $255 \mathrm{TBq} / \mathrm{g}$ \\
Specific volume of $\mathrm{T}_{2}$ at STP & $10.3 \mathrm{fL} / \mathrm{Bq}$ \\
\hline
\end{tabular}

cently, Nagamine's group has reported an updated experimental result that the $\omega_{\mathrm{s}}$ value is around $0.4 \%$ or less in a high density $\mathrm{D}-\mathrm{T}$ system. The result revealed that the $\mu \mathrm{CF}$ cycle per muon was more than 200 and that the energy production would be essentially possible [20].

\section{Tritium and its production}

Tritium is a radioactive hydrogen isotope. It was discovered in 1938. Following the discovery of deuterium in 1932 by Urey et al. [28], efforts were made to discover hydrogen of mass three by two groups; one in Cambridge University and the other in Princeton University. In 1934, the Cambridge group led by Rutherford reported the production of hydrogen-3 by bombarding a deuterium target with fast deuterons [29]. In the same year, the Princeton group reported positive evidence for the existence of hydrogen- 3 in natural sources [30]. However, both groups thought that the newly discovered hydrogen isotope was stable [31, 32]. In 1938, tritium was suggested to be radioactive by Bonner's group from observing the formation of an excited ${ }^{3} \mathrm{He}$ in the product of the $\mathrm{D}(\mathrm{d}, \mathrm{p}) \mathrm{T}$ reaction [33]. In 1939, Alvarez and Cornog demonstrated that tritium produced by the $\mathrm{D}(\mathrm{d}, \mathrm{p}) \mathrm{T}$ reaction was definitely radioactive and had a long half-life [34]. Current determination accords the half-life of tritium $12.3232 \pm 0.043$ mean solar years where there are 365.25 days/year $[35,36]$.

Natural tritium is produced by cosmic radiation in the upper atmosphere, where fast neutrons, protons and deuterons collide with molecules to induce tritium; e.g. ${ }^{14} \mathrm{~N}+\mathrm{n} \rightarrow \mathrm{T}+{ }^{12} \mathrm{C}$. The natural occurrence of tritium originated from cosmic radiation was 0.5 to 5 tritium units (1 tritium unit, denoted 1 T.U., equals a ratio of 1 tritium atom to $10^{18}$ atoms of hydrogen) before March 1954 [37, 38]. Since this time of the beginning of thermonuclear-weapon testing, samples of rain water have contained more than 500 T.U. of tritium [39]. Natural tritium was first detected in the atmospheric hydrogen by Faltings and Harteck [40] and was later shown to be in rain water by Libby's group [41].
Table 3. Tritium producing reactions with relatively high cross sections

\begin{tabular}{lccc}
\hline Reaction & $Q$-value & $\begin{array}{c}\text { Energy region } \\
\text { of incident } \\
\text { particles } \\
\mathrm{eV}\end{array}$ & Cross section \\
& $\mathrm{MeV}$ & $10^{-24} \mathrm{~cm}^{2}$ \\
\hline $\mathrm{D}(\mathrm{n}, \gamma) \mathrm{T}$ & 6.258 & $<0.625$ & $5 \times 10^{-4}$ \\
${ }^{3} \mathrm{He}(\mathrm{n}, \mathrm{p}) \mathrm{T}$ & 0.765 & $\sim 0.025$ & $5.33 \times 10^{3}$ \\
${ }^{6} \mathrm{Li}(\mathrm{n}, \alpha) \mathrm{T}$ & 4.794 & $<0.625$ & $9.53 \times 10^{2}$ \\
${ }^{7} \mathrm{Li}\left(\mathrm{n}, \mathrm{n}^{\prime} \alpha\right) \mathrm{T}$ & -2.465 & $(3-6) \times 10^{6}$ & $8.6 \times 10^{-2}$ \\
${ }^{10} \mathrm{Be}(\mathrm{n}, 2 \alpha) \mathrm{T}$ & 0.88 & $(1-5) \times 10^{6}$ & $3.2 \times 10^{-2}$ \\
& & $2.4 \times 10^{6}$ & $9.5 \times 10^{-2}$ \\
${ }^{6} \mathrm{Li}\left(\mathrm{d},{ }^{5} \mathrm{Li}\right) \mathrm{T}$ & 0.59 & $4.1 \times 10^{6}$ & $1.6 \times 10^{-1}$ \\
${ }^{7} \mathrm{Li}\left(\mathrm{d},{ }^{6} \mathrm{Li}\right) \mathrm{T}$ & -1.00 & $(1.5-7.7) \times 10^{6}$ & $2.3 \times 10^{-2}$ \\
${ }^{9} \mathrm{Be}\left(\mathrm{d},{ }^{8} \mathrm{Be}\right) \mathrm{T}$ & 4.59 & $20 \times 10^{6}$ & $1.0 \times 10^{-2}$ \\
${ }^{12} \mathrm{C}\left(\mathrm{d},{ }^{11} \mathrm{C}\right) \mathrm{T}$ & -1.25 & $8.7 \times 10^{6}$ & $3.9 \times 10^{-3}$ \\
${ }^{19} \mathrm{~F}\left(\mathrm{~d},{ }^{18} \mathrm{~F}\right) \mathrm{T}$ & -4.17 & & \\
\hline
\end{tabular}

Tritium decays to ${ }^{3} \mathrm{He}$ by the reaction,

$$
{ }^{3} \mathrm{H} \rightarrow{ }^{3} \mathrm{He}+\beta^{-}+\bar{v},
$$

emitting low-energy pure $\beta$-radiation. The average energy of the $\beta^{-}$particle is $5.685 \pm 0.008 \mathrm{keV}[42,43]$ and the maximum energy is $18.54 \pm 0.1 \mathrm{keV}$ [44]. The $\beta^{-}$particle is the most conspicuous missile shot forth from the decaying tritium nucleus. The $\beta^{-}$particles bounce off the molecular electron clouds and leave a bit of energy in each collision. This goes on until the electron is thermalized. Eventually it finds a positive charge with which to combine [43].

Tritium is unusual in not emitting a $\gamma$ ray in addition to the $\beta^{-}$particle. No electromagnetic radiation comes from the nucleus. However, the beta particle produces radiation as it plows through the nearby matter. There are two kinds of radiation: bremsstrahlung and fluorescence [45]. Bremsstrahlung is X-ray radiation given off by the $\beta^{-}$particle as it decelerates near a molecule. Its spectrum is continuous, as is the $\beta^{-}$particle spectrum. The bremsstrahlung yield increases with the atomic number of the adsorbing material. The fluorescence radiation is produced from particular atomic transitions. The beta particle knocks out an electron from an atom. The other electrons then cascade down through the energy levels to fill the hole left by the collision. As the electrons drop to lower energy levels, they emit $X$ rays. We should note that, once produced, $\mathrm{X}$ rays are more penetrating than $\beta^{-}$ particles [43]. The physical properties of tritium are summarized in Table 2.

The environmental impact of the released tritium has been the subject of many years of investigation. The tritium is much more hazardous in its water form (HTO, DTO, $\mathrm{T}_{2} \mathrm{O}$ ) than in its hydrogen gas form (HT, DT, $\mathrm{T}_{2}$ ). The potential hazard from inhalation is 25000 times greater for HTO than for HT [46]. However, the low energy $\beta^{-}$particles and its short biological halflife in the body (6-12 days) lead to low radiotoxity. The tritium gas oxidation rate at ambient temperatures is very low (half-life of 6.5 days). The kinetics of the conversion depend on the tritium concentration in air. 


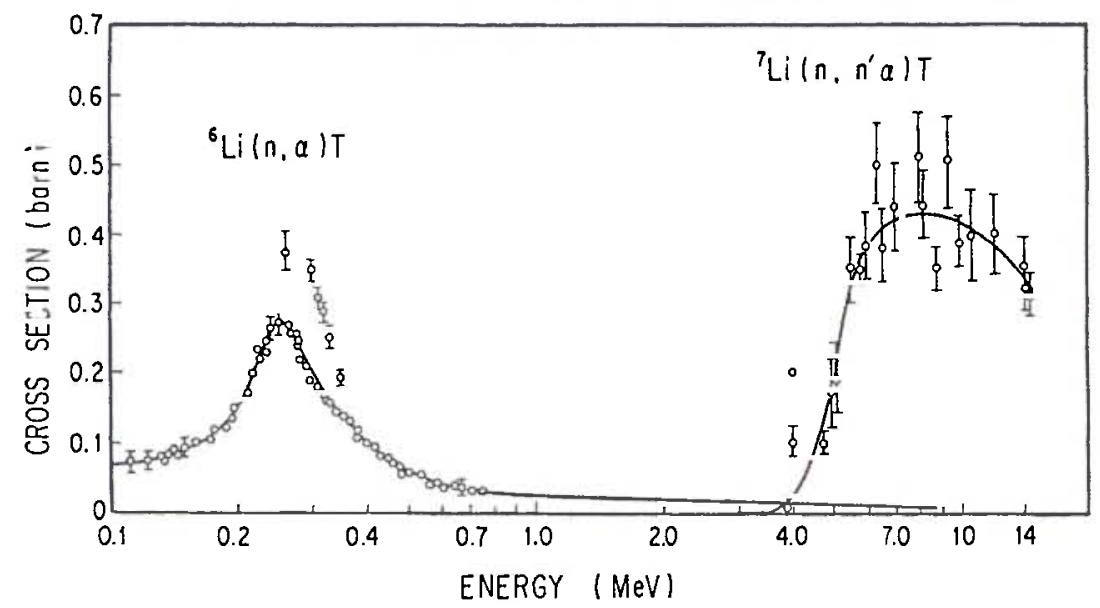

Fig. 7. Excitation functions of the ${ }^{6} \mathrm{Li}(\mathrm{n}, \alpha) \mathrm{T}$ and ${ }^{7} \mathrm{Li}\left(\mathrm{n}, \mathrm{n}^{\prime} \alpha\right) \mathrm{T}$ reactions [7]. The circles represent experimental points from several sources.

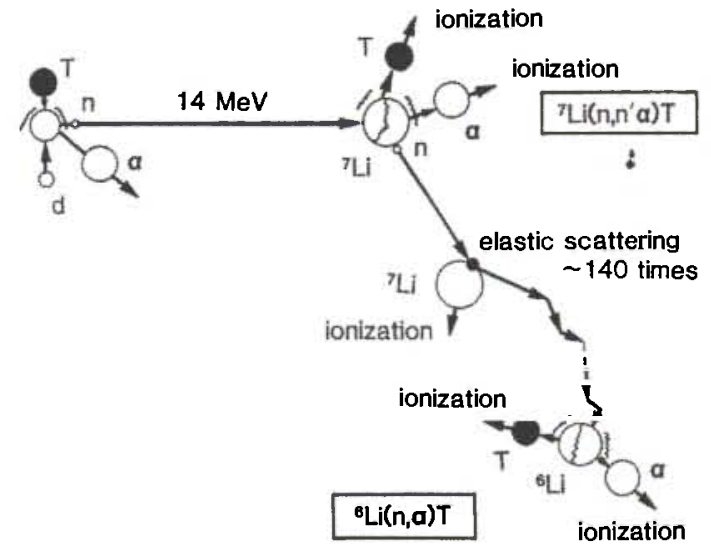

Fig. 8. Pictorial expression of fundamental tritium breeding mechanism.

Table 4. Properties of tritium breeding materials of current interest

\begin{tabular}{llccc}
\hline Type of blanket & Material & \multicolumn{3}{c}{ Properties } \\
\cline { 3 - 5 } & & $\begin{array}{c}\text { Melting } \\
\text { point } \\
\mathrm{K}\end{array}$ & $\begin{array}{c}\text { Density } \\
\mathrm{g} \mathrm{cm}^{-3}\end{array}$ & $\begin{array}{c}\text { Li-atom } \\
\text { density } \\
10^{22} \mathrm{~cm}^{-3}\end{array}$ \\
\hline Liquid blanket & $\mathrm{Li}$ & 459 & 0.53 & 4.4 \\
& $\mathrm{Li}_{17} \mathrm{~Pb}_{83}$ & 508 & 9.5 & 0.56 \\
Solid-state & $\mathrm{Li}_{2} \mathrm{O}$ & 1711 & 2.02 & 8.16 \\
blanket & $\mathrm{LiA1O}_{2}$ & 1883 & 2.61 & 2.38 \\
& $\mathrm{Li}_{5} \mathrm{AlO}_{4}$ & 1320 & 2.22 & 5.34 \\
& $\mathrm{Li}_{2} \mathrm{SiO}_{3}$ & 1474 & 2.52 & 3.38 \\
& $\mathrm{Li}_{4} \mathrm{SiO}_{4}$ & 1529 & 2.39 & 4.81 \\
& $\mathrm{Li}_{2} \mathrm{TiO}_{3}$ & 1820 & 3.46 & 3.80 \\
& $\mathrm{Li}_{2} \mathrm{ZrO}_{3}$ & 1873 & 4.15 & 3.27 \\
& $\mathrm{Li}_{8} \mathrm{ZrO}_{6}$ & 1568 & 2.99 & 5.93 \\
\hline
\end{tabular}

The presence of a gamma radiation field may inhibit the conversion, and fields of $80 \%$ neutrons and $20 \%$ gamma have been observed to lead to a substantial limitation of the water formation rate in air [47].
Once a $\mathrm{D}-\mathrm{T}$ fusion reactor is operated successfully, the fuel tritium is produced or bred in a blanket, but we have to produce large amounts of tritium for the first inventory beforehand. Nuclear reactions to produce tritium are summarized in Table 3. Of these reactions, the following reactions would be practically applied to the large scale production:

$$
\begin{aligned}
{ }^{3} \mathrm{He}+\mathrm{n} & \rightarrow \mathrm{T}+\mathrm{p} \\
{ }^{6} \mathrm{Li}+\mathrm{n} & \rightarrow \mathrm{T}+{ }^{4} \mathrm{He} \\
\mathrm{D}+\mathrm{n} & \rightarrow \mathrm{T}+\gamma \\
{ }^{235} \mathrm{U}+\mathrm{n} & \rightarrow \mathrm{FP} \\
{ }^{7} \mathrm{Li}+\mathrm{n} & \rightarrow \mathrm{T}+{ }^{4} \mathrm{He}+\mathrm{n}^{\prime} .
\end{aligned}
$$

Reactions (10)-(13) are exothermic and induced by thermal neutrons. Reaction (10) has a relatively high cross section against thermal neutrons (5330 b), and is frequently used for producing tritium in basic research. However, this reaction should not be applied to the tritium production for fusion reactor fuel, because the natural abundance of ${ }^{3} \mathrm{He}$ is only 1.3 $\times 10^{-4} \%$ or less. We usually utilize reaction (11) for producing fusion fuel tritium, irradiating lithium-containing materials such as ${ }^{6} \mathrm{Li}-\mathrm{Al}$ alloys in a nuclear reactor [48, 49]. In the past, several kilograms per year of tritium have been produced in this manner for the weapon use. This reaction is plausible to produce large amounts of tritium fuel for the first inventory of fusion reactors.

Although the cross section of reaction (12) is rather small, large amounts of tritium are accumulated in a heavy water reactor for a long period of operation. In these days, $2.5 \mathrm{~kg}$ per year of tritium is recovered from CANDU reactors in Canada [50]. Nuclear fission of reaction (13) accompanies the ternary fission which produce tritium. Although the probability is very low, significant amounts of tritium would be accumulated in a core of current fission reactors. The tritium recovery from nuclear fuel reprocessing is anticipated to be a way of ensuring the fuel tritium. 


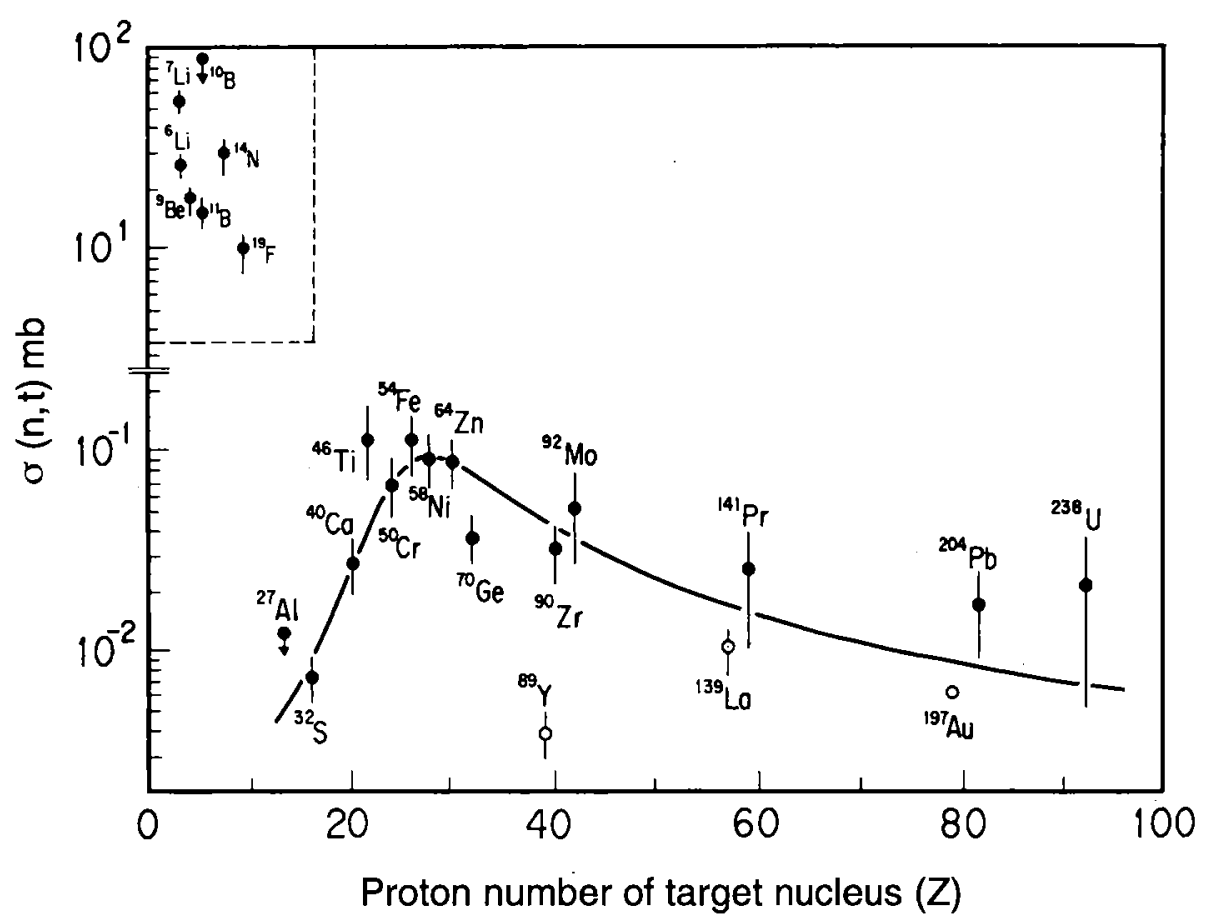

Fig. 9. Systematics in cross section of the $(n, t)$ reactions at $14.6 \mathrm{MeV}$ [68]; the open circles are partial cross sections.

Reaction (14) is endothermic $(Q=-2.47 \mathrm{MeV})$ and is effective only for fast neutrons having kinetic energies higher than $2.16 \mathrm{MeV}$. In Fig. 7 the excitation functions for the ${ }^{6} \mathrm{Li}(\mathrm{n}, \alpha) \mathrm{T}$ and ${ }^{7} \mathrm{Li}\left(\mathrm{n}, \mathrm{n}^{\prime} \alpha\right) \mathrm{T}$ reactions are compared [4]. The ${ }^{7} \mathrm{Li}\left(\mathrm{n}, \mathrm{n}^{\prime} \alpha\right) \mathrm{T}$ reaction greatly contributes to the tritium breeding in a blanket of fusion reactors. The fundamental tritium breeding mechanism is depicted in Fig. 8.

Of many lithium-bearing materials, only a few types of materials would be the most promising for practical use. Table 4 lists the candidate breeding materials of current interest. Lithium metal and $\mathrm{Li}_{17} \mathrm{~Pb}_{83}$ will be used in the liquid state (liquid blanket) and the oxidic materials with a higher melting point such as $\mathrm{Li}_{2} \mathrm{O}$ are the candidate for solid-state blankets $[3,51]$. The high lithium-atom density is favorable for the blanket materials. Although the lithium-atom density is relatively low, $\mathrm{Li}_{17} \mathrm{~Pb}_{83}$ can give a viable tritium breeding rate because of an excellent neutron multiplication by the $(n, 2 n)$ reaction in the constituent lead [52]. The tritium recovery from breeding materials is a key factor in establishing the viability of blanket concept, and a number of fundamental as well as technological studies have been carried out on the behavior of tritium produced in lithium containing materials [53-63].

Tritium is produced also in the first-wall materials, such as graphite, $\mathrm{B}_{4} \mathrm{C}$ and $\mathrm{SiC}$, by the $(\mathrm{d}, \mathrm{t})$ reactions listed in Table 3. The use of low- $Z$ materials has been suggested for structural component which are in direct contact with the plasma; e.g., limiters in tokamak device $[64,65]$. Graphite is an important candidate for first wall components and, in fact, graphite and carbide coatings are most widely used in today's fusion ma- chines $[66,67]$. In addition, $14-\mathrm{MeV}$ fusion neutron produce tritium by the $(n, t)$ reactions in structural materials. Figure 9 shows systematics of the $(\mathrm{n}, \mathrm{t})$ cross sections at $14.6 \mathrm{MeV}$ compiled by Qaim and Stöcklin [68].

\section{Activation products of fusion reactors}

During the operation of a $\mathrm{D}-\mathrm{T}$ fusion reactor, there will inevitably develop an inventory of induced radioactivity, or activation products, in the first wall, blanket and other components. Neutron-activation products are formed when 14-MeV fusion neutrons strike the main constituents and impurities in the reactor materials. The amounts and assortment of radioactivity are dependent on the nature of the neutron fluence and, more importantly, on the structural materials. Between 20 and $30 \%$ of radioactivity in the structural materials is associated with the first wall; and over $95 \%$ of it is in the first-wall/blanket components [69]. The relative concentration of radioactivity in various candidate structural materials is shown in Figs. 10 and 11 [70]. It is clear that several materials provide a lower inventory of radioactivity than stainless steel; most notably the $\mathrm{V}-20 \% \mathrm{Ti}$ alloy and the $\mathrm{SiC}$ ceramic which can be termed a low-activation material. Aluminum is a material of practical interest. Furthermore, it has been proposed that isotopic tailoring may be employed in the long term to reduce the activation in the steel [71].

The biological hazard potential (BHP) of radioactivity induced in the structural material, represented by ${ }^{54} \mathrm{Mn},{ }^{58} \mathrm{Co}$ and ${ }^{60} \mathrm{Co}$, is about 100 times as high as that of tritium. However, the radiotoxity of the struc- 


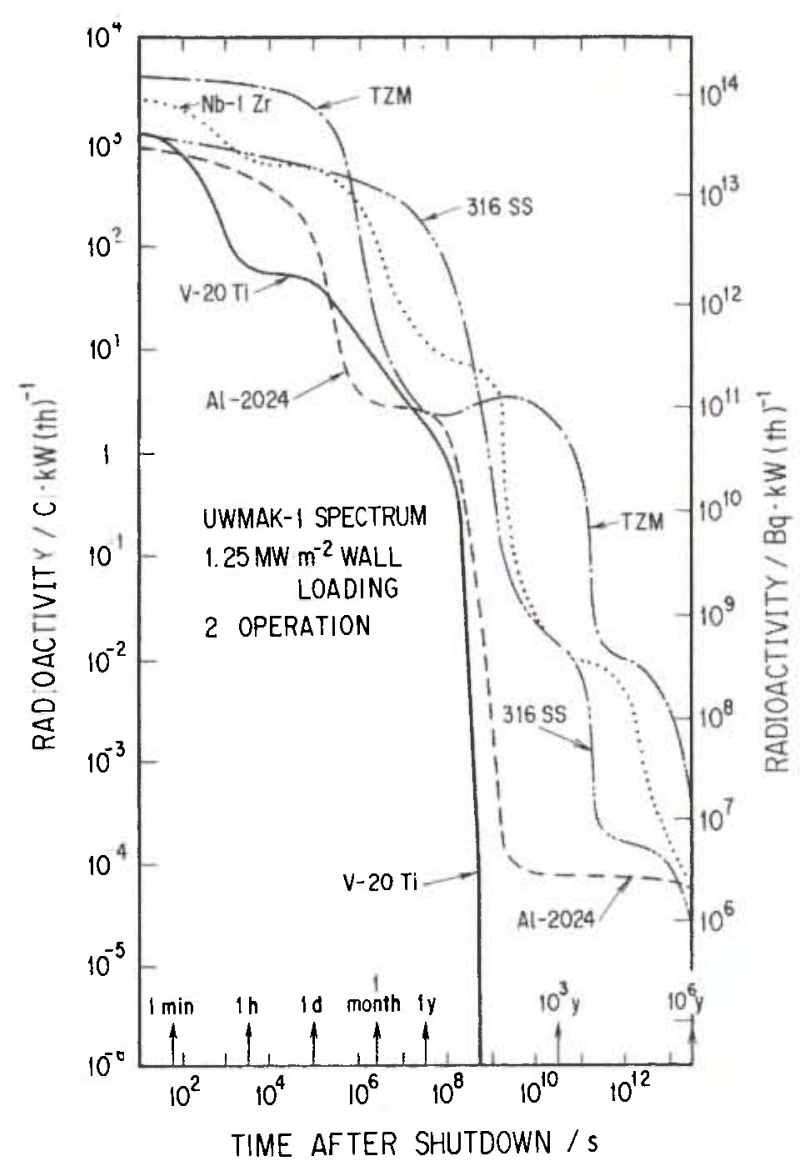

Fig. 10. Blanket radioactivity levels after shutdown for different structural alloys; the neutron spectrum from fusion reactor UWMAK-I [70].

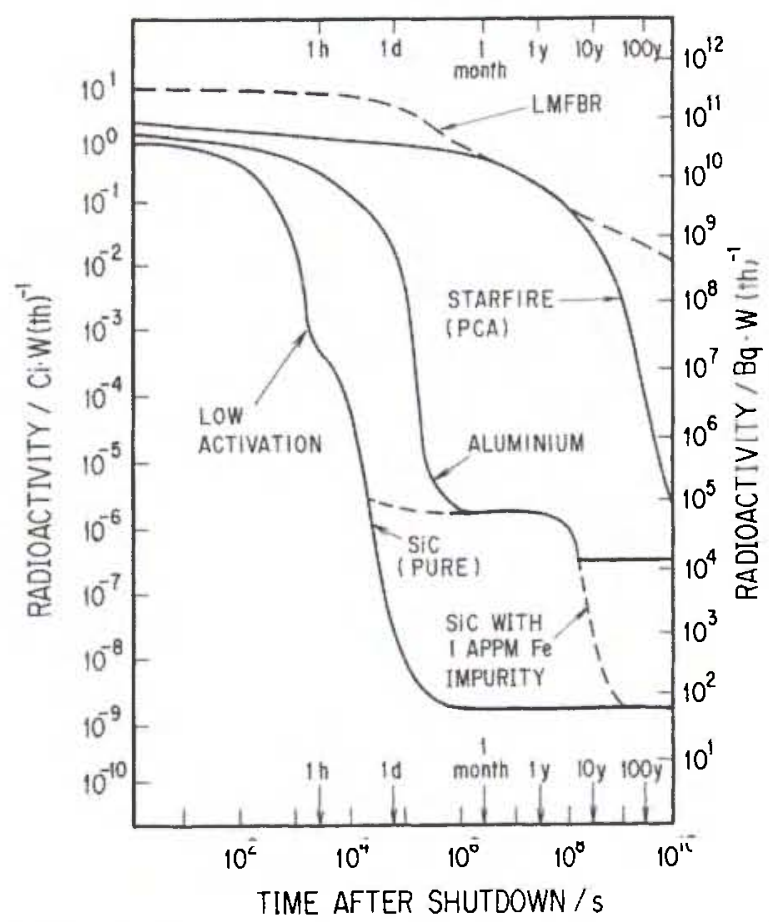

Fig. 11. Radioactivity for reactors after two years of typical operation [70]. STARFIRE is a fusion reactor; the first wall and blanket structures from aluminum, steel and $\mathrm{SiC}$. LMFBR is a fission reactor. tural materials is several order of magnitudes less hazardous than that of ${ }^{242} \mathrm{Pu}$ and ${ }^{238} \mathrm{U}$, present in fission reactor waste [72]. From radiological point of view, we should also pay attention to activation products such as ${ }^{13} \mathrm{~N},{ }^{16} \mathrm{~N},{ }^{40} \mathrm{Cl},{ }^{41} \mathrm{Ar}$ and ${ }^{37} \mathrm{~S}$ in the atmosphere around the fusion reactor, although the toxity of these radionuclides is very low because of their short lifetime.

A major difference between fusion and fission is that most of waste from nuclear fusion is produced on the power plant site. This is not the case for fission where substantial amounts of waste are generated during fuel acquisition and processing. A fusion reactor would be easier to control because the fuel is continuously supplied from outside. In case of an emergency, the fusion reaction could be stopped quickly by turning off the fuel supply switch. A fusion reactor does not pose the danger of a meltdown, as a fission reactor does.

Conclusively, the safe handling of huge amounts of tritium must be one of the prime technological subjects of developing $\mathrm{D}-\mathrm{T}$ fusion reactors. The clue to solving a variety of problems will be found in the plasma experiments on the TFTR and JET devices fueled with tritium [73-75].

\section{References}

1. Dolan, T. J.: Fusion Research, Pergamon Press, New York (1982).

2. Cox, P. A.: The Elements. Their origin, abundance and distribution, Oxford Univ. Press, Oxford (1989).

3. INTOR group: International Tokamak Reactor, Phase Two A, Part III, IAEA, Vienna (1988).

4. JET Team: Nucl. Fusion 32, 187 (1992).

5. Strachan, J. D., et al.: Phys. Rev. Lett. 72, 3526 (1994).

6. Hawryluk, R. J., et al.: Phys. Rev. Lett. 72, 3530 (1994).

7. Crocker, V. S., Blow, S., Watson, C. J. H.: CLM-P240 (1970).

8. Post, R. F.: Ann. Rev. Nucl. Sci. 20, 509 (1970).

9. Sheffield, J.: Rev. Mod. Phys. 66, 1015 (1994).

10. McNally, J. R., Jr.: Nucl. Technol./Fusion 2, 9 (1981).

11. Mills, R. G.: PPL-TM-74191, Princeton Plasma Physics Laboratory (1971).

12. McNally, J. R., Jr.: Nucl. Fusion 18, 133 (1978).

13. Kulcinski, G. L., Emmet, G. A., Blanchard, J. P., El-Guebaly, L. A., Khater, H. Y., Satarius, J. F., Sawan, M. E., Sviatoslavsky, I. N., Wittenberg, L. J., Witt, R, J.: Fusion Technol. 15, 1233 (1989).

14. Shuy, G. W., Conn, R. W.: PPG-522, University of California, Los Angeles (1980).

15. Petitjean, C.: Fusion Eng. Des. 11, 255 (1989).

16. Jones, S. E.: Muon. Cat. Fusion 1, 21 (1987).

17. Caffrey, A. J., Anderson, A. N., van Sichen, C. D., Watts, K. D.: Muon Cat. Fusion 1, 53 (1987).

18. Petitjean, C., Breunlich, W. H., Cargnelli, M., Kammel, P., Marton, J., Nägele, N., Pawlek, P., Scrinzi, A., Werner, J., Zmeskal, J.: Muon Cat. Fusion 1, 89 (1987).

19. Petitjean, C., et al.: Muon Cat. Fusion 2, 37 (1988).

20. Nagamine, K., Matsuzaki, T., Ishida, K., Hirata, Y., Watanabe, Y., Kadono, R., Miyake, Y., Nishiyama, K., Jones, S. E., Maltrud, H. R.: Muon Cat. Fusion 1, 137 (1987).

21. Vesman, E. A.: JETP Lett. 5, 9 (1967).

22. Gerstein, S. S., Ponomarev, L. I.: Phys. Lett. 72B, 80 (1977).

23. Nagamine, K., Matsuzaki, T., Ishida, K., Watanabe, Y., Sakamoto, S., Iwasaki, M., Miyake, Y, Nishiyama, K., Tori- 
kai, E., Kurihara, H., Kudo, H., Tanase, M., Kato, M., Kurosawa, K., Sugai, H., Fujie, M., Umezawa, H.: Muon Cat. Fusion 5/6, 289 (1991).

24. Kamimura, M.: Proc. $\mu$ CF-88 Workshop, Sanibel Island, USA (1988).

25. Bogdanova, L. N., Markushin, V. E., Melezhik, V. S., Ponomarev, L. I.: Sov. J. Nucl. Phys. 50, 848 (1989).

26. Markushin, V. E.: Muon Cat. Fusion 3, 395 (1988).

27. Cohen, J. S.: Muon Cat. Fusion 3, 395 (1988)

28. Urey, H. C., Brickwedde, F. G., Murphy, G. M.: Phys. Rev. 39, 164 (1932).

29. Oliphant, M. L. E., Harteck, P., Rutherford, L.: Proc. Roy. Soc. A 141, 259 (1933).

30. Breit, G., McIntosh, J. S.: Phys. Rev. 83, 1254 (1951).

31. Nefkens, B. M. K.: Phys. Rev. Lett. 10, 55 (1963).

32. Alvarez, L. W., Cornog, R.: Phys. Rev. 57, 248 (1940).

33. Bonner, T. W.: Phys. Rev. 53, 711 (1938),

34. Alvarez, L. W., Cornog, R.: Phys. Rev. 56, 613 (1939).

35. Rudy, C. R., Jordan, K. C.: Tritium Half-life, Monsanto Research Corporation Report MLM-2458, Mound Laboratory, Maiamisburg, Ohio (1977)

36. Jordan, K. C., Blanke, B. C., Dudley, W. A.: J. Inorg. Nucl. Chem. 29, 2129 (1967).

37. Kaufmann, S., Libby, W. F.: Phys. Rev. 93, 1337 (1954).

38. Lujanas, V.: Liet. TSR Mokslu Akad. Darb. Ser. B. 1, 21 (1963).

39. Evans, E. A.: Tritium and its Compounds, 2nd. ed., Butterworths, London (1974).

40. Faltings, V., Harteck, P.: Z. Naturforsch. 5a, 438 (1950).

41. Grosse, A. V., Johnston, W. H., Wolfgang, R. L., Libby, W. F.: Science, N.Y. 113, 1 (1951).

42. Pillinger, W. L., Hentges, J. J., Blair, J. A.: Phys. Rev. 121 232 (1961).

43. Souers, P. C.: Hydrogen Properties for Fusion Energy, Univ. of California Press, Berkeley (1986).

44. Lewis, V. E.: Nucl. Phys. 151A, 120 (1970).

45. Souers, P. C., Tsugawa, R. T., Stone, R. R.: Rev. Sci. Instrum. 46, 682 (1975).

46. International Commission on Radiological Protection: ICPR Publication No. 30, Pergamon Press, Oxford (1979).

47. Easterly, C. E., Bennett, M. R.: Nucl. Technol./Fusion 42 , 16 (1983).

48. Rhinehammer, T. B., Wittenberg, L. J.: MLM-2419 (1978),

49. Hugony, P., Sauvage, H., Roth, E.: B.I.S.T., Commissariat à l'Energie Atomique, No. 178, 3 (1973).
50. Sood, S. K., Sissingh, R.A.P., Kveton, O. K.: Fusion Technol. 8, 2478 (1985).

51. Sako, K., Ohta, M., Yamato, H., Hiraoka, T., Tanaka, K., Asami, N., Mori, S.: KAERI-M 5502 (1973).

52. Meier, W. R.: UCRL-87499 (1982).

53. Kudo, H.: J. Nucl. Mater. 87, 185 (1979).

54. Kudo, H., Okuno, K.: J. Nucl. Mater. 101, 38 (1981), (1983).

55. Okuno, K., Kudo, H.: J. Nucl. Mater. 116, 82 (1983).

56. Kudo, H., Okuno, K.: Radiochim. Acta 33, 223 (1983).

57. Kudo, H., Okuno, K.: J. Nucl. Mater. 133/134, 192 (1985).

58. Okuno, K., Kudo, H.: J. Nucl. Mater. 138, 31 (1986).

59. Okuno, K., Kudo, H.: J. Nucl. Mater. 138, 210 (1986).

60. Kudo, K., Okuno, K.: J. Nucl. Mater. 155-157, 524 (1988).

61. Okuno, K., Kudo, H.: Fusion Eng. Des. 8, 355 (1989).

62. Kudo, H.: Radiochim. Acta 50, 71 (1990).

63. Kurasawa, T., Watanabe, H., Roth, E., Vollath, D.: J. Nucl. Mater. 155-157, 544 (1988).

64. Kulcinski, G. L., Conn, W. R., Lang, G.: Nucl. Fusion 15, 327 (1975)

65. Conn, W. R., Kesner, J.: Nucl. Fusion 15, 775 (1975).

66. Winter, J.: J. Nucl. Mater. 145-147, 131 (1987).

67. Dietz, K. J.: J. Nucl. Mater. 155-157, 8 (1988).

68. Qaim, S. M., Stöcklin, G.: J. Inorg. Nucl. Chem. 35, 19 (1973).

69. Holdren, J. P.: Ann. Rev. Energy Environ. 16, 235 (1991).

70. Kazimi, M. S.: Nucl. Fusion 24, 1461 (1984).

71. Conn, R. W., Okula, K., Johnson, W.: Nucl. Technol. 41, 289 (1978)

72. Smith, C. F., Kastenberg, W. E.: Nucl. Eng. Des. 39, 293 (1976).

73. Anderson, J. L., Gentile, C., Hosea, J., Kalish, M., Kamperschroer, J., Kozub, T., LaMarche, P., Murray, H., Nagy, A., Raftopoulis, S., Rossmassler, R., Sissingh, R., Swanson, J., Viola, M., Voorhees, D., VonHalle, A., Walters, R. T.: IAEA-CN/F-2-II-1 (1994).

74. Andrew, P., Cadwell-Nichols, C. J., Coad, J. P., Dietz, K. J., Ehrenberg, J., Goodall, D. H. J., Hemmerich, J., Horton, L., How, J., Lasser, R., Lomas, P., Loughlin, M., McCracken, G. M., Peacock, A., Saibene, G., Sartori, R., Thomas, P., Winkel, T.: J. Nucl. Mater. 196-198, 143 (1992).

75. Goodall, D. H. J., Andrew, P., Ehrenberg, J., McCracken, G. M., Peacock, A. T., Saibene, G., Sartori, R., van Belle, P.: J. Nucl. Mater. 196-198, 1002 (1992). 


\section{Author Index}

Adloff, J. P., MacCordick, H. J., The Dawn of Radiochemistry 13 Ardisson, G., Hussonnois, M., Radiochemical Investigations of Cluster Radioactivities 123

Beneš, P., see Zeman, A. 23

Choppin, G. R., Nash, K. L., Actinide Separation Science 225

Draganić, I. G., Radioactivity and Radiation Chemistry of Water 317

Gäggeler, H. W., Radioactivity in the Atmosphere 345

Genet, M., The Discovery of Uranic Rays: A Short Step for Henri Becquerel but a Giant Step for Science 3

Guillaumont, R., Trubert, D., On the Discovery of Artificial Radioactivity 39

von Gunten, H. R., Radioactivity: A Tool to Explore the Past 305

Hahn, R. L., The Physics and (Radio)chemistry of Solar Neutrino Experiments 177

Herrmann, G., The Discovery of Nuclear Fission - Good Solid Chemistry Got Things on the Right Track 51

Hoffman, D. C., Lane, M. R., Spontaneous Fission 135

Hofmann, S., Proton Radioactivity 93

Hussonnois, M., see Ardisson, G. 123

Jones, A. G., Technetium in Nuclear Medicine 289

Koch, L., Radioactivity and Fission Energy 397

Kratz, J. V., Radiochemical Studies of Complex Nuclear Reactions 147

Kudo, H., Radioactivity and Fusion Energy 403

Kuroda, P. K., Formation of Heavy Elements in Nature 299

Lane, M. R., see Hoffman, D. C. 135

Lieser, K. H., Radionuclides in the Geosphere: Sources, Mobility, Reactions in Natural Waters and Interactions with Solids 355

MacCordick, H. J., see Adloff, J. P. 13

Maddock, A. G., Radioactivity and the Nuclear Environment 323

Münzenberg, G., Discovery, Synthesis and Nuclear Properties of the Heaviest Elements 193

Nash, K. L., see Choppin, G. R. 225

Newton, G. W. A., History of the Unraveling of the Natural Decay Series 31

Nitsche, H., see Silva, R. J. 377

Qaim, S. M., Radiochemical Studies of Complex Particle Emission in Low and Intermediate Energy Reactions 163

-, see Stöcklin, G. 249

Roeckl, E., Alpha Radioactivity 107

Rösch. F.. see Stöcklin. G. 249
Schädel, M., Chemistry of the Transactinide Elements 207

Seaborg, G. T., Transuranium Elements: the Synthetic Actinides 69

Silva, R. J., Nitsche, H., Actinide Environmental Chemistry 377

Stöcklin, G., Qaim, S. M., Rösch, F., The Impact of Radioactivity on Medicine 249

Thakur, M. L., see Weiner, R. E. 273

Trautmann, N., Fast Radiochemical Separations for Heavy Elements 237

Trubert, D., see Guillaumont, R. 39

Weiner, R. E., Thakur, M. L., Metallic Radionuclides: Applications in Diagnostic and Therapeutic Nuclear Medicine 273

Yoshihara, H. K., X-Rays and Radiochemistry 333

Zeman, A., Beneš, P., St. Joachimsthal Mines and their Importance in the Early History of Radioactivity 23 